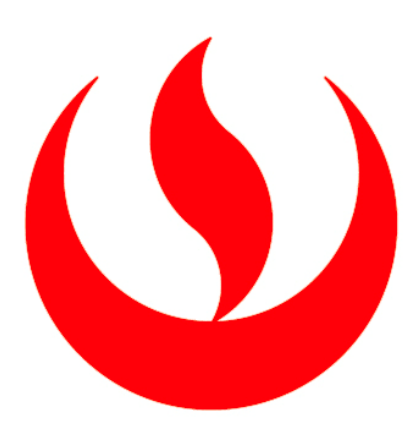

UNIVERSIDAD PERUANA DE CIENCIAS APLICADAS

FACULTAD DE INGENIERÍA

CARRERA DE INGENIERÍA INDUSTRIAL

\title{
PROPUESTA DE UN PROCESO DE COSTOS DENTRO DE UN MODELO DE GESTIÓN PARA MYPE DEL SUBSECTOR RESTAURANTES EN LIMA METROPOLITANA
}

TESIS

para optar el título profesional de : Ingeniero Industrial

\author{
AUTOR \\ Jesús Nima, Carlos Fernando Justo (0000-0002-8922-0557) \\ ASESOR DE TESIS \\ Sotelo Raffo, Juan Luis Fernando (0000-0001-5452-369X)
}

Lima, 05 de Abril de 2018 
Dedicada a la memoria de mi querida y única hermana Andrea Valeria Jesús Nima (2000-2017), a 6 meses de su sensible fallecimiento, y a la memoria de mi bisabuelaAgustina Chirinos Cárdenas (1919-2006), a casi 12 años de su partida. 


\section{Agradecimientos}

Agradezco a mi padre y madre, quienes ahora más que nunca me necesitan y apoyan; a mi abuela Natividad Rosas Chirinos, quien siempre veló por mí y a mi hermana, Andrea Valeria Jesús Nima, quien siempre me dijo que termine esta tesis. Agradecimientos especiales a mi asesor, Fernando Sotelo, por su ayuda en la investigación presentada. 


\section{RESUMEN}

En esta tesis se realiza una investigación sobre la situación del proceso de costos en las MYPE del subsector restaurantes en Lima Metropolitana, realizando un estudio del manejo actual de los mismos y los conocimientos en costos de los dueños de las empresas. En base a eso, junto con la teoría de costos $\mathrm{ABC}$, se plantea un modelo teórico que permitirá a las MYPE de este subsector mejorar su gestión de costos, así como mejorar la gestión de sus dueños. El presente modelo cuenta con la opinión de expertos en temas de costos, tanto nacionales como internacionales, que, además, validan su efectividad al momento de plantearse una implementación. Agregando un análisis de los posibles impactos que tendría, se concluye que el modelo de proceso de costos brindará mejoras empresariales a las MYPE, así como nuevas herramientas que mejoran la gestión de las mismas.

PALABRAS CLAVE: Gestión de costos, Costeo ABC, MYPE, Restaurantes, Gestión por procesos 


\begin{abstract}
In this thesis, a research is made on the situation of the cost process in the MYPE, of the restaurants sub-sector in Metropolitan Lima, carrying out a study of the current management of the same and the knowledge in costs of the owners of the companies. Based on that, together with the ABC cost theory, a theoretical model is proposed that will allow MYPE in this subsector to improve their cost management, as well as improve the management of their owners. This model has the opinion of experts in cost issues, both national and international, which also validate its effectiveness when considering an implementation. Adding an analysis of the possible impacts that would have, it is concluded that the cost process model will provide business improvements to the MSEs, as well as new tools that improve the management of them.
\end{abstract}

KEYWORDS: Cost management, $\mathrm{ABC}$ costing, MYPE, Restaurants, Process management 


\section{ÍNDICE}

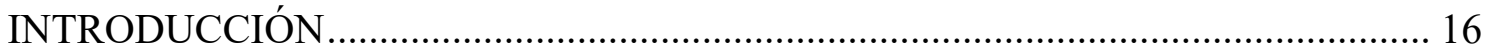

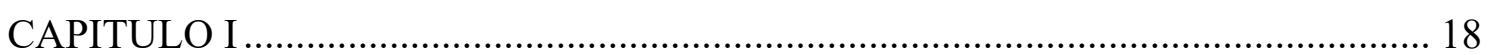

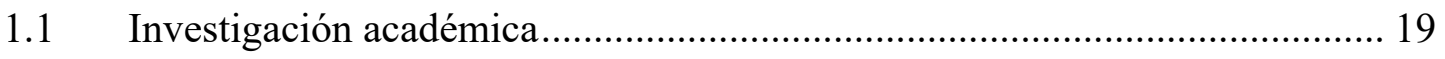

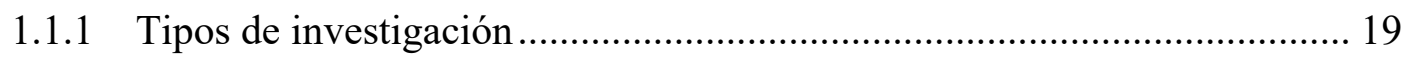

1.1.2 Elección del enfoque de la investigación ............................................... 20

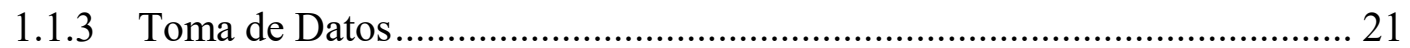

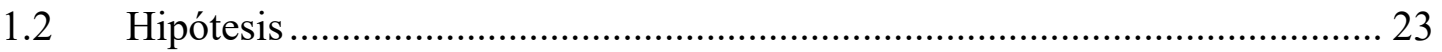

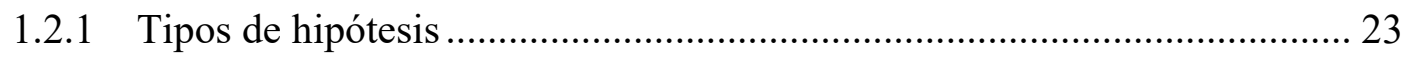

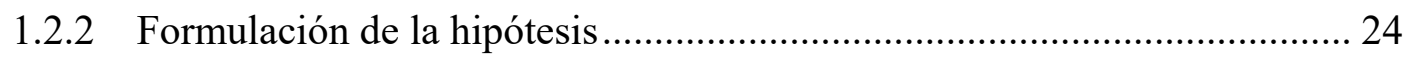

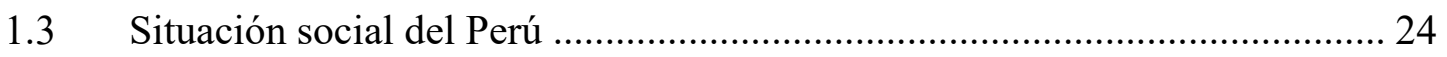

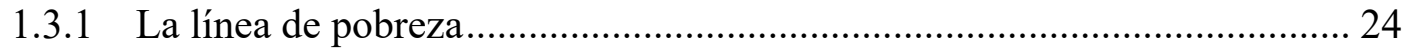

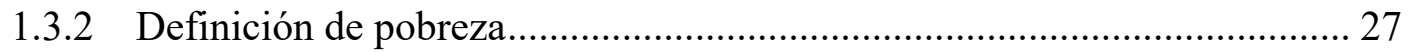

1.3.3 Pobreza en el Perú ...................................................................................... 28

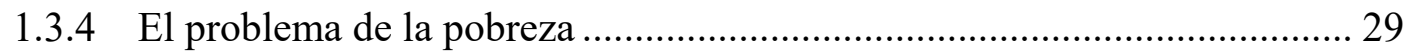

1.4 Situación económica del Perú ........................................................................ 30

1.4.1 Situación actual del crecimiento del PBI.................................................. 30

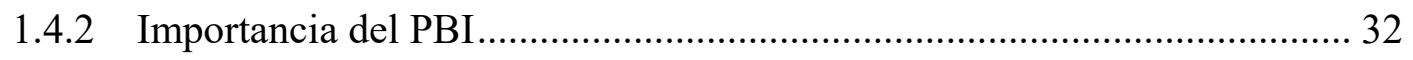

1.4.3 Predicciones de crecimiento para el 2017 ............................................... 33

1.5 Situación empresarial del Perú ...................................................................... 34

1.5.1Sectores productivos en el Perú....................................................................... 34

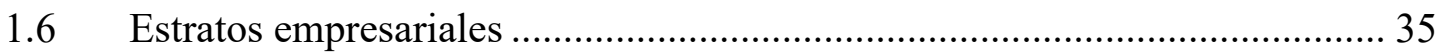

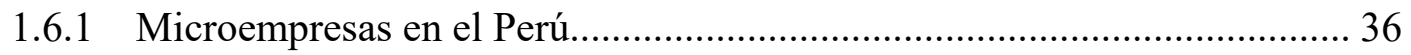

1.6.2 Pequeñas empresas en el Perú ................................................................ 38

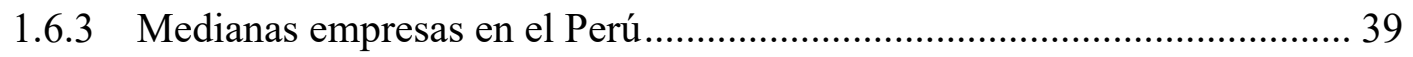

1.6.4 Grandes empresas en el Perú .................................................................. 39

1.6.5 Situación de los estratos empresariales ................................................. 40

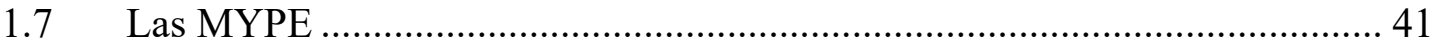

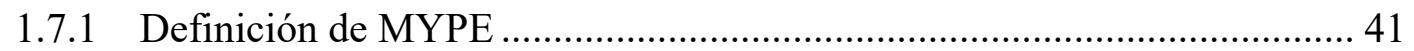

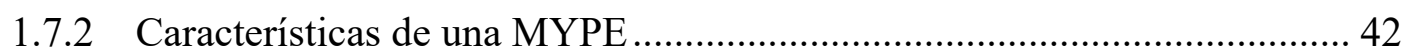

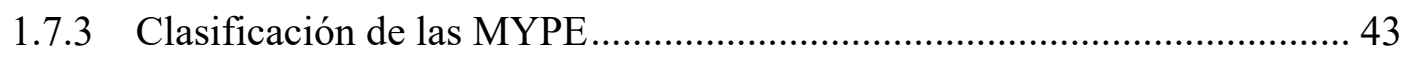

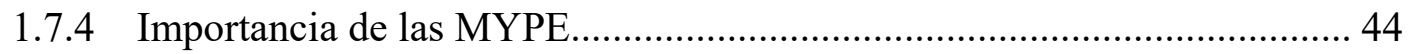




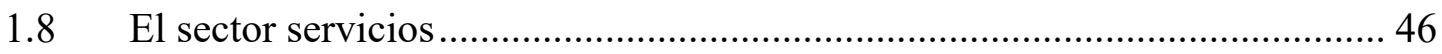

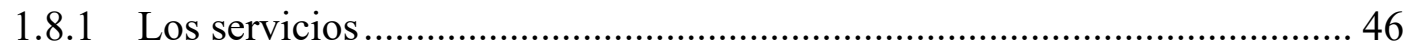

1.8.2 El sector servicios: un sector en constante crecimiento .......................... 47

1.8.3 El sector alojamientos y restaurantes ..................................................... 49

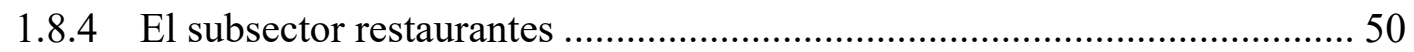

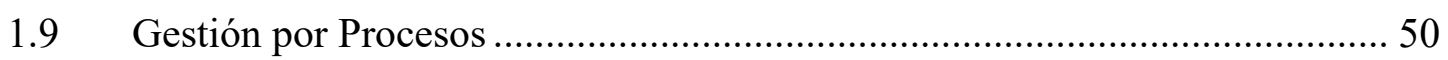

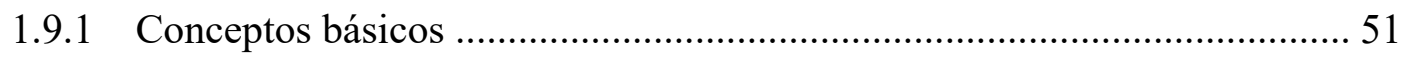

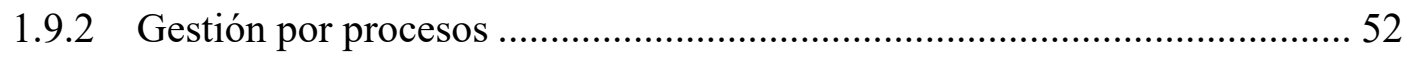

1.9.3 Análisis dentro de la gestión por procesos ............................................. 55

1.9.4 Herramientas para una gestión por procesos …......................................56

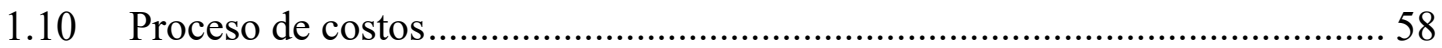

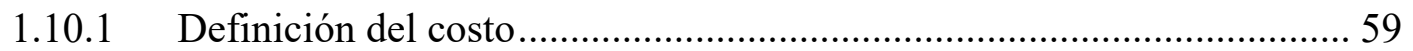

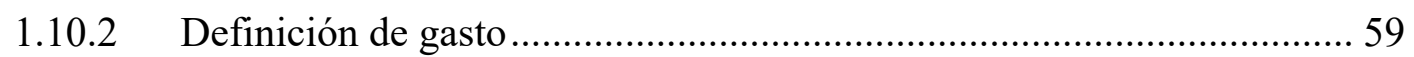

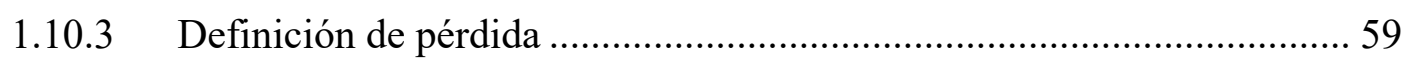

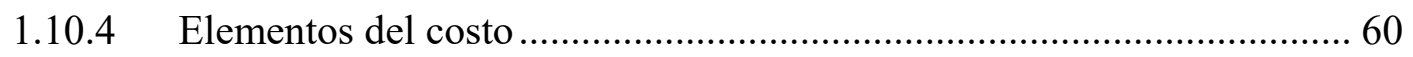

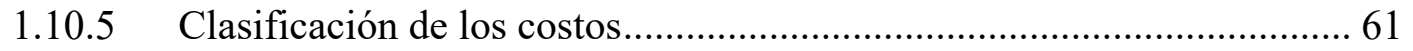

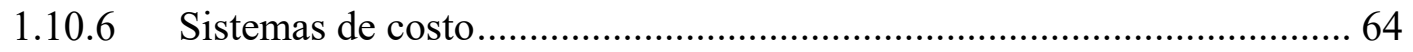

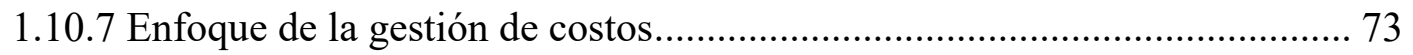

1.10.8 Normativa peruana sobre el costeo.................................................... 74

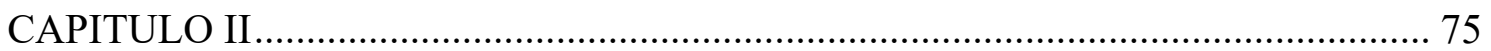

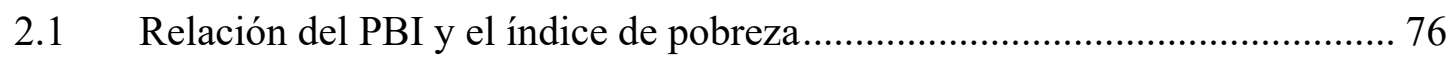

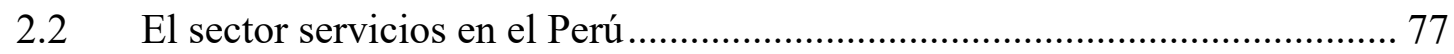

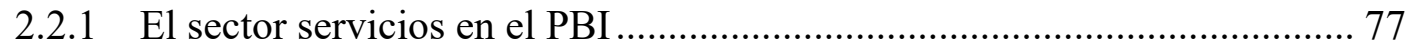

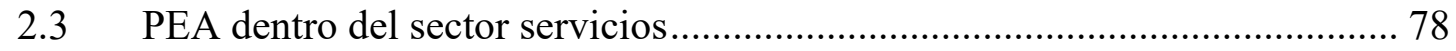

2.3.1 PEA ocupada del sector servicios en el Perú............................................ 78

2.3.2 PEA ocupada del sector servicio en Lima Metropolitana ........................ 79

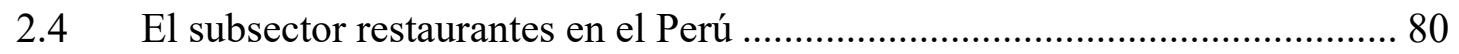

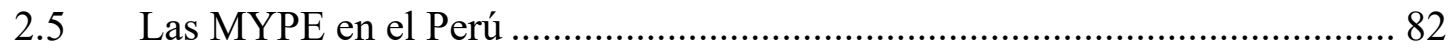

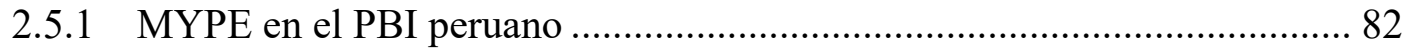

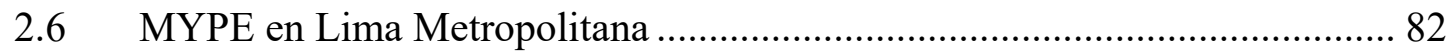

2.6.1 PEA Ocupada en las MYPE de Lima Metropolitana ................................ 83

2.6.2 El sector servicios y las MYPE de Lima Metropolitana ........................... 83

2.7 MYPE del subsector restaurantes en Lima Metropolitana ............................. 84

2.8 Encuesta a MYPE del subsector restaurantes en Lima Metropolitana............ 85

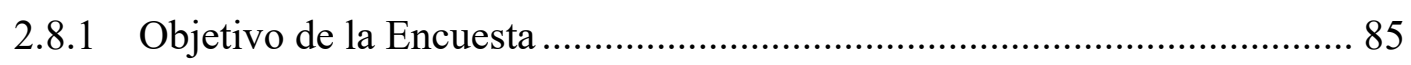




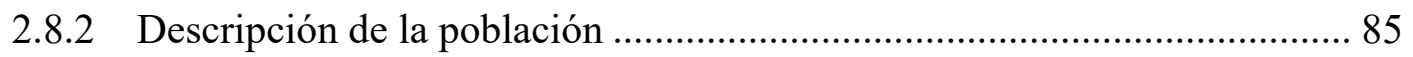

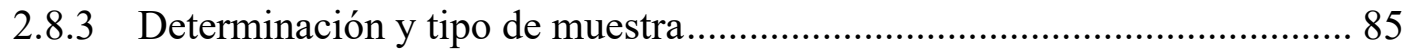

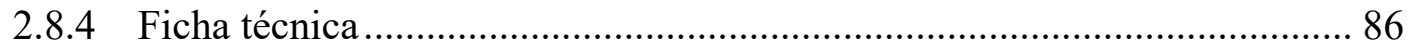

2.9 Análisis de los resultados de la encuesta a las MYPES en el subsector restaurantes en Lima Metropolitana

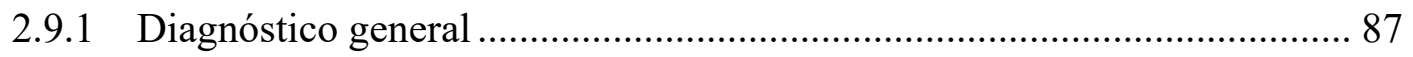

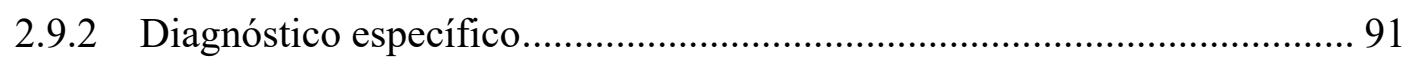

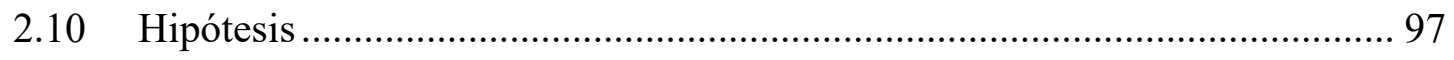

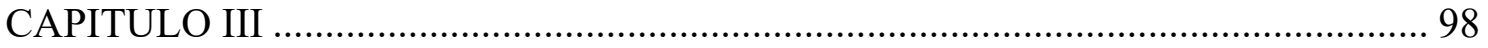

3.1 Contextualización de las MYPE del subsector restaurantes en Lima Metropolitana antes del modelo de costos dentro de un modelo de gestión ............... 98

3.2 Gestión por procesos aplicada a MYPE del subsector restaurantes ............... 99

3.2.1 Misión y objetivos de la Gestión por Procesos ....................................... 100

3.2.2 Propuesta basada en la Gestión por Procesos para una MYPE del subsector

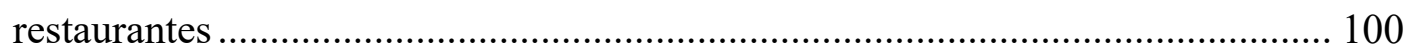

3.3 Modelo de costos MYPE del subsector restaurantes .................................. 110

3.3.1 Objetivos del modelo de costos .......................................................... 110

3.3.2 Mapa interrelacional del proceso de costos........................................... 111

3.3.3 Mapa de subprocesos de costos ........................................................... 112

3.3.4 Descripción de los subprocesos del modelo de costos ........................... 115

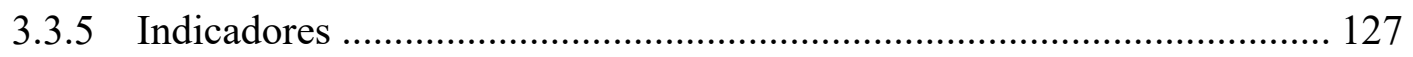

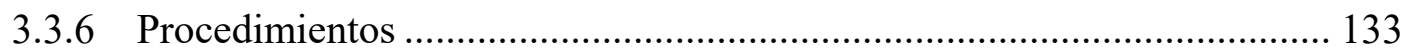

3.3.7 Modelo de costeo ABC estándar para MYE del subsector restaurantes .. 134

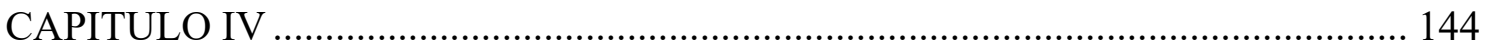

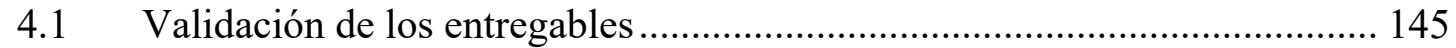

4.2 Validación de la bibliografía .................................................................. 146

4.2.1 Validación de entregables del Capítulo I................................................ 146

4.2.2 Validación de entregables del Capítulo 2 ............................................ 157

4.2.3 Validación de entregables del Capítulo 3 ............................................. 159

4.2.4 Validación del Capítulo 4 ...................................................................... 160

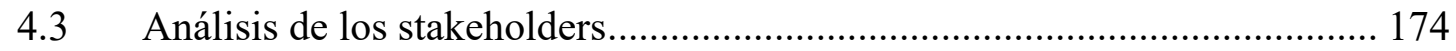

4.4 Análisis de la matriz de impactos del proceso de costos ............................. 178

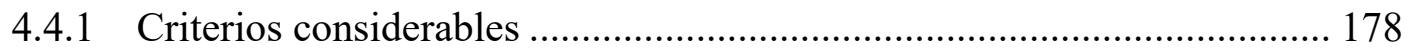

4.4.2 Actividades de consideración ............................................................. 179

4.4.3 Matriz de Leopold y rango de calificación............................................ 180 


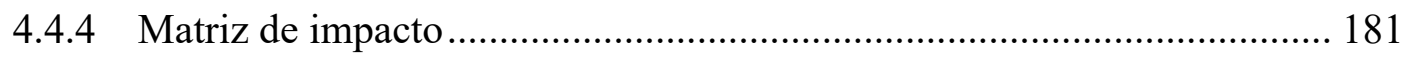

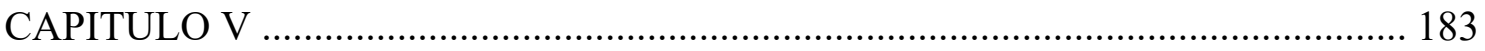

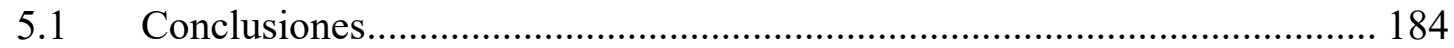

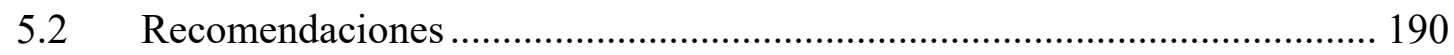




\section{ÍNDICE DE TABLAS}

Tabla $\mathrm{N}^{\mathrm{o}}$ 1. Características de los enfoques de una investigación................................. 21

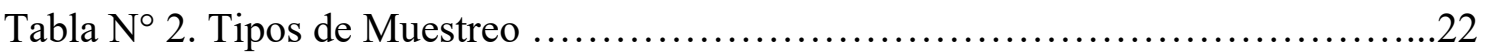

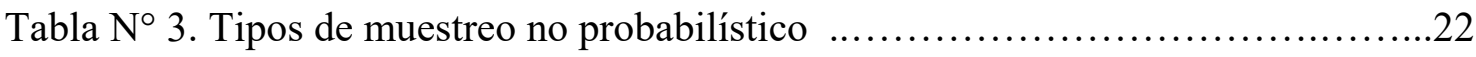

Tabla $\mathrm{N}^{\circ}$ 4. Tipos de hipótesis con sus respectivas definiciones $\ldots \ldots \ldots \ldots \ldots \ldots \ldots \ldots \ldots \ldots \ldots \ldots \ldots \ldots$

Tabla $\mathrm{N}^{0}$ 5. Definición de los sectores productivos en el Perú...................................... 34

Tabla $\mathrm{N}^{\circ}$ 6. Cantidad de microempresas formales por regiones entre el periodo 2010-2015

Tabla N ${ }^{0}$ 7. Cantidad de pequeñas empresas formales por regiones entre el periodo 20102015

Tabla $N^{o}$ 8. Cantidad de medianas empresas formales por regiones entre el periodo 20102015 39

Tabla N ${ }^{o}$ 9. Evolución de la cantidad de empresas por estrato empresarial en el Perú 20122015 40

Tabla $N^{\circ}$ 10. Características de una MYPE según la Ley Nª 28015 42

Tabla $\mathrm{N}^{\mathrm{o}}$ 11. Principales características y responsabilidades de un dueño de una MYPE 43

Tabla $\mathrm{N}^{\mathrm{o}}$ 12. Características fundamentales de los servicios ...................................... 46

Tabla $\mathrm{N}^{\mathrm{o}}$ 13. Requisitos para realizar una gestión por procesos.................................... 53

Tabla $\mathrm{N}^{\mathrm{o}}$ 14. Ventajas de la gestión por procesos ....................................................... 54

Tabla $\mathrm{N}^{\mathrm{o}}$ 15. Clasificación de los costos de acuerdo a su función ................................ 61

Tabla $\mathrm{N}^{\mathrm{o}}$ 16. Clasificación de los costos de acuerdo a la actividad................................. 62

Tabla $\mathrm{N}^{\mathrm{o}}$ 17. Clasificación de los costos de acuerdo a su comportamiento ..................... 62

Tabla $\mathrm{N}^{\mathrm{o}}$ 18. Clasificación de los costos de acuerdo a su control .................................6 63

Tabla $\mathrm{N}^{\mathrm{o}}$ 19. Clasificación de los costos de acuerdo a como se enfrentan con los ingresos

Tabla N ${ }^{o}$ 20. Clasificación de costo de acuerdo a su función en la toma de decisiones. 64

Tabla N $\mathrm{N}^{\mathrm{o}} 21$. Ficha del indicador Margen de Ganancia. 128

Tabla $\mathrm{N}^{\mathrm{o}}$ 22. Ficha del indicador Porcentaje de documentos contabilizados para el costeo

Tabla N $\mathrm{N}^{\mathrm{o}}$ 23. Ficha del indicador Variación de Costos Directos ................................ 130

Tabla N $\mathrm{N}^{\mathrm{o}}$ 24. Ficha del indicador Variación de Costos Indirectos............................... 131 
Tabla $\mathrm{N}^{\mathrm{o}} 25$. Ficha del indicador Variación de costos unitarios. 132

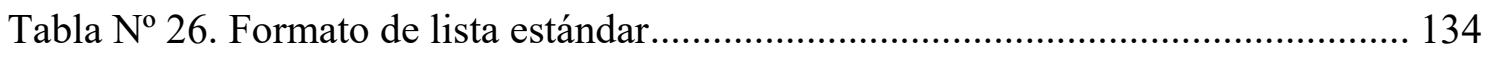

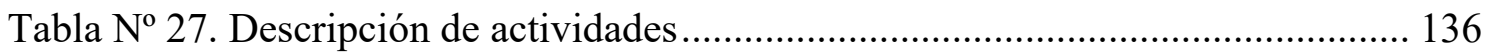

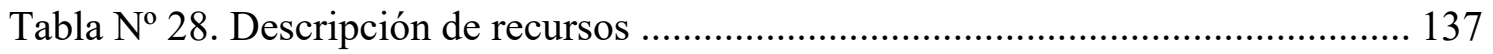

Tabla N $\mathrm{N}^{\mathrm{o}}$ 29. Formato de matriz de Actividades y Recursos ........................................ 138

Tabla No 30. Matriz de Actividades y Recursos para el modelo estándar.................... 139

Tabla N ${ }^{0}$ 31. Cuadro de relación Recurso-Actividad y Cost Driver ............................. 141

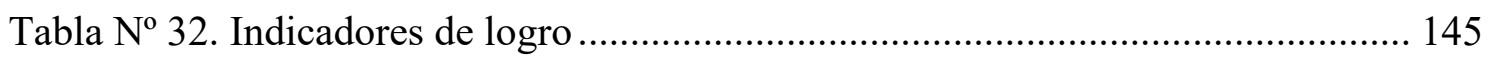

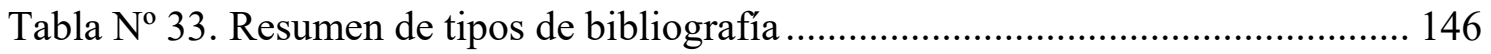

Tabla No 34. Artículos científicos generales ............................................................. 147

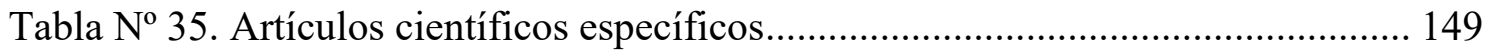

Tabla No 36. Leyes y normativas de la República del Perú ......................................... 150

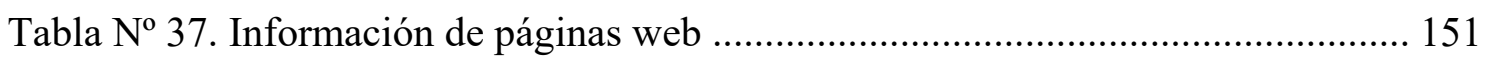

Tabla $\mathrm{N}^{\mathrm{o}}$ 38. Información de entidades gubernamentales y no gubernamentales ......... 153

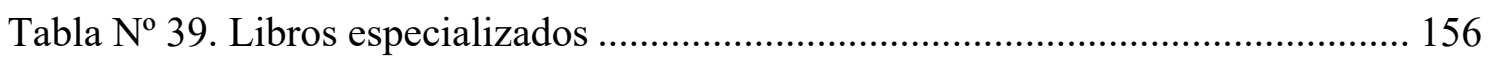

Tabla N $\mathrm{N}^{\mathrm{o}}$ 40. Tabla de MYPE del subsector restaurante encuestadas .......................... 158

Tabla $N^{o}$ 41. Cumplimiento de entregables del proceso de costos .............................. 160

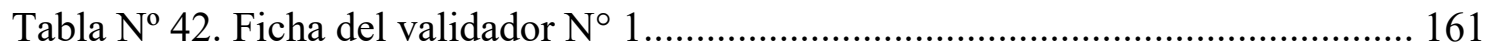

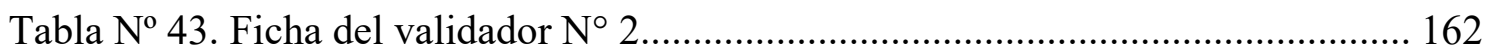

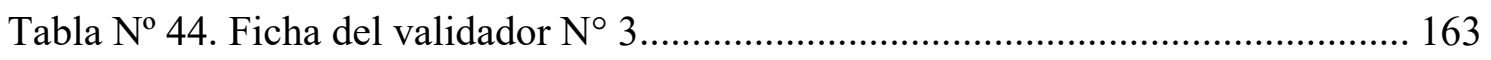

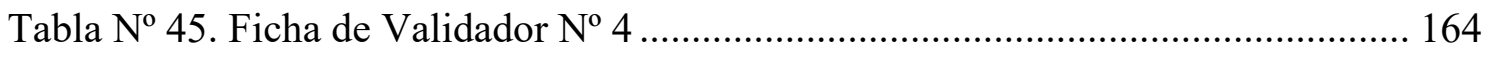

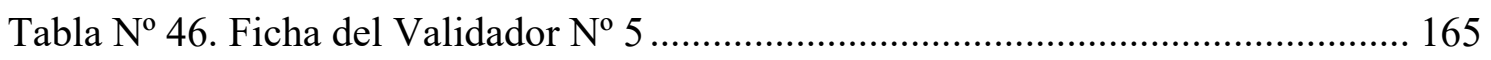

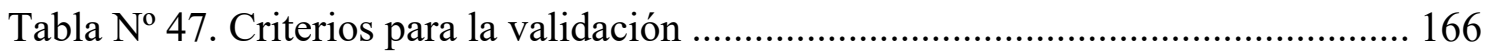

Tabla $\mathrm{N}^{\mathrm{o}}$ 48. Formato de validación para el modelo de costos .................................... 167

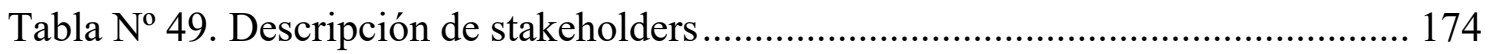

Tabla No 50. Descripción de las dimensiones de los stakeholders .............................. 176

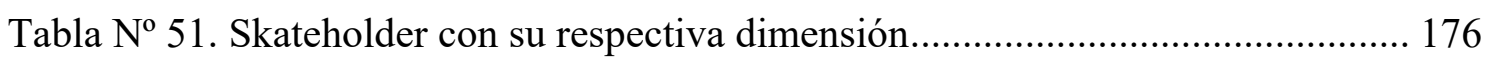

Tabla $\mathrm{N}^{\mathrm{o}}$ 52. Valores de calificación para la matriz de impactos ................................. 180

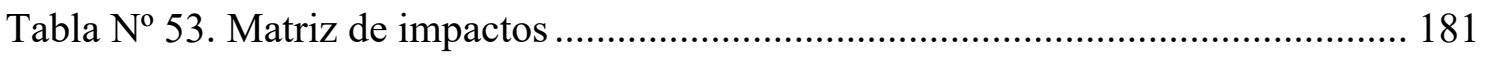




\section{ÍNDICE DE ILUSTRACIONES}

Ilustración N ${ }^{o}$ 1. Línea de Pobreza (Gasto Per Cápita vs Población).............................. 25

Ilustración N N 2. Evolución de la Línea de Pobreza 2007-2016 (en Soles).................... 26

Ilustración No 3. Evolución de la Línea de Pobreza Extrema 2007-2016 (En Soles) .... 26

Ilustración $\mathrm{N}^{\mathrm{o}}$ 4. Evolución de la pobreza (en porcentaje de peruanos) .......................... 28

Ilustración N 5. Cantidad de PBI del Perú desde el 2007 hasta el 2016 (en millones de

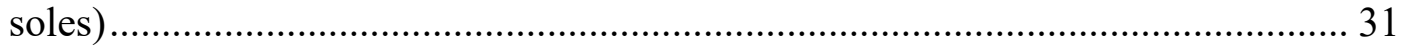

Ilustración $\mathrm{N}^{\mathrm{o}}$ 6. Evolución del crecimiento porcentual del PBI desde el 2006 hasta el 2016 . 32

Ilustración No 7. Evolución del PBI por sector económico 2015-2016. 35

Ilustración $\mathrm{N}^{\circ}$ 8. Nivel de ventas a cumplir para ser catalogado dentro algún estrato empresarial 36

Ilustración $N^{o}$ 9. Evolución del producto bruto interno en el cuarto trimestre del 201648

Ilustración $\mathrm{N}^{\mathrm{o}}$ 10. Crecimiento del PBI por actividad económica 2015-2016 49

Ilustración $\mathrm{N}^{\mathrm{o}}$ 11. Crecimiento del sector alojamiento y restaurantes en el Perú 2008-2016

Ilustración $\mathrm{N}^{\mathrm{o}}$ 12. Evolución del crecimiento del sector alojamiento y restaurantes en el 2016 . 50

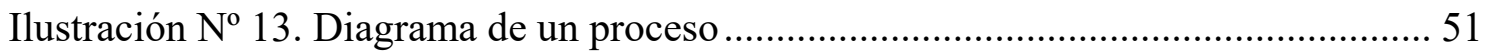

Ilustración $\mathrm{N}^{\mathrm{o}}$ 14. Beneficios de la gestión por procesos .............................................. 55

Ilustración $\mathrm{N}^{\mathrm{o}}$ 15. Ventajas del uso del SIPOC en la gestión por procesos..................... 58

Ilustración $\mathrm{N}^{\mathrm{o}}$ 16. Ventajas del costeo basado en órdenes de trabajo.............................. 68

Ilustración $\mathrm{N}^{\mathrm{o}}$ 17. Desventajas del costeo basado en órdenes de trabajo .........................69

Ilustración $\mathrm{N}^{\mathrm{o}}$ 18. Ventajas del empleo del costeo ABC ................................................ 71

Ilustración $\mathrm{N}^{\mathrm{o}}$ 19. Desventajas del empleo del costeo ABC.......................................... 72

Ilustración $\mathrm{N}^{\mathrm{o}}$ 20. Enfoque de la gestión de costos según el costeo ABC ...................... 73

Ilustración N N 21. PBI (en millones de Soles) vs Índice de Pobreza (en \%) ................... 76

Ilustración $\mathrm{N}^{\mathrm{o}}$ 22. Porcentaje del PBI por sector económico desde el 2010 hasta el 2016

Ilustración $\mathrm{N}^{\mathrm{o}}$ 23. PEA ocupada por sector económico.............................................. 78

Ilustración $N^{\circ}$ 24. PEA ocupada por actividades económicas en Lima Metropolitana 2016 
Ilustración $\mathrm{N}^{\mathrm{o}} 25$. Ponderación del sector Alojamiento y restaurantes en el Perú 80

Ilustración $\mathrm{N}^{\mathrm{o}} 26$. Evolución del crecimiento mensual del subsector restaurantes en el 2016 . 81

Ilustración $\mathrm{N}^{\mathrm{o}}$ 27. Cantidad de MIPYMES formales por actividad empresarial en el Perú 2015

Ilustración $N^{o}$ 28. Ficha Técnica de la encuesta para MYPE del subsector restaurantes en Lima Metropolitana

Ilustración N ${ }^{\circ}$ 29. Porcentaje de MYPE del subsector restaurantes en Lima Metropolitana con respecto al número de establecimiento que posee

Ilustración $\mathrm{N}^{\mathrm{o}} 30$. Porcentaje de MYPE del subsector restaurantes en Lima Metropolitana que contaron con un Plan de Negocio 88

Ilustración $N^{o}$ 31. Porcentaje de MYPE del subsector restaurantes en Lima Metropolitana que han innovado su servicio

Ilustración $N^{o}$ 32. Porcentaje de MYPE del subsector restaurantes en Lima Metropolitana que piensan expandirse 90

Ilustración $\mathrm{N}^{\mathrm{o}} 33$. Porcentaje de representación del total de problemas que presentan las MYPE del subsector restaurantes de Lima Metropolitana 91

Ilustración $\mathrm{N}^{\mathrm{o}} 34$. Encargado de manejar los costos dentro de la MYPE del subsector restaurante en Lima Metropolitana

Ilustración $N^{o}$ 35. Jerarquía de costos basado en las opiniones de las MYPE del subsector restaurantes en Lima Metropolitana

Ilustración $N^{o}$ 36. Porcentaje de MYPE del subsector restaurantes en Lima Metropolitana que conocen el Costo Unitario de sus productos. 94

Ilustración $\mathrm{N}^{\mathrm{o}}$ 37. Situación del precio unitario de los productos de las MYPE del subsector restaurantes en Lima Metropolitana 95

Ilustración N ${ }^{o}$ 38. Porcentaje de MYPE del subsector restaurantes en Lima Metropolitana que opinan acerca de un sistema de costos

Ilustración $N^{o} 39$. Porcentaje de opiniones de las MYPE del subsector restaurantes acerca de un modelo de costos. 96

Ilustración $N^{o}$ 40. Mapa de Procesos para una MYPE del subsector restaurantes ........ 102

Ilustración No 41. Diagrama relacional de procesos..................................................... 104

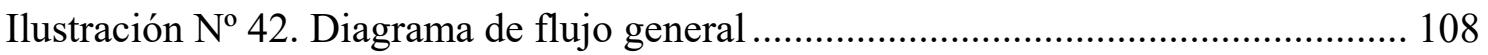

Ilustración $\mathrm{N}^{\mathrm{o}}$ 43.Mapa interrelacional del proceso de costos.................................... 111

Ilustración $\mathrm{N}^{\mathrm{o}}$ 44. Mapa de subprocesos de costos de una MYPE del subsector restaurantes 
Ilustración $\mathrm{N}^{\mathrm{o}}$ 45. Diagrama de flujo del subproceso Lineamientos del proceso 116

Ilustración $\mathrm{N}^{\circ}$ 46. Diagrama SIPOC del subproceso Lineamientos del proceso 118

Ilustración No 47. Diagrama de flujo del subproceso de Control Documentario 119

Ilustración No 48. Diagrama SIPOC del subproceso Control Documentario. 120

Ilustración $N^{o}$ 49. Diagrama de flujo del subproceso de Clasificación de costos 122

Ilustración $\mathrm{N}^{0} 50$. Diagrama SIPOC tortuga del subproceso de Clasificación de costos 123

Ilustración $\mathrm{N}^{\mathrm{0}}$ 51. Diagrama de flujo del subproceso de Asignación y cálculo del costo unitario 125

Ilustración $N^{0}$ 52. Diagrama SIPOC tortuga del subproceso Asignación y cálculo del costo unitario 126

Ilustración $\mathrm{N}^{\mathrm{o}}$ 53. Año de publicación. 157

Ilustración N ${ }^{\mathrm{o}} 54$. Resultados de validación de Juan Paulo Rivero Zanatta. 168

Ilustración No 55 . Resultados de la validación de Humberto Gálvez Raimondi 169

Ilustración $\mathrm{N}^{\mathrm{0}}$ 56. Resultados de la validación de Juan Carlos Cruz. 170

Ilustración $N^{0}$ 57. Resultados de la validación de Otto Arellano Cepeda 171

Ilustración No 58. Resultados de la validación de Elsa Álvarez Morales 172

Ilustración $\mathrm{N}^{\mathrm{o}} 59$. Resumen de los resultados generales de los validadores 173 


\section{ÍNDICE DE ANEXOS}

Anexo $\mathrm{N}^{0}$ 1. Procedimiento del subproceso Lineamientos del proceso ........................ 192

Anexo No 2. Procedimiento del subproceso Control Documentario ............................. 196

Anexo $N^{o}$ 3. Procedimiento del subproceso Clasificación de costos ............................ 198

Anexo $N^{o}$ 4. Procedimiento del subproceso Asignación y cálculo del costo unitario.. 200

Anexo No 5. Formato estandarizado de costeo ABC - Platillos .................................... 202

Anexo $N^{o}$ 6. Formato estandarizado de costeo ABC - Postres preparados .................. 205

Anexo $\mathrm{N}^{\circ}$ 7. Formato estandarizado de costeo ABC - Postres adquiridos................... 206

Anexo $\mathrm{N}^{\mathrm{o}}$ 8. Formato estandarizado de costeo ABC - Bebidas.................................... 207

Anexo $\mathrm{N}^{\mathrm{o}}$ 9. Formato estandarizado de costo ABC - Bebidas adquiridas .................... 208

Anexo No 10. Procedimiento para el uso del Formato Estándar de Costos................... 209 


\section{INTRODUCCIÓN}

Durante muchos años se ha enfocado a mejorar la economía desde un punto de vista muy diferente a la realidad de la mayoría de empresarios del Perú. El Gobierno Peruano ha fomentado leyes o modificado artículos para poder brindar mayores facilidades a los empresarios para que puedan desarrollar sus negocios sin tantas trabas burocráticas o impuestos. La mayoría de mejoras, sean pocas o muchas en un año, han enfocado su atención hacia las grandes empresas ya que son las que más aportan tanto en tributos como en nivel de ventas.

Sin embargo, existe un grupo empresarial que es grande en cantidad a lo largo del Perú: Las micro y pequeñas empresas. Las MYPE han experimentado una evolución considerable a lo largo de la última mitad del siglo XX y, ahora, llegan a abarcar más del 90\% del total de empresas que existe en el Perú. Sin embargo, solo han llegado a tener mediana atención por parte de los estudiosos debido a que, muchas de ellas, no cuentan con la infraestructura necesaria como para poder crecer en el corto plazo.

El propósito de esta tesis no es aportar un estudio irreal de una determinada situación de las MYPE, es proporcionar una herramienta, al nivel académico, para un propietario o encargado de una MYPE; con el fin de que pueda manejar y controlar sus procesos, sean básicos o complejos, de una manera más adecuada de como lo viene realizando hasta el momento.

Uno de los principales problemas que atraviesa este tipo de empresas es el escaso o nulo conocimiento sobre el manejo y control de sus costos lo que los lleva, muchas veces, a tener pérdidas y a desaparecer como empresa. La presente investigación propone un modelo de costos que puede ser utilizado tanto en una MYPE como en un conjunto de las mismas. Este documento será desarrollado durante 6 capítulos donde se ajustará los 
conocimientos teóricos acumulados, durante cerca de 5 años de carrera, a la realidad del microempresario y pequeño empresario de la ciudad de Lima. 


\section{CAPITULO I}

En el presente capítulo, se busca realizar una investigación en base a textos y artículos, los cuales permitan definir y entender todos los conceptos relacionados a las MYPE en el Perú. Después de recopilar y analizar toda la información proporcionada por las fuentes, se seleccionará un subsector económico en específico, el cual será desarrollado en el presente documento. 


\subsection{Investigación académica}

Se puede definir como investigación al conjunto de procesos tantos críticos como empíricos que, de forma sistemática, se aplican para el estudio y, posterior, entendimiento de un fenómeno ${ }^{1}$.

\subsubsection{Tipos de investigación}

La investigación se puede clasificar en ramas independientes entre sí:

1. Investigación experimental

Es aquella investigación la cual se basa, como su nombre bien lo dice, en un experimento. Se les denomina así porque manipulan las variables independientes de un entorno para, posteriormente, analizar las consecuencias generadas sobre las variables dependientes ${ }^{2}$.

2. Investigación no experimental

Es aquella investigación la cual se realiza sin manipular las variables que la conforman; lo que se hace en este tipo de investigación es observar aquellos fenómenos que se dan en su contexto actual y natural para, posteriormente, someterlos a un análisis detallado ${ }^{3}$.

Dentro de las investigaciones no experimentales, encontramos dos clasificaciones que son:

- Longitudinal: Es aquella en la cual el estudio recopila diferentes variables en diferentes momentos del tiempo para analizar sus causas, su evolución y sus efectos ${ }^{4}$.

- Transaccional: Es aquella que describe variables y analiza su interrelación en un momento dado dentro de un único tiempo ${ }^{5}$. Esta, además, se subdivide en tres:

- Exploratorio: Su propósito es explorar una determinada cuestión de un problema nuevo o poco explorado ${ }^{6}$.

\footnotetext{
${ }^{1}$ Cfr. Hernández 2010:4

${ }^{2}$ Cfr. Hernández 2010: 121

${ }^{3}$ Cfr. Hernández 2010: 149

${ }^{4}$ Cfr. Hernández 2010: 158

${ }^{5}$ Cfr. Hernández 2010: 151

${ }^{6}$ Cfr. Hernández 2010: 152
} 
- Correlacionales-causales: La finalidad de este estudio es determinar la relación y/o grado de asociación que existe entre dos o más variables dentro de un contexto ${ }^{7}$.

- Descriptivo: Son aquellos estudios que describen una o varias variables dentro de una modalidad, población o situación $^{8}$. Su valor radica en mostrar las diferentes dimensiones de un contexto o situación 9 .

El tipo de investigación que se desarrollará en el presente documento es de tipo no experimental transeccional descriptiva debido a que se describirán y analizarán las variables de un determinado sector o subsector económico del Perú sin tener que interferir directamente en ellas.

\subsubsection{Elección del enfoque de la investigación}

Existen 2 enfoques principales de investigación: cualitativo y cuantitativo. El enfoque cualitativo busca ajustar las preguntas o proporcionar nuevas interrogantes a través de la recolección y análisis de datos; por otro lado, el enfoque cuantitativo recolecta datos con la finalidad de probar la hipótesis con base a la medición y análisis estadístico. ${ }^{10}$ Asimismo, se puede enfocar una investigación con la combinación de ambas. A continuación, se describe las principales características de estos enfoques; cabe resaltar que la información de la tabla es una combinación de puntos de vista de dos libros con autores distintos ${ }^{11}$.

\footnotetext{
${ }^{7}$ Cfr. Hernández 2010: 85

${ }^{8}$ Cfr. Hernández 2010: 152

${ }^{9}$ Cfr. Hernández 2010: 85

${ }^{10}$ Cfr. Hernández 2014: 4-6

${ }^{11}$ Cfr. Creswel 2003: 19; Hernández 2010: 10-13. La tabla 1. Características de los enfoques de una investigación, es un "mix" de información del artículo de Creswell del año 2003 y del libro de los autores Hernández, Fernández y Baptista del año 2010.
} 
Tabla $\mathrm{N}^{\mathrm{o}}$ 1. Características de los enfoques de una investigación

\begin{tabular}{|c|c|c|c|}
\hline & Enfoque cualitativo & Enfoque cuantitativo & Enfoque Mixto \\
\hline Metas & $\begin{array}{l}\text { Exploración } \\
\text { entendimiento. }\end{array}$ & $\begin{array}{l}\text { Descripción } \\
\text { explicación. }\end{array}$ & $\begin{array}{ll}\text { Utiliza } & \text { ambos } \\
\text { enfoques } \\
\text { (cuantitativo } \\
\text { cualitativo). }\end{array}$ \\
\hline $\begin{array}{|ll|}\text { Estrategias } & \text { de } \\
\text { investigación } & \\
\end{array}$ & $\begin{array}{l}\text { Teoría, caso de } \\
\text { estudio y narrativa. }\end{array}$ & $\begin{array}{l}\text { Encuestas } \\
\text { experimentos. }\end{array}$ & $\begin{array}{ll}\text { Secuencial } & \text { y } \\
\text { simultáneo. } & \\
\end{array}$ \\
\hline Hipótesis & $\begin{array}{l}\text { Las hipótesis nacen } \\
\text { durante } \\
\text { investigación o al final } \\
\text { de esta. }\end{array}$ & $\begin{array}{l}\text { Las hipótesis } \\
\text { establecen antes de la } \\
\text { investigación. Se acepta } \\
\text { o se rechaza de acuerdo } \\
\text { a los resultados. }\end{array}$ & $\begin{array}{l}\text { Se establecen antes, } \\
\text { durante o al final de } \\
\text { la investigación. }\end{array}$ \\
\hline Métodos & $\begin{array}{l}\text { Preguntas abiertas, } \\
\text { enfoques emergentes, } \\
\text { análisis de texto. }\end{array}$ & $\begin{array}{lr}\text { Preguntas } & \text { cerradas, } \\
\text { enfoques } & \\
\text { predeterminados, } & \text { datos } \\
\text { numéricos, } & \text { análisis } \\
\text { estadísticos. } & \end{array}$ & $\begin{array}{l}\text { Preguntas abiertas y } \\
\text { cerradas, enfoques } \\
\text { predeterminados y } \\
\text { emergentes. Datos y } \\
\text { análisis cualitativos y } \\
\text { cuantitativos. }\end{array}$ \\
\hline Datos & $\begin{array}{l}\text { Enriquecedores } \\
\text { profundos. Se } \\
\text { comprender }\end{array}$ & $\begin{array}{l}\text { Confiables y } \text { duros. El } \\
\text { análisis de los } \\
\text { servirá para describir las } \\
\text { variables y } \\
\text { cambionder sus } \\
\text { estadístico. }\end{array}$ & $\begin{array}{l}\text { Se utilizan ambos: } \\
\text { Primero aplica uno y } \\
\text { luego el otro. } \\
\text { Predomina uno } \\
\text { sobre el otro. } \\
\text { Combina ambos } \\
\text { durante toda la } \\
\text { investigación. } \\
\end{array}$ \\
\hline Resultados & $\begin{array}{l}\text { Diagramas, videos, } \\
\text { fotografias, } \\
\text { narraciones. } \\
\text { presenta de forma } \\
\text { personal, emotiva. }\end{array}$ & \begin{tabular}{lrr|} 
Diagramas, & tablas, \\
modelos & estadísticos. \\
Formato & estándar. & Se \\
presenta & de & forma \\
objetiva, & impersonal, no \\
emotiva. & &
\end{tabular} & $\begin{array}{l}\text { Utiliza y presenta } \\
\text { ambas herramientas. }\end{array}$ \\
\hline
\end{tabular}

Fuente: Adaptado de Hernández, Fernández y Baptista 2010 y Creswell 2003

\subsubsection{Toma de Datos}

Existen dos tipos de muestreo: probabilístico y no probabilístico. El muestreo probabilístico es aquel en el cual todos los individuos participantes cuentan con la misma probabilidad de ser seleccionados para formar parte de una muestra ${ }^{12}$. Mientras que el muestreo no probabilístico, los sujetos no tienen igual probabilidad de ser seleccionados. Los tipos de muestreo probabilísticos y no probabilísticos más usados son:

${ }^{12}$ La definición puede encontrarla en la página 1 del artículo proporcionado por la Universidad de Sonora titulado Muestreo. Confrontar en la bibliografía. 
Tabla $\mathrm{N}^{\circ}$ 2. Tipos de muestreo

\begin{tabular}{|c|l|}
\hline Tipos & \multicolumn{1}{|c|}{ Definición } \\
\hline Aleatorio Simple & $\begin{array}{l}\text { Este método es muy usado y atractivo debido a su simpleza; es } \\
\text { muy práctico cuando se trabaja con una población pequeña o } \\
\text { mediana. }\end{array}$ \\
\hline $\begin{array}{c}\text { Aleatorio } \\
\text { Sistemático }\end{array}$ & $\begin{array}{l}\text { Puede ser utilizado en poblacionales homogénea por lo que es } \\
\text { conveniente su uso en poblaciones que no presentan } \\
\text { periodicidades. }\end{array}$ \\
\hline $\begin{array}{c}\text { Aleatorio } \\
\text { estratificado }\end{array}$ & $\begin{array}{l}\text { Este tipo de muestreo consiste en considerar a todos los estratos } \\
\text { que conforman una población para que se encuentren } \\
\text { adecuadamente representados en la muestra. }\end{array}$ \\
\hline $\begin{array}{c}\text { Aleatorio por } \\
\text { conglomerados }\end{array}$ & $\begin{array}{l}\text { Se conforman grupos de interés de una población para tratarlos } \\
\text { como una unidad de muestra. }\end{array}$ \\
\hline
\end{tabular}

Fuente: Adaptado de Universidad de Sonora

Por otro lado, los tipos de muestreo no probabilísticos son:

Tabla $\mathrm{N}^{\circ}$ 3. Tipos de muestreo no probabilístico

Fuente: Adaptado de Universidad de Sonora

\begin{tabular}{|l|l|}
\hline Tipos & Definición \\
\hline Por cuotas & $\begin{array}{l}\text { Generalmente, es usado cuando se tiene un buen conocimiento } \\
\text { acerca de los estratos más "representativos" de una población }\end{array}$ \\
\hline Por conveniencia & $\begin{array}{l}\text { Obtiene muestras "representativas" al trabajar en base a una } \\
\text { muestra de un grupo "típico" dentro de una población. }\end{array}$ \\
\hline Bola de nieve & $\begin{array}{l}\text { Se caracteriza por localizar un determinado grupo de individuos, } \\
\text { los cuales conducen a otro, y así sucesivamente hasta conseguir } \\
\text { una muestra adecuada. }\end{array}$ \\
\hline
\end{tabular}

La selección del tipo de muestreo que se utilizará dentro de la investigación será presentada en el capítulo 2. Esto se debe a que aún hay detalles que deben ser descritos y analizados durante el largo de este capítulo. 


\subsection{Hipótesis}

Se le denomina hipótesis a aquella explicación tentativa sobre un determinado fenómeno o situación que es objeto de investigación y que está formulada como una proposición; por lo tanto, estas surgen del planteamiento de un problema ${ }^{13}$. Una característica de una hipótesis es que es una respuesta provisional a una determinada cantidad de preguntas dentro de la investigación ${ }^{14}$. Además, una hipótesis busca relacionar lo observado con lo teórico, así como la observación con la teoría y, generalmente, está elaborada en base a dos o más variables ${ }^{15}$.

\subsubsection{Tipos de hipótesis}

Tabla $\mathrm{N}^{\circ} 4$. Tipos de hipótesis con sus respectivas definiciones

\begin{tabular}{|l|l|}
\hline Tipos de hipótesis & Definición \\
\hline Hipótesis de investigación & $\begin{array}{l}\text { Son las proposiciones, de carácter tentativo, sobre } \\
\text { la o las posibles relaciones existentes entre dos o } \\
\text { más variables de estudio. Estas pueden aplicarse a } \\
\text { situaciones descriptivas, correlaciónales, de } \\
\text { diferencia o causales. }\end{array}$ \\
\hline Hipótesis de nulas & $\begin{array}{l}\text { Son proposiciones que niegan o refutan alguna } \\
\text { relación entre determinadas variables. }\end{array}$ \\
\hline Hipótesis alternativas & $\begin{array}{l}\text { Son aquellas posibilidades que son alternas o } \\
\text { diferentes ante un hipótesis de investigación o } \\
\text { nula. Deben ser formuladas solo sí existe una línea } \\
\text { alterna a hipótesis de investigación y nula. }\end{array}$ \\
\hline Hipótesis estadísticas & \begin{tabular}{l} 
Son aquellas propias de un estudio cuantitativo. \\
\hline
\end{tabular}
\end{tabular}

Fuente: Adaptado de Hernández 2010

El tipo de hipótesis que se planteará es una hipótesis de investigación debido al enfoque que tiene el presente trabajo. Por otro lado, su elección se debe a que se manejan distintas variables y se brindará una proposición tentativa acerca de cómo estas se relacionan entre sí y como tratarlas en su conjunto.

\footnotetext{
${ }^{13}$ Cfr. Hernández 2010: 92-93

${ }^{14}$ Cfr. Hernández 2010: 92

${ }^{15}$ Cfr. Abreu 2012: 187
} 


\subsubsection{Formulación de la hipótesis}

Para la formulación de una hipótesis es totalmente indispensable definir las variables que se utilizarán ya que se debe asegurar que estas puedan ser medidas y evaluadas con datos que se puedan obtener de la realidad; su definición ayuda a evaluar adecuadamente los resultados que se obtienen de una investigación ${ }^{16}$. De forma simultánea, se define los siguientes puntos con respecto a las variables:

- Definición conceptual: se refiere a aquellas definiciones provenientes de libros o diccionarios especializados que describen las características de una variable ${ }^{17}$.

- Definición operacional: engloba todos los procedimientos necesarios para poder medir una determinada variable ${ }^{18}$.

\subsection{Situación social del Perú}

\subsubsection{La línea de pobreza}

Para que se pueda definir y analizar todo lo relacionado a la pobreza monetaria, es necesario plantear ciertos parámetros que permitan facilitar su estudio. La línea de pobreza es un valor monetario el cual se compara con el gasto per capita mensual de un hogar, para poder establecer si es que se encuentra en condiciones de pobreza o no ${ }^{19}$. En el año 2016, el valor de la línea de pobreza ascendió a S/ 328.00 per capita mensual, aumentando con respecto al año $2015^{20}$.

Además, la línea de pobreza está conformada por la línea de pobreza extrema y el componente no alimentario $^{21}$, esto ayuda a diferenciar a las personas pobres de las personas que se encuentran en extrema pobreza.

- Línea de pobreza extrema: También llamado componente alimentario, está conformada por todos los productos de una canasta alimentaria que es aceptada socialmente, el cual, actualmente, equivale a S/ 176.00 Soles por persona que conforma un hogar ${ }^{22}$.

\footnotetext{
${ }^{16}$ Cfr. Hernández 2010: 109-110

${ }^{17}$ Cfr. Hernández 2010: 110

${ }^{18}$ Cfr. Hernández 2010: 111

${ }^{19}$ Cfr. INEI 2017: 33

${ }^{20} \mathrm{Cfr}$. INEI 2017: 36

${ }^{21}$ Cfr. INEI 2017: 33

${ }^{22}$ Cfr. INEI 2017: 33
} 
Los productos que la componen han sido previamente establecidos sobre la base de los patrones de consumo real de los hogares; considerando el mínimo de energía que requiere un poblador para que pueda efectuar sus actividades, dependiendo de su sexo, edad y lugar donde viven ${ }^{23}$.

- Componente no alimentario: El componente no alimentario está constituido por el valor de todos aquellos servicios y/o bienes el cual una persona necesita para satisfacer sus necesidades con respecto a vestimenta, calzado, cultura, educación, etc. El valor de dicho componente se realiza mediante una indexación de los precios de los productos nos alimentarios; este monto, sumado con el componente alimentario, da el valor de la línea de pobreza actual (S/ 328.00 Soles per capita mensual) $)^{24}$.

De acuerdo a lo mencionado anteriormente, se muestra la siguiente imagen:

\section{Ilustración Nº 1 . Línea de Pobreza (Gasto Per Cápita vs Población)}

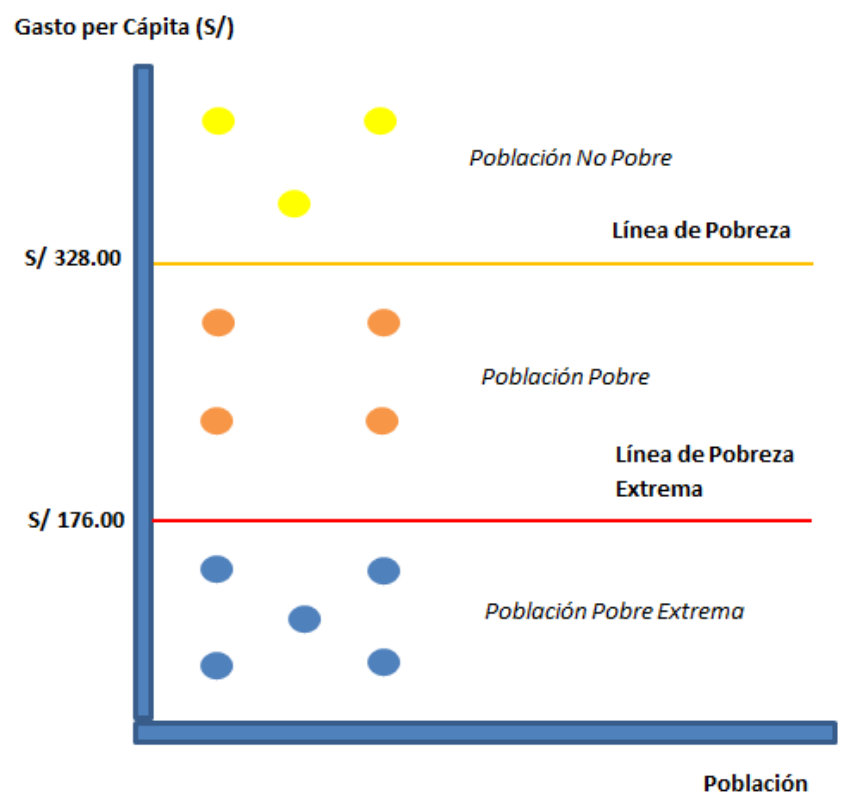

Fuente: Adaptado del INEI 2017

En el año 2016, la línea de pobreza extrema tiene un valor de S/ 176.00 soles mensuales por cada persona miembro de un hogar. Esto significó un aumento de $4.6 \%$ con respecto al año 2015 (S/ 169.00) ${ }^{25}$. A continuación, se muestra la siguiente gráfica:

\footnotetext{
${ }^{23}$ Cfr. INEI 2017: 33

${ }^{24}$ Cfr. INEI 2017: 36

${ }^{25}$ Cfr. INEI 2017: 33
} 
Ilustración Nº 2. Evolución de la Línea de Pobreza 2007-2016 (en Soles)

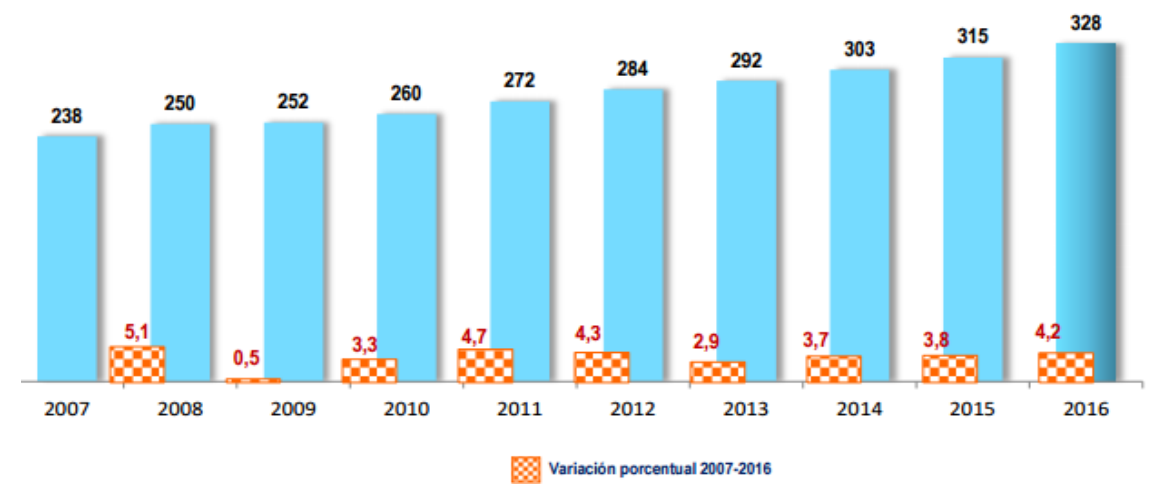

Fuente: INEI 2017

Como se puede observar, la línea base ha aumentado en $\mathrm{S} / 90.00$ en lo últimos 9 años; teniendo un aumento de $4.2 \%$ en el año 2016, con respecto al 2015. Esta tendencia va de la mano con el aumento de la línea de pobreza extrema.

Ilustración No 3. Evolución de la Línea de Pobreza Extrema 2007-2016 (En Soles)

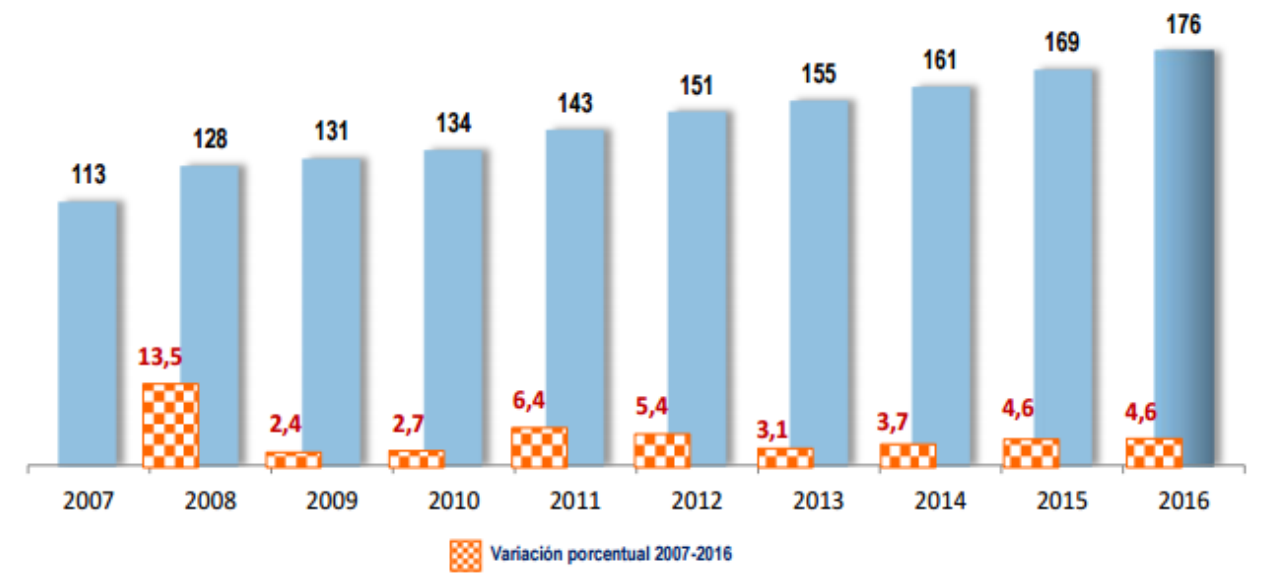




\section{Fuente: INEI 2017}

Al comparar el aumento porcentual de la línea de pobreza (imagen anterior) con el aumento porcentual de la línea de pobreza extrema, se puede evidenciar que el segundo ha sido mayor en los últimos 9 años. Entre el año 2016 y el 2007, la línea de pobreza extrema aumentó en S/ 63.00, teniendo un aumento de 4.6\% en el año 2016, con respecto al año 2015.

Si bien es cierto que la tendencia ascendente de la línea de pobreza pudiera llegar a ser un punto preocupante, no necesariamente esta tendencia puede suponer un aumento de la cantidad de pobre y pobres extremos en el Perú. De acuerdo a informes del INEI, al cierre del año 2016, el porcentaje de pobres extremos disminuyó a 4.8\%, con respecto al año 2015 (4.1\%); esto significa que 70,000 peruanos, aproximadamente, salieron de la pobreza extrema ${ }^{26}$. Adicional a esto, para el año 2016, el $20.7 \%$ del total de peruanos se encontraba en una situación de pobreza (teniendo gastos inferiores a la canasta básica de consumo); en comparación con el año 2015, en el cual el $21.8 \%$ se encontraba en dicha situación. Esto supone una disminución de la pobreza de $1.1 \%$, lo que a su vez quiere decir que 264 mil persona dejaron de ser pobres al cierre del año $2016^{27}$.

\subsubsection{Definición de pobreza}

Existen muchos estudiosos y organizaciones definen la pobreza de diversas maneras; esto se puede deber a que, dependiendo de cómo la definan, marca el rumbo de su investigación. El Profesor de la Facultad de Economía de la Pontificia Universidad Católica del Perú, Ivan Rivera, en uno de sus artículos académicos, define a la pobreza de la siguiente forma:

- Pobreza total: Se considera esta situación cuando los ingresos de una persona o de un determinado grupo de personas es igual o inferior a los dos dólares al día ${ }^{28}$.

- Pobreza extrema: Se considera a aquellas personas que perciben un ingreso que es igual o inferior a un dólar por día ${ }^{29}$.

Por otro lado, la pobreza es definida, en el glosario del Instituto Peruano de Economía (IPE), como la insuficiencia de gasto de una persona de cada hogar, tomando como base el valor de la línea de pobreza ${ }^{30}$. Sin embargo, se tomará la definición de Pobreza Monetaria proporcionada por el Instituto Nacional de Estadística e Informática (INEI).

\footnotetext{
${ }^{26}$ Cfr. Diario Perú 212017

${ }^{27}$ Cfr. INEI 2017: 41

${ }^{28}$ Cfr. Rivera 2012:12

${ }^{29}$ Cfr. Rivera 2012:12

${ }^{30}$ Cfr. IPE 2009
} 
Esta, en definición del INEI, es el valor, en términos monetarios, el cual se contrasta con el gasto per cápita mensual de un hogar para lograr determinar si se encuentran en condiciones de pobreza o no ${ }^{31}$.

\subsubsection{Pobreza en el Perú}

A mediados del 2017, el Centro para la Competitividad y el Desarrollo (CCD) ${ }^{32}$, brindó una entrevista al Diario Gestión en el cual aseguran que se puede disminuir la pobreza de un $21 \%$ a un $14 \%$ para el año 2021 , si es que se llevara a cabo los diversos proyectos mineros que, a día de hoy, aún no se ejecutan ${ }^{33}$.

Esto conlleva a que el Estado promueva leyes que beneficien a los sectores de grandes inversiones con el fin de mejorar los indicadores de niveles de pobreza del país.

Sin embargo, en palabras del Licenciado Eduardo Lastra, el gobierno aún no comprende que dichas leyes deben ser beneficiosas para las grandes, medianas y pequeñas inversiones; ya que la disminución de la pobreza no es tarea de un solo sector con gran poder económico ${ }^{34}$. A continuación, se muestra la evolución del porcentaje de pobreza en el Perú del 2007 al 2016, según el último informe del 2016 emitido por el INEI:

Ilustración $N^{o}$ 4. Evolución de la pobreza (en porcentaje de peruanos)

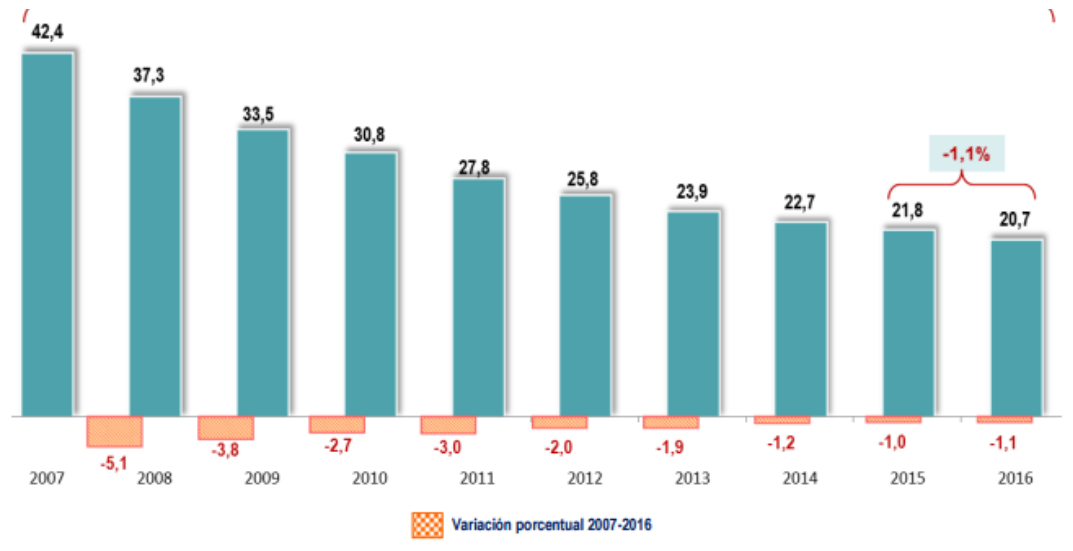

Fuente: INEI 2017

Como se muestra en el cuadro anterior, en los últimos 9 años, la pobreza ha disminuido en $21.7 \% \mathrm{y}$, además, ha mantenido su tendencia a bajar. A pesar de ello, resulta

\footnotetext{
${ }^{31}$ Cfr. INEI 2017: 33

${ }^{32}$ Centro de Competitividad y Desarrollo (CCD). Es una empresa privada con experiencia en asesorar empresas en temas relacionados a la inversión pública. Para más información: http://www.ccdcompetitividad.com/

${ }^{33}$ Cfr. Diario Gestión 2017

${ }^{34}$ Licenciado Eduardo Lastra Domínguez, administrador de profesión con 40 años de experiencia en MYPE. Es miembro del Instituto Latinoamericano de Desarrollo Empresarial (ILADE). ILADE es una institución que brinda asesoramiento a las MYPE que buscan mejorar sus negocios y ser más competitivos. (http://www.ilade.edu.pe/)
} 
importante resaltar que el porcentaje de disminución de la pobreza ha bajado entre cada año entre el 2007 y el 2016.

\subsubsection{El problema de la pobreza}

Para ningún ciudadano peruano es un secreto que la pobreza es un problema dentro del país. Sin embargo, la opinión pública ha cambiado su percepción de esta en los últimos años; en el 2010, la encuestadora Ipsos Apoyo, en el marco de su Sexta Encuesta Nacional sobre corrupción de Proética, indicó que el 35\% de peruanos consideraba a la pobreza como el principal problema del país, cifra mucho menor al 51\% que representaba en el año $2008^{35}$.

Sin embargo, en la última Encuesta Nacional de Hogares (Enaho) realizada por el INEI este año, solo el $19.8 \%$ de peruanos, mayores de 18 años, consideran que la pobreza es el principal problema del país ${ }^{36}$. Esto quiere decir que, en casi 10 años, el porcentaje de peruanos que consideran a la pobreza como el mayor problema del país ha disminuido en $31.2 \%$; esto se puede explicar ya que, en comparación con el 2008, el Perú se encuentra un poco mejor en temas sociales como económicos. A pesar de que la opinión pública sobre la pobreza ha cambiado, sigue siendo un problema principal que tiene el país ya que (como se muestra anteriormente en la ilustración 4.) aún hay un $20.7 \%$ de peruanos que son pobres.

Es importante recalcar que muchos peruanos que son considerados pobres tienen la dificultad de salir de su condición debido a que sus ingresos son tan bajos que, con el pasar de los días, se vuelven sumamente volátiles ${ }^{37}$. Esta situación está muy ligada a que la pobreza es el resultado de la exclusión social y la desigualdad existentes en el Perú; esto se debe a que bajo el modelo capitalista que maneja la economía, el Perú se encuentra sobrepoblado en lo que respecta a oferta laboral ya que el mercado laboral actual no es capaz de atender a este gran volumen de personas ${ }^{38}$.

Si bien no se puede despreciar el trabajo que se está realizando para disminuir poco a poco la cantidad de personas pobres en el Perú, aún se tiene mucho trabajo por adelante para poder "erradicar" la pobreza del suelo patrio. El Banco Mundial opina que, para lograr este cometido, el estado debe lograr que el crecimiento económico experimentado

\footnotetext{
${ }^{35}$ Cfr. El Comercio 2010. Artículo periodístico que toma como base la información del estudio de la encuestadora nacional Ipsos Apoyo, sobre la percepción de los peruanos en relación a los principales problemas del país.

${ }^{36}$ Cfr. Diario Perú 21 2017. Artículo periodístico que expone los resultados de la Encuesta Nacional de Hogares realizada por el INEI.

${ }^{37}$ Cfr. Rivera 2012: 18

${ }^{38}$ Cfr. Verdera 2007:48-49
} 
sea sustentable y disminuir la desigualdad de ingresos entre los peruanos para que cada uno aproveche los beneficios del bienestar económico ${ }^{39}$.

\subsection{Situación económica del Perú}

Desde el 2005 hasta la actualidad, el Perú ha presentado un índice de crecimiento económico positivo, superior en comparación a otras naciones de la región debido a que cuenta con una mayor exportación de materias primas, commodities, minerales, etc. Esto permite al estado generar más programas sociales, obras de infraestructura de mayor escala y otros beneficios relacionados al crecimiento del PBI nacional.

En el año 2008, el futuro del crecimiento económico se encontraba entre dos posibles escenarios:

- Escenario conservador: Es aquel escenario en el cual se cree que los determinantes del crecimiento van a evolucionar de acuerdo a sus tendencias históricas ${ }^{40}$.

- Escenario optimista: Es aquel en el cual se espera que los determinantes crezcan a un nivel elevado pero, casi siempre, inaccesible dado la coyuntura ${ }^{41}$.

El escenario para el Perú seguía siendo el más optimista, sin embargo en el 2011, el Perú ascendió 4 puestos en el ranking mundial de competitividad, sin embargo, esto no se debía tanto a una mejora de la competitividad empresarial peruano sino, más bien, a que otros países habían descendido en el ranking ${ }^{42}$. Esto puede ser tomado como la primera muestra de que el Perú iba a atravesar momentos difíciles.

Ya en el año 2013, la economía peruana estaba atravesando un proceso de desaceleración producto de dos eventos extremadamente negativos: la caída de los precios de las materias primas que se exportan y la salida de importantes capitales en mayo del $2013^{43}$.

Como era de esperarse, muchos economistas apoyaron el escenario optimista en su momento, sin embargo, las condiciones actuales no favorecen esa postura.

\subsubsection{Situación actual del crecimiento del PBI}

El Producto Bruto Interno (PBI) es el valor monetario del total de bienes y servicios finales que son producidos por una economía dentro de un periodo determinado. Es considerado como el indicador de medición de la economía peruana más relevante, y resulta de sumar el consumo efectuado por las familias (demanda interna, ya sea por

\footnotetext{
${ }^{39}$ Cfr. Banco Mundial: 2015. La información fue brindada en su página web.

${ }^{40}$ Cfr. Loayza 2008: 20

${ }^{41}$ Cfr. Loayza 2008: 20

${ }^{42}$ Cfr. García-Vega 2011: 114

${ }^{43}$ Cfr. Cuba 2015: 18
} 
medio de compra de bienes o servicios), inversión (gasto de las empresas para mayor producción en las mismas); el gasto del Gobierno; y compras en el exterior e interior del país (exportadores e importadores) ${ }^{44}$.

A continuación, se presenta el siguiente gráfico:

Ilustración No 5. Cantidad de PBI del Perú desde el 2007 hasta el 2016 (en millones de soles)

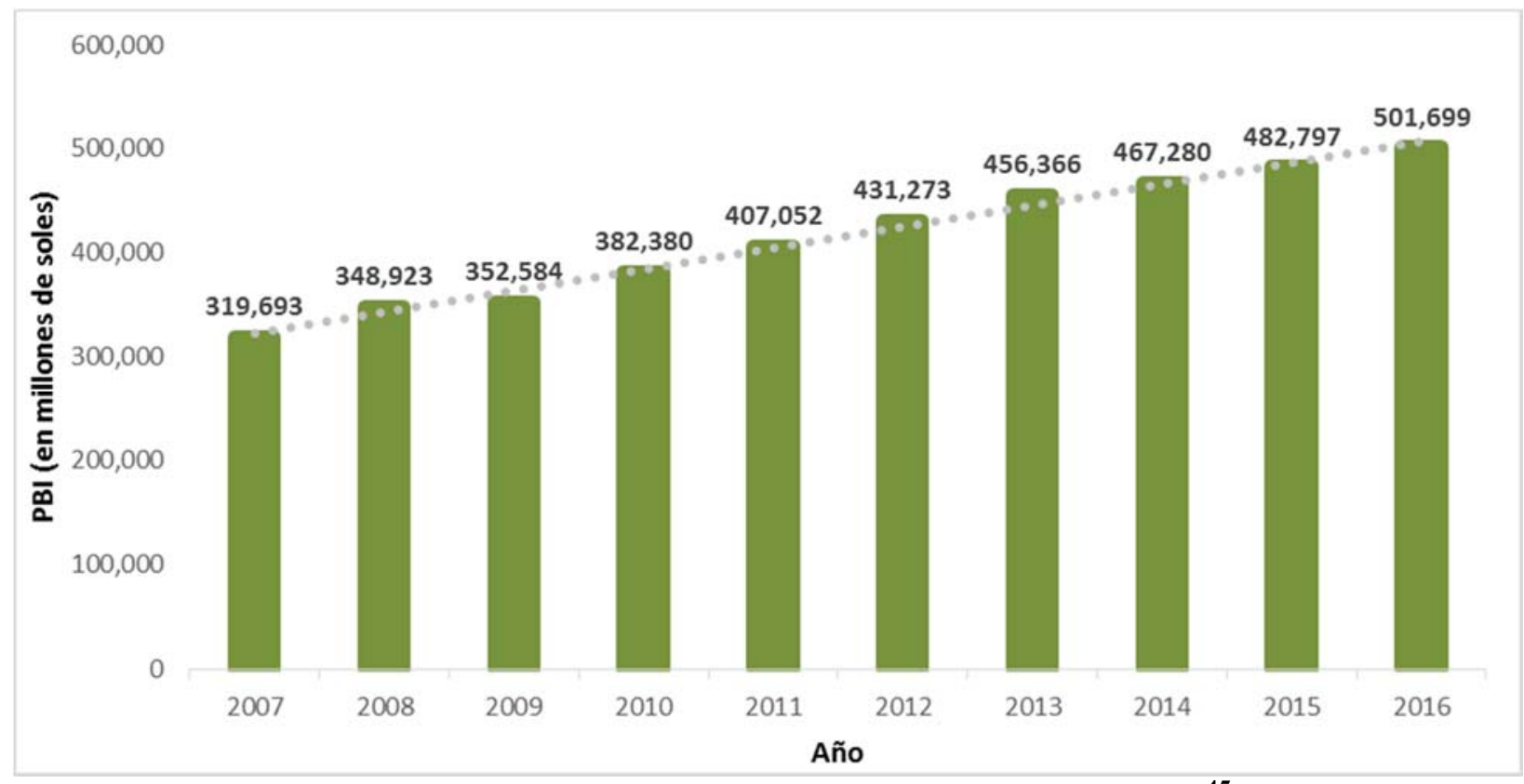

Fuente: Adaptado del Banco Central de Reserva del Perú ${ }^{45}$

Como se apreciar en la imagen anterior, el PBI del Perú ha crecido en los últimos años, pasando de 319,693 millones de soles en el 2007 ha 501,699 millones de soles en el 2016. Además, como se muestra en la imagen, en los últimos años ha habido una tendencia positiva, lo que significa que el PBI peruano se encuentra creciendo.

A pesar de esta tendencia, esto no significa que el PBI ha crecido en un porcentaje constante; a continuación, se muestra su evolución de crecimiento (en \%) en los últimos años.

44 Definición brindada por el Ministerio de Economía y Finanzas, por vía web. (https://www.mef.gob.pe/index.php?option $=$ com_content\&view $=$ article\&id=61\%3Aconoce-losconceptos-basicos-para-comprender-la-economia-del-pais\&Itemid=100694\&lang=es)

${ }^{45}$ Información proporcionada por el Banco Central de Reserva del Perú en su página web dedicada a Cuadros Anuales Históricos. Sin fecha indicada de publicación. 


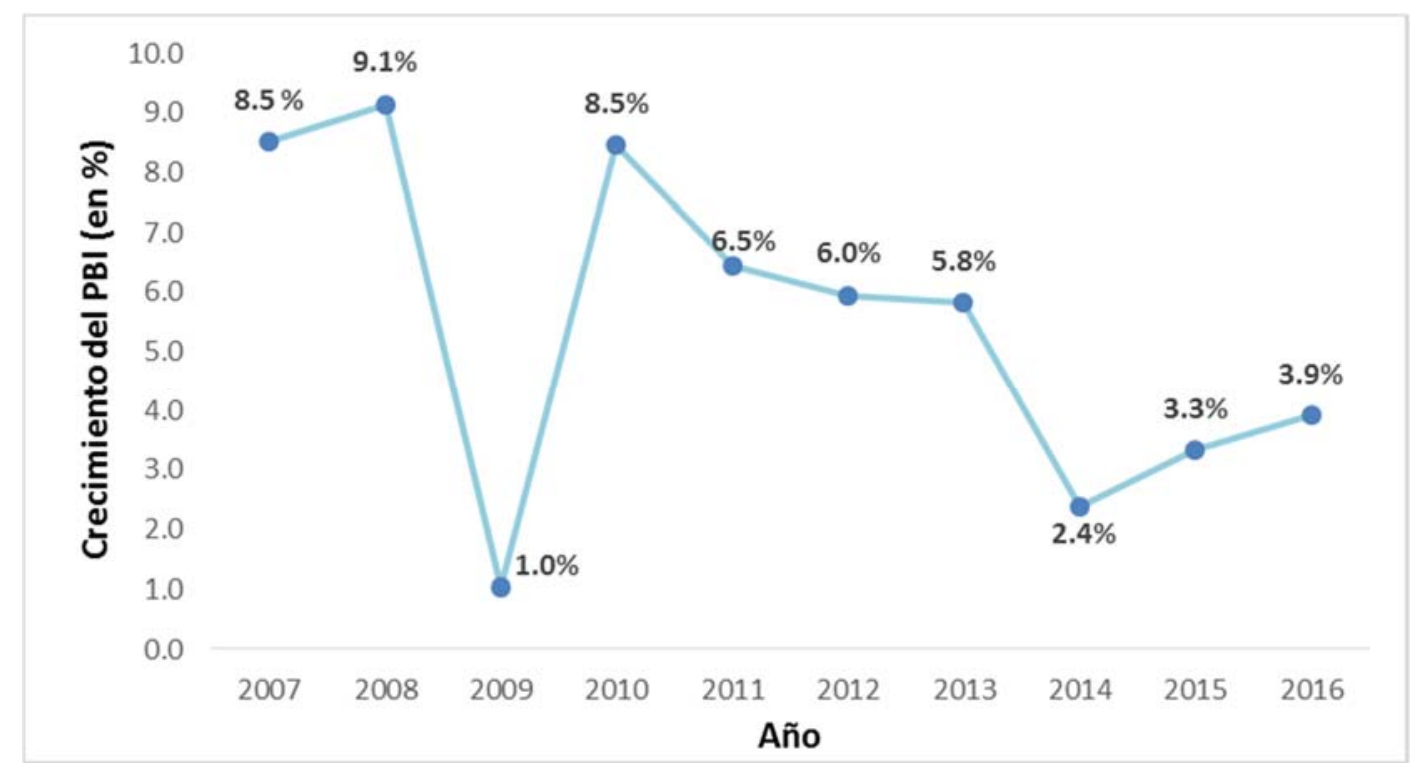

Fuente: Adaptado del Banco Central de Reserva ${ }^{46}$

Como se puedes apreciar en la gráfica, el porcentaje de crecimiento del PBI peruano no ha sido constante en los últimos años; experimentando su mayor caída en el 2009 (1.0\%) y su mayor auge en el 2008 (9.1\%). En los últimos 3 años (2014, 2015 y 2016) el porcentaje de crecimiento del PBI ha ido aumentando paulatinamente; sin embargo, este porcentaje no se compara con los índices alcanzados hace 10 años.

\subsubsection{Importancia del PBI}

Como se menciona anteriormente, el PBI peruano ha comenzado a retroceder en lo que respecta a variación porcentual. En un artículo periodístico del Diario El Comercio, Nicolás Castillo sostiene que un menor crecimiento del PBI representa que uno de los indicadores de medición de la economía se encuentra en procesos de desaceleración ${ }^{47}$.

La base del PBI se sustenta en el consumo de distintos tipos de productos manufactureros y de servicios; si esto no sucediera, el PBI comenzaría a mostrar una tendencia a la baja lo cual podría causar que las inversiones comiencen a disminuir ${ }^{48}$. Es por esto que el PBI fundamental al momento de realizar una inversión dentro del país; ya que evidencia si el mercado de consumo es atractivo para una empresa; por ende, representa cuánto dinero genera las diferentes actividades económicas del Perú.

\footnotetext{
${ }^{46}$ Información proporcionada por el Banco Central de Reserva del Perú en su página web dedicada a Cuadros Anuales Históricos. Sin fecha indicada de publicación

${ }^{47}$ Cfr. Diario el Comercio 2014. Nicolás Castillo es redactor de la sección de Economía y Finanzas del Diario el Comercio.

${ }^{48}$ Cfr. Diario El Comercio 2014. El editor cita este ejemplo para demostrar el impacto general que tiene el PBI dentro de la economía.
} 


\subsubsection{Predicciones de crecimiento para el 2017}

La perspectiva sobre el crecimiento del PBI peruano ha variado mucho en los últimos meses. En el mes de enero del presente año, el Fondo Monetario Internacional (FMI) elevó los proyección de crecimiento de $4.1 \%$ a $4.3 \%$ para el 2017 , debido a que se esperaba un aumento importante del precio cobre, así como mayores gastos públicos y de los diversos consumidores ${ }^{49}$.

Sin embargo, solo 3 meses después de haber brindado esta proyección, el FMI realizó un reajuste a las proyecciones de crecimiento económico para varios países de Latinoamérica; el resultado no fue muy alentador. La prestigiosa institución pronosticó que el PBI peruano solo iba a crecer en $3.5 \%$ para el final del año $2017^{50}$, lo que supone una baja de $0.8 \%$ con respecto al pronóstico inicial.

Si bien panorama aún parecía alentador, solo un mes después, el FMI volvió a realizar un recalculo de la proyección de crecimiento del PBI peruano para finales del 2017; debido a problemas nacionales como el caso de corrupción de Odebrecht y los daños a la infraestructura nacional debido al Fenómeno El Niño, el organismo internacional proyectó que el Perú solo crecería en un $2.7 \%{ }^{51}$. Esto supone un descenso de $0.8 \%$ con respecto a la proyección del mes de abril.

Un punto importante a resaltar, es que el crecimiento del PBI peruano en el primer trimestre del 2017 llegó a ser de $2.1 \%{ }^{52}$, un porcentaje no muy alejado de la última proyección anual del FMI.

A pesar de este panorama, el FMI sostiene que si es que se llevan a cabo reformas como un mejor sistema tributario para las pequeñas y medianas empresas, mayor inversión en infraestructura y la reducción de procesos administrativos, junto con las reformas actuales de modernización económica y formalización empresarial, la economía peruana tendrá una mayor sostenibilidad para poder crecer más ${ }^{53}$.

Lo expuesto por el FMI resulta importante, sobre todo, en el punto que expone la formalización de las empresas como eje para lograr un crecimiento económico sustentable, que, a su vez, va de la mano con la disminución de la pobreza en el país.

\footnotetext{
${ }^{49}$ Cfr. Diario Gestión 2017. El Director del Departamento del Hemisferio Occidental del FMI, Alejandro Werner, brinda una entrevista sobre la proyección del PBI peruano para finales del 2017.

${ }^{50}$ Cfr. Diario Gestión 2017. En este artículo, el FMI explica las razones de sus nuevas proyecciones de crecimiento para distintos países.

${ }^{51}$ Cfr. Diario El Comercio 2017. En este artículo, el FMI explica las razones de la nueva proyección de crecimiento del PBI peruano.

${ }^{52}$ Cfr. INEI 2017: 1

${ }^{53}$ Cfr. Diario El Comercio 2017. En este artículo, el FMI explica las razones de la nueva proyección de crecimiento del PBI peruano.
} 


\subsection{Situación empresarial del Perú}

\subsubsection{Sectores productivos en el Perú}

\subsubsection{Tipos de sectores productivos}

Según Instituto Peruano de Economía (IPE), dentro de la economía nacional, se puede dividir las actividades económicas en relación al tipo de proceso de producción el cual desarrollan ${ }^{54}$. A continuación, se muestra un diagrama de las definiciones que cada sector productivo proporcionado por el IPE

Tabla $N^{0}$ 5. Definición de los sectores productivos en el Perú

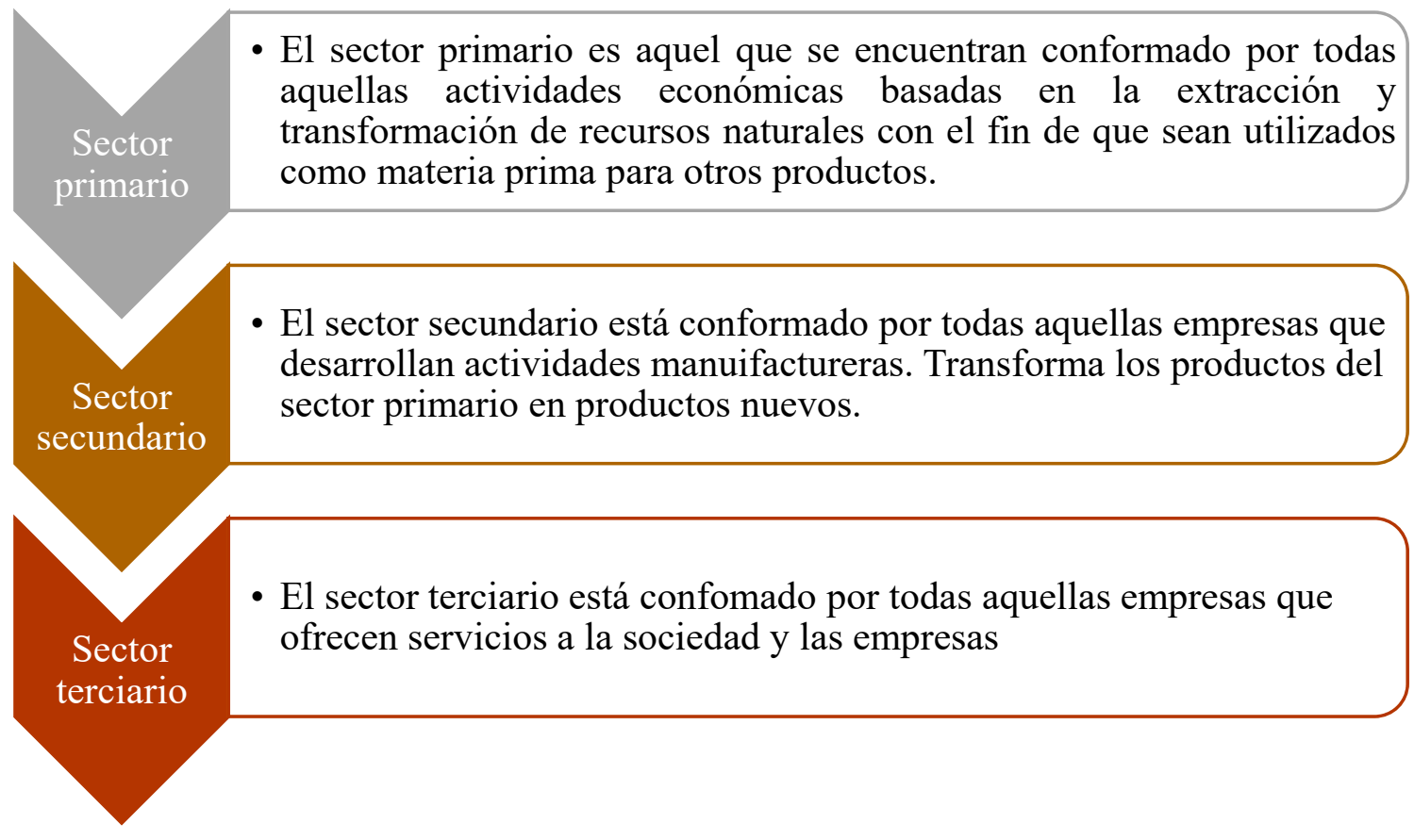

Fuente: Adaptado del Instituto Peruano de Economía 2014

\subsubsection{Situación de los sectores productivos}

Es necesario invertir recursos en aquel sector económico que contribuya más al incremento del PBI del Perú para que el crecimiento no se desacelere y se pueda disminuir, en el mediano, la pobreza. A continuación, se muestra el siguiente cuadro:

\footnotetext{
${ }^{54} \mathrm{Cfr}$. Instituto Peruano de Economía 2014. IPE es una institución fundada sin fines de lucro cuyo propósito promocionar el desarrollo sostenible en el Perú. Sus actividades se enfocan a proponer la discusión de medidas políticas y económicas, así como a fomentar las alternativas de solución sobre reformas no concluidas. Actualmente, es considerado uno de los think tanks más importantes en lo que respecta a política económicas del Perú. Puede revisar su página web: (http://www.ipe.org.pe)
} 
Ilustración Nº 7. Evolución del PBI por sector económico 2015-2016

\begin{tabular}{|c|c|c|c|c|c|c|c|c|c|c|}
\hline \multirow{2}{*}{ Oferta y Demanda Global } & \multicolumn{5}{|c|}{$2015 / 2014$} & \multicolumn{5}{|c|}{$2016 / 2015$} \\
\hline & 1 Trim. & II Trim. & III Trim. & IV Trim. & Añ̄o & 1 Trim. & 11 Trim. & III Trim. & IV Trim. & Año \\
\hline Producto Bruto Interno & 2,0 & 3,2 & 3,2 & 4,6 & 3,3 & 4,3 & 3,7 & 4,5 & 3,0 & 3,9 \\
\hline Extractivas & 3,5 & 6,9 & 8,0 & 11,9 & 7,6 & 11,5 & 12,6 & 12,9 & 8,8 & 11,5 \\
\hline Transtormación & $-5,2$ & $-2,4$ & $-4,1$ & $-0,6$ & $-3,0$ & $-1,4$ & $-5,3$ & 0,1 & $-1,7$ & $-2,1$ \\
\hline Servicios & 4,9 & 4,9 & 4,8 & 5,0 & 4,9 & 4,7 & 4,2 & 3,6 & 3,0 & 3,9 \\
\hline Importaciones & $-1,4$ & $-2,4$ & 0,6 & $-0,2$ & $-0,8$ & $-0,3$ & $-2,9$ & 1,8 & 2,3 & 0,3 \\
\hline Oferta y Demanda Global & 1,2 & 1,9 & 2,6 & 3,6 & 2,4 & 3,4 & 2,3 & 3,9 & 2,9 & 3,1 \\
\hline Demanda Interna & 2,1 & 2,6 & 2,9 & 2,5 & 2,5 & 3,0 & $=0,6$ & 0,6 & 0,5 & 0,9 \\
\hline Consumo Final Privado & 3,0 & 3,4 & 3,6 & 3,6 & 3,4 & 3,8 & 2,9 & 4,1 & 3,1 & 3,5 \\
\hline Consumo de Gobierno & 3,2 & 7,0 & 5,1 & 7,5 & 5,8 & 12,8 & 9,7 & 2,3 & $-3,1$ & 4,9 \\
\hline Formacion Bruta de Capital & $-0,4$ & $-0,6$ & 0,3 & $-2,4$ & $.0,8$ & $-2,9$ & $-12,7$ & $-8,7$ & $-3,8$ & $\cdot 7,1$ \\
\hline Formación Bruta de Capital Fijo & $-7,1$ & $-8,7$ & $-6,4$ & $-3,6$ & $-6,4$ & $-2,3$ & $-3,7$ & $-4,3$ & $-6,1$ & $-4,2$ \\
\hline Público & $-21,9$ & 2,1 & $-9,7$ & 4,7 & $.5,7$ & 30,3 & 3,9 & 2,2 & $-14,6$ & 3,1 \\
\hline Privado & $-3,1$ & $-11,9$ & $-5,4$ & $-6,0$ & $\cdot 6,6$ & $-9,3$ & $-6,3$ & $-6,1$ & $-3,5$ & $-6,3$ \\
\hline Exportaciones & $-2,4$ & $-1,2$ & 1,4 & 8,3 & 1,6 & 5,0 & 15,8 & 18,1 & 12,3 & 12,9 \\
\hline
\end{tabular}

Fuente: INEI 2017

Como se aprecia en la cuadro anterior, en el último trimestre del año 2016, el sector extractivo (primario) fue aquel que creció más (8.8\%) con respecto al último trimestre del 2015; por dicho motivo, en el 2016 crecieron en un 11.5\%. En contra posición, el sector transformación sufrió una caída de $2.1 \%$ en el año 2016. Por otro lado, el sector servicios logró crecer en un 3.9\% durante ese año.

Si bien es cierto que las actividades extractivas son las que, porcentualmente, más han crecido, no necesariamente supone que estas tenga un crecimiento estable en el tiempo. Como se aprecia en la tabla, el porcentaje de crecimiento a finales del cuarto trimestre del 2015 disminuyó en durante el mismo periodo en el 2016. Esto demuestra que las actividades extractivas pueden crecer mucho pero, en determinados periodos, pueden caer.

En el caso del sector transformación (secundario), su nulo crecimiento representa dos cosas: el sector no es muy dinámico y la industria peruana está estancada. De los tres sectores económicos, este es el menos atractivo.

Por otro lado, el sector servicios (terciario) tiene un crecimiento que puede ser considerado estable en el tiempo. Si bien es cierto que desde el primer trimestre del 2015 al último trimestre del 2016 hubo un descenso en el crecimiento, este no ha sido abrupto. Por esta razón, las actividades de servicios representan una gran oportunidad desde el punto de vista conservador.

\subsection{Estratos empresariales}

Los sectores productivos están conformados por diferentes estratos empresariales. Es conveniente realizar un análisis de los estratos empresariales para conocer su situación actual y saber cuál presenta un mayor potencial de crecimiento. Según la Ley º 30056, 
promulgada por el Congreso de la República del Perú en el año 2013, se establece que una empresa tiene que cumplir con ciertas condiciones, en su nivel de venta anual, para poder ser catalogada dentro de alguno de los 4 estratos empresariales existentes ${ }^{55}$.

Ilustración $\mathrm{N}^{\mathrm{o}} 8$. Nivel de ventas a cumplir para ser catalogado dentro algún estrato empresarial

Microempresa Ventas

Pequeña empresa
Monto de ventas
anuales superiores
a 150 UIT y hasta un
máx. de 1700 UIT

Mediana empresa

Monto de ventas

anuales superiores a

1700 UIT y hasta un

máx. de 2300 UIT

\section{Gran empresa}

Monto de ventas anuales superiores a las 2300 UIT

\section{Fuente: Adaptado de la Ley No 300562013}

Luego de describir, según la ley, la característica más importante de cada estrato empresarial y la que los define como tal, es necesario realizar una evaluación de su situación actual.

\subsubsection{Microempresas en el Perú}

El incremento de las microempresas en el Perú ha sido notorio en los últimos años. Esto se evidencia en la siguiente tabla:

\footnotetext{
${ }^{55}$ El gráfico presentado está basado en el Artículo 11 de la Ley $\mathrm{N}^{\circ}$ 30056. Es puntual decir que la UIT (Unidad Impositiva Tributaria) es un valor referente que es aplicado en normas tributarias según el Código Tributario. Actualmente el valor de una UIT es el equivalente a S/. 3,850 Nuevos Soles. Información sacada de: https://mef.gob.pe/index.php?option=com_content\&view=article\&id=301\&Itemid=100877\&lang=es.
} 
Tabla $\mathrm{N}^{\mathrm{0}}$ 6. Cantidad de microempresas formales por regiones entre el periodo 2010-2015

\begin{tabular}{|l|r|r|r|r|r|r|}
\hline \multirow{2}{*}{ Región } & \multicolumn{7}{|c|}{ Año } \\
\cline { 2 - 7 } & \multicolumn{1}{|c|}{2010} & \multicolumn{1}{c|}{2011} & \multicolumn{1}{c|}{2012} & \multicolumn{1}{c|}{2013} & \multicolumn{1}{c|}{2014} & \multicolumn{1}{c|}{2015} \\
\hline Lima & 547,067 & 579,411 & 597,448 & 678,536 & 716,278 & 752,047 \\
\hline Arequipa & 66,413 & 70,658 & 73,123 & 82,079 & 87,371 & 92,002 \\
\hline La Libertad & 59,920 & 64,093 & 67,371 & 75,846 & 80,457 & 84,681 \\
\hline Cusco & 40,437 & 44,850 & 49,248 & 56,943 & 60,886 & 67,539 \\
\hline Otros & 424,253 & 462,331 & 482,819 & 546,374 & 573,292 & 611,036 \\
\hline Total & $\mathbf{1 , 1 3 8 , 0 9 0}$ & $\mathbf{1 , 2 2 1 , 3 4 3}$ & $\mathbf{1 , 2 7 0 , 0 0 9}$ & $\mathbf{1 , 4 3 9 , 7 7 8}$ & $\mathbf{1 , 5 1 8 , 2 8 4}$ & $\mathbf{1 , 6 0 7 , 3 0 5}$ \\
\hline
\end{tabular}

Fuente: Adaptado del Ministerio de la Producción 2016

Como se aprecia en el cuadro anterior, la cantidad de microempresas en el Perú ha crecido significativamente en los último 5 años; creciendo en más de 450,000 empresas entre el 2010 y el 2015. Según los últimos datos proporcionados por el Ministerio de la Producción, hasta el 2015, la cantidad de microempresas formales es de 1'607,305 empresas.

Lima, con un 46,79\%, es la región que más alberga a este tipo de empresas; seguido por Arequipa y La Libertad. Es importante destacar que un posible motivo por el cual Lima es la región que más microempresas alberga es su estatus como ciudad capital y porque tiene la mayor cantidad de población del país.

Sin embargo, a pesar de su relevancia empresarial en cuanto a cantidad, las microempresas adolecen de muchos problemas. De acuerdo a la Encuesta Nacional de Empresas 2015, solo el 20\% del total de microempresas del Perú contaron con un plan de negocio sólido cuando comenzaron sus operaciones ${ }^{56}$.

Por otro lado, el $84.2 \%$ del total siente que tiene una alta competencia informal, lo que afectaría el desempeño de su producto dentro de su nicho ${ }^{57}$. Además, carecen de un avanzado uso de la tecnología en sus instalaciones ya que solo el 69.6\% usa computadoras dentro de sus actividades cotidianas ${ }^{58}$.

Es importante resaltar que este tipo de empresas (junto con las pequeñas empresas) no han logrado no solo tener todo el éxito que podrían tener en Perú, tampoco han podido adecuar su producto a los requerimientos de otros mercados ajenos al peruano debido a la escasez de información que manejan ${ }^{59}$.

\footnotetext{
${ }^{56}$ Cfr. Ministerio de la Producción 2016: 34

${ }^{57}$ Cfr. Ministerio de la Producción 2016: 34

${ }^{58}$ Cfr. Ministerio de la Producción 2016: 35

${ }^{59}$ Cfr. Choy 2010: 131
} 


\subsubsection{Pequeñas empresas en el Perú}

$\mathrm{Al}$ igual que las microempresas, las pequeñas empresas también han experimentado un aumento en los últimos años, sin embargo, este no es comparable, en ningún punto, con respecto a las microempresas.

Tabla $N^{0}$ 7. Cantidad de pequeñas empresas formales por regiones entre el periodo 2010-2015

\begin{tabular}{|l|r|r|r|r|r|r|}
\hline \multirow{2}{*}{ Región } & \multicolumn{7}{|c|}{ Año } \\
\cline { 2 - 7 } & \multicolumn{1}{|c|}{2010} & \multicolumn{1}{|c|}{2011} & \multicolumn{1}{c|}{2012} & \multicolumn{1}{c|}{2013} & \multicolumn{1}{c|}{2014} & \multicolumn{1}{c|}{2015} \\
\hline Lima & 34,321 & 37,890 & 41,473 & 42,157 & 42,827 & 43,709 \\
\hline Arequipa & 2,585 & 2,770 & 3,180 & 3,374 & 3,408 & 3,545 \\
\hline La Libertad & 2,173 & 2,468 & 2,829 & 3,010 & 2,999 & 3,110 \\
\hline Piura & 1,769 & 1,942 & 2,097 & 2,210 & 2,193 & 2,313 \\
\hline Otros & 14,741 & 16,101 & 18,664 & 19,957 & 19,886 & 19,987 \\
\hline Total & $\mathbf{5 5 , 5 8 9}$ & $\mathbf{6 1 , 1 7 1}$ & $\mathbf{6 8 , 2 4 3}$ & $\mathbf{7 0 , 7 0 8}$ & $\mathbf{7 1 , 3 1 3}$ & $\mathbf{7 2 , 6 6 4}$ \\
\hline
\end{tabular}

Fuente: Adaptado del Ministerio de la Producción 2016

Entre el año 2010 y 2015, la cantidad de pequeñas empresas a nivel nacional ha crecido en un 30.72\%. Sin embargo, solo entre el 2014 y el 2015, la cantidad de pequeñas empresas aumento en poco más de 1,300 empresas. Con estos datos se puede deducir que muy pocas empresas llegan a tener ventas mayores a 150 UIT.

Por otro lado, la cantidad de estas empresas en las regiones, que no son Lima, es escasa en comparación con la presencia de microempresas. El crecimiento de la cantidad de pequeñas empresas en el Perú ha sido lento.

Sin embargo, hay un punto importante que supone una ventaja en comparación con las microempresas, el $40 \%$ de las pequeñas empresas formales contaron con un plan de negocio al inicio de sus operaciones ${ }^{60}$. Esto supone que, a pesar de no crecer mucho, hay una buena cantidad de empresas pequeñas que nacen con una base sólida, lo cual impide que desaparezcan rápidamente en el tiempo; cabe agregar, que otro punto importante de las pequeñas empresas es su capacidad y flexibilidad de adaptarse a importantes cambios tecnológicos y cuentan con un gran potencial de generación de empleo ${ }^{61}$.

\footnotetext{
${ }^{60}$ Cfr. Ministerio de la Producción 2016: 34

${ }^{61}$ Ministerio de la Producción 2016: 24
} 


\subsubsection{Medianas empresas en el Perú}

Tabla $\mathrm{N}^{\mathrm{o}} 8$. Cantidad de medianas empresas formales por regiones entre el periodo 2010-2015

\begin{tabular}{|l|r|r|r|r|r|r|}
\hline \multirow{2}{*}{ Región } & \multicolumn{7}{|c|}{ Año } \\
\cline { 2 - 7 } & 2010 & 2011 & 2012 & \multicolumn{1}{c|}{2013} & \multicolumn{1}{c|}{2014} & \multicolumn{1}{c|}{2015} \\
\hline Lima & 1,385 & 1,537 & 1,626 & 1,679 & 1,714 & 1,808 \\
\hline Arequipa & 72 & 92 & 114 & 103 & 100 & 104 \\
\hline Callao & 68 & 93 & 82 & 84 & 98 & 92 \\
\hline La Libertad & 67 & 65 & 79 & 88 & 91 & 80 \\
\hline Otros & 439 & 538 & 550 & 566 & 632 & 628 \\
\hline Total & $\mathbf{2 , 0 3 1}$ & $\mathbf{2 , 3 2 5}$ & $\mathbf{2 , 4 5 1}$ & $\mathbf{2 , 5 2 0}$ & $\mathbf{2 , 6 3 5}$ & $\mathbf{2 , 7 1 2}$ \\
\hline
\end{tabular}

\section{Fuente: Adaptado del Ministerio de la Producción 2016}

En los últimos 5 años, el número de medianas empresas formales solo ha crecido en 681 . Esto refleja que en el país hay muy pocas empresas que pueden ser catalogadas en este estrato empresarial.

Al igual que en los otros estratos, Lima es la región que más medianas empresas establecidas tiene. En otras regiones, como en La Libertad, se puede observar que el número de estas empresas ha caído, al igual que en El Callao.

Sin embargo, es un estrato que se mira a sí mismo como estable. El 65.3\% de ellas considera que su mercado no se ve afectado por empresas que trabajan en la informalidad, además, las medianas empresas, junto con las grandes empresas, son las que generan una mayor cantidad de contratación de personal nuevo ${ }^{62}$.

\subsubsection{Grandes empresas en el Perú}

Las grandes empresas en el Perú son consideradas un gran motor de crecimiento, a pesar que, en comparación, no son tan numerosas como las pequeñas empresas.

\footnotetext{
${ }^{62}$ Cfr. Ministerio de la Producción 2016:34
} 
En el 2012, la cantidad de grandes empresas en el Perú era de 7,908 empresas ${ }^{63}$; para el año 2015 , la cantidad es de 8,781 empresas ${ }^{64}$. El 52\% del total de empresas grandes en el país tienen sus procesos de compras completamente estandarizados, y el 40\% tiene su proceso de comercialización estandarizado ${ }^{65}$. Sin embargo, solo el $28 \%$ de estas cuentan con una certificación de los cuales el $50 \%$ opina que esta certificación se debió a que buscaban ser más eficientes y productivos ${ }^{66}$.

\subsubsection{Situación de los estratos empresariales}

Tabla $\mathrm{N}^{\mathrm{0}}$ 9. Evolución de la cantidad de empresas por estrato empresarial en el Perú 2012-2015

\begin{tabular}{|l|r|r|r|r|}
\hline \multirow{2}{*}{ Estrato Empresarial } & \multicolumn{2}{|c|}{2012} & \multicolumn{2}{c|}{2015} \\
\cline { 2 - 5 } & \multicolumn{1}{|c|}{ Cantidad } & Porcentaje & Cantidad & Porcentaje \\
\hline Microempresa & $1,270,009$ & $94.17 \%$ & $1,607,305$ & $95.02 \%$ \\
\hline Pequeña Empresa & 68,243 & $5.06 \%$ & 72,664 & $4.30 \%$ \\
\hline Total PYME & $1,338,252$ & $99.23 \%$ & $1,679,969$ & $99.32 \%$ \\
\hline Mediana Empresa & 2,451 & $0.18 \%$ & 2,712 & $0.16 \%$ \\
\hline Total MIPYME & $1,340,703$ & $99.41 \%$ & $1,682,681$ & $99.48 \%$ \\
\hline Gran Empresa & 7,908 & $0.59 \%$ & 8,781 & $0.52 \%$ \\
\hline Total & $\mathbf{1 , 3 4 8 , 6 1 1}$ & $\mathbf{1 0 0 . 0 0 \%}$ & $\mathbf{1 , 6 9 1 , 4 6 2}$ & $\mathbf{1 0 0 . 0 0 \%}$ \\
\hline
\end{tabular}

Fuente: Adaptado del Ministerio de la Producción 2013 y 2015

Como se puede apreciar en la tabla anterior, en total, las empresas en el Perú aumentado en casi de 350 mil entre el año 2012 y 2015; sin embargo, resulta interesante que los tipos de empresas que más han crecido, en cantidad, en los últimos 3 años son las MYPE. Solo en el 2012, del porcentaje total de empresas que había en el Perú, las MYPE representaban el $99.23 \%$ del total; para el 2015, el porcentaje aumentó a $99.32 \%$.

Si bien es cierto que solo aumentó en un $0.09 \%$, la cantidad total de MYPE aumentó en casi 340 mil en solo 3 años, en contraposición con el estrato empresarial correspondientes a las grandes empresas que, en conjunto, solo aumentaron en casi 1000.

Este aumento de micro, pequeñas y medianas empresas se ve reforzado con el crecimiento de la economía peruana ya que, el experimentar un crecimiento continuo, ha permitido que las MIPYME crezcan a un ritmo anual de 7.5\% entre el año 2007 y $2015^{67}$. Si bien es cierto que el aumento de las MYPE, especialmente en el caso de las microempresas,

\footnotetext{
${ }^{63}$ Cfr. Ministerio de la Producción 2013:105

${ }^{64}$ Cfr. Ministerio de la Producción 2016: 116

${ }^{65} \mathrm{Cfr}$. Ministerio de la Producción 2016: 36

${ }^{66} \mathrm{C}$ fr. Ministerio de la Producción 2016: 36

${ }^{67}$ Cfr. Ministerio de la Producción 2016:116
} 
puede suponer un aumento de puestos trabajo así como el desarrollo de nuevos sectores empresariales, también expone una debilidad que tiene la estructura empresarial peruana: la ausencia de una base sólida que permita a las grandes empresas poder tercerizar algunos procesos suyos, así como la falta de una oferta estable de proveedores de calidad y en crecimiento $^{68}$.

Solo en el 2015, las 10 principales empresas peruanas movieron cerca del 15\% del total del PBI de ese año ${ }^{69}$, en comparación con el total de MYPE que, a pesar de su gran cantidad, solo llegaron a representar el $40 \%$ del total del PBI nacional en el mismo año ${ }^{70}$. Esta poca representación en el PBI total se debe, principalmente, a que muchas de estas empresas son las denominadas "empresas de subsistencia", cuyos ingresos solo les permite cubrir sus necesidades empresariales básicas, lo que les priva de poder generar utilidades, mejorar sus procesos o incrementar su productividad ${ }^{71}$. Es por esta razón que las grandes empresas no suelen trabajar con empresas muy pequeñas ya que pueden llegar a ser perjudiciales para sus procesos o su negocio.

A pesar de ello, las MYPE representan la mayor fuerza empresarial que tiene el Perú y, si bien es cierto que la mayoría de ellas pueden ser consideradas como empresas de subsistencias, conforme vayan creciendo con el tiempo, la economía se volverá más dinámica ya que lograrán posicionarse en el mercado, ampliar su nivel de producción, aumentar el requerimiento de mano de obra y proporcionar una mejor tributación al estado peruano $^{72}$.

\subsection{Las MYPE}

Como se evidencia en el punto anterior, las MYPE son muy representativas en cantidad, pero no han logrado desarrollarse plenamente. En este punto, describiremos y analizaremos, más a fondo, la situación de las MYPE.

\subsubsection{Definición de MYPE}

Las pequeñas empresas existen en todas las economías del mundo, el porcentaje, según el estrato empresarial, puede variar según las economías desarrolladas y las economías de nuestra región. Si se habla del caso de América Latina, se puede encontrar que las MYPE

\footnotetext{
${ }^{68}$ Cfr. Ministerio de la Producción 2016:115

${ }^{69}$ Cfr. Diario El Comercio 2015

${ }^{70}$ Cfr. Asociación de Emprendedores del Perú 2015

${ }^{71}$ Cfr. Ministerio de la Producción 2016:115

${ }^{72}$ Cfr. Asociación de Emprendedores del Perú 2015
} 
tienen una presencia notable y significativa ya que son una categoría económica, social y política importante en cada estado ${ }^{73}$.

Sin embargo, para proporcionar una definición de MYPE se presenta un contexto de variabilidad, ya que cada país toma criterios diferentes, tales como: cantidad de trabajadores, ventas, activos y otros. También existe diferencia en la definición dependiendo si la unidad económica es manufacturera, comercial o de servicios. Además, pueden existir variaciones según la institución que establece la definición ${ }^{74}$.

La diversidad de criterios utilizados para la definición de MYPE en cada país hace que no sea posible proporcionar una definición única. Sin embargo, en términos generales, se ha visto que en los países de América Latina, las instituciones se basan en la definición basada en el número de trabajadores y la facturación anual ${ }^{75}$.

En términos de la legislación peruana, según la Ley $\mathrm{N}^{\circ} 30056$, la microempresa se caracteriza por tener ventas anuales hasta el monto máximo de 150 UIT y la pequeña empresa se caracteriza por tener ventas anuales superiores a 150 UIT y hasta el monto máximo de $1700 \mathrm{UIT}^{76}$.

\subsubsection{Características de una MYPE}

En la siguiente tabla, se presenta las características más importantes de una MYPE según la Ley Peruana $\mathrm{N}^{\circ} 28015$.

Tabla No 10. Características de una MYPE según la Ley Na 28015

\begin{tabular}{|c|c|c|}
\hline \multirow{2}{*}{ Tipo } & $\begin{array}{c}\text { Número de } \\
\text { trabajadores } \\
\text { (promedio) }\end{array}$ & $\begin{array}{c}\text { Niveles de ventas anuales (unidades } \\
\text { impositivas tributarias-UII) }\end{array}$ \\
\hline Microempresa & 1 hasta 10 & 150 \\
\hline $\begin{array}{c}\text { Pequeña } \\
\text { empresa }\end{array}$ & 1 hasta 50 & 150 hasta 850 \\
\hline
\end{tabular}

Fuente: Adaptado de la Ley ${ }^{\circ} 28015$

Por otro lado, otra característica de las MYPE es el empresario emprendedor (dueño), quien es el que asume la responsabilidad de que la empresa funcione de la mejor manera; teniendo así responsabilidades adquiridas desde la formación de este tipo de empresa.

\footnotetext{
${ }^{73}$ Cfr. Villarán 2010:263

${ }^{74}$ Cfr. Zevallos 2003:55

${ }^{75}$ Cfr. Ferraro 2011: 435-438

${ }^{76}$ Cfr. Ley N $N^{\circ} 30056$
} 
Tabla $N^{o} 11$. Principales características y responsabilidades de un dueño de una MYPE

- Conoce todos los procesos dentro de la empresa. Generalmente, es el único que sabe todo lo relacionado con el funcionamiento de la empresa.

-Fijar las metas de la empresa.

- Plantear la forma de trabajo de los empleados para lograr los objetivos de la empresa.

-Lidera el trabajo dentro de la empresa.

-Vigila e inspecciona la labor de los empleados.

Fuente: Adaptado de Guía para el desarrollo de la micro y pequeña empresa 2006

\subsubsection{Clasificación de las MYPE}

La clasificación de las MYPE se basa en factores de capacidad de autofinanciamiento, generación de valor económico, productividad, diferenciación, capacidad de innovación y crecimiento ${ }^{77}$. En base a esto, se han definido en dos estratos ${ }^{78}$ :

\section{MYPE de Acumulación}

- Cuenta con capacidad empresarial para generar utilidades.

- Mantienen su capital original e invierten en procesos que permitan el crecimiento de la empresa.

- Cuentan con menos de 10 trabajadores.

- Tienen un gran potencial de crecimiento y de aumento de productividad.

${ }^{77}$ Cfr. Ministerio de trabajo y promoción del empleo 2006: 19

${ }^{78}$ Cfr. CEDAL 2010: 6 
- Empresas generadoras de trabajo remunerado.

2. MYPE de Subsistencia

- No cuentan con la capacidad empresarial para generar utilidades.

- Generan perdida del capital invertido.

- Generalmente conformado por un grupo de familias o unipersonal.

- Cuentan con una baja productividad, lo que los vuelve inestables en su mercado.

- Generalmente son empresas informales.

Según Teresa Quezada, coordinadora nacional de programa MI EMPRESA, el 80\% de las MYPE se ubican en el estrato de subsistencia ${ }^{79}$. Es por esta razón que, en este punto, las MYPE que serán analizadas, posteriormente, serán las MYPE de acumulación debido que tienen más posibilidades de expandirse, generar trabajo y buenos ingresos monetarios.

\subsubsection{Importancia de las MYPE}

Resulta muy pertinente comentar que en los países desarrollados, las PYME dan empleo a cerca de 300 millones de personas y representan hasta el $95 \%$ del total de negocios existentes $^{80}$. En el caso peruano, solo las microempresas representan el $95.0 \%$ del total de empresas existentes y, por otro lado, las pequeñas empresas representan el $4.3 \%$ del total $^{81}$.

En su conjunto, las MYPE representan el 99.3\% del total de empresas existentes dentro de suelo patrio. Tan solo por la cantidad de empresas MYPE que existen, se puede afirmar que son importantes dentro de nuestro país ya que son la mayor fuerza empresarial que se tiene. Hacia el año 2006, las MYPE ya eran consideradas como un componente muy importante dentro de la economía peruana porque, en ese entonces, brindaban empleo al $80 \%$ de la población catalogada como económicamente activa ${ }^{82}$.

Esto llevo a que, mundialmente, se reconozca que una gran ventaja que tiene la MYPE sea su capacidad de cambiarse o adaptarse de forma rápida; sin embargo, no logran aumentar su nivel de accesibilidad a otros mercados ${ }^{83}$.

\footnotetext{
${ }^{79}$ Cfr. Yamakawa 2010: 19

${ }^{80}$ Cfr. Llamas y otros 2014: 6

${ }^{81}$ Cfr. Ministerio de la Producción 2016: 25

${ }^{82}$ Cfr. Sánchez Barraza 2006: 128

${ }^{83}$ Cfr. Herrera 2011: 70
} 
En aquellos años, las MYPE eran consideradas importantes porque ayudaban a disminuir la tasa de desempleo dentro del país ${ }^{84}$. Sin embargo, el modo de ver a las MYPE ha cambiado desde aquel año, en una entrevista personal concebida por el Sr. Eduardo Lastra, experto en temas de MYPE, sostiene que la nueva visión que se tiene sobre las MYPE es verlas como empresas que aseguren el crecimiento del Perú dentro de los próximos años ${ }^{85}$. El punto de vista de que las MYPE son empresas de subsistencia y que solo sirven para "cubrir necesidades" de determinadas familias está llegando a su fin.

Según Fernando Villarán, las MYPE pueden ser negocios exitosos, ya que poseen la percepción de las necesidades de los clientes, lo que permite que estén enfocados en el mercado y, por su menor tamaño, tener flexibilidad para adaptarse a nuevas circunstanciadas rápidamente; además, la creatividad y habilidades personales, les permite diseñar soluciones de negocios que corresponden a su disponibilidad efectiva de recursos $^{86}$. Por otro lado, entre las misma MYPE hay una elevada diferencia en productividad, lo que ocasiona que existan brechas y no permita el trabajo mutuo entre las mismas. Debido a su debilidad estructural, este tipo de empresas queda en desventaja frente a otras empresas de su rubro ${ }^{87}$.

El Fondo Monetario Internacional sostiene que, para sustentar el crecimiento sostenido actual que experimenta el país, es necesario promover el desarrollo de las PYME $^{88}$ (Pequeña y mediana empresa). Ajustando los comentarios un poco más a la realidad peruana, para llegar a lo propuesto por el FMI es necesario, primero, fomentar el crecimiento de las MYPE para que puedan llegar a ser PYME; de esta forma, la actual importancia de las MYPE radica en que en su potencial se encuentra lo necesario para poder asegurar no solo la cantidad de empleos, sino también, el crecimiento del país.

Además, en años más recientes, las MYPE ya han evolucionado y ahora tienen una gran responsabilidad social empresarial ya que ha aumentado el personal que trabaja en este tipo de empresas; lo que a su vez ha generado que exista un aumento de la demanda y de la generación de ingresos ${ }^{89}$. Cabe resaltar que para mejorar el potencial de las MYPE es

\footnotetext{
${ }^{84}$ Cfr. Sánchez Barraza 2006: 128

${ }^{85}$ Entrevista personal con el Administrador Eduardo Lastra realizada en abril del 2015.

${ }^{86} \mathrm{Cfr}$. ProInversion 2006: 107

${ }^{87}$ Cfr. ORGANIZACIÓN PARA LA COOPERACIÓN Y EL DESARROLLO ECONÓMICOS (OCDE) y COMISIÓN ECONÓMICA PARA AMÉRICA LATINA Y EL CARIBE 2013:46

${ }^{88}$ Cfr. Diario Oficial El Peruano 2015. El subdirector gerente del Fondo Monetario Internacional, Min Zhu, opina, en esta publicación, acerca del desempeño pronosticado que tendrá la economía peruana.

${ }^{89}$ Cfr. Hernani y Hamann 2013: 293
} 
necesario fortalecer su capacidad de gestión, su capacidad para generar planes de negocios, así como mejorar su accesibilidad a recursos y nuevos mercados para que puedan desarrollarse ${ }^{90}$.

\subsection{El sector servicios}

\subsubsection{Los servicios}

\subsubsection{Definición}

Previamente, se presentó la definición del sector terciario, en palabras del Instituto Peruano de Economía. Sin embargo, es conveniente que se ahonde un poco más en la definición de qué es un servicio y qué cosas involucra.

Los servicios se definen como aquellos que se encuentran basados en hechos, actividades o desempeños que suelen ser de carácter intangible ${ }^{91}$. Durante años, suele existir una discrepancia entre bienes y servicio debido a que ambos pueden coexistir en un mismo rubro o en una misma empresa, sin embargo, se suele atribuir la característica de “intangibilidad” a toda definición de servicio ${ }^{92}$.

\subsubsection{Características de los servicios}

Los servicios cuentan con 4 características fundamentales que los diferencian de los otros 3 sectores productivos.

Tabla $\mathrm{N}^{\mathrm{o}}$ 12. Características fundamentales de los servicios

\begin{tabular}{|l|l|}
\hline Características & \multicolumn{1}{|c|}{ Descripción } \\
\hline Intangibilidad & En su definición más concreta, \\
es la principal característica de \\
los servicios ya que estos no \\
pueden ser sentidos o tocados en \\
comparación a los bienes \\
físicos. Esto genera que los \\
servicios no puedan ser \\
inventariados como sí lo son su \\
contraparte.
\end{tabular}

\footnotetext{
${ }^{90}$ Cfr. Armestár 2013: 7

${ }^{91}$ Cfr. Hoffman y Bateson 2012: 4

${ }^{92}$ Cfr. Hoffman y Bateson 2012: 4
} 


\begin{tabular}{|c|c|}
\hline Inseparabilidad & $\begin{array}{l}\text { Esta es la característica más } \\
\text { intrigante ya que, a diferencia de } \\
\text { los productores de bienes, los } \\
\text { proveedores de servicios, } \\
\text { clientes y otros clientes tiene } \\
\text { que interactuar constantemente } \\
\text { antes, durante y, posiblemente, } \\
\text { después del servicio. No es } \\
\text { posible separarlos ya que los } \\
\text { clientes siempre se encuentran } \\
\text { presentes durante el proceso de } \\
\text { elaboración del servicio. }\end{array}$ \\
\hline Heterogeneidad & $\begin{array}{l}\text { A diferencia de los bienes, los } \\
\text { servicios presentan una } \\
\text { variación entre una operación de } \\
\text { servicio y la otra. Esto se debe a } \\
\text { que cada servicio entregado al } \\
\text { cliente es personalizado y único. }\end{array}$ \\
\hline Naturaleza perecedera & $\begin{array}{l}\text { Todos los servicios finales no } \\
\text { pueden ser inventariados o } \\
\text { reservados lo que produce que } \\
\text { estos sean considerados como } \\
\text { pérdida si es que no llegan a ser } \\
\text { consumidos por el cliente final. }\end{array}$ \\
\hline
\end{tabular}

Fuente: Adaptado de Hoffman y Bateson 2012

\subsubsection{El sector servicios: un sector en constante crecimiento}

A continuación, se muestra el crecimiento de las diversas actividades que conforman los 3 sectores productivos en el Perú: 
Ilustración $\mathrm{N}^{0}$ 9. Evolución del producto bruto interno en el cuarto trimestre del 2016

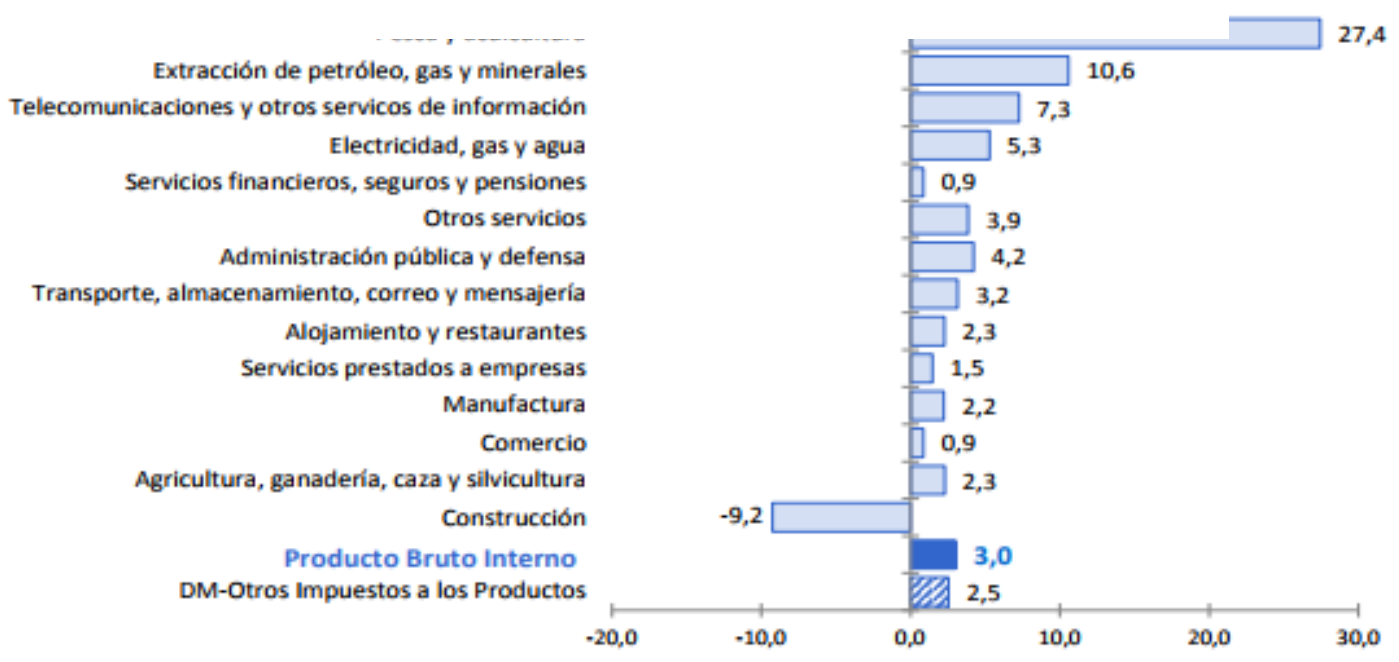

\section{Fuente: INEI 2017}

Si bien es cierto que la actividad de pesca y acuicultura, perteneciente al sector extractivo, es la actividad económica que más creció en el cuarto trimestre del 2016, las demás actividades que conforman el sector no demuestran este crecimiento (extracción de petróleo, gas y minerales y agricultura, ganadería, caza y silvicultura). Esto demuestra que el sector no crece a la par.

Por otro lado, el sector de transformación tampoco presenta grandes o constantes avances. Sin embargo, el sector servicios, que si bien no creció demasiado, mantiene a todas sus actividades económicas en crecimiento, lo cual asegura que el sector genera ganancias que van en un aumento constante. El crecimiento experimentado en el cuarto trimestre del 2016 se debió gracias al buen desempeño de 5 actividades que pertenecen al sector servicios: alojamiento y restaurantes, telecomunicaciones y otros servicios de información, otros servicios, administración pública y defensa y transporte, almacenamiento, correo y mensajería ${ }^{93}$.

\footnotetext{
${ }^{93}$ Cfr. INEI 2017: 9.5 de las 10 actividades que más aportaron al crecimiento del PBI en el cuarto trimestre
} del 2016 pertenecen al sector servicios. 
Ilustración $\mathrm{N}^{\mathrm{o}}$ 10. Crecimiento del PBI por actividad económica 2015-2016

\begin{tabular}{|c|c|c|c|c|c|c|c|c|c|c|}
\hline \multirow{2}{*}{ Actividades } & \multicolumn{5}{|c|}{$2015 / 2014$} & \multicolumn{5}{|c|}{$2016 / 2015$} \\
\hline & I Trim. & II Trim. & III Trim. & IV Trim. & Año & I Trim. & II Trim. & III Trim. & IV Trim. & Año \\
\hline Economía Total (PBI) & 2,0 & 3,2 & 3,2 & 4,6 & 3,3 & 4,3 & 3,7 & 4,5 & 3,0 & 3,9 \\
\hline Agricultura, ganadería, caza y silvicultura & 1,0 & 3,8 & 4,3 & 2,5 & 3,0 & 1,6 & 1,5 & 1,9 & 2,3 & 1,8 \\
\hline Pesca y acuicultura & $-10,1$ & 32,6 & $-25,4$ & 41,9 & 15,9 & 1,8 & $-56,1$ & 71,6 & 27,4 & $-10,1$ \\
\hline Extracción de petróleo, gas y minerales & 4,8 & 7,6 & 10,2 & 14,9 & 9,5 & 15,7 & 23,3 & 16,3 & 10,6 & 16,3 \\
\hline Manufactura & $-4,5$ & 0,2 & $-3,0$ & 0,3 & $-1,7$ & $-2,8$ & $-7,9$ & 2,0 & 2,2 & $-1,6$ \\
\hline Electricidad, gas y agua & 4,9 & 5,4 & 6,0 & 7,6 & 6,0 & 10,4 & 7,1 & 6,5 & 5,3 & 7,3 \\
\hline Construcción & $-6,8$ & $-8,2$ & $-6,5$ & $-2,1$ & $-5,8$ & 2,0 & 0,8 & $-3,9$ & $-9,2$ & $-3,1$ \\
\hline Comercio & 3,7 & 4,1 & 4,3 & 4,0 & 4,0 & 2,8 & 2,3 & 1,4 & 0,9 & 1,8 \\
\hline Transporte, almacenamiento, correo y mensajeria & 2,2 & 2,8 & 3,2 & 2,5 & 2,7 & 3,9 & 3,2 & 3,4 & 3,2 & 3,4 \\
\hline Alojamiento y restaurantes & 2,9 & 3,2 & 3,3 & 2,6 & 3,0 & 2,9 & 2,6 & 2,6 & 2,3 & 2,6 \\
\hline Telecomunicaciones y otros servicios de información & 9,9 & 6,8 & 9,6 & 10,9 & 9,3 & 7,7 & 10,6 & 6,9 & 7,3 & 8,1 \\
\hline Servicios financieros, seguros y pensiones & 10,7 & 9,1 & 8,5 & 10,6 & 9,7 & 8,6 & 6,8 & 5,1 & 0,9 & 5,4 \\
\hline Servicios prestados a empresas & 5,0 & 5,4 & 4,2 & 3,9 & 4,6 & 3,0 & 2,1 & 2,2 & 1,5 & 2,2 \\
\hline Administración pública y defensa & 3,2 & 3,6 & 3,6 & 5,0 & 3,9 & 4,7 & 4,7 & 4,6 & 4,2 & 4,6 \\
\hline Otros servicios & 4,5 & 5,1 & 4,3 & 4,4 & 4,5 & 4,3 & 4,2 & 4,0 & 3,9 & 4,1 \\
\hline Total Industrias (VAB) & 2,2 & 3,6 & 3,3 & 5,0 & 3,5 & 4,6 & 3,9 & 4,6 & 3,0 & 4,0 \\
\hline DM-Otros Impuestos a los Productos & $-0,6$ & $-1,0$ & 1,6 & 1,6 & 0,4 & 1,7 & 2,0 & 3,3 & 2,5 & 2,4 \\
\hline
\end{tabular}

Fuente: INEI 2017

Además, como se aprecia en la imagen anterior, las actividades económicas que pertenecen al sector servicios han mantenido un crecimiento constante e ininterrumpido entre el 2015 y 2016. Cabe resaltar que actividades económicas como el de alojamiento y restaurantes, transporte y otros servicios han mantenido un porcentaje de crecimiento constante.

\subsubsection{El sector alojamientos y restaurantes}

Ilustración No 11. Crecimiento del sector alojamiento y restaurantes en el Perú 20082016 


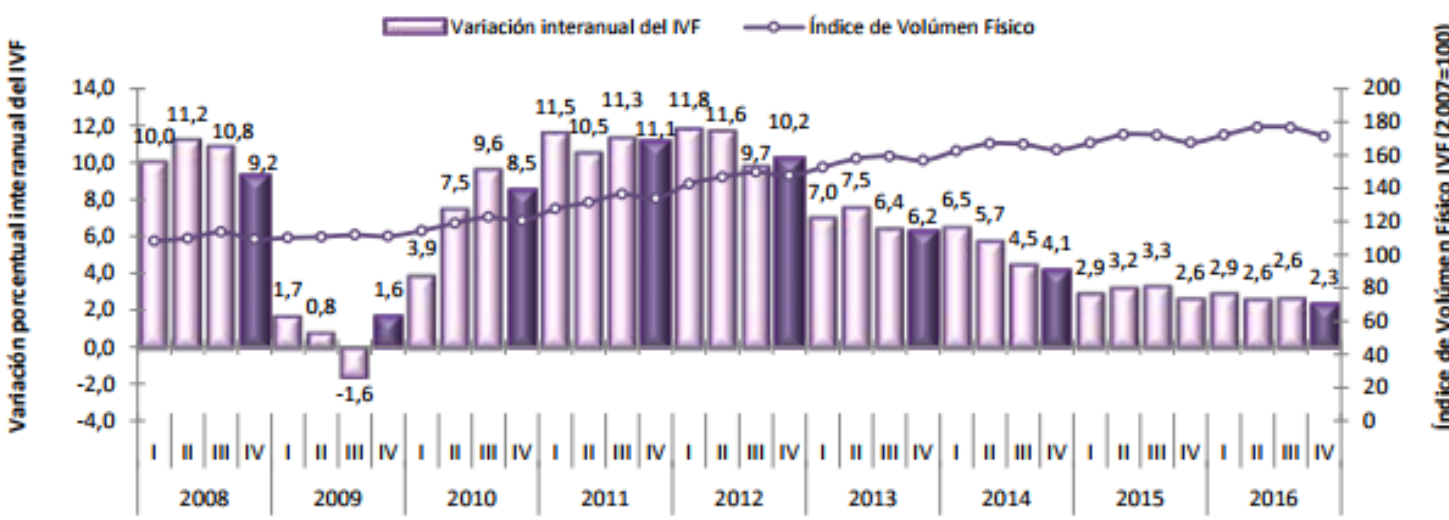

Fuente: INEI 2017

Si bien es cierto que entre el 2010 y el 2012 el sector experimentó un auge de crecimiento que no se puede comparar con el crecimiento actual, el sector ha sabido mantener un crecimiento constante en cada una de sus etapas de crecimiento dependiendo del año. En los últimos 2 años, el sector ha mantenido un crecimiento constante.

\subsubsection{El subsector restaurantes}

Ilustración $\mathrm{N}^{\mathrm{o}} 12$. Evolución del crecimiento del sector alojamiento y restaurantes en el 2016

\begin{tabular}{|lc|c|c|c|c|}
\hline \multirow{2}{*}{ Actividades } & \multicolumn{5}{c|}{ 2016/2015 } \\
\cline { 2 - 6 } & I Trim. & II Trim. & III Trim. & IV Trim. & Año \\
\hline Alojamiento y restarurantes & 2,9 & 2,6 & 2,6 & 2,3 & 2,6 \\
Alojamiento & 4,1 & 1,5 & 6,9 & 2,0 & 3,7 \\
Restaurantes & 2,7 & 2,8 & 1,7 & 2,3 & 2,4 \\
\hline
\end{tabular}

Fuente: INEI 2017

Sin embargo, como se muestra en la imagen anterior, el subsector restaurantes es el que ha mantenido un porcentaje crecimiento constante en el último año. Esto resulta ventajoso ya que, en comparación con el subsector alojamiento, el subsector es estable en su crecimiento y no tiene una variación de crecimiento abrupta. Además, al ser Perú un país considerado culinario, se puede esperar que el subsector no caiga y mantenga un crecimiento a un porcentaje constante.

\subsection{Gestión por Procesos}

Las organizaciones y empresas son tan eficientes como lo son sus procesos. El panorama que enfrentan las empresas en este siglo XXI es el incremento de la competencia y la 
apertura al mundo; a través de la tecnología, los clientes son cada vez más exigentes, por lo que mejorar el rendimiento operativo y alcanzar la eficiencia, se convierte en un deber estratégico $^{94}$.

Ante esto aparece la Gestión por Procesos, la cual deja de lado la cadena de mandos y funciones departamentales, para centrarse en desarrollar la misión de la organización, a través del cumplimiento de las expectativas de sus Stakeholders, clientes, proveedores, accionistas, empleados, sociedad y así optimizar sus actividades ${ }^{95}$.

Cabe resaltar que el documento básico de una gestión por proceso es la ficha de proceso donde se encuentra paso a paso la planificación del proceso ya que esto ayuda a que prevalezca el enfoque hacia un sistema integrado ${ }^{96}$.

\subsubsection{Conceptos básicos}

\subsubsection{Proceso}

Para determinados autores, un proceso es cualquier actividad o conjunto de actividades de actividades en las que se transforman uno o más insumos para obtener uno o más productos para los clientes ${ }^{97}$. Para otros autores, un proceso es un conjunto de recursos (personal, financiero, instalaciones, etc.) y actividades interrelacionados que transforman elementos de entrada en elementos de salida ${ }^{98}$.

- Entradas (input): Es un producto que proviene de un suministrador, sea externo o interno. Es la salida de otro proceso precedente ${ }^{99}$.

- Secuencias de actividades: Son los medios y recursos con determinados requisitos para ejecutar de manera correcta el proceso ${ }^{100}$.

- Salidas (output): Es un producto cuyo destinatario es un usuario o cliente (interno o externo). Asimismo, debe tener un valor medible o evaluable para su cliente y es a la vez la entrada y/o el input de otro proceso $^{101}$.

Ilustración $\mathrm{N}^{\mathrm{o}}$ 13. Diagrama de un proceso

\footnotetext{
${ }^{94}$ Cfr. Mallar 2010

${ }^{95}$ Cfr. Mallar 2010

${ }^{96}$ Cfr. Llanes-Font y otros 2014: 259

${ }^{97}$ Cfr. Krajewski, Ritzman y Malhotra 2008: 4

${ }^{98}$ Cfr. Pérez, Ruíz y Parra 2007: 261

${ }^{99}$ Cfr. Pérez 2010:55

${ }^{100}$ Cfr. Pérez 2010:55

${ }^{101}$ Cfr. Pérez 2010: 55
} 


\section{RECURSOS}

ENTRADAS

PROCESO
SALIDAS

\section{Fuente: Elaboración propia}

\subsubsection{Clasificación de los procesos}

Los procesos se pueden clasificar en:

- Procesos estratégicos: Son aquellos que están relacionados con la directriz de la organización y realizan la planificación a largo plazo. Estos procesos marcan la estrategia de la organización, así como también definen los objetivos y políticas que se despliegan en toda la compañía ${ }^{102}$.

- Procesos operativos: Llamados también procesos centrales. Son los que conforman la cadena de actividades que agregan valor directamente a los clientes externos $\mathrm{y} / \mathrm{o}$ finales ${ }^{103}$. Aquí están agrupados todos aquellos relacionados directamente con la realización del producto o la prestación del servicio ${ }^{104}$.

- Procesos de apoyo: Son los que dan soporte a los procesos operativos por medio de recursos e insumos para que puedan cumplir con sus objetivos. ${ }^{105}$

\subsubsection{Gestión por procesos}

\subsubsection{Definición y características}

La gestión por procesos considera a una empresa como un gran sistema conformado por un conjunto de procesos que se encuentran interrelacionados, con el fin de conseguir el cumplimiento de un objetivo global ${ }^{106}$. Debido a que, bajo este enfoque, un proceso es la parte fundamental dentro de una empresa, se comienza a determinar la forma de cómo mejorar cada proceso basándose en la administración de sus restricciones y la eliminación de aquellas actividades que no agregan valor ${ }^{107}$.

\footnotetext{
${ }^{102}$ Cfr. Granero y Ferrando 2005: 71; Pérez, Ruíz y Parra 2007: 262

${ }^{103}$ Cfr. Krajewski, Ritzman y Malhotra 2008:9

${ }^{104}$ Cfr. Granero y Ferrando 2005:71

${ }^{105}$ Cfr. Krajewski, Ritzman y Malhotra 2008:9

${ }^{106}$ Cfr. Pérez, Ruíz y Parra 2007: 261

${ }^{107}$ Cfr. Krajewski, Ritzman y Malhotra 2008: 18
} 
Para la ISO 9000:2008, este enfoque introduce la gestión horizontal dentro de una empresa ya que cruza las barreras existentes entre las distintas unidades funcionales, logrando que unifiquen sus enfoques hacia el cumplimiento de las principales metas de la organización ${ }^{108}$.

Por otro lado, la gestión por procesos presenta las siguientes características:

- Repetitividad: La gestión por proceso se caracteriza porque sus procesos son repetitivos, lo que genera que puedan crearse procedimientos que especifiquen la forma en cómo realizar una operación. Esto, a la vez, genera que sea posible el hecho de invertir recursos en la mejora de los mismos ${ }^{109}$.

- Susceptibilidad a la mejora: Debido a su naturaleza repetitiva, la gestión por procesos nos brinda herramientas para mejorar los procesos. Además, los procesos deben de adaptarse a los requisitos cambiantes y variantes del mercado, de la empresa, etc ${ }^{110}$.

\subsubsection{Requisitos para una gestión por procesos}

El desempeño dentro de una organización puede ser mejorado si es que se tiene la visión de un enfoque basado en los procesos ${ }^{111}$. Sin embargo, para que se logre este cometido, se debe tener un ambiente propicio para la gestión por procesos; es por esto, que se deben cumplir y/o trabajar, a mediano y largo plazo, los siguientes requisitos:

Tabla $N^{o}$ 13. Requisitos para realizar una gestión por procesos

\begin{tabular}{|l|l|}
\hline Requisito & Concepto \\
\hline \multirow{2}{*}{ Enfoque estratégico } & $\begin{array}{l}\text { La empresa debe contar con una misión y } \\
\text { visión que sirvan como la piedra angular } \\
\text { dentro de la organización. Estos puntos } \\
\text { representan lo que es la empresa y lo que } \\
\text { quiere en el futuro. }\end{array}$ \\
\hline Liderazgo & $\begin{array}{l}\text { La formación de líderes es indispensable ya } \\
\text { que ellos deben motivar al personal para que } \\
\text { se sientan identificados con los objetivos y } \\
\text { metas de la empresa. }\end{array}$ \\
\hline
\end{tabular}

\footnotetext{
${ }^{108}$ Cfr. ISO 9000 2008: 5

${ }^{109}$ Cfr. Ruiz y otros 2013: 6

${ }^{110}$ Cfr. Ruiz y otros 2013: 6

${ }^{111}$ Cfr. ISO 9000 2008: 6
} 


\begin{tabular}{|l|l|}
\hline Enfoque de procesos & $\begin{array}{l}\text { Todos los recursos y actividades deben ser } \\
\text { gestionados como un proceso. }\end{array}$ \\
\hline Satisfacción del cliente & $\begin{array}{l}\text { Toda organización depende del consumo de } \\
\text { sus clientes, es por esto que se debe } \\
\text { comprender sus necesidades para } \\
\text { transformarlas en requisitos que sean } \\
\text { mejorados con el tiempo. }\end{array}$ \\
\hline Mejora continua & $\begin{array}{l}\text { El propósito de la mejora continua es } \\
\text { incrementar la satisfacción de los clientes } \\
\text { internos y externos. Todas las acciones } \\
\text { tomadas deben estar destinadas a la mejora }\end{array}$ \\
\hline Orientación a los resultados & $\begin{array}{l}\text { La gestión por procesos debe analizar si los } \\
\text { resultados obtenidos en relación a los } \\
\text { clientes son iguales a los que se esperaban. }\end{array}$ \\
\hline
\end{tabular}

Fuente: Adaptado de ISO 90002005 y Lamas y Ramos2011

\subsubsection{Ventajas de la gestión por procesos}

A continuación se listarán las ventajas más relevantes:

Tabla $\mathrm{N}^{\mathrm{o}} 14$. Ventajas de la gestión por procesos

\begin{tabular}{|c|}
\hline VENTAJAS \\
\hline - Compresión y cumplimiento de requisitos \\
\hline - Necesidad de priorizar a los procesos que agreguen valor \\
\hline - Obtención de resultados sobre la eficiencia del proceso \\
\hline - Mejora continua del proceso a través de mediciones objetivas. \\
\hline $\begin{array}{l}\text { - Al incrementar la flexibilidad y reducir las actividades sin valor, } \\
\text { se genera la satisfacción del cliente. }\end{array}$ \\
\hline $\begin{array}{l}\text { - Elimina las barreras departamentales y permite observar el } \\
\text { panorama completo }\end{array}$ \\
\hline
\end{tabular}

Fuente: Adaptado de Hernández 2002

\section{9.2.4 Beneficios de la gestión por procesos}

Entre los beneficios que se obtiene por aplicar la gestión por procesos se tiene: 
Ilustración $\mathrm{N}^{\mathrm{o}} 14$. Beneficios de la gestión por procesos

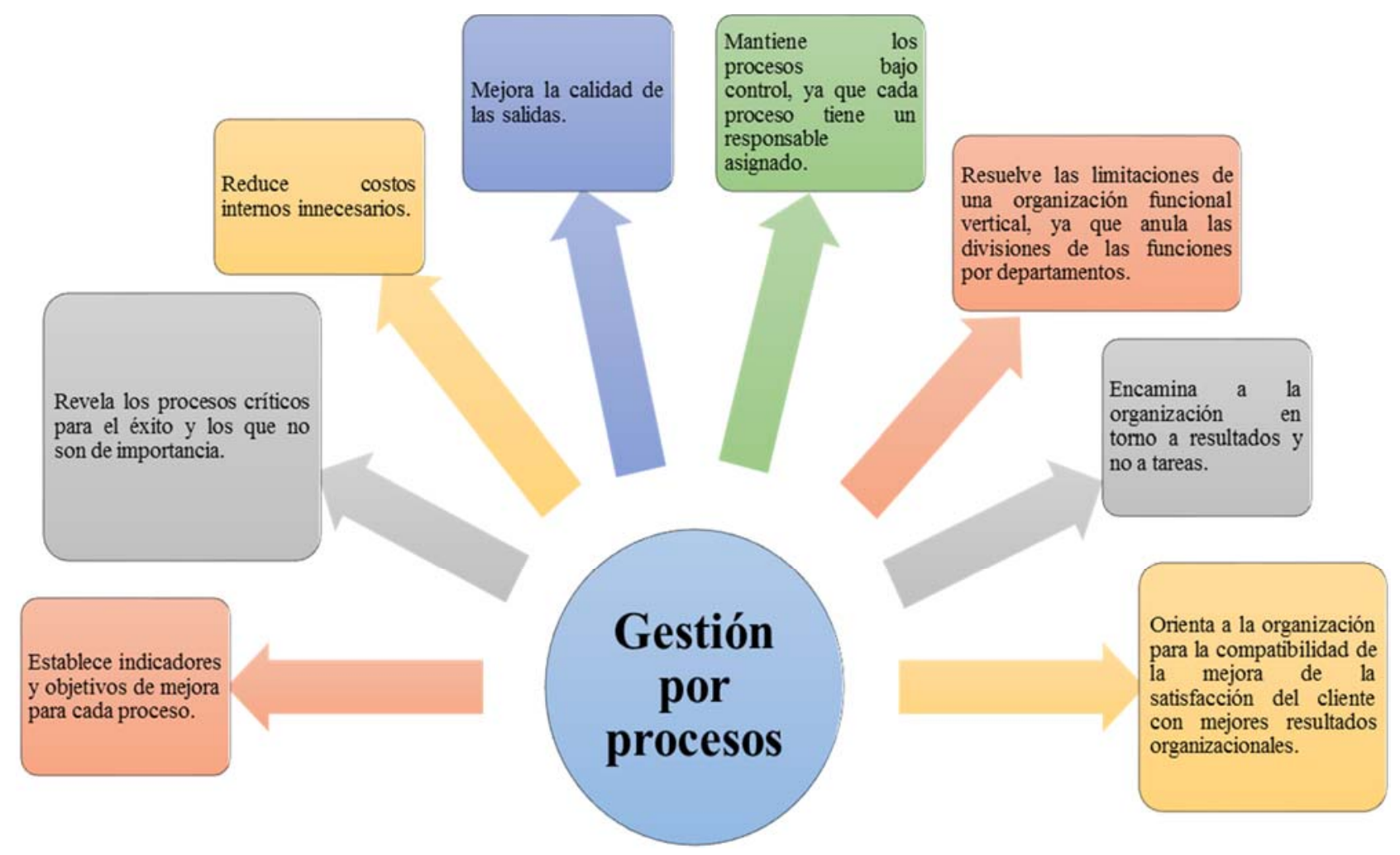

Fuente: Adaptado de Moreyra 2007

Cabe agregar, que otro beneficio de la gestión por procesos es su uso como indicador de satisfacción del cliente interno y externo, esto acompañado de una adecuada evaluación al desempeño ${ }^{112}$.

\subsubsection{Análisis dentro de la gestión por procesos}

\subsubsection{Pasos para un análisis de procesos}

Se debe seguir los siguientes pasos cuando se trata de analizar un proceso mediante la gestión por procesos.

${ }^{112}$ Cfr. Torres 2014: 163 
- Paso 1: Analizar y evaluar la información obtenida del proceso a partir de datos cuantitativos de seguimiento y medición; cuando se considere apropiado, se debe utilizar métodos estadísticos ${ }^{113}$.

- Paso 2: Comparar los resultados obtenidos del proceso con los requisitos definidos para este, con la finalidad de identificar alguna no conformidad que necesite una acción correctiva $^{114}$.

- Paso 3: Identificar las oportunidades de mejora basándose en el análisis de los resultados obtenidos del desempeño del proceso $^{115}$.

- Paso 4: Informar sobre el desempeño del proceso crítico a la alta dirección para que elija la solución más viable ${ }^{116}$.

\subsubsection{Herramientas para una gestión por procesos}

Para que se lleve a cabo una gestión por procesos, es necesario que se cuente con determinadas herramientas que faciliten la comprensión y medición de los procesos. A continuación, se presentan las herramientas más usadas.

\subsubsection{Mapa de procesos}

El mapa de procesos es la representación gráfica de nivel de agregación empresarial más alto puesto que en él se encuentran relacionados todos los procesos dentro de la organización $^{117}$. La directiva gestiona, controla y rediseña la empresa mediante el uso del mapa de procesos; por otro lado, la esencia del Balanced Scorecard se fundamenta dentro de los procesos descritos en el mapa ${ }^{118}$.

Toda esta representación de los distintos procesos dentro de la empresa tiene como motivo realizar la mejora continua de las actividades y los procesos con la finalidad de poder brindar un mejor producto $y / o$ servicio al cliente final ${ }^{119}$.

\footnotetext{
${ }^{113}$ Cfr. ISO 9000 2008: 11

${ }^{114}$ Cfr. ISO 9000 2008: 11

${ }^{115}$ Cfr. ISO 9000 2008: 11

${ }^{116}$ Cfr. ISO 9000 2008: 11

${ }^{117}$ Cfr. Caselles 2009: 59

${ }^{118}$ Cfr. Caselles 2009: 60

${ }^{119}$ Cfr. Caselles 2009: 60
} 


\subsubsection{Documentos}

Es necesaria la documentación de los procesos debido a que facilita su comprensión y su futuro análisis. En estos documentos debe estar definido la misión de cada proceso, las entradas, las salidas y todos los recursos asociados que participan en el proceso ${ }^{120}$.

El valor de la documentación se encuentra en que facilita la comunicación entre los procesos y permite tomar medidas de mejora coherentes con cada proceso ${ }^{121}$. Por otro lado, su uso en una empresa contribuye a:

- Proveer información apropiada y coherente, tanto interna y externa, acerca de los procedimientos de un proceso $^{122}$.

- Insertar los requisitos de los clientes internos o externos en un proceso con la finalidad de lograr la mejorar de los procesos ${ }^{123}$.

- Lograr que los procesos tengan tareas estandarizadas al definir claramente las actividades que los conforman ${ }^{124}$.

- Contar con documentos que contengan todos los antecedentes de un proceso, así como los resultados que se están obteniendo ${ }^{125}$.

\subsubsection{Diagramas de flujo}

El propósito de la elaboración de un diagrama de flujo es representar de forma gráfica los pasos que se deben tener en cuenta durante la ejecución de un proceso ${ }^{126}$. Además, al describir todos los pasos que se relacionan entre si dentro un proceso, estos pueden ser analizados con mayor detenimiento y se puede llegar a encontrar problemas potenciales con mayor facilidad ${ }^{127}$. El diagrama de flujo es muy importante en la gestión por procesos porque este sistema busca que prevalezca el uso de herramientas clásicas de calidad ${ }^{128}$. Una de las principales ventajas del uso de esta herramienta es que no supone la necesidad de invertir tiempo, dinero y esfuerzo para poder encontrar un problema o una mejora potencial; es por esto que son muy útiles cuando se trata de realizar diagnósticos de $\operatorname{procesos}^{129}$.

\footnotetext{
${ }^{120}$ Cfr. Pérez, Ruíz y Parra 2007: 262

${ }^{121}$ Cfr. ISO 9000 2005: 4

${ }^{122}$ Cfr. ISO 9000 2005: 4

${ }^{123}$ Cfr. ISO 9000 2005: 5

${ }^{124}$ Cfr. ISO 9000 2005: 5

${ }^{125}$ Cfr. ISO 9000 2005: 5

${ }^{126}$ Cfr. Sociedad Latinoamericana para la Calidad 2000: 1

${ }^{127}$ Cfr. Sociedad Latinoamericana para la Calidad 2000: 1

${ }^{128}$ Cfr. Llanes-Font y otros 2014: 259

${ }^{129}$ Cfr. Sociedad Latinoamericana para la Calidad 2000: 6
} 


\subsubsection{SIPOC}

SIPOC, acrónimo de Suppliers-Inputs-Process-Outputs-Customers (ProveedoresEntradas-Proceso-Salidas-Clientes), es una importante herramienta dentro de la identificación de problemas debido a que presenta información acerca de proveedores, requerimientos de recursos, entrada, salida y clientes de un proceso ${ }^{130}$.

Los principales beneficios de utilizar un SIPOC para cada proceso son:

Ilustración $\mathrm{N}^{\mathrm{o}} 15$. Ventajas del uso del SIPOC en la gestión por procesos

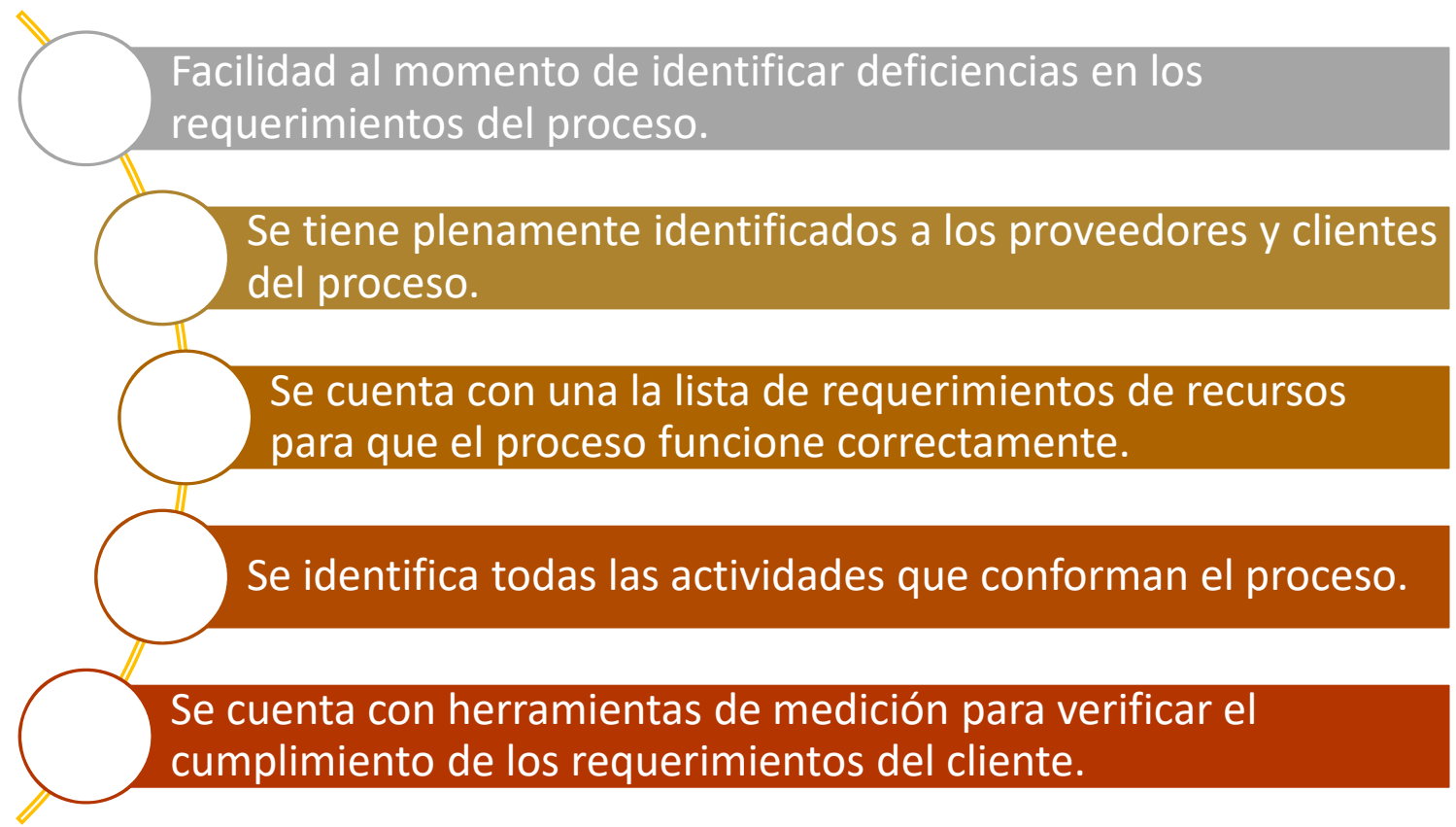

Fuente: Adaptado de Advanced Integrated Technologies Group Incorporated 2005

\subsection{Proceso de costos}

Uno de los procesos más importantes dentro de una organización es el de costos. En la revista académica Quipukamayoc ${ }^{131}$ del año 2012, Elsa Esther Choy ${ }^{132}$ argumenta que la economía mundial se encuentra plenamente globalizada, lo que provoca que las empresas

${ }^{130}$ Cfr. Advanced integrated technologies group Incorporated 2005: 3-4

${ }^{131}$ Quipukamayoc es la revista de la Facultad de Ciencias Contables de la Universidad Nacional Mayor de San Marcos. Cuenta con certificación ISSN y publica artículos académicos referentes a temas contables.

${ }^{132}$ Docente asociada de la Facultad de Ciencias Contables de la Universidad Nacional Mayor de San Marcos. 
experimenten un crecimiento más rápido y que sus costos sean más altos y demuestren mayor complejidad al momento de ser determinados ${ }^{133}$.

\subsubsection{Definición del costo}

En palabras de Charles Horngren, se puede definir el costo de la siguiente manera:

"El costo [es] (...) un sacrificio de recursos que se asigna para lograr un objetivo específico. Un costo (...) por lo general se mide como la cantidad monetaria que debe pagarse para adquirir bienes o servicios." (Horngren 2012: 27)

Complementaria a esta definición, se puede afirmar que el costo es la suma de todos esos sacrificios monetarios con el fin de generar ingresos en el futuro ${ }^{134}$.

\subsubsection{Definición de gasto}

Una definición conceptual de gasto es que este es un costo el cual dio un beneficio y que, actualmente, se encuentra expirado ${ }^{135}$. Sin embargo, esta definición puede crear confusión en las empresas debido al manejo de la palabra "costo" dentro de su definición; es por esto que se asocia el término "gasto" a todo el dinero desembolsado por los departamentos administrativos y que contribuyen, de forma indirecta, en la generación de ingresos ${ }^{136}$. Términos comunes son "gastos administrativos" y "gastos de venta" $"$ "

\subsubsection{Definición de pérdida}

Se considera "pérdida" cuando un activo, el cual posee la empresa, pierde su valor sin haber generado un beneficio económico ${ }^{138}$. Por otro lado, también es posible referirse como "pérdida" a la situación en la cual las participaciones que obtuvo una empresa no han estado a la altura de los valores esperados en relación a lo que se invirtió ${ }^{139}$. Por ejemplo, una empresa invirtió S/. 1'000,000 Nuevos Soles en un nuevo producto, sin embargo, las utilidades han sido solo S/. 600,000 Nuevos Soles; esto supone una pérdida de S/. 400,000 Nuevos Soles con respecto al capital invertido.

\footnotetext{
${ }^{133}$ Cfr. Choy 2012: 8

${ }^{134}$ Cfr. Choy 2012:8

135 Cfr. Sánchez Barraza 2009: 96

${ }^{136}$ Cfr. Sánchez Barraza 2009: 97

${ }^{137}$ Cfr. Sánchez Barraza 2009: 97

138 Cfr. Sánchez Barraza 2009: 97

${ }^{139}$ Cfr. Sánchez Barraza 2009: 97
} 


\subsubsection{Elementos del costo}

Los elementos del costo en una empresa de producción o de servicios son tres. Sin embargo, como esta tesis está enfocada hacia el sector servicios, los elementos que serán descritos, a continuación, estarán enfocados hacia este sector con el fin de ser más objetivos en cuanto a definiciones.

\subsubsection{Materiales directos}

- Los materiales directos son todos aquellos insumos o recursos que son empleados en la producción y son transformados en productos terminados ${ }^{140}$.

- En su definición general, los costos de materiales directos son aquellos producto de la adquisición de todos los materiales que llegarán a formar parte del producto terminado al que se le denominará Objeto de costo ${ }^{141}$.

- Generalmente, los costos de materiales directos son muy significativos con respecto al monto total de costos de un producto terminado ${ }^{142}$.

- En los servicios, los materiales se incorporan a los costos cuando existe una orden de salidaque puede ser para una prestación de servicio o por un órden de trabajo ${ }^{143}$.

- En los servicios, se debe formular el inventario de materiales para que puedan ser valorizados ${ }^{144}$.

\subsubsection{Mano de obra}

- Es uno de los principales elementos del costo debido a que las empresas de servicio son intensas en el uso del capital humano ${ }^{145}$.

- El costo de mano de obra está conformado por el total de costos de los servicios de todos los trabajadores que están directamente relacionados con la prestación de un servicio ${ }^{146}$.

\footnotetext{
${ }^{140}$ Cfr. Sánchez Barraza 2009: 99

${ }^{141}$ Cfr. Horngrem 2012:37

${ }^{142}$ Cfr. Sánchez Barraza 2009:98

${ }^{143}$ Cfr. Gavelán Izaguirre 2014: 124

${ }^{144}$ Cfr. Gavelán Izaguirre 2014: 125

${ }^{145}$ Cfr. Choy 2012: 10

${ }^{146}$ Cfr. Gavelán Izaguirre 2014: 127
} 
- Los sistemas de costos, como el basado en actividades, no toman en cuenta las consecuencias en el comportamiento de los integrantes de este elemento del $\operatorname{costo}^{147}$.

- Se debe costear en base a la mano de obra que ha intervenido directamente con la prestación del servicio $^{148}$.

\subsubsection{Gastos indirectos de fabricación}

- Son todos aquellos gastos que no pueden ser aplicados de forma directa sobre el servicio prestado pero son necesarios para dar mantener la operatividad del servicio $^{149}$. Estos pueden ser:

1. Material indirecto: son aquellos que no influyen directamente en el servicio ofrecido $^{150}$.

2. Mano de obra indirecta: este gasto está conformado por los trabajadores de la empresa que no trabajan físicamente y/o directamente en la prestación del servicio ofrecido ${ }^{151}$.

3. Gastos indirectos generales: Este gasto engloba a todos los recursos y servicios adicionales necesarios para realizar una prestación de servicios adecuada $^{152}$.

- Debido a su naturaleza, se les debe asignar una base sistemática de asignación o prorrateo para que puedan ser "identificables" con el servicio ${ }^{153}$.

\subsubsection{Clasificación de los costos}

Los costos pueden ser clasificados mediante diversas técnicas o de acuerdo a las funciones que cumplen dentro de una empresa.

\subsubsection{De acuerdo a su función}

Tabla $\mathrm{N}^{\mathrm{0}} 15$. Clasificación de los costos de acuerdo a su función

\begin{tabular}{|l|l|}
\hline \multicolumn{1}{|c|}{ TIPOS } & \multicolumn{1}{|c|}{ CONCEPTO } \\
\hline C. de producción & $\begin{array}{l}\text { Son aquellos costos generados durante el } \\
\text { proceso de transformación de la materia prima } \\
\text { a productos finales. Ej: Mano de obra, materia } \\
\text { prima, costos indirectos de fabricación. }\end{array}$ \\
\hline
\end{tabular}

\footnotetext{
${ }^{147}$ Cfr. Sánchez Barraza 2013: 72

148 Cfr. Sánchez Barraza 2013: 72

${ }^{149}$ Cfr. Gavelán Izaguirre 2014: 127

${ }^{150}$ Cfr. Gavelán Izaguirre 2014: 127

${ }^{151}$ Cfr. Gavelán Izaguirre 2014: 127

${ }^{152}$ Cfr. Gavelán Izaguirre 2014: 127

${ }^{153}$ Cfr. Gavelán Izaguirre 2014: 1272
} 


\begin{tabular}{|l|l|}
\hline C. de distribución & $\begin{array}{l}\text { Son aquellos relacionados con la forma en } \\
\text { cómo se lleva el producto terminado hasta el } \\
\text { cliente final. Ej: Salario de transportistas }\end{array}$ \\
\hline $\begin{array}{l}\text { C. } \\
\text { administración }\end{array}$ & $\begin{array}{l}\text { Son todos los costos que se generan en el área } \\
\text { administrativa. Ej. Sueldo del gerente }\end{array}$ \\
\hline
\end{tabular}

Fuente: Adaptado de la Universidad Veracruzana 2013

\subsubsection{De acuerdo a la actividad}

Tabla $N^{0}$ 16. Clasificación de los costos de acuerdo a la actividad

\begin{tabular}{|l|l|}
\hline \multicolumn{1}{|c|}{ TIPOS } & \multicolumn{1}{|c|}{ CONCEPTO } \\
\hline C. Directos & $\begin{array}{l}\text { Son aquellos que pueden identificarse de } \\
\text { forma rápida y fácil con el objeto de costo. Este } \\
\text { puede ser controlado, medido y valorado con } \\
\text { respecto al objeto de costo. Ej: Materiales } \\
\text { directos de fabricación. }\end{array}$ \\
\hline C. Indirectos & $\begin{array}{l}\text { Son aquellos que resultan difíciles de asociar } \\
\text { con el objeto de costo o con una actividad } \\
\text { específica; es por esto que solo pueden ser } \\
\text { controlados de forma global. Ej: Sueldo del } \\
\text { gerente. }\end{array}$ \\
\hline
\end{tabular}

Fuente: Adaptado de la Universidad Veracruzana 2013 y García

2012

\subsubsection{De acuerdo a su comportamiento}

Tabla $N^{o} 17$. Clasificación de los costos de acuerdo a su comportamiento

\begin{tabular}{|l|l|}
\hline \multicolumn{1}{|c|}{ TIPOS } & \multicolumn{1}{|c|}{ CONCEPTO } \\
\hline C. Variable & $\begin{array}{l}\text { Son considerados aquellos costos que varían } \\
\text { dependiendo del nivel de la actividad, de } \\
\text { donde se generan, o el volumen total }\end{array}$ \\
\hline
\end{tabular}




\begin{tabular}{|l|l|}
\hline C. Fijo & $\begin{array}{l}\text { Es aquel que siempre se mantiene "estable" y } \\
\text { no se ve afectado por alguna variación en su } \\
\text { entorno. }\end{array}$ \\
\hline
\end{tabular}

Fuente: Adaptado de Horngrem 2012

1.10.5.4 De acuerdo a su control

Tabla $\mathrm{N}^{\mathrm{o}}$ 18. Clasificación de los costos de acuerdo a su control

\begin{tabular}{|l|l|}
\hline TIPOS & CONCEPTO \\
\hline C. Controlables & $\begin{array}{l}\text { Son aquellos costos sobre los cuales el } \\
\text { encargado tiene autoridad para generarlos o } \\
\text { no. Ej: El aumento del salario del trabajador. }\end{array}$ \\
\hline C. No controlables & $\begin{array}{l}\text { Son aquellos sobre los cuales no se puede tener } \\
\text { control. Ej: Pago de alquiler. }\end{array}$ \\
\hline
\end{tabular}

Fuente: Adaptado de la Universidad Veracruzana 2013

1.10.5.5 De acuerdo a como se enfrentan con los ingresos

Tabla $\mathrm{N}^{\mathrm{o}}$ 19. Clasificación de los costos de acuerdo a como se enfrentan con los ingresos

\begin{tabular}{|l|l|}
\hline \multicolumn{1}{|c|}{ TIPOS } & \multicolumn{1}{|c|}{ CONCEPTO } \\
\hline C. del periodo & $\begin{array}{l}\text { Son aquellos costos que son identificables en } \\
\text { un determinado periodo de tiempo más no con } \\
\text { el producto. }\end{array}$ \\
\hline C. del producto & $\begin{array}{l}\text { Estos costos solo son asociados con los } \\
\text { ingresos si es que han contribuido a generarlos } \\
\text { directamente. En otras palabras, es el costo de } \\
\text { la mercadería puesta en venta. }\end{array}$ \\
\hline
\end{tabular}

Fuente: Adaptado de la Universidad Veracruzana 2013 


\subsubsection{De acuerdo a su función en la toma de decisiones}

Tabla $\mathrm{N}^{\mathrm{o}} 20$. Clasificación de costo de acuerdo a su función en la toma de decisiones

\begin{tabular}{|l|l|}
\hline \multicolumn{1}{|c|}{ TIPO } & \multicolumn{1}{|c|}{ CONCEPTO } \\
\hline C. Relevantes & $\begin{array}{l}\text { Son costos que forman parte activa dentro de } \\
\text { la toma de decisiones y que, por ende, son } \\
\text { propensos a sufrir variaciones debido a una } \\
\text { decisión. }\end{array}$ \\
\hline C. Irrelevantes & $\begin{array}{l}\text { Estos costos no se ven afectados por alguna } \\
\text { decisión tomada. }\end{array}$ \\
\hline
\end{tabular}

Fuente: Adaptado de García 2012

\subsubsection{Sistemas de costo}

Hoy en día, una de las principales misiones de las empresas es tener un sistema de costos confiable y preciso para poder desarrollar correctamente a una empresa. Las empresas, que actualmente buscan alcanzar ventajas competitivas, tienen claro que necesitan una visión sistemática que permita crear estructuras de optimización de $\operatorname{costos}^{154}$. Sin embargo, en algunos países de Latinoamérica, como en el caso de Colombia, las investigaciones referentes a los temas de costo no han ocupado un lugar destacado en la mayoría de revistas académicas especializadas ${ }^{155}$.

\subsubsection{Definición de un sistema de costos}

Un sistema de costos es aquel conjunto de procedimientos y técnicas basadas en un conjunto secuencial de índices que se deben seguir para poder establecer una política de manejo de los $\operatorname{costos}^{156}$.

\footnotetext{
${ }^{154}$ Cfr. Chacón 2007: 30

${ }^{155}$ Cfr. Duque y Osorio 2013: 26

${ }^{156}$ Cfr. UMICH 2013: 2
} 
Tener claro la clasificación de los costos es muy importante para poder entender los sistemas de costo, su definición y su metodología para tratarlos.

\subsubsection{Sistemas tradicionales}

Con anterioridad, se definieron los tres elementos del costo (los costos de materiales, mano de obra directa y los indirectos de fabricación); estos son los elementos tradicionales dentro de un sistema tradicional de $\operatorname{costos}^{157}$. Por otro lado, la clasificación de los costos en directos e indirectos también es parte del sistema tradicional; los costos de producción y los gastos de la misma forma ${ }^{158}$.

\subsection{Costeo por absorción}

1. Concepto

Es también conocido como costeo total porque, su mayor característica, supone que todos los costos de producción, anteriormente clasificados, deben de ser absorbidos por el objeto de costo ${ }^{159}$. El costeo por absorción solo reconoce, como costos de producción, a los costos de materia prima directa, mano de obra directa $\mathrm{y}$ los costos indirectos de fabricación ${ }^{160}$.

2. Metodología

El costeo por absorción divide los costos en dos secciones:

- La primera sección está conformada por los costos de fabricación (variables o fijos), también llamados inventariables, puesto que sirven para valorizar el inventario de productos en proceso y productos terminados existentes dentro de una empresa ${ }^{161}$.

- La segunda sección la conforman los costos no relacionados a la producción (gastos) y no llegan a ser considerados dentro del inventario de productos en procesos o productos terminados ${ }^{162}$.

En el caso de los costos de operación (gastos), estos recién son imputados cuando son llevados al estado de resultado del periodo al cual pertenecen ${ }^{163}$.

\footnotetext{
${ }^{157}$ Cfr. Bellido 2003: 12

${ }^{158}$ Cfr. Bellido 2003: 13

${ }^{159}$ Cfr. Bellido 2003: 13

${ }^{160}$ Cfr. UMICH 2013: 7

${ }^{161}$ Cfr. Bellido 2003: 14

${ }^{162}$ Cfr. Bellido 2003: 14

${ }^{163}$ Cfr. UMICH 2013: 7
} 


\subsection{Costeo directo}

\section{Concepto}

Es un sistema de costo el cual se basa en clasificar a los costos de acuerdo a su comportamiento (fijo y variable) dependiendo del volumen de la producción o de las ventas ${ }^{164}$. El objetivo de este sistema es proporcionar información relevante a la gerencia general para que puedan realizar la planificación estratégica de la empresa ${ }^{165}$.

2. Metodología

Este sistema solo toma en cuenta los costos de materia prima, la mano de obra y los costos indirectos de fabricación al momento de realizar la clasificación entre fijo o variable ${ }^{166}$. De esta manera, el costo del producto terminado solo está conformado por los costos variables de fabricación, dejando de lado a los costos fijos de fabricación al considerándolos como un gasto del periodo en el que han sido incurridos ${ }^{167}$.

3. Desventajas de un costeo tradicional

Pedro Alberto Bellido cita a Robert S. Kaplan al mencionar que los sistemas tradicionales han perdido vigencia debido a que son muy poco competitivos en la actualidad ${ }^{168}$. Una de las tantas desventajas que presenta un costeo tradicional es que no supieron adaptarse a los cambios que han experimentado sus procesos, los cuales son la base de asignación de costo, produciendo que sus informes sean muy inexactos ${ }^{169}$. Por otro lado, en su objetivo primario se encuentra el mayor problema de este sistema ya que busca valorizar un inventario en vez de generar un informe preciso sobre el costo real del producto terminado; lo que ha llevado a que los gerentes no cuenten con una información precisa para la toma de decisiones $^{170}$.

\subsubsection{Costeo por órdenes de trabajo}

1. Concepto

\footnotetext{
${ }^{164}$ Cfr. UMICH 2013: 7; Bellido 2003: 14

165 Cfr. UMICH 2013: 7

${ }^{166}$ Cfr. UMICH 2013: 7

${ }^{167}$ Cfr. Bellido 2003: 14

${ }^{168}$ Cfr. Bellido 2003: 186

${ }^{169}$ Cfr. Bellido 2003: 185

${ }^{170}$ Cfr. Bellido 2003: 185
} 
El principio de un costeo por órdenes de trabajo es que el objeto de costos es una determinada unidad o cantidad de unidades de un producto o servicio determinado que están marcadamente diferenciados, a esto se le denomina orden de trabajo ${ }^{171}$.

2. Metodología

El costeo por órdenes de trabajo es muy común en empresas manufactureras y de servicios cuyos productos son distintos, esto permite que los costos se acumulen de una manera separada para cada producto y/o servicio ${ }^{172}$.

Los pasos a seguir son:

\section{Paso 1: Identificar la orden de trabajo}

Es importante que la orden de trabajo sea el objeto de costo seleccionado para poder acumular los $\operatorname{costos}^{173}$. Se debe contar con un documento fuente el cual recopile toda aquella información necesaria para poder costear y poder generar el registro de costos de un trabajo, en el cual se registra y acumula todos los costos involucrados en una orden de trabajo ${ }^{174}$.

\section{Paso 2: Identificar los costos directos}

Los costos directos están relacionados con los costos de los materiales directos, los cuales deben estar presentes en un registro de materiales, y los costos de mano de obra, que deben estar registrados en una hoja de tiempo por trabajo específico ${ }^{175}$.

\section{Paso 3: Seleccionar las bases de aplicación de costos}

Con esto se podrá realizar la asignación respectiva de los costos indirectos de fabricación ya que estos no pueden ser atribuidos, directamente, a un trabajo en específico ${ }^{176}$. Las compañías utilizan muchas bases de aplicación de costos debido a que los costos indirectos tienen distintos generadores de $\operatorname{costos}{ }^{177}$.

\section{Paso 4: Identificar los costos indirectos}

${ }^{171}$ Cfr. Horngren 2012:100

${ }^{172}$ Cfr. Horngren 2012: 101

${ }^{173}$ Cfr. Horngren 2012: 104

${ }^{174}$ Cfr. Horngren 2012: 104

${ }^{175}$ Cfr. Horngren 2012: 106

${ }^{176}$ Cfr. Horngren 2012: 106

${ }^{177}$ Cfr. Horngren 2012: 106 
Esto se realiza para poder asociarlos con sus respectivas bases de aplicación de $\operatorname{costos}^{178}$.

\section{Paso 5: Calcular la tasa por unidad de cada base de aplicación de costo}

Esto se consigue al dividir la cantidad total de costos indirectos entre la base de la cantidad total de aplicación de $\operatorname{costos}^{179}$.

\section{Paso 6: Calcular los costos indirectos asignados a la orden de trabajo}

Se calcula multiplicando la cantidad total de cada base de aplicación por la tasa por unidad de base ${ }^{180}$.

El costo unitario de cada producto se obtiene al dividir el costo total de cada orden entre las unidades del producto que se han elaborado ${ }^{181}$.

3. Ventajas

Ilustración $\mathrm{N}^{\mathrm{o}} 16$. Ventajas del costeo basado en órdenes de trabajo

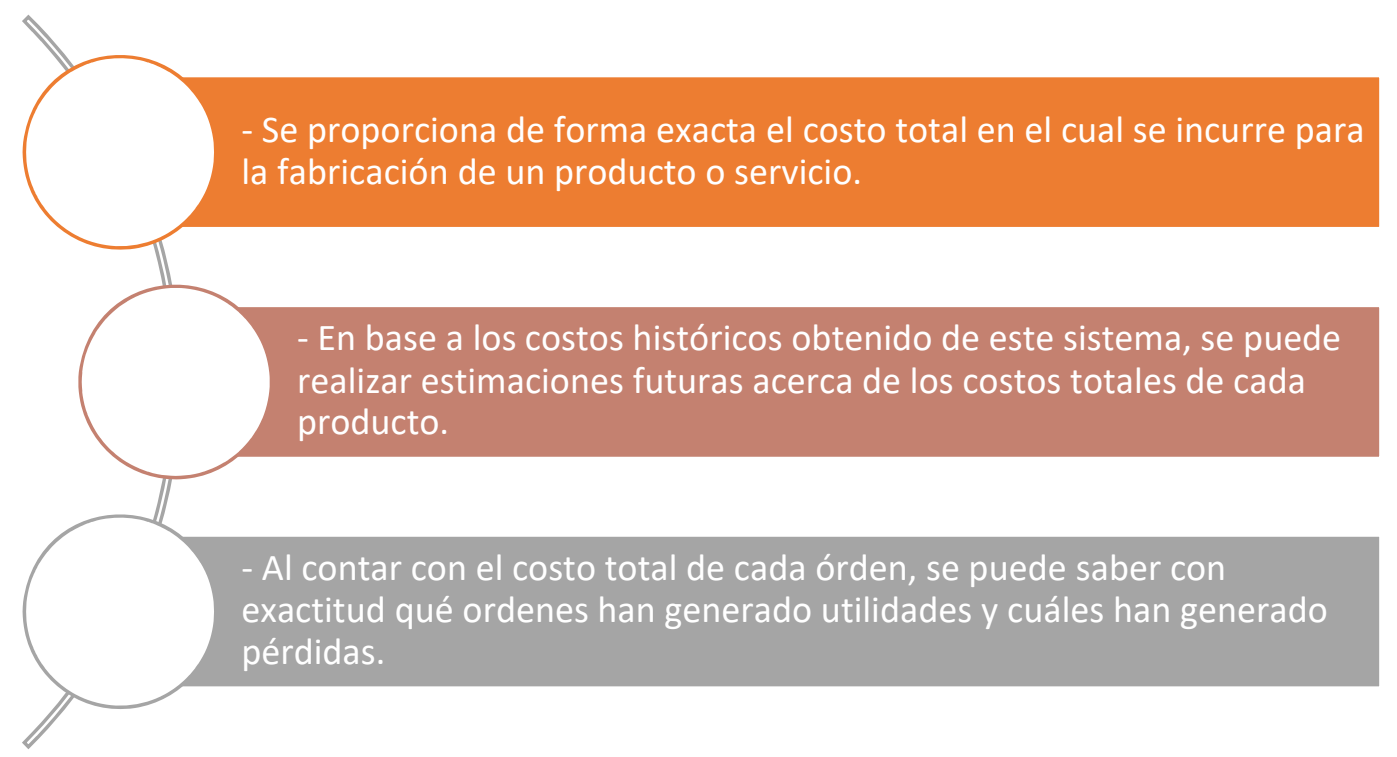

Fuente: Adaptado de la UNICH 2013

${ }^{178}$ Cfr. Horngren 2012: 107

${ }^{179}$ Cfr. Horngren 2012: 107

${ }^{180}$ Cfr. Horngren 2012: 107

${ }^{181}$ Cfr. UMICH 2013: 12 


\section{Desventajas}

Ilustración $\mathrm{N}^{\mathrm{o}}$ 17. Desventajas del costeo basado en órdenes de trabajo

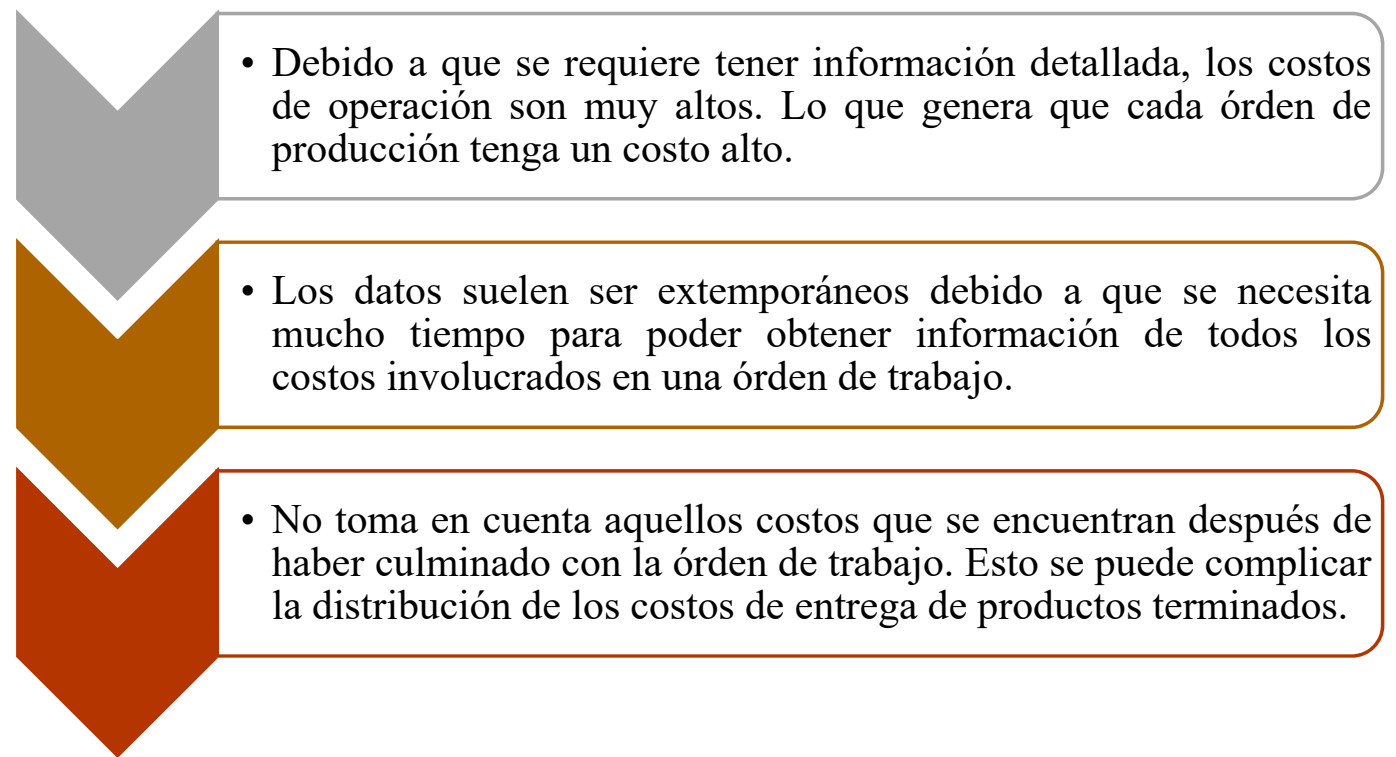

Fuente: Adaptado de UMICH 2013

\subsubsection{Costeo Basado en Actividades (ABC)}

1. Concepto

El costeo ABC (Activity Based Costing) es un método desarrollado por los profesores de la Universidad de Harvad, Robert Kaplan y Robin Cooper, el cual tiene como hipótesis que todos los costos generados en una empresa son producto de las actividades que se desarrollan dentro de la misma ${ }^{182}$.

182 Cfr. Sánchez 2013: 66 
Esta metodología de costeo surge, a finales de los años 80, como alternativa al sistema de costeo tradicional. Las empresas buscaban la manera de evaluar adecuadamente sus costos para poder ser más competitivos y rentables ${ }^{183}$. El costeo $\mathrm{ABC}$ debe funcionar como una herramienta de gestión que ayude a la toma de decisiones, con el fin de que no se vea interrumpida la marcha continua del negocio ${ }^{184}$.

El costeo basado en actividades analiza todas las actividades de todos los departamentos de la empresa para calcular el costo de los productos terminados ${ }^{185}$. El costeo basado en actividades tiene los siguientes principios:

- Las actividades son las que consumen los recursos disponibles de las empresas $^{186}$.

- Por ende, los productos son los que consumen actividades ${ }^{187}$.

- La mayoría de los costos o gastos indirectos son tratados como fijos ${ }^{188}$.

- La variación de los costos no depende de la variación de la producción, sino, depende de los niveles de las actividades ${ }^{189}$.

Además, el principal principio para que un sistema de costeo $\mathrm{ABC}$ funcione al momento de ser implementado es el compromiso por parte de la alta dirección de una empresa. No solo se debe estar dispuesto a aportar dinero o recursos, también es importante liderar el proyecto de implementación y servir de ejemplo a seguir para todas las áreas involucradas ${ }^{190}$.

2. Metodología

\section{Paso 1: Recursos}

Es determinante la identificación de todos los recursos (expresados en unidades monetarias) que la empresa consume para realizar sus actividades productivas ${ }^{191}$.

Paso 2: Actividades

${ }^{183}$ Cfr. Bustamante 2015: 113

${ }^{184}$ Cfr. Ocampo y otros 2011: 75

${ }^{185}$ Cfr. Sánchez Barraza 2013: 67

${ }^{186}$ Cfr. Sánchez Barraza 2013: 67

${ }^{187}$ Cfr. Sánchez Barraza 2013: 67

${ }^{188}$ Cfr. Sánchez Barraza 2013: 67

${ }^{189}$ Cfr. Sánchez Barraza 2013: 67

${ }^{190}$ Cfr. Arbeláez y Marín

${ }^{191}$ Cfr. Sánchez Barraza 2013: 69 
Identificar las actividades de los procesos de toda la empresa para poder asignar los costos que han consumido; de esta forma, se crean grupos de costos con mayor homogeneidad al ser relacionadas con una misma actividad ${ }^{192}$.

\section{Paso 3: Cost driver de los recursos}

Se debe determinar cómo las actividades consumen los recursos de la empresa; de esta forma, se crea un nexo entre recursos y actividades ${ }^{193}$.

\section{Paso 4: Medición de las actividades}

Se deben encontrar y fundamentar las "medidas" de cada actividad (base de aplicación) para poder encontrar el origen y la variación de todos los costos indirectos de producción ${ }^{194}$. Mientras más unidades de actividad se consuman, el consumo de los costos indirectos de cada actividad será mayor ${ }^{195}$.

\section{Paso 5: Calcular la tasa de unidad}

El cálculo se realiza con cada base de aplicación ${ }^{196}$.

\section{Paso 6: Calcular los costos indirectos asignados a los productos}

Se debe asignar los costos indirectos a los productos mediante la multiplicación de la tasa de unidad y el total de productos elaborados ${ }^{197}$.

3. Ventajas

Ilustración $\mathrm{N}^{\mathrm{o}} 18$. Ventajas del empleo del costeo ABC

${ }^{192}$ Cfr. Sánchez Barraza 2013: 69

${ }^{193}$ Cfr. Sánchez Barraza 2013: 69

${ }^{194}$ Cfr. Sánchez Barraza 2013: 69

${ }^{195}$ Cfr. Sánchez Barraza 2013: 69

${ }^{196}$ Cfr. Horngren 2012: 152

${ }^{197}$ Cfr. Sánchez 2013: 69 


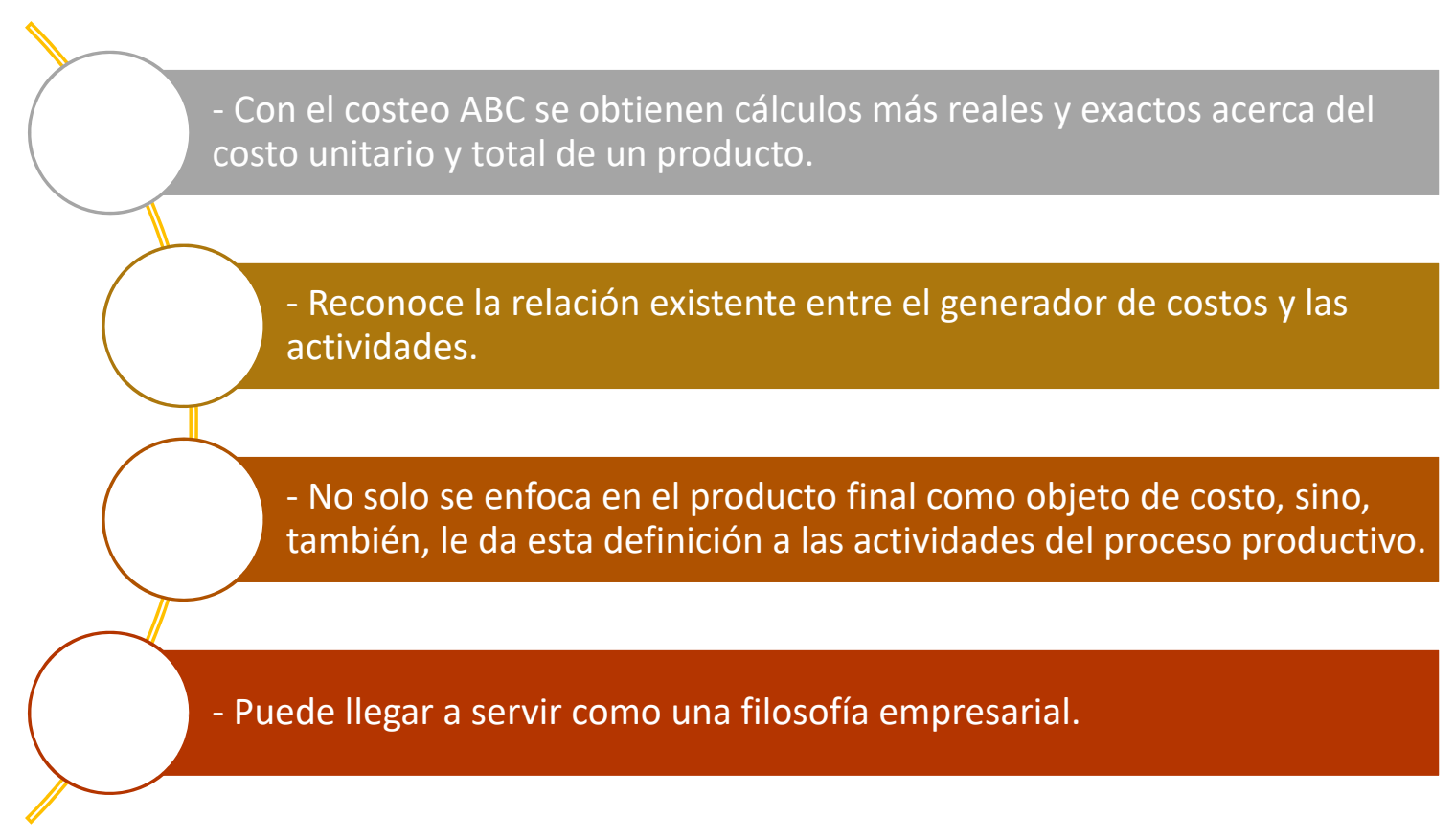

Fuente: Adaptado de Sánchez 2013

4. Desventajas

Ilustración $\mathrm{N}^{\circ}$ 19. Desventajas del empleo del costeo ABC 
- Debe existir toda una filosofía basada en actividades para que el sistemas $A B C$ pueda funcionar con éxito.

1

- Tanto organismos internacionales como la ley peruana solo reconocen al costeo tradicional (absorción) como la fuente para poder calcular los 2 tributos.

\section{Fuente: Adaptado de Sánchez 2013}

A pesar de todas estas desventajas, desde hace unos años ya se viene plateando el hecho de que en algunas empresas peruanas se diseñe el Plan Contable en base a actividades y no en centros de costos. Por otro lado, a pesar de que un sistema $\mathrm{ABC}$ puede significar una gran inversión de recursos, siguiendo el plan adecuado se puede llegar a su implementación disminuyendo el impacto de la inversión ${ }^{198}$.

\subsubsection{Enfoque de la gestión de costos}

El costeo $\mathrm{ABC}$ no solo es un sistema que permite calcular los costos de un determinado surtido de productos, también es un enfoque de gestión que tiene como finalidad la reducción de los costos e identificar la rentabilidad de los productos, de los clientes y saber en qué actividades se está desembolsando una mayor cantidad de dinero ${ }^{199}$.

$\mathrm{El}$ costeo $\mathrm{ABC}$ permite tener un enfoque en las actividades que realmente generan valor para la empresa ya que, si se descuida o se elimina alguna actividad necesaria, se puede generar un deterioro innecesario en la empresa ${ }^{200}$. Se puede identificar 3 enfoques en lo que respecta a una adecuada gestión de costos:

Ilustración $\mathrm{N}^{\mathrm{o}} 20$. Enfoque de la gestión de costos según el costeo $\mathrm{ABC}$

\footnotetext{
${ }^{198}$ Cfr. Carrión 2005: 47

${ }^{199}$ Cfr. Escobar 2009: 81

${ }^{200}$ Cfr. Vergiu 2005: 42
} 


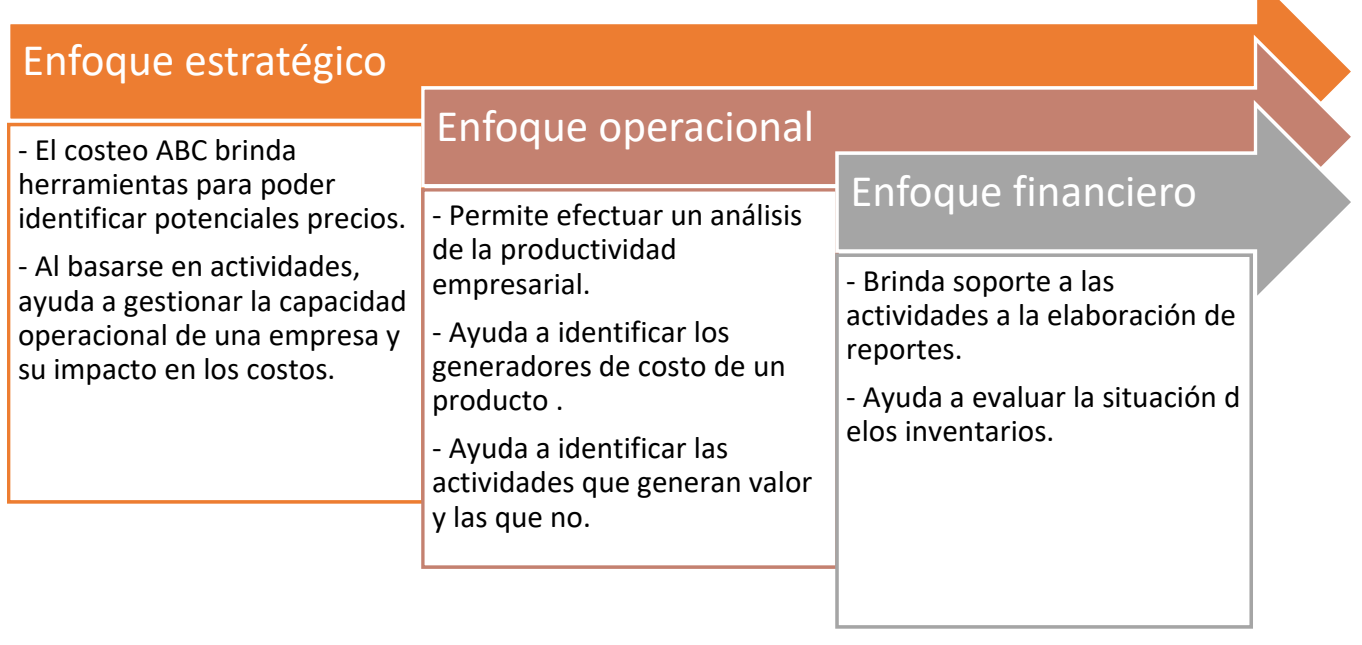

Fuente: Adaptado de Escobar 2009

La posterior implementación de un sistema de costos debe estar sujeta a todos estos enfoques ya que debe ajustarse a las necesidades de la empresa para que esta pueda ser competitiva en una economía globalizada ${ }^{201}$.

\subsubsection{Normativa peruana sobre el costeo}

Al igual que muchos estados alrededor del mundo, la República del Perú tiene políticas claras en lo que respecta a declaración de tributos. En este caso, es la Superintendencia Nacional de Administración Tributaria (SUNAT) la que se encarga de fijar dichas políticas que todas las empresas formales deben de tomar en cuenta para presentar su declaración de impuestos.

En La Ley del Impuesto a la Renta, en el Artículo N 35 del Capítulo Nª IX “Del Régimen para Determinar la Renta", dice:

“En el transcurso del ejercicio gravable, los deudores tributarios podrán llevar un Sistema de Costo Estándar que se adapte a su giro, pero al formular cualquier balance para efectos del impuesto, deberán necesariamente valorar sus existencias al costo real (...).” (Ley del Impuesto a la Renta - SUNAT)

Como se puede evidenciar, el régimen normativo obliga a todas las empresas formales a presentar sus declaraciones tributarias basándose en el costeo estándar.

${ }^{201}$ Cfr. Vaca 2012: 9 


\section{CAPITULO II}

En el presente capítulo se realizará un diagnóstico general acerca de la situación más realista de las MYPE del subsector restaurantes basada en la información recolectada a lo largo del capítulo anterior. Con el apoyo de encuestas realizadas a diversas empresas que se desempeñan en este rubro, se elaborará un diagnóstico de la situación actual del manejo de costos, así como sus tendencias y su forma en las cuales son administradas. De esta forma, se comprobará si el diseño de un modelo de costeo más apropiado para las MYPE puede volverlas más competitivas. Las empresas serán seleccionadas de la página del Ministerio de Trabajo y Promoción del Empleo. 


\subsection{Relación del PBI y el índice de pobreza}

Para poder afirmar que existe una relación entre el PBI (en millones de soles) y el índice de pobreza, el crecimiento o decrecimiento de uno de ellos debe de afectar al otro. A continuación, se muestra la siguiente gráfica.

Ilustración N² 21. PBI (en millones de Soles) vs Índice de Pobreza (en \%)

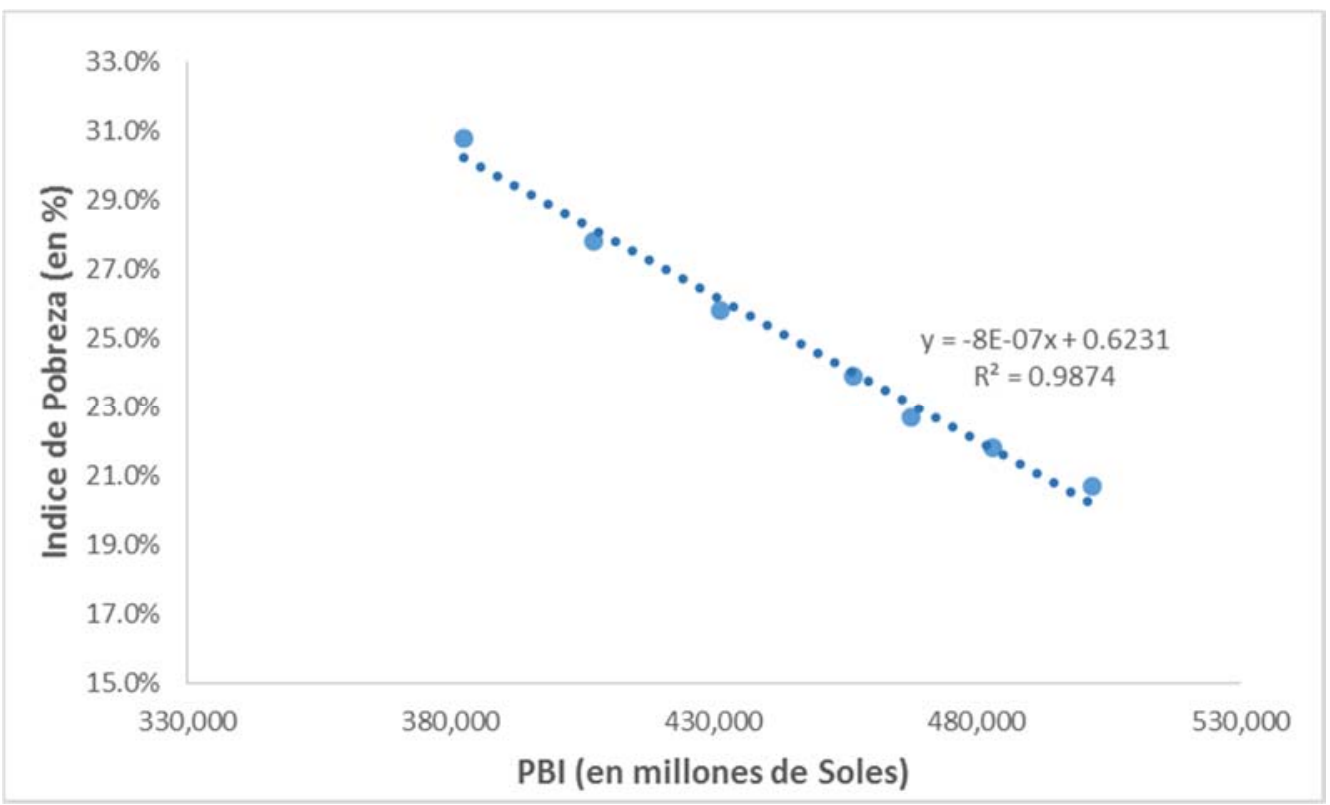

Fuente: Adaptado del Banco Central de Reserva del Perú y INEI 2017

El gráfico anterior muestra la relación del PBI (en millones de soles) y el índice de pobreza de un determinado año desde el 2010 hasta el 2016. Como se puede apreciar, la 
relación entre ambos puede ser explicada, en un $98.74 \%$, por un modelo lineal; esto significa que existe un alto grado de relación entre ambos.

Además, su relación tiene una pendiente negativa, esto quiere decir, que a mayor cantidad de PBI, el índice de pobreza disminuye. Por consiguiente, para lograr una disminución del porcentaje de la pobreza se necesita consolidar el crecimiento sostenido del PBI; y, como se menciona en el capítulo I, este se encuentra creciendo debido a la participación y el crecimiento sostenido de los servicios. Entonces, se concluye que el principal motor para el aumento del PBI en el Perú y la disminución de la pobreza es el desarrollo de este sector.

\subsection{El sector servicios en el Perú}

\subsubsection{El sector servicios en el PBI}

Como está explicado en el capítulo anterior, el sector servicios es uno de los que más ha aportado al crecimiento del PBI durante el año pasado. A continuación, se muestra la siguiente gráfica:

Ilustración No 22. Porcentaje del PBI por sector económico desde el 2010 hasta el 2016

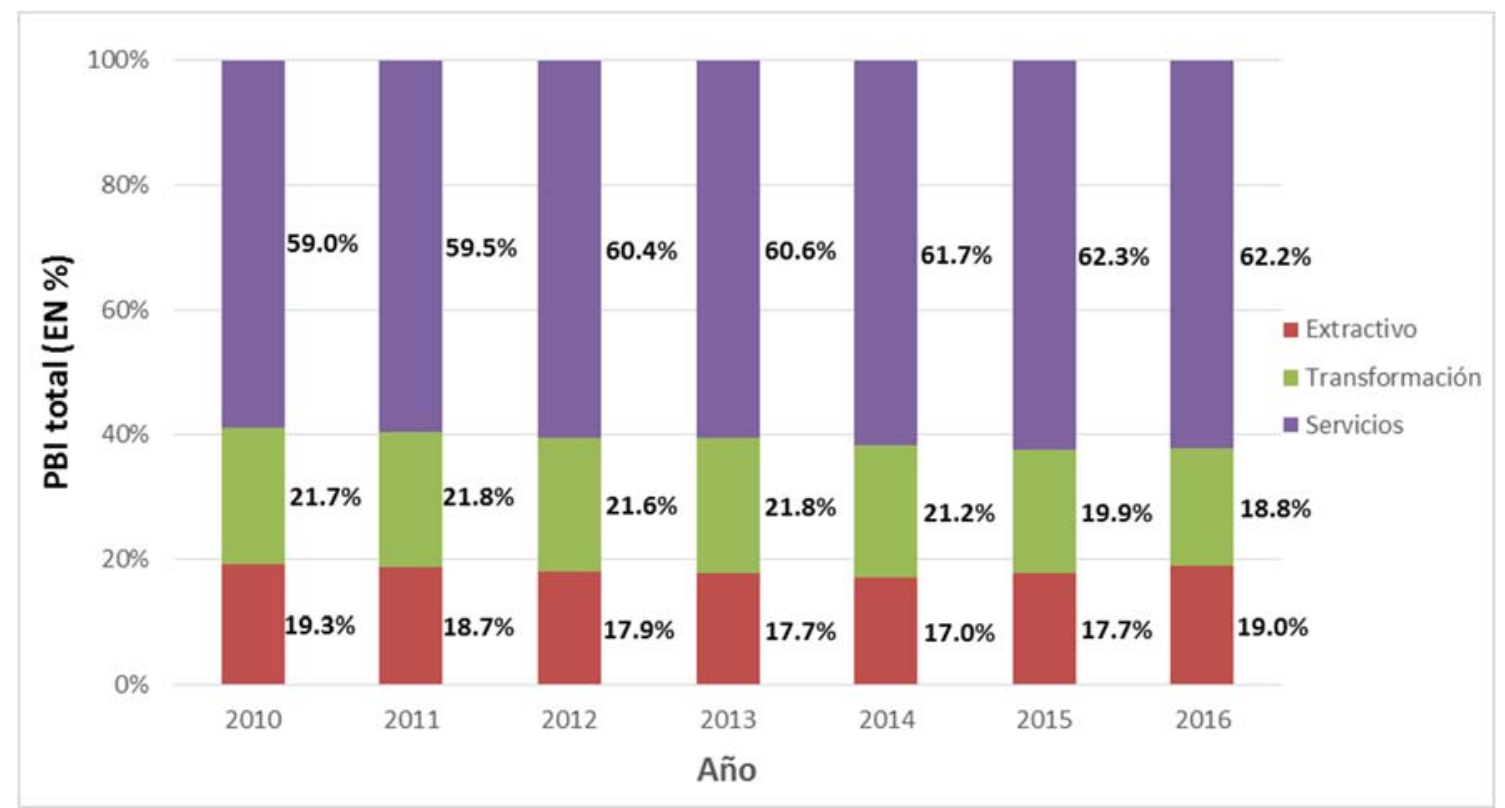




\section{Fuente: Adaptado del Instituto Nacional de Estadística e Informática}

Como se aprecia en la imagen, en los últimos 6 años, el sector servicios es el que más porcentaje de participación ha tenido dentro del PBI anual correspondiente. Solo en el año 2016 , este sector tuvo un $62.2 \%$ de participación dentro del PBI; siendo muy superior a los sectores de extracción y transformación.

\subsection{PEA dentro del sector servicios}

\subsubsection{PEA ocupada del sector servicios en el Perú}

Debido a su gran participación y aporte dentro del PBI peruano, resulta pertinente que se aprecie, también, la cantidad de población económicamente activa (PEA) ocupada ${ }^{202}$ que conforma este sector. A continuación, se presenta un gráfico proporcionado por el Ministerio de Producción:

Ilustración $\mathrm{N}^{\circ}$ 23. PEA ocupada por sector económico

\footnotetext{
${ }^{202}$ Según el INEI, para finales del año 2015, la PEA ocupada era de, aproximadamente, 15 millones 918 min 900 personas. Información sacada de los cuadros estadísticos del INEI. (https://www.inei.gob.pe/estadisticas/indice-tematico/employed-economically-active-population/)
} 


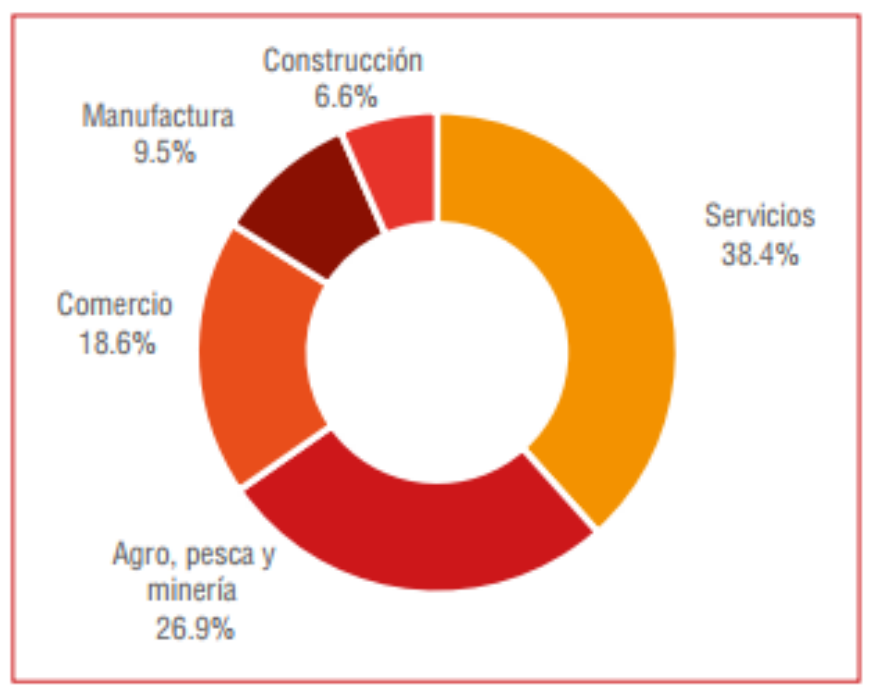

Fuente: Ministerio de la Producción 2016

Teniendo en cuenta que "Comercio" también es parte del sector servicio, en total, el 57\% de la PEA se encuentra laborando para empresas que se dedican a brindar cualquier tipo de servicio. Esto evidencia y refuerza, aún más, la importancia de este sector en el país.

\subsubsection{PEA ocupada del sector servicio en Lima Metropolitana}

Hacia finales del año 2016, había 7 millones 539 mil personas que se encontraban en edad para poder trabajar. De esta cantidad, el 68.9\% pertenecía a las PEA ${ }^{203}$.

De la PEA de Lima Metropolitana, alrededor de 4 millones 873 mil 500 personas cuenta con un trabajo (PEA ocupada), lo cual representa el 93.8\% del total ${ }^{204}$. 
Ilustración $\mathrm{N}^{\mathrm{o}}$ 24. PEA ocupada por actividades económicas en Lima Metropolitana

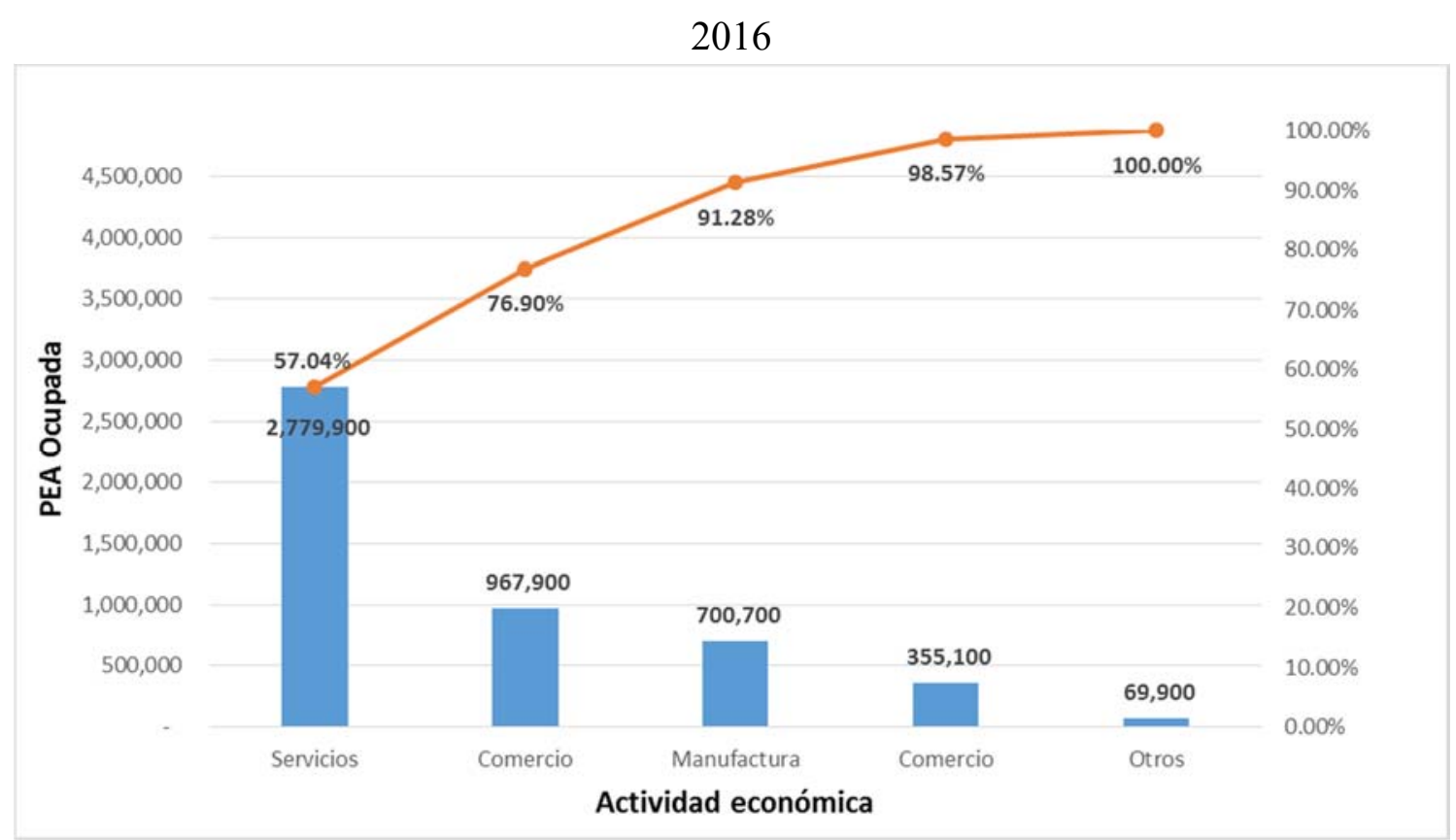

Fuente: INEI 2017

Como observa en la gráfica anterior, el $76.90 \%$ del total de la PEA ocupada de Lima Metropolitana, trabaja en alguna actividad que está relacionada con el sector servicios. Es por esta razón, que este sector es el principal motor de trabajo en la ciudad capital; siendo muy superior a los otros dos sectores.

\subsection{El subsector restaurantes en el Perú}

Como se explica en el capítulo anterior, el subsector restaurantes es el más estable dentro de su sector (alojamiento y restaurantes). Si bien es cierto que durante el 2016 no tuvo un crecimiento tan grande en comparación con el subsector alojamiento, el subsector restaurantes mantiene un porcentaje de crecimiento casi constante, lo que puede significar que ayuda a los empresarios de este sector a tomar nuevos proyectos sin que signifiquen un gran riesgo.

Por otro lado, este subsector domina, en cantidad, el sector de alojamiento y restaurantes.

Ilustración $\mathrm{N}^{\mathrm{o}} 25$. Ponderación del sector Alojamiento y restaurantes en el Perú 


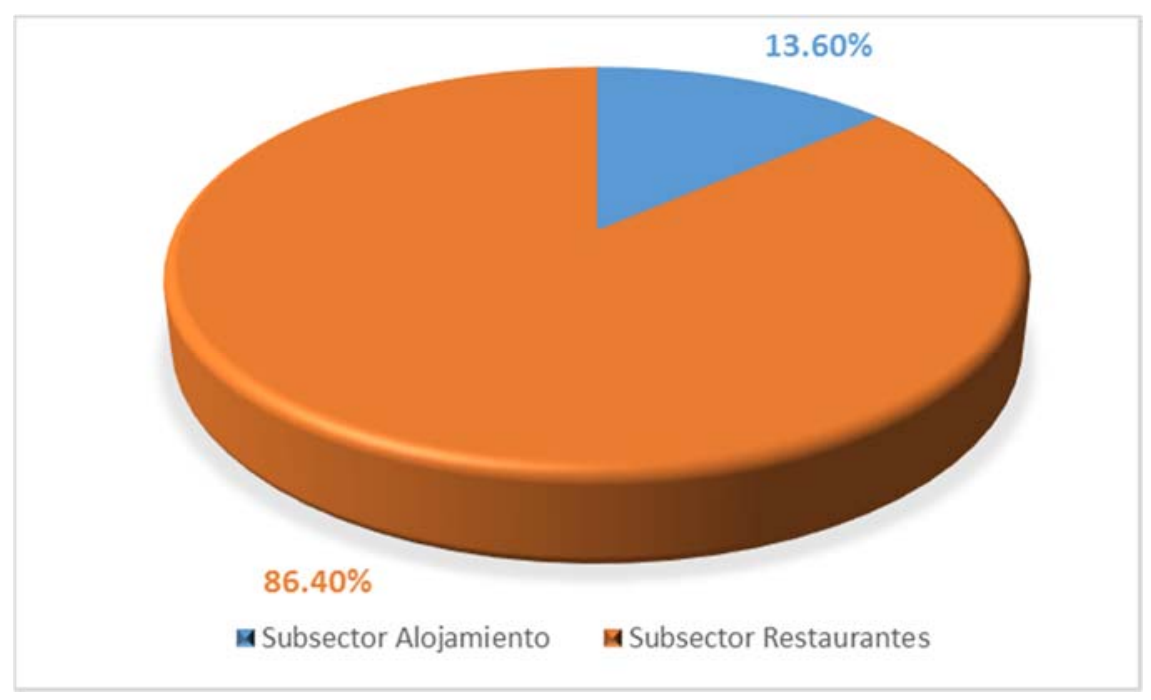

Fuente: Adaptado del INEI 2017

Como se aprecia en la imagen, el subsector restaurantes es el que domina el sector en lo que corresponde cantidad de empresas. Del total de empresas registradas, el $86.40 \%$ pertenece a este subsector; de enero a diciembre del 2016, el subsector incrementó sus actividades en un $2.4 \%{ }^{205}$.

Ilustración $\mathrm{N}^{\mathrm{0}} 26$. Evolución del crecimiento mensual del subsector restaurantes en el 2016

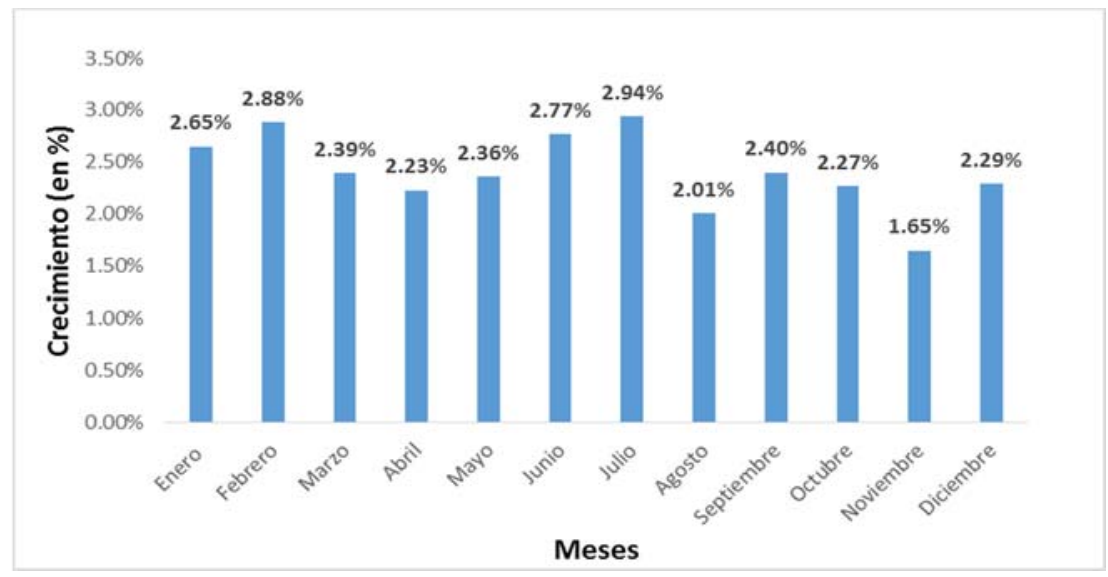

Fuente: Adaptado del INEI 2017

Como se observa en la gráfica anterior, el crecimiento durante el año 2016 ha sido casi constante. No se ha presentado algún pico significativo. Esto demuestra el crecimiento sostenido de este subsector.

Este crecimiento es producto de grandes iniciativas, tanto empresariales como gubernamentales, que han permitido el fomento de la actividad económica que

${ }^{205}$ Cfr. INEI 2017: 27 
desempeñan. Diversas actividades gastronómicas como la Fería de Gastronomía Mistura, el Día del Ceviche, el Día del Pollo a la Brasa, así como el mejor desempeño de restaurantes de comida rápida, pollerías y chifas, han permitido que el subsector restaurantes pueda crecer en el $2016^{206}$.

\subsection{Las MYPE en el Perú}

\subsubsection{MYPE en el PBI peruano}

Las MYPE, como se vio en el capítulo anterior, constituyen una de las principales fuerzas empresariales al conformar más del 99\% del total de empresas peruanas. Sin embargo, el panorama con respecto a su contribución al PBI peruano es un tanto desalentador.

En el año 2017, los aportes de estas empresas al PBI nacional han disminuido. Jessica Luna, gerente general de Comex Perú, en una entrevista para el Diario Gestión, comentó que los aportes de las MYPE ha descendido de $21 \%$ a $20.6 \%{ }^{207}$.

En el 2005, las MYPE llegaron a aportar cerca del 49\% del PBI peruano ${ }^{208}$, sin embargo, la informalidad fue un factor que siempre persiguió a este sector ${ }^{209}$, siendo, posiblemente, una de las razones por el cual, con los años, su aporte al PBI disminuyera.

Según Eduardo Lastra, para aumentar el nivel de participación del PBI de las MYPE no se necesitan leyes rígidas, se necesitan leyes que permitan el fomento y el crecimiento de estas empresas para que realmente puedan ser catalogadas como las empresas que guiaran el crecimiento sostenido del PBI y del Perú; así como procesos que permitan que su negocio marche adecuadamente ${ }^{210}$.

\subsection{MYPE en Lima Metropolitana}

Como se evidenció en el capítulo anterior, las MYPE son muy abundantes en el Departamento de Lima. Esto tiene sentido debido a que es el departamento donde habita una mayor cantidad de ciudadanos. Sin embargo, sin contar a la Provincia Constitucional del Callao, es Lima Metropolitana quien alberga una mayor cantidad de este tipo de empresas.

En años recientes, alrededor del 47.1\% de las empresas formales del país se encuentran operando en Lima Metropolitana y, a nivel de estratos empresariales, más del 98\% de

\footnotetext{
206 Cfr. INEI 2017: 27

${ }^{207}$ Cfr. Diario Gestión 2017.

${ }^{208}$ Cfr. Arbulú 2006: 32

${ }^{209}$ Cfr. Arbulú 2006: 33

${ }^{210}$ Entrevista personal con Eduardo Lastra, experto en tema de MYPE.
} 
estas empresas pertenecen al grupo empresarial conformado por las micro y pequeñas empresas $^{211}$. Por esta razón, Lima Metropolitana es la principal ciudad que lidera el motor económico del país; y las MYPE dominan este lugar.

\subsubsection{PEA Ocupada en las MYPE de Lima Metropolitana}

Para Sánchez Barraza, la principal contribución de las MYPE siempre ha sido la generación de puestos de trabajo a pesar de que muchas veces las condiciones laborales de estas empresas sean las más adecuadas ${ }^{212}$.

Como se explica anteriormente, hacia finales del años 2016, había 7 millones 539 mil personas que se encontraban en edad para poder trabajar. De esta cantidad, el $68.9 \%$ pertenecía a las $\mathrm{PEA}^{213}$.

De la PEA de Lima Metropolitana, alrededor de 4 millones 873 mil 500 personas cuenta con un trabajo (PEA ocupada), lo cual representa el $93.8 \%$ del total ${ }^{214}$. Del total de la PEA de Lima Metropolitana, 2 millones 911 mil 700 personas trabajan en microempresas y 492 mil 700 personas trabajan en pequeñas empresas ${ }^{215}$, representando más del $69 \%$ del total.

Esto confirma la gran importancia laboral que tienen las MYPE en Lima Metropolitana.

\subsubsection{El sector servicios y las MYPE de Lima Metropolitana}

Ilustración $\mathrm{N}^{\mathrm{o}} 27$. Cantidad de MIPYMES formales por actividad empresarial en el Perú 2015

211 Cfr. INEI 2014: 97

${ }^{212}$ Cfr. Sánchez Barraza 2006: 128

${ }^{213}$ Cfr. INEI 2017: 1

${ }^{214}$ Cfr. INEI 2017: 2

${ }^{215}$ Cfr. INEI 2017: 7 


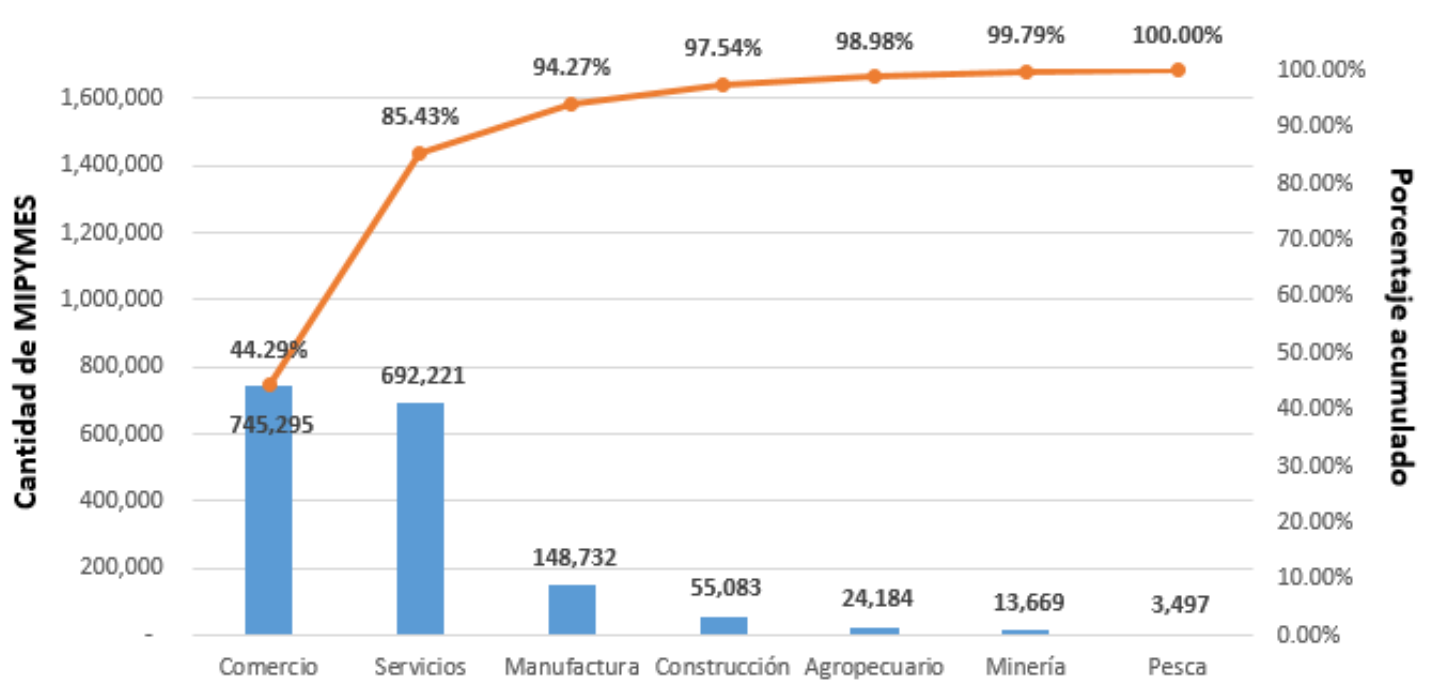

Actividades económicas

Fuente: Adaptado del Ministerio de la Producción 2016

Como se evidencia en el cuadro anterior, el 85.43\% del total de MIPYMES (Micro, pequeña y mediana empresa) del Perú se desempeña dentro del sector servicios. Si bien es cierto que el cuadro toma en cuenta la cantidad medianas empresas que hay en el Perú, su cantidad e irrelevante en comparación de las MYPE, por lo que su inclusión no cambia el panorama de que estas se desempeñan más en actividades del sector servicios.

Aproximadamente el $88.3 \%$ del total de microempresas de Lima Metropolitana trabaja brindando algún tipo de servicio; de la misma forma, cerca del 78\% de las pequeñas empresas trabajan en este sector ${ }^{216}$. De esto, se puede concluir que las MYPE se desempeñan mejor en este sector debido a su dinamismo y al gran mercado que ofrecen.

\subsection{MYPE del subsector restaurantes en Lima Metropolitana}

A lo largo del presente capítulo, se ha concluido los siguientes puntos: la importancia de las MYPE en la economía y empleo, la vitalidad del sector servicios como principal fuente de desarrollo y las grandes oportunidades de desarrollo y crecimiento del subsector restaurantes. Dada la importancia de estos 3 puntos, es necesario estudiar cómo se relacionan entre si y, de darse dicha relación, conocer la situación actual en la que se encuentran.

Por esta razón, la presente tesis abarcará conocer, más a detalle, a las MYPE del subsector restaurantes que se encuentran en Lima Metropolitana.

${ }^{216}$ Cfr. INEI 2016: 125 


\subsection{Encuesta a MYPE del subsector restaurantes en Lima Metropolitana}

\subsubsection{Objetivo de la Encuesta}

1. Objetivo General

- Analizar la situación actual de las MYPE que pertenecen al subsector restaurantes.

2. Objetivos Particulares

- Conocer la realidad de los distintos procesos que manejan.

- Encontrar los procesos particulares que son críticos para estas empresas.

- Analizar los problemas principales que aquejan a estas empresas.

\subsubsection{Descripción de la población}

La población considerada para el presente estudio será todas las MYPE del subsector restaurantes que se encuentren en Lima Metropolitana y que estén registradas en las bases del Ministerio de Trabajo. La condición de que sean empresas que figuren en la lista oficial del Ministerio de Trabajo se da porque, para este estudio, se busca trabajar con empresas formales.

Según esta institución, en Lima Metropolitana existen 670 empresas que cumplen con estas características ${ }^{217}$.

\subsubsection{Determinación y tipo de muestra}

Debido a que el fin de esta investigación no es realizar un censo a todas las MYPE del subsector restaurantes en Lima Metropolitana, es necesario tomar una muestra que sea representativa de la población para poder realizar el estudio correspondiente.

Para calcular la muestra representativa, se utiliza la siguiente fórmula estadística:

$$
\mathrm{n}=\frac{\mathrm{N} \times Z_{\frac{\alpha}{2}}^{2} \times \mathrm{p} \times(1-\mathrm{p})}{(\mathrm{N}-1) \times e^{2}+\mathrm{p} \times(1-\mathrm{p}) \times Z^{2}}
$$

Donde:

${ }^{217}$ Cfr. MINTRA 2015. El documento presenta una lista de todos las MYPE del subsector restaurantes en el área de Lima Metropolitana que son formales. 
- $\mathrm{n}$ : Tamaño de la muestra

- $\quad \mathrm{N}$ : Tamaño de la población

- p: Probabilidad a favor

- $\mathrm{q}$ : Probabilidad en contra

- Z: Inversa de la distribución Normal

- e: Error Muestral

De los cuales:

- "p" toma el valor de 0.5 .

- "q" toma el valor de 0.5 .

- "N" toma el valor de 670 .

- El nivel de confianza que se utilizará es del 92\%.

- $\quad$ El error muestral es de $8 \%$.

Con la ayuda de la tabla de la distribución Normal, se calcula el $Z(\propto / 2)$ el cual es $1.41^{218}$. Con estos datos, se completa la siguiente fórmula:

$$
\begin{gathered}
n=\frac{670 * 0.5 * 0.5 * 1.41^{2}}{(670-1) * 0.08^{2}+0.5 * 0.5 * 1.41^{2}} \\
n \approx 69 \text { restaurantes }
\end{gathered}
$$

El tipo de muestreo que se utilizará para la investigación será el muestreo aleatorio estratificado debido a que es el que mejor se adapta a los propósitos de la investigación.

\subsubsection{Ficha técnica}

En base a los 2 puntos anteriores, se tiene la siguiente ficha técnica que sustenta el proceso de encuesta que se realizó a diversas MYPE del subsector restaurantes de Lima Metropolitana.

\footnotetext{
${ }^{218}$ Confrontar con la bibliografía correspondiente.
} 
Ilustración $\mathrm{N}^{\mathrm{o}}$ 28. Ficha Técnica de la encuesta para MYPE del subsector restaurantes en Lima Metropolitana

\begin{tabular}{|l|c|}
\hline \multicolumn{2}{|c|}{ Ficha Técnica - Encuesta } \\
\hline Zona Geográfica & Lima Metropolitana \\
\hline Tipo de empresas & Micro y Pequeñas Empresas \\
\hline Sector & Servicios \\
\hline Subsector & Restaurantes \\
\hline Población & 670 \\
\hline Muestra & 69 \\
\hline Tipo de muestreo & Aleatorio Estratificado \\
\hline Nivel de Confianza & $92 \%$ \\
\hline Error & $8 \%$ \\
\hline
\end{tabular}

Fuente: Elaboración Propia

\subsection{Análisis de los resultados de la encuesta a las MYPES en el subsector restaurantes en Lima Metropolitana}

Luego de realizar las encuestas a diversas MYPE del subsector restaurantes de Lima Metropolitana, se obtuvieron diversos resultados de los cuales resaltan los siguientes:

\subsubsection{Diagnóstico general}

\subsubsection{MYPE del subsector restaurantes respecto al número de establecimientos} que posee

Ilustración $\mathrm{N}^{\mathrm{o}}$ 29. Porcentaje de MYPE del subsector restaurantes en Lima Metropolitana con respecto al número de establecimiento que posee

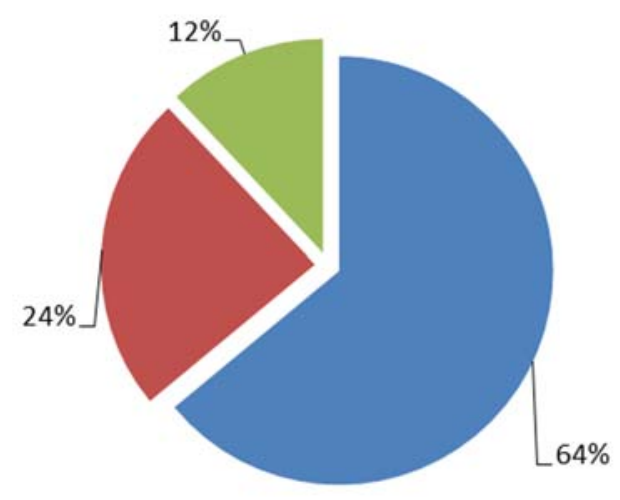

$$
\begin{aligned}
& \text { = Un establecimiento } \\
& \text { — Dos establecimientos } \\
& \text { — Tres o cuatro } \\
& \text { establecimientos }
\end{aligned}
$$

Fuente: Elaboración propia 
Como se observa en la gráfica anterior, el 64\% de las MYPE del subsector restaurantes en Lima Metropolitana cuenta con solo un establecimiento; el 24\%, con dos establecimientos y el $12 \%$, con tres o cuatro establecimientos.

Dentro del total de empresas que solo cuentan con un local, el $60 \%$ tiene planes de expandirse pero no cuentan con el capital suficiente para poder hacerlo. Resulta preocupante este punto ya que demuestra que muchas de estas MYPE tienen problemas de liquidez de dinero para poder tomar decisiones a mediano o largo plazo.

Por otro lado, del total de MYPE que tiene más de 2 locales, al 65\% le costó mucho esfuerzo poder realizar una expansión.

\subsubsection{Plan de negocio}

Como parte de la encuesta, se preguntó a las empresas si, antes de comenzar sus operaciones comerciales, contaron con un plan de negocio que los guie durante los primeros meses. A continuación, se muestra los resultados:

Ilustración $\mathrm{N}^{\mathrm{o}} 30$. Porcentaje de MYPE del subsector restaurantes en Lima Metropolitana que contaron con un Plan de Negocio

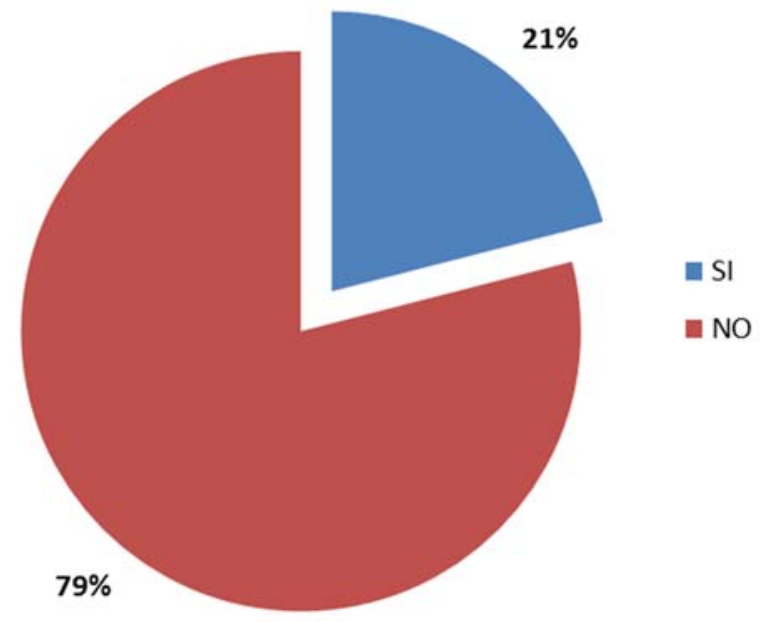

\section{Fuente: Elaboración propia}

Solo el 21\% de las MYPE tuvo un plan de negocio antes de comenzar las operaciones de su negocio. Esto refleja que muchas MYPE dentro de este subsector, sean o no exitosas, surgen como experimentos aleatorios por parte de los dueños con el fin de tener un negocio propio y poder generar más dinero para mejorar sus condiciones económicas. Dentro del 79\% de MYPE que no tuvieron un plan de negocio original, el 38\% tuvo éxito regular al inicio de sus operaciones y pudieron recuperar el capital invertido. Mientras el 
$62 \%$ restante tuvo que esperar más tiempo de lo que planificaron para poder recuperar su inversión.

\subsubsection{Innovación de su servicio}

Los años han demostrado que una empresa que no innova su servicio o producto, comúnmente está destinada al colapso. En el subsector restaurantes, la innovación de platillos o del servicio juega un papel importante.

Ilustración $\mathrm{N}^{\mathrm{o}}$ 31. Porcentaje de MYPE del subsector restaurantes en Lima Metropolitana que han innovado su servicio

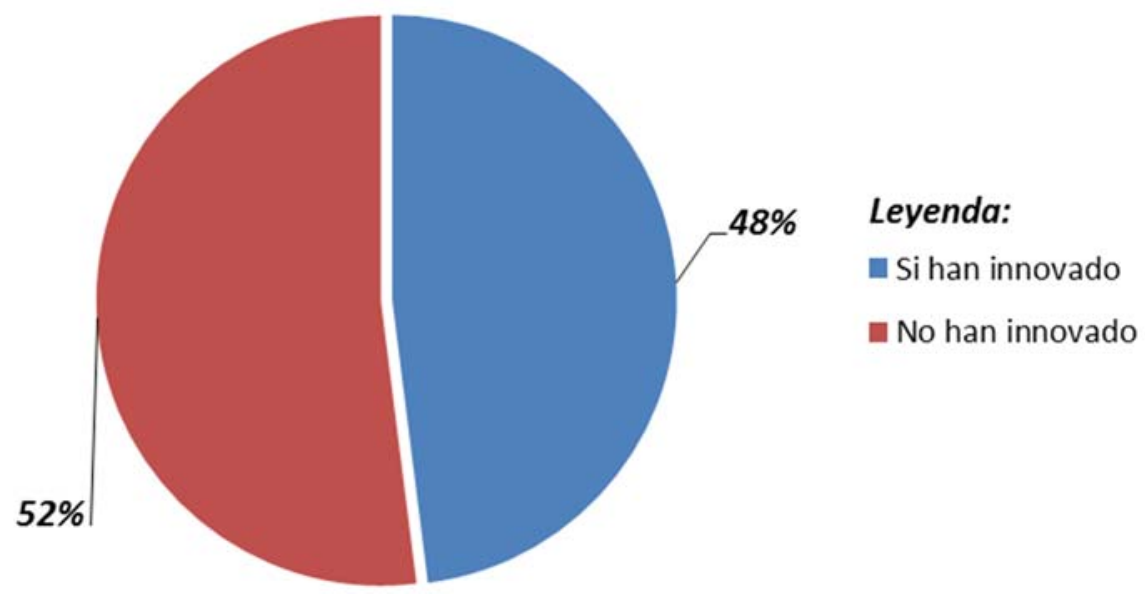

\section{Fuente: Elaboración propia}

El porcentaje de diferencia entre MYPE que han o no han innovado su servicio es muy corto. Dentro del total de empresas que aseguran haber innovado en su servicio, el $76 \%$ asegura que lo hizo con el fin de poder generar más dinero al atraer a nuevos comensales; el 10\$, lo hizo para retener a sus comensales y no se vayan a empresas de la competencia; mientras que el 14\% restante, lo hizo por ambos motivos. Se puede asegurar que su nicho de mercado es muy competitivo, por lo cual siempre están en constante innovación y mejora de sus procesos. Si entrara alguna otra empresa a su nicho, la capacidad de respuesta sería rápida.

Del total de empresas que no han innovado su servicio, el $70 \%$ asegura que no innovara porque sienten que ganan muy bien con el servicio que dan. El 30\% restante, no tiene interés en innovarlo ya que lo consideran una pérdida de tiempo y dinero. Estos resultados son importantes ya que muchos empresarios se encuentran totalmente satisfechos con sus 
nichos de mercados; si bien esto podría ser bueno, demuestra que muchas MYPE no tendrían capacidad de respuesta si es que alguna otra empresa ingresa a su nicho.

\subsubsection{Expansiones futuras}

Como toda empresa, las MYPE no son ajenas a querer ampliar sus operaciones. A continuación, se muestra la siguiente gráfica:

Ilustración No 32. Porcentaje de MYPE del subsector restaurantes en Lima Metropolitana que piensan expandirse

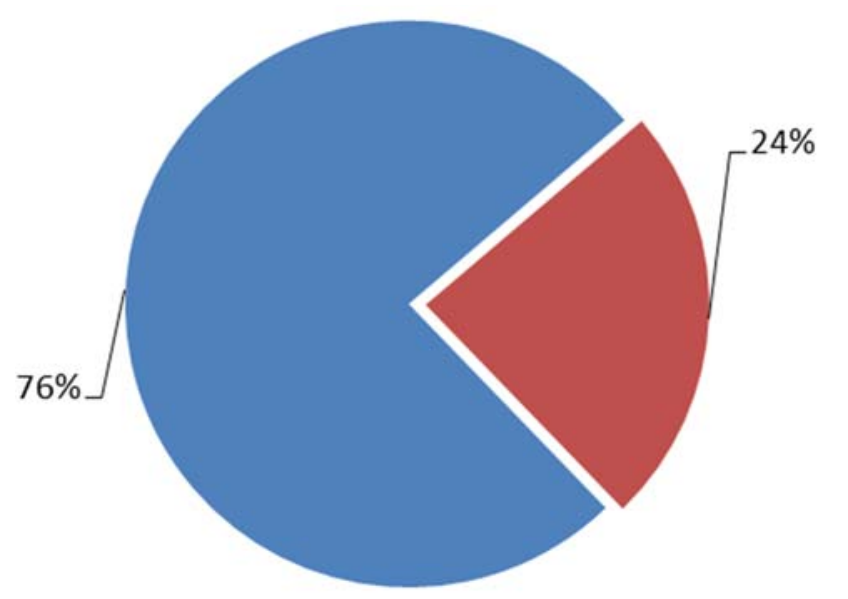

\section{Leyenda:}

Pensamiento expansionista

Sin pensamiento expansionista

\section{Fuente: Elaboración Propia}

El 76\% de MYPE encuestadas piensan expandir sus negocios, mientras que el 24\% no ha pensado en expandirse. Si bien es cierto que muchas MYPE dentro de este subsector solo cuentan con un local, en su conjunto, muchas de ellas buscan expandirse para poder generar más ingresos a la empresa. Aquí radica una de las principales virtudes de las MYPE: su emprendimiento. Sin embargo, el diagrama también muestra un alto porcentaje de empresas del subsector restaurantes que no tienen un pensamiento expansionista. Esto puede ser algo crítico ya que, si es que sus negocios no marchan adecuadamente, pueden desaparecer. 


\subsubsection{Principales problemas}

Ilustración $\mathrm{N}^{\mathrm{o}} 33$. Porcentaje de representación del total de problemas que presentan las MYPE del subsector restaurantes de Lima Metropolitana

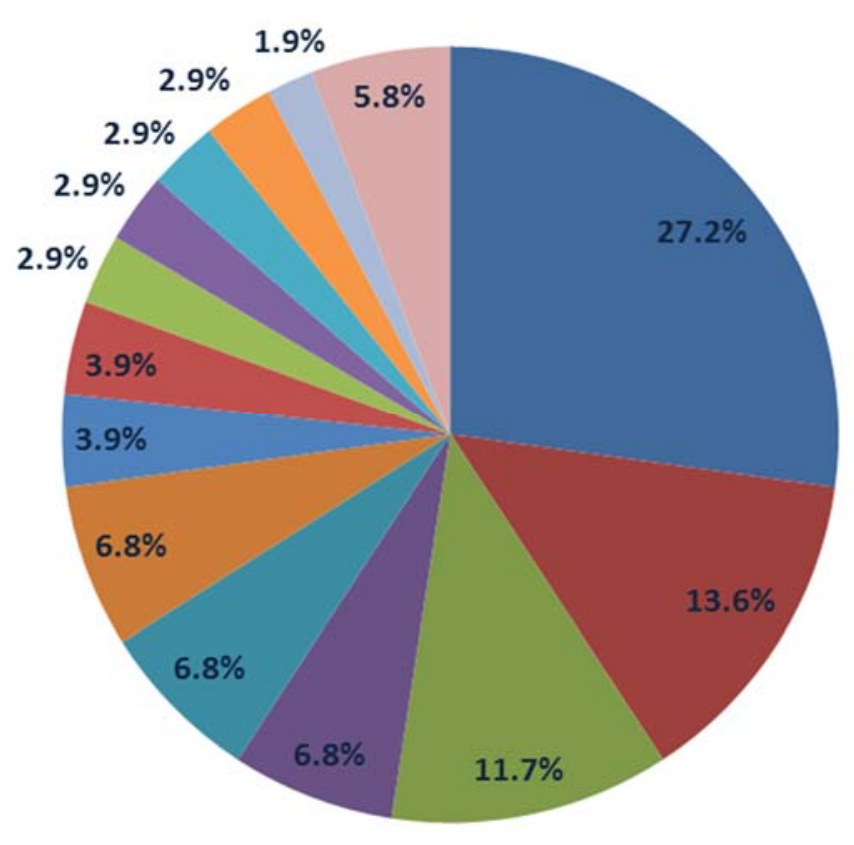

Leyenda:

n Compras

n Capacitaciones

Calidad

- Costos

- Estandarización de procesos

Innovación

- Inventarios

- Financiamiento

Mantenimiento

- Seguridad y salud ocupacional

motación de personal

Ventas

- Consumo excesivo de recursos

Otros

\section{Fuente: Elaboración Propia}

Del total de empresas encuestadas, se han registrado un total de 103 problemas relevantes para las MYPE del subsector restaurantes. De este total de problemas, el $27.2 \%$ corresponde a su proceso de compras; $13.6 \%$, a capacitación del personal; 11.7\%, a mantenimiento. Resulta interesante analizar que el proceso de costos solo representan el $6.8 \%$ del total de problemas identificados. A simple vista, podría darse a entender que estas costean adecuadamente, tienen precios adecuados y tienen mucho conocimiento en esta materia.

\subsubsection{Diagnóstico específico}

Basado en el punto anterior, se examinó cuál es la situación del manejo de los costos en las MYPE del subsector restaurantes de Lima Metropolitana. A continuación, se presenta los resultados de la misma: 


\subsubsection{Responsable de los costos}

Ilustración $\mathrm{N}^{\circ}$ 34. Encargado de manejar los costos dentro de la MYPE del subsector restaurante en Lima Metropolitana

\section{Fuente:}

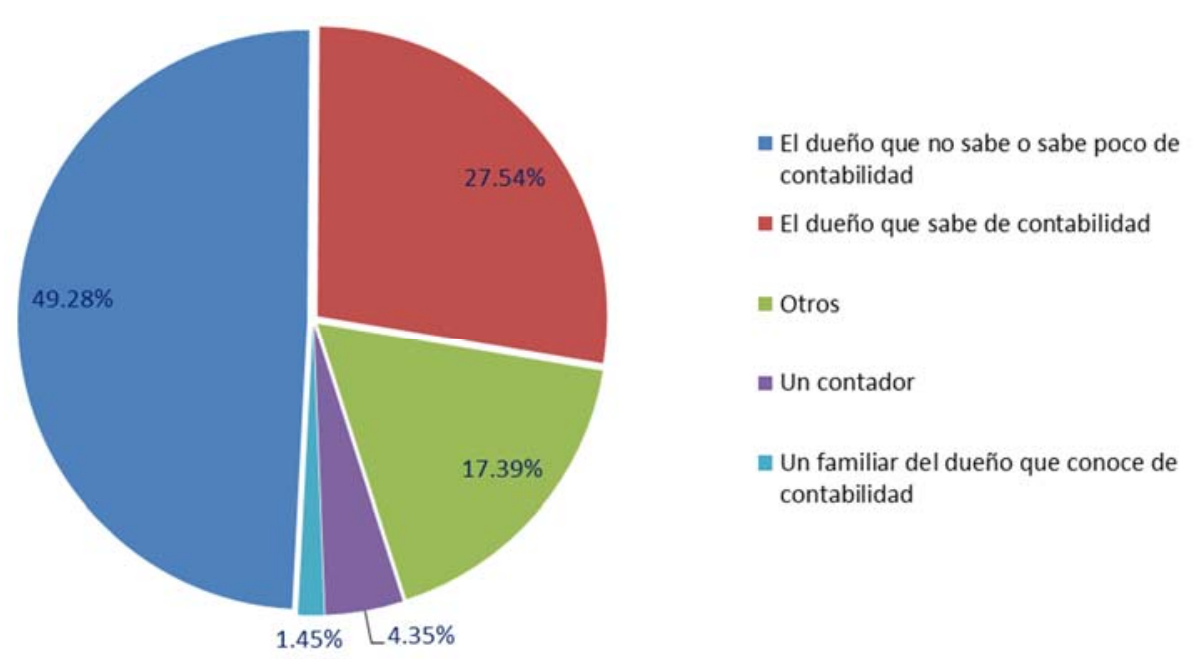

\section{Elaboración propia}

En su conjunto, más del 76\% de las MYPE encuestadas del subsector restaurantes delega el manejo de sus costos a su dueño. Sin embargo, el 49.28\% de empresas encuestadas tiene un dueño que maneja los costos de empresa que no sabe manejar el proceso o tiene poco sustento académico sobre cómo llevar a cabo un correcto manejo de los costos de su empresa. Esto denota que si bien las MYPE son producto del emprendimiento de muchas personas, no siempre estas se encuentran totalmente preparadas para hacer frente al manejo de los costos de su empresa.

Por otro lado, casi el 18\% de las MYPE del subsector restaurantes delegan su manejo de costos a un contador; si bien esto es algo positivo, también refleja que las MYPE no están gestionando sus propios costos ya que delegan esta responsabilidad a alguien ajena a la empresa. 


\subsubsection{Jerarquía de los costos dentro de las MYPE}

Ilustración $\mathrm{N}^{\mathrm{o}}$ 35. Jerarquía de costos basado en las opiniones de las MYPE del subsector restaurantes en Lima Metropolitana

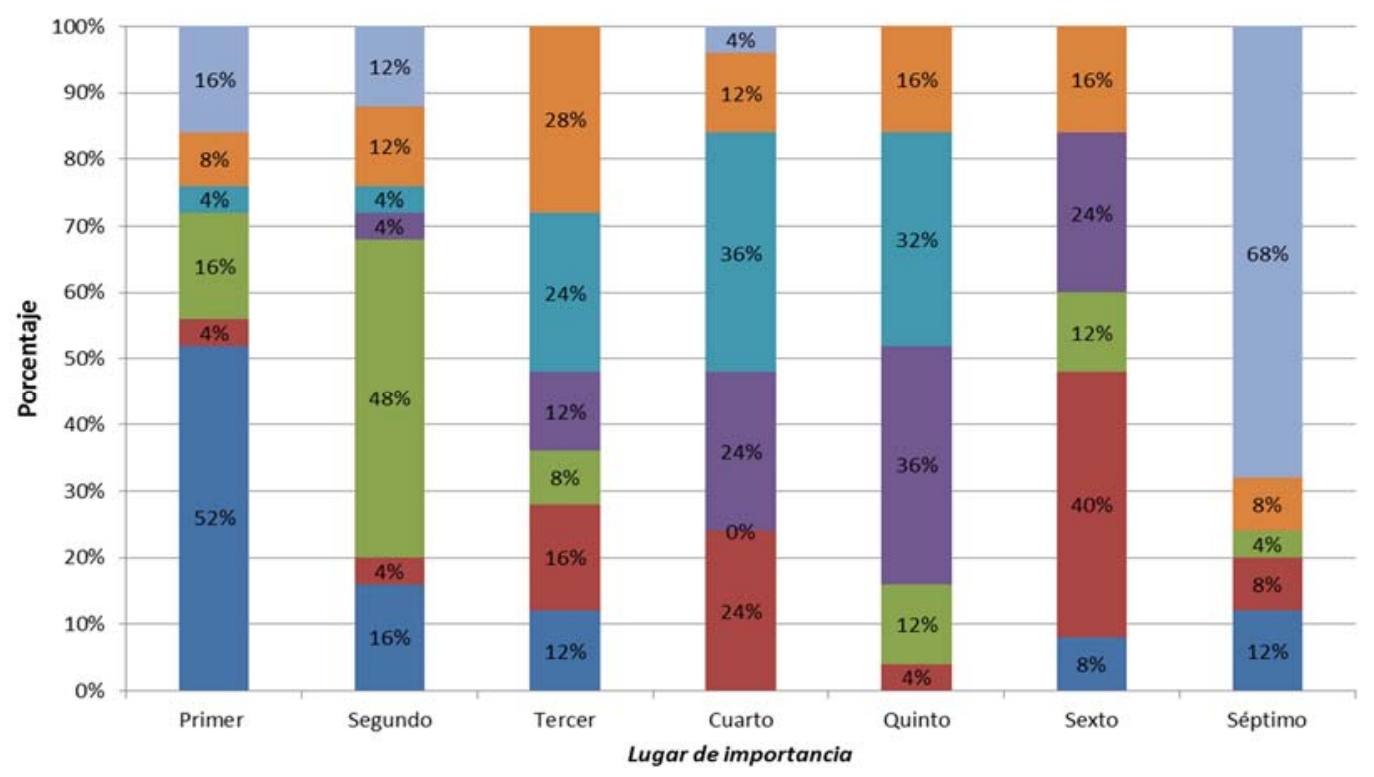

Indice:

= Otros

a. Admistrativos

= Utensilios

- Mantenimiento

= Salarios

= Limpieza

= Materias primas

Fuente: Elaboración Propia

El 52\% de las MYPE encuestadas opinan que la adquisición de materias primas es su principal desembolso de dinero. El 48\% opina que los salarios de sus trabajadores es el segundo gran desembolso que hace la empresa. Los gastos administrativos conforman, con un $28 \%$, el tercer mayor desembolso de dinero que realiza la empresa.

La figura anterior evidencia uno de los mayores problemas de su sector, solo consideran importante los costos que genere la materia prima, los salarios y los gastos administrativos. Estos conceptos son parte del denominado costeo tradicional que, como se explica en el capítulo I, presenta muchas desventajas y ya no es óptimo su desempeño dentro de una empresa. 


\subsubsection{El costo unitario}

Ilustración No 36. Porcentaje de MYPE del subsector restaurantes en Lima Metropolitana que conocen el Costo Unitario de sus productos

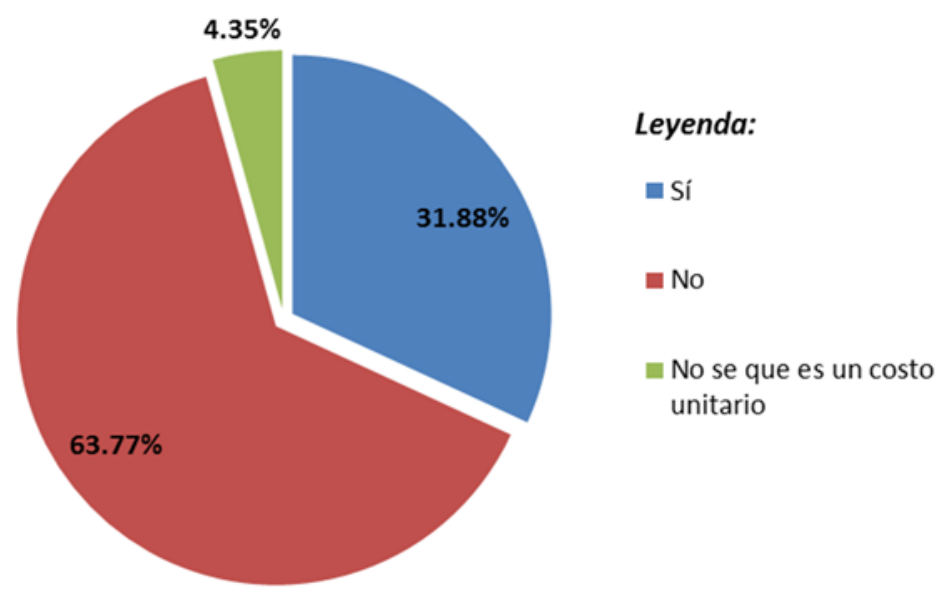

\section{Fuente: Elaboración Propia}

El $63.77 \%$ de MYPE no conocen el costo unitario de sus platillos, esto significa que muchas empresas no manejan este concepto. El 4.35\% de encuestados no conocía la definición del costo unitario ni tenía alguna técnica para hallarlos; este resultado, aunque pequeño, es muy importante ya que demuestra que algunas de esas MYPE puede llegar a desaparecer en algún momento si es que sus ingresos son menores a sus gastos.

Del total de MYPE que conocen su costo unitario, el 60\% lo obtuvo utilizando una metodología similar al costeo tradicional; mientras que el porcentaje restante lo hizo en base a su experiencia en el negocio. Esto demuestra que la gran mayoría no tiene un sistema que les permita calcular su costo unitario real.

\subsubsection{Situación del precio unitario de los productos}

En base al punto anterior, queda una disyuntiva la cual es cómo entonces las MYPE fijan su precio unitario si no conocen de forma plena el costo unitario de sus productos. En la gráfica presentada, a continuación, se responde a esta interrogante. 
Ilustración $\mathrm{N}^{\mathrm{0}} 37$. Situación del precio unitario de los productos de las MYPE del subsector restaurantes en Lima Metropolitana

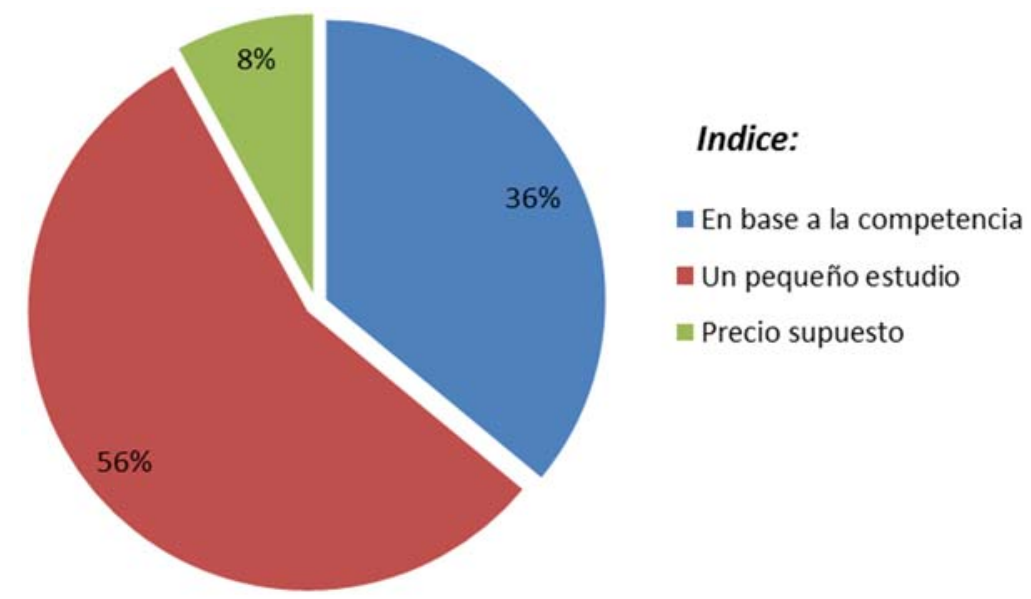

Fuente: Elaboración Propia

El 36\% de MYPE del subsector restaurantes fijaron su precio en base al precio de las empresas de la competencia. Esto resulta algo lógico debido a que en, en determinados casos, una empresa no se arriesga a aumentar su precio por temor a la pérdida de clientes. Por otro lado, el 56\% asegura que realizó un pequeño estudio previo en base a los costos variables para poder fijar un precio unitario. Sin embargo, a pesar de que su porcentaje es bajo, resulta alarmante que el 8\% de las MYPE coloque el precio unitario de sus productos "porque se les ocurrió", literalmente. En el caso del precio basado en la competencia y el último descrito, se evidencia que hay una carencia de conocimientos y de un sistema de costos que les permita fijar realmente cuánto les cuesta producir su producto.

\subsubsection{Opiniones acerca de un sistema de costo}

Durante la encuesta realizada, se les preguntó a los encuestados sobre su opinión acerca de un sistema de costos. Los resultados son los siguientes: 
Ilustración $\mathrm{N}^{\mathrm{o}}$ 38. Porcentaje de MYPE del subsector restaurantes en Lima Metropolitana que opinan acerca de un sistema de costos

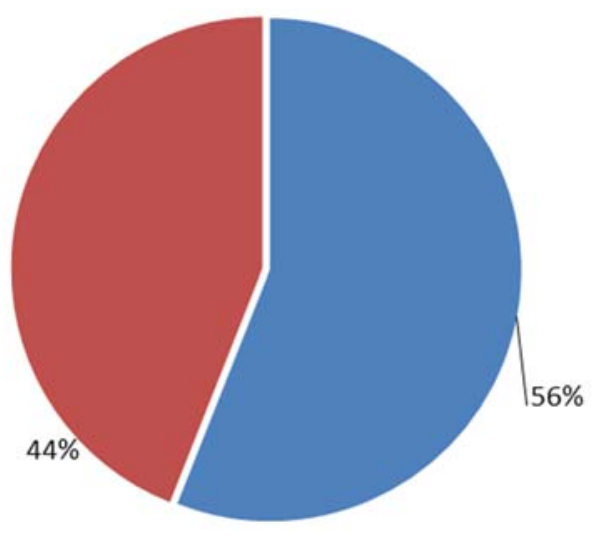

nYPE que quisieran mejorar su sistema de costos

MYPE que no quieren mejorar su sistema de costos

\section{Fuente: Elaboración Propia}

Las encuestas revelan que el 56\% de MYPE que se desenvuelven en el subsector restaurantes quisieran mejorar, de alguna manera, su actual sistema de costos o manejo de costos. De esto se puede inferir que las MYPE admiten que no están realizando un correcto manejo de sus costos $\mathrm{y}$, por ende, quisieran encontrar algún modelo o sistema que les permita conocer mejor sus costos.

Ilustración $\mathrm{N}^{\mathrm{o}} 39$. Porcentaje de opiniones de las MYPE del subsector restaurantes acerca de un modelo de costos

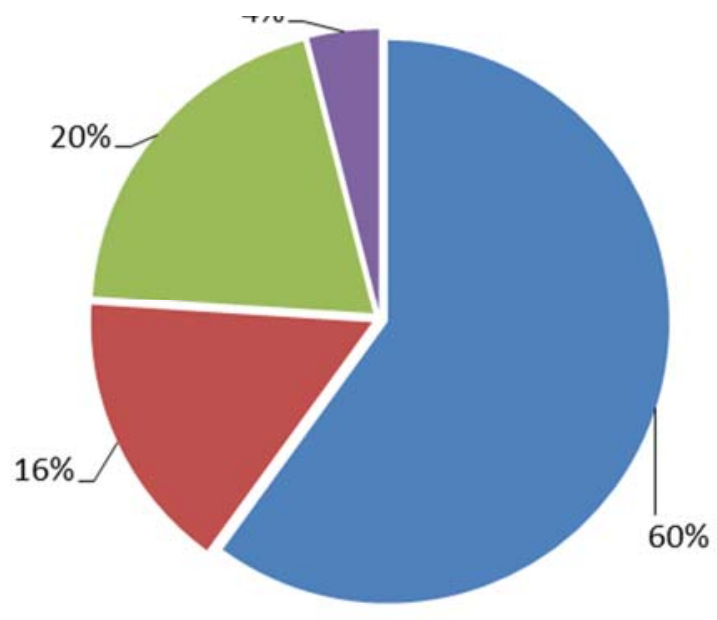

- Inversión necesaria

- Gasto innecesario

- Sin interés

- Otras opiniones

Fuente: Elaboración Propia

A pesar de que el 20\% de MYPE considera que sería un gasto innecesario la creación de un modelo de costos, el 60\% considera que la creación de un modelo de costos acorde a sus empresas es una inversión por la que estarían dispuestos a pagar. 


\subsection{Hipótesis}

Mediante la aplicación de un proceso de costos basado en la metodología ABC se logra que una MYPE del subsector restaurantes mejore el manejo, control y distribución de sus costos; así como una mejor fijación de los precios de sus productos ofrecidos y un aumento de su competitividad en su nicho de mercado. 


\section{CAPITULO III}

El presente capítulo engloba el análisis del capítulo previo y la teoría del capítulo I, y los une al proponer un modelo de costos basado en el costeo por actividades. En este capítulo se podrá encontrar el modelo de costos, así como el mapa de proceso de la asociación y el mapa de procesos específico, los indicadores y los formatos que el micro y pequeño empresario deben utilizar para manejar sus costos de la manera más real.

\subsection{Contextualización de las MYPE del subsector restaurantes en Lima Metropolitana antes del modelo de costos dentro de un modelo de gestión}

Como se evidencia en el capítulo 2 del presente documento, las MYPE tienen limitantes que impiden su crecimiento tanto comercial como físico. Estos limitantes son comunes 
en la mayoría de MYPE del subsector restaurante y es por esto que, no muchas, han podido desarrollarse en el mediano o largo plazo. Por otro lado, las MYPE carecen de modelos que les permita saber, de forma clara y concisa, que es lo que tienen que hacer para poder mejorar no solo el servicio de su negocio, sino también, su rentabilidad y su situación.

Por otro lado, se evidencia que las MYPE son una de las principales fuerzas de generación de trabajo dentro del país debido a que abarcan un gran porcentaje del total de empresas que existen en el Perú. Sin embargo, esta acumulación de mano de obra que depende de una MYPE para su existencia puede traer un efecto adverso al planeado; en otro palabras, si bien una MYPE del subsector restaurantes genera empleo, son pocas las probabilidades que esta empresa se puedan expandir en el corto plazo; lo que generaría que sus empleados tampoco pudieran desarrollarse o mejorar su actual nivel de vida. Es por esto que las MYPE del subsector restaurantes no solo necesitan desarrollarse como empresas en términos de utilidades, también necesitan desarrollarse para poder desarrollar o mejorar el nivel de vida de sus colaboradores.

Por otro lado, el 6.8\% del total de MYPE del subsector restaurantes considera que su proceso de costos es uno de sus principales problemas.

El 49.28\% del total de MYPE del subsector restaurantes permite que su proceso de costos sea controlado por el dueño del negocio, el cual no tiene las competencias necesarias ni conocimientos que requiere este proceso.

El $63.77 \%$ de MYPE no conocen su costo unitario y esto repercute en que el $36 \%$ fije su precio en base a los precios de las empresas de la competencia; y un 56\% fije su precio en base a un pequeño estudio basado solo en los costos directos o variables.

Debido a esta situación, el 60\% de empresas está convencido en que necesitan tener un modelo de costos ajustado a su realidad para poder conocer cuál es su verdadero costo, con el fin de poder fijar un adecuado margen de rentabilidad.

De acuerdo a todos estos antecedentes, las MYPE del subsector restaurantes necesitan un modelo de costos, sustentado en la gestión por procesos, que les permita administrar sus salidas de dinero, de una forma más real y precisa.

\subsection{Gestión por procesos aplicada a MYPE del subsector restaurantes}

Para sustentar la creación de un proceso, en este caso el de costos, debe existir, previamente, una metodología de gestión por procesos el cual le de sustento. 


\subsubsection{Misión y objetivos de la Gestión por Procesos}

1. Misión

Aportar el mejor servicio a los comensales mediante procesos claros y ordenados, los cuales permitan generar ingresos a la empresa

2. Objetivos

- Mejorar la calidad del servicio y producto.

- Generar mayores ingresos y disminuir los costos.

- Fomentar la mejora en todos los procesos.

\subsubsection{Propuesta basada en la Gestión por Procesos para una MYPE del subsector restaurantes}

\subsubsection{Procesos propuestos}

Una correcta definición de procesos sería de ayuda al empresario propietario de una MYPE del subsector restaurantes ya que le permitiría gestionar y administrar su empresa de una forma más ordenada y precisa.

De esta forma, los procesos propuestos son:

- Planificación de producción y servicio: Proceso encargado de realizar la programación diaria, semanal o mensual, de platillos que se van a ofrecer; así como la cantidad de personas que atendería en el local, dependiendo de la fecha o algún otro factor.

- Calidad e Inocuidad: Proceso encargado de emitir las reglas básicas sobre la producción y el servicio para lograr la satisfacción del cliente.

- Innovación de producción y servicio: Proceso diseñado para generar nuevas propuestas y experiencias de comidas y servicios. De esta forma, el cliente siempre se encontrará un atractivo en la empresa.

- Marketing: Proceso encargado de realizar propaganda a la empresa, así como promociones y demás actividades relacionadas. Logrando retener a los clientes y atrayendo a nuevos.

- Atención al cliente: Proceso en el cual interactúan el cliente con el personal de la empresa. Aquí se realiza el primer contacto y define la estadía del cliente en el local; así como la orden que va a tomar, junto con sus respectivas especificaciones. 
- Producción: Proceso el cual se encarga de realizar el pedido del cliente. Este proceso es uno de los que más valor genera al cliente.

- Entrega de producto y prestación del servicio: Proceso en el cual se hace entrega del producto solicitado por el cliente, con las respectivas especificaciones solicitadas. Además, aquí se realiza una atención continua al cliente.

- Cobranza: Proceso el cual se encarga de realizar el cobro por los productos vendidos. Además, se encarga de realizar el registro en caja.

- Recursos Humanos: Proceso encargado de realizar la selección del personal que trabaja en la empresa.

- Seguridad, higiene y mantenimiento: Proceso que vela por la integridad de los trabajadores y clientes, así como por la infraestructura del local.

- Costos: Proceso encargado de manejar, principalmente, las salidas de dinero de la empresa; así como controlarlas.

- Logística: Proceso encargado de suministrar las materias e insumos necesarios para la producción de platillos, así como su conservación.

- Finanzas: Proceso encargado de gestionar la situación económica de la empresa.

\subsubsection{Mapa de procesos}

En base a los procesos propuestos en el punto anterior, se presenta el Mapa de Procesos 
Ilustración No 40. Mapa de Procesos para una MYPE del subsector restaurantes

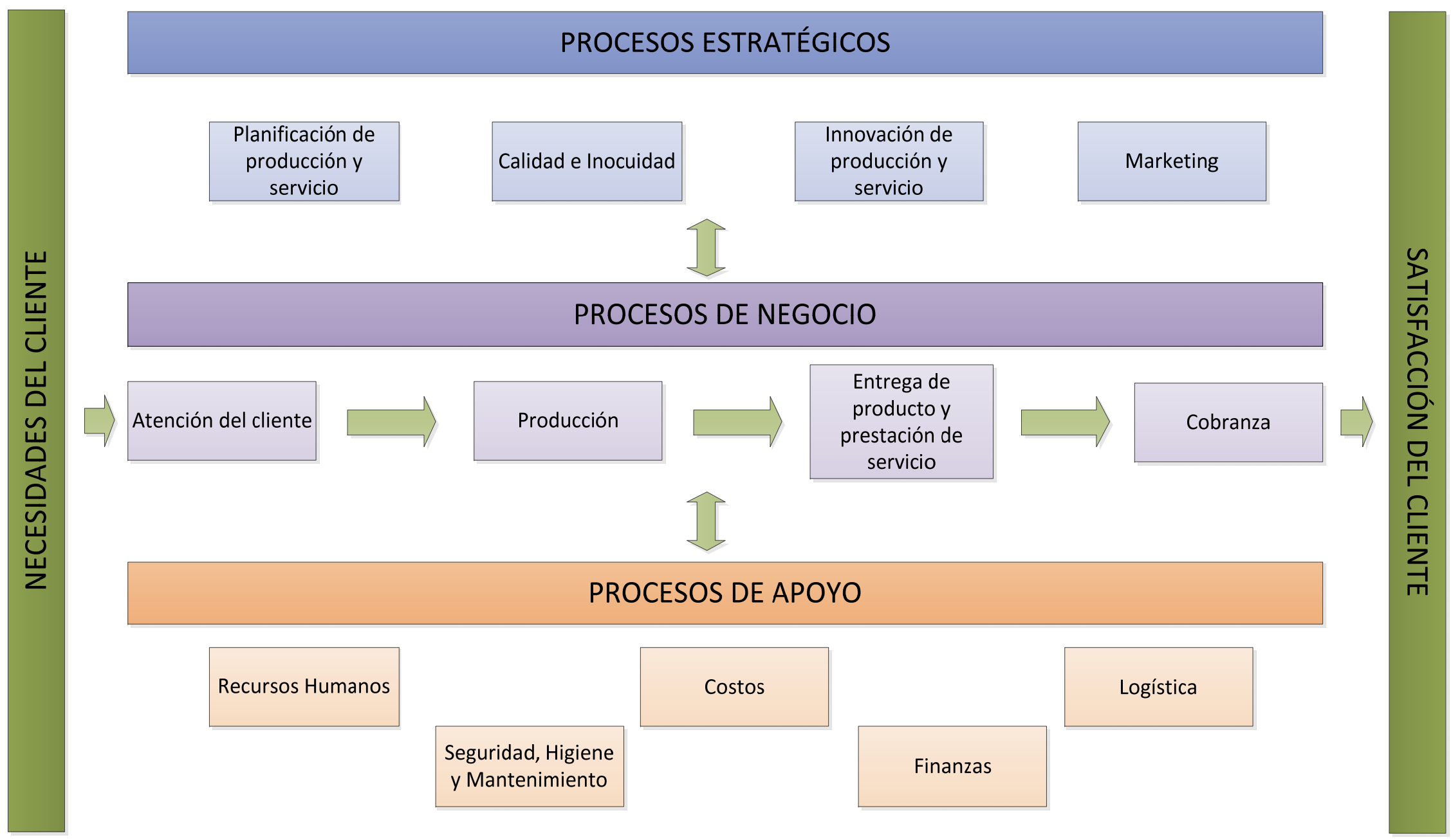

Fuente: Elaboración propia 
Dentro del Mapa de Procesos, todos los procesos propuestos en el punto anterior serán clasificados en: estratégicos, de negocio, de apoyo y de control.

Los procesos de Planificación de producción y servicio, Calidad e Inocuidad, Innovación de producción y servicio y Marketing conforman los procesos estratégicos. Del correcto manejo de estos procesos dependerá la capacidad de la empresa para poder atraer más clientes y ofrecer una buena experiencia en base a políticas claras en la producción y servicio.

Los procesos de Atención del cliente, Producción, Entrega de Producto y prestación de servicio y cobranzas conforman los procesos de negocio u operativos. Estos procesos interactuarán con el cliente de forma directa o indirecta. Además, estos procesos se encargarán de llevar acabo las directrices que provengan de los procesos estratégicos con el fin de maximizar los ingresos de la empresa. Estos procesos son secuenciales y comienzan con el proceso de Atención del cliente, luego con el proceso de Producción, después con el proceso de Entrega de Producto y Prestación y Servicio, y finaliza con el proceso de Cobranza.

Los procesos de Costos, Seguridad, Higiene y Mantenimiento, Finanzas, Logística, Finanzas y Recursos Humanos conformarán los procesos de apoyo. Estos procesos velaran por proveer los recursos necesarios a los demás procesos para que puedan ser ejecutados sin ningún problema. 
1. Planificación de producción y servicio

2. Calidad e Inocuidad

3. Innovación de producción y servicio
1 Producción : Lista de platillos a producir según cronograma

2 Recursos Humanos : Head Count de personal requerido

3 Logística

: Requerimientos de materias primas, utensilios e insumos
1 Atención al cliente

2 Producción

3 Entrega de Producto prestación del servicio

4 Recursos Humanos

5 Logística

6 Seguridad, Higiene Mantenimiento
: Políticas de atención al cliente

: Política de inocuidad en la producción de platillos

: Políticas de atención al cliente

: Políticas para la capacitación del personal

: Políticas de calidad para compras y almacenamiento

$y$ : Política para realizar el mantenimiento e higiene del local
1 Producción

2 Atención al cliente

3 Planificación producción y servicio
: Diseño de nuevos platillos de comida

: Metodologías nuevas de atención al cliente

de : Propuestas de nuevos platillos de comida y atención a clientes 
4. Marketing

1 Planificación

de : Lista de pedidos masivos especiales

producción y servicio

5. Atención al cliente

1 Producción

: Orden de pedido

6. Producción

1 Entrega de Producto $y$ : Entrega de pedido listo

prestación del servicio

\section{Entrega de Producto y}

1 Cobranza

: Cuenta total del pedido

prestación del servicio

8. Cobranza

9. Recursos Humanos
1 Finanzas

1 Atención al cliente

2 Producción

3 Seguridad, Higiene Mantenimiento
: Copia de las facturas y/o boletas de las ventas y efectivo

: Capacitación a los mozos

: Capacitación a cocineros

$y$ : Capacitación en temas de seguridad e higiene

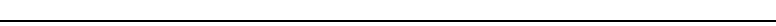


10. Costos

1 Planificación

producción y servicio de : Reporte de costos unitarios de los platillos de comida

: Programa de seguridad, higiene y mantenimiento del almacén

: Programa de seguridad, higiene y mantenimiento de la cocina

\section{Logística}

1 Producción

1 Planificación

producción y servicio

2 Planificación

producción y servicio

3 Recursos Humanos

4 Logística

5 Seguridad, Higiene Mantenimiento
: Entrega de materiales, materias primas e insumos

de : Estados de resultados de la empresa

de : Presupuesto de la empresa

: Pago de planillas y presupuesto para capacitaciones

: Presupuesto para compras de materia prima, utensilios e insumos

$y$ : Presupuesto para el mantenimiento e higiene del local 


\subsubsection{Diagrama de flujo general}

Ilustración $\mathrm{N}^{0} 42$. Diagrama de flujo general

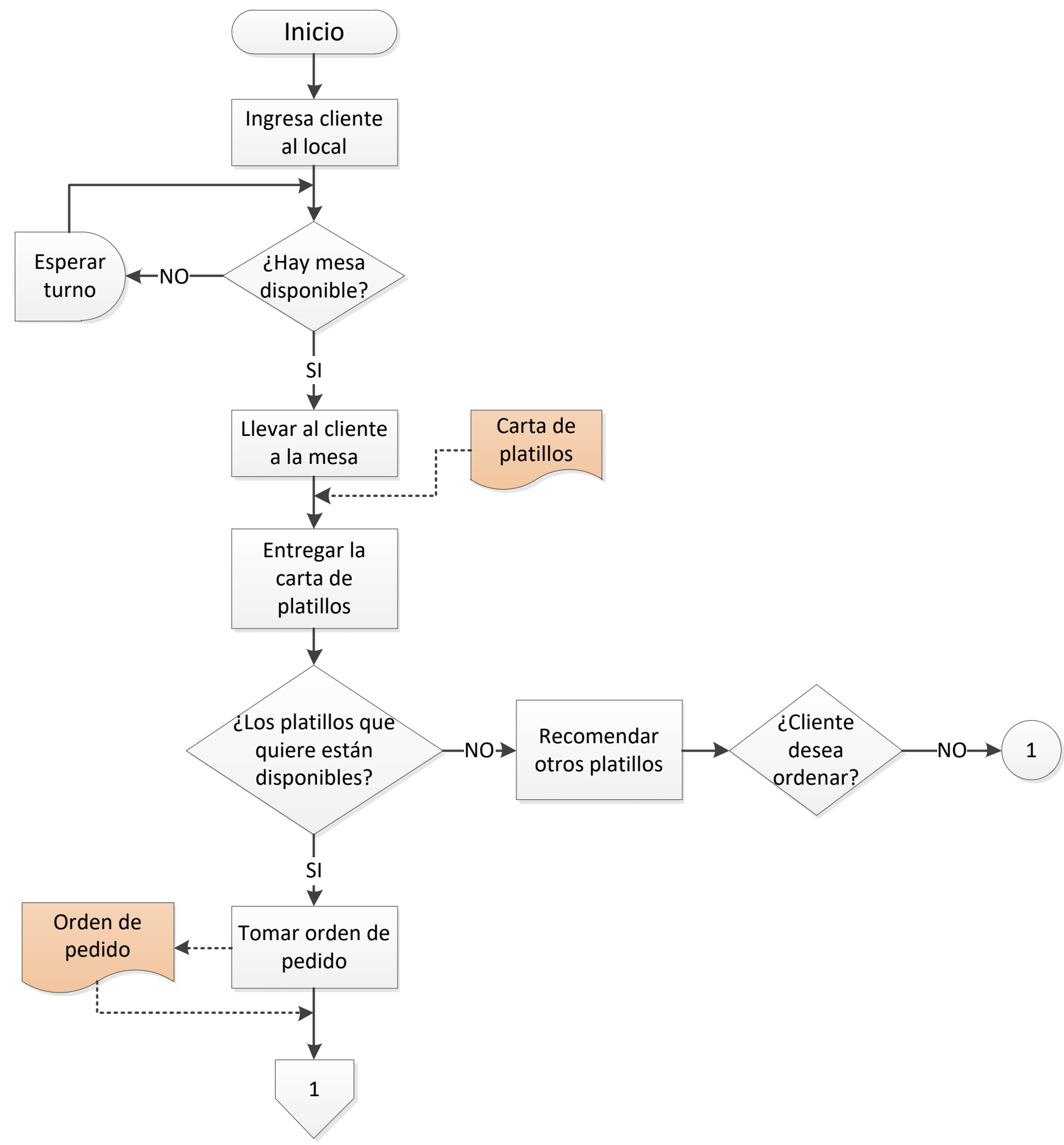




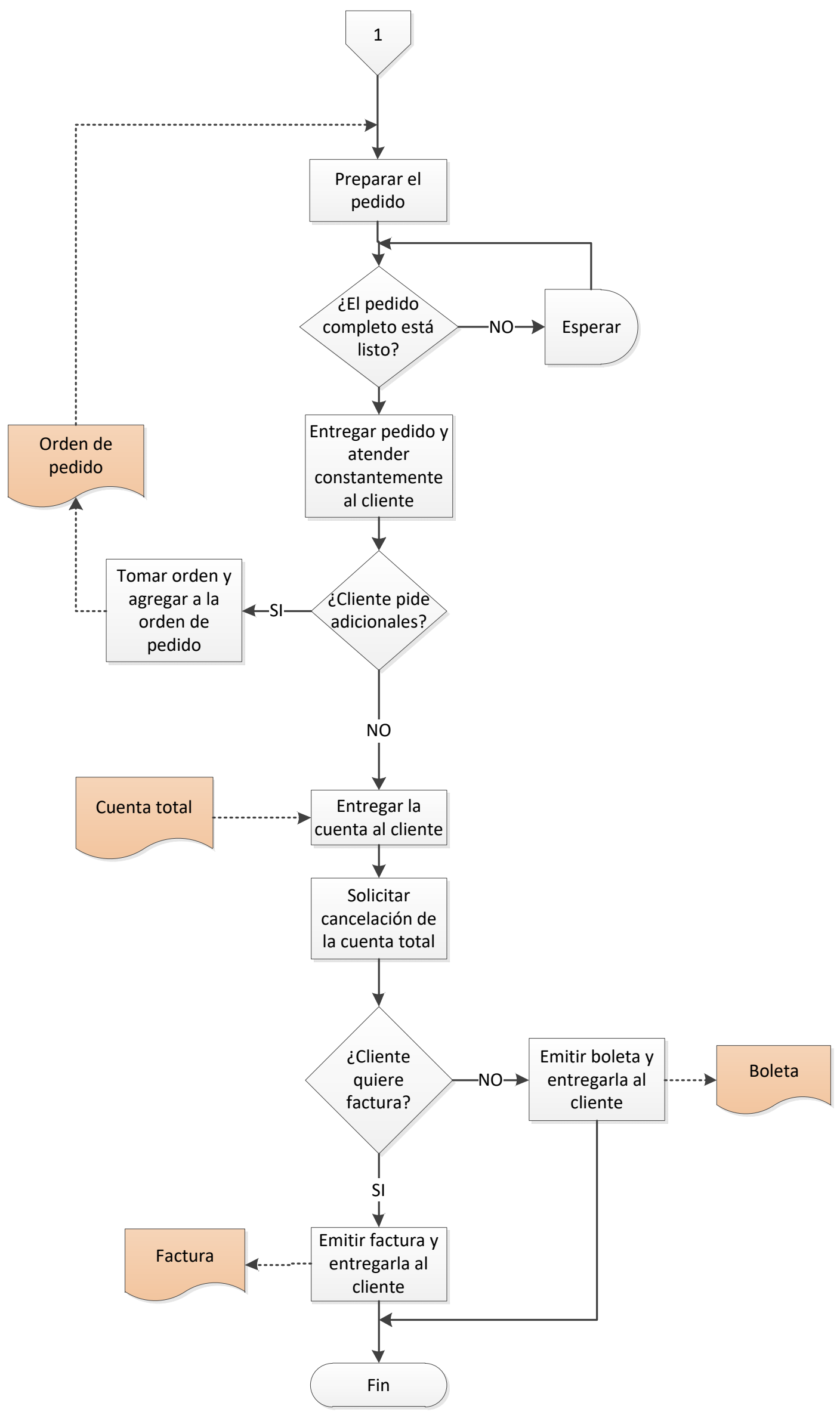

Fuente: Elaboración propia 
La ilustración $\mathrm{N}^{\circ} 42$ es la representación del diagrama de flujo general de la actividad cotidiana de una MYPE del subsector restaurantes. Como se evidencia, todo comienza con el ingreso del cliente al establecimiento; debe haber una mesa disponible para poder comenzar el servicio.

Luego se procede a dar la carta de platillos al cliente. Es importante persuadir a que el cliente elija algún plato de comida y no abandone el establecimiento si es que no está disponible lo que desea.

Una vez que el cliente elige algún platillo, se procede a redactar la orden de pedido; la cual ingresará al proceso de producción para prepararlo. Es importante que toda la orden este completa para poder dársela al cliente.

La atención al cliente tiene que ser constante ya que existe la posibilidad de que realice un nuevo pedido. Una vez que el cliente ya no desee ordenar algo, se tiene que calcular la cuenta total y dársela para que pueda cancelarla en caja; donde se emitirá una factura o boleta dependiendo de la elección del cliente.

\subsection{Modelo de costos MYPE del subsector restaurantes}

\subsubsection{Objetivos del modelo de costos}

\subsubsection{Objetivo general}

El objetivo general del modelo de costos es brindar un apoyo al empresario dueño de una MYPE del subsector restaurantes para que tenga la capacidad de poder controlar y manejar sus costos de una manera más real, independiente de otras personas y que pueda tomar decisiones basados no en la intuición sino en su realidad plasmada en costos de la empresa.

\subsubsection{Objetivos específicos}

Los objetivos específicos del modelo de costos son:

- Proporcionar una metodología sencilla, clara y ajustada a la realidad para que empresario pueda manejar sus costos.

- Brindar una herramienta para la correcta toma de decisiones.

- Brindar una herramienta que permita sentar las bases para una correcta fijación de precios basado en los costos de los platillos de comida. 
- Brindar una herramienta con la que el micro y pequeño empresario pueda reducir sus costos en determinadas áreas.

\subsubsection{Mapa interrelacional del proceso de costos}

Debido a que la presente propuesta está basada en la gestión por procesos, el proceso de costo no debe encontrarse en una situación independiente o trabajar aisladamente. A continuación, se presenta el mapa interrelacional del proceso de costos:

Ilustración $\mathrm{N}^{\mathrm{o}}$ 43.Mapa interrelacional del proceso de costos

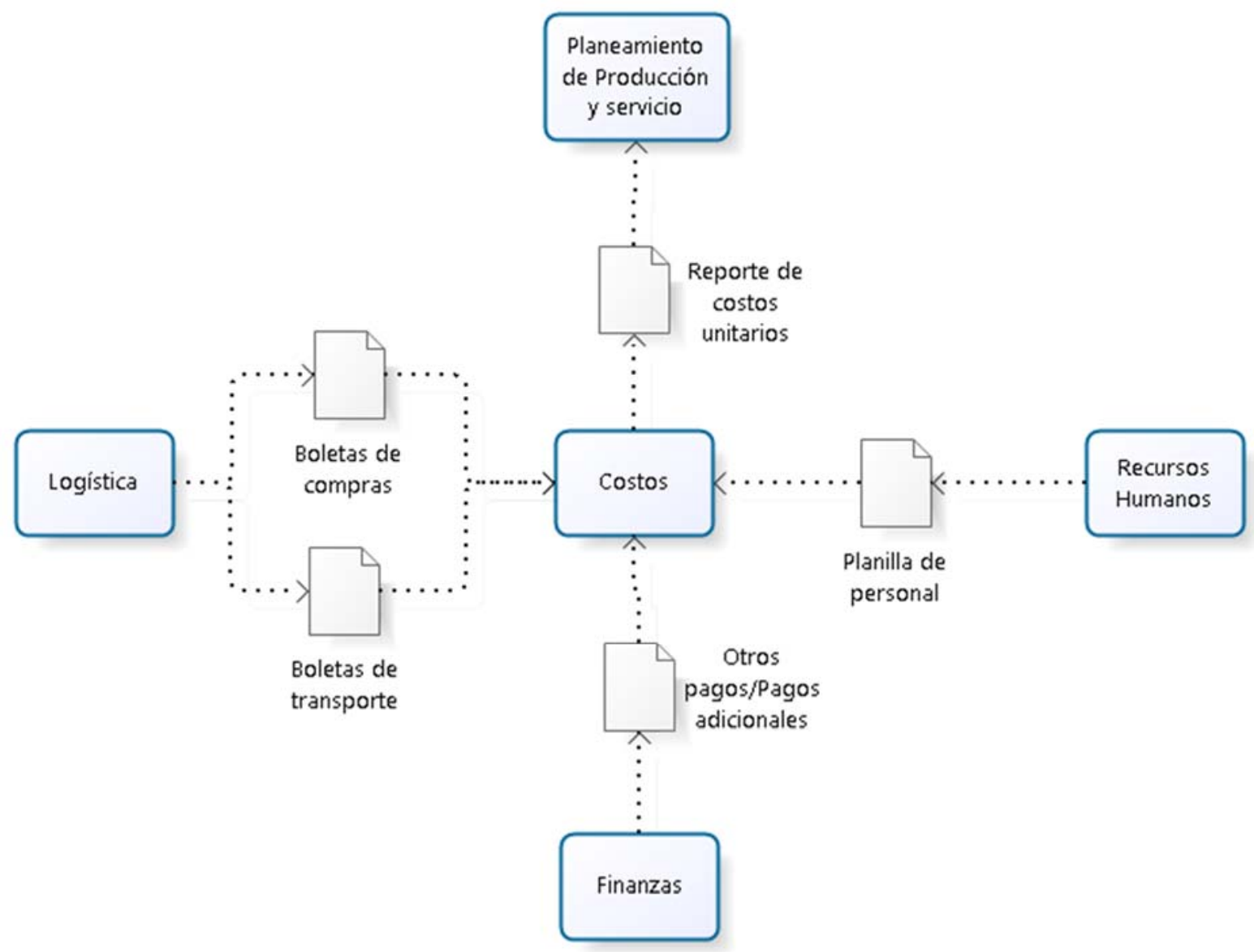

Fuente: Elaboración propia

Como se observa en el mapa, el proceso de costos tiene relación directa con los procesos de Planeamiento de Producción y Servicio, Logística y Recursos Humanos. El proceso de costos le reporta directamente al subproceso de Planeamiento de Producción y Servicio sobre los costos unitarios de los platillos que se ofrecen en el menú. Esto es importante ya que, de esta forma, se puede tomar una mejor decisión sobre qué platillos se deben 
producir más, cuáles deben ser disminuidos y para otras decisiones que el proceso de Planeamiento de Producción y Servicio crea conveniente.

Para esto, costos se relaciona muy directamente con logística, quien es el encargado de suministrar todas las boletas donde se encuentre los distintos costos tanto de materia prima, insumos y transporte, y con el proceso de recursos humanos, quien es el encargado de suministrar todos los salarios de todas las personas que se ven involucradas dentro del proceso. Es importante, también, el apoyo del proceso de Finanzas ya que este brindará información de pagos adicionales que no tienen un encargado de costo fijo.

\subsubsection{Mapa de subprocesos de costos}

El proceso de costos maneja un propio mapa de subprocesos donde se encuentran agrupadas las actividades que se deben tomar en cuenta dentro de este subproceso.

En la siguiente página, se muestra el mapa del subproceso de costos: 
Ilustración $\mathrm{N}^{\mathrm{o}}$ 44. Mapa de subprocesos de costos de una MYPE del subsector restaurantes

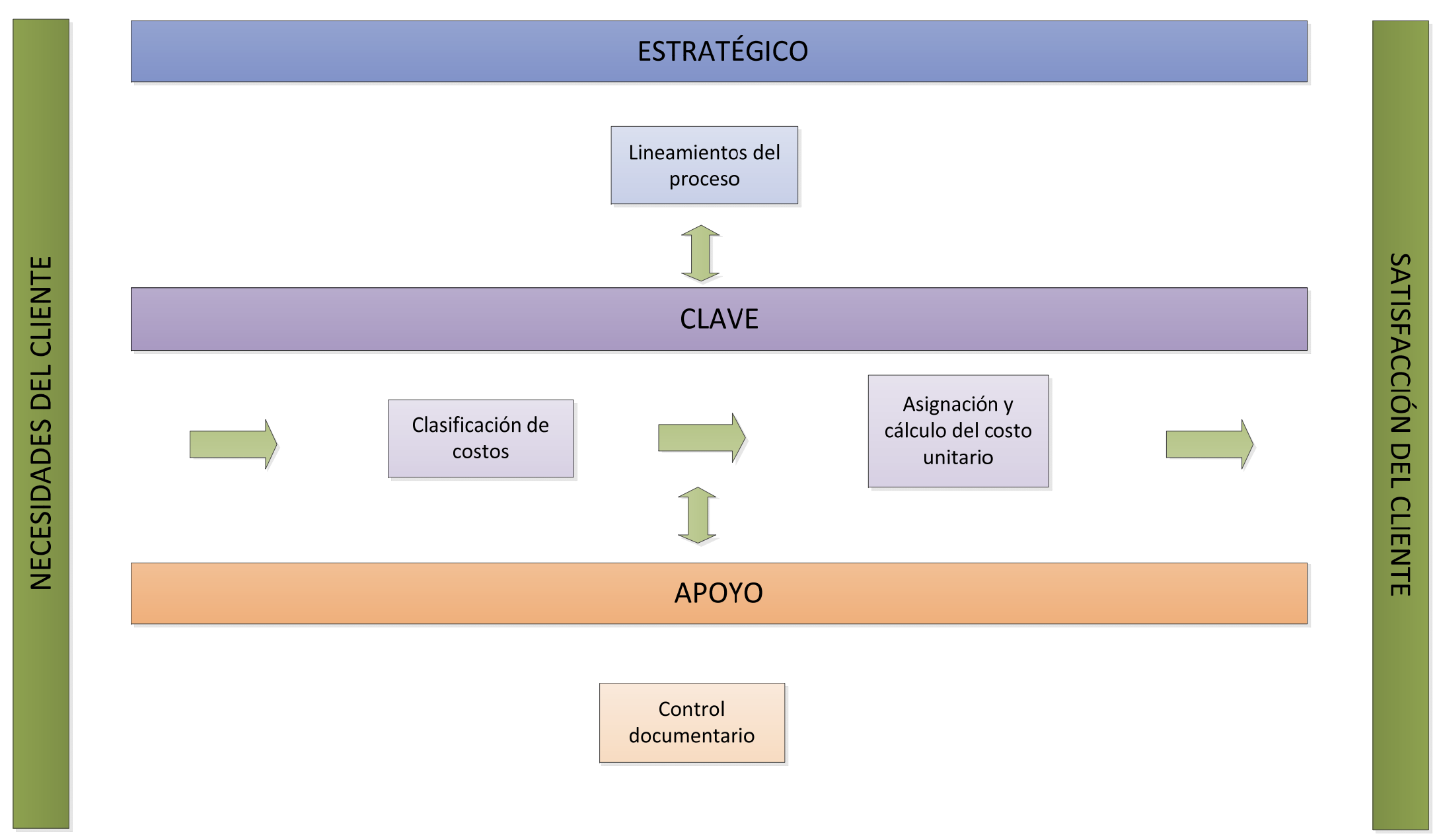

Fuente: Elaboración Propia 
El proceso de costo se encuentra conformado por los siguientes subprocesos:

- Lineamientos del proceso

Este subproceso estratégico se encarga de nombrar a todos aquellos costos que se ven involucrados en la elaboración de un platillo de comida. Es por esto que este proceso marca qué información necesita de los otros procesos para que todo el proceso de costos pueda desarrollarse sin problemas.

Por otro lado, en este subproceso proporciona los generadores de costos que serán tomados en cuenta para los procesos clave. Por otro lado, este subproceso es el encargado de manejar los indicadores del proceso de costos, así como es el encargado de realizar los reportes necesarios al proceso de Planeamiento de Producción y Servicios.

- Control Documentario

En este subproceso se recopila toda la información proveniente de los dos procesos relacionados directamente con el proceso de costo: logística y recursos humanos. Con esto, se busca tener todos los costos agrupados para poder enviarlos al subproceso de Clasificación.

- Clasificación de costos

Es un subproceso clave ya que recibe todos los costos del subproceso de Control Documentario y se los clasifica. De esta manera, se puede identificar los costos directos e indirectos de la elaboración de los platillos para luego ser enviados al siguiente subproceso.

- Asignación y cálculo del costo unitario

Este subproceso clave necesita de la información que se obtiene en el subproceso de Clasificación de costos y trabaja bajo los parámetros del subproceso estratégico de Lineamientos del proceso ya que utiliza los generadores de costo que se plantean en dicho subproceso para poder asignar los costos indirectos acumulados. Por último, el subproceso tiene como resultado la obtención del costo unitario de un producto. 


\subsubsection{Descripción de los subprocesos del modelo de costos}

\subsubsection{Subproceso de Lineamientos del proceso}

\subsection{Descripción del subproceso}

Su carácter de subproceso estratégico lo vuelve la piedra angular en la relación entre los procesos clave y la misión del proceso de apoyo.

$\mathrm{Su}$ misión es entablar la mejor relación entre los dos subprocesos clave mediante la generación de los generadores de costo adecuados; esto para que los costos indirectos puedan ser mejor distribuidos y asignación adecuada. De la misma forma

Por otro lado, el subproceso fija que costos deben ser tomados en cuenta para que el proceso de apoyo pueda recopilarlos.

Además, este subproceso se encarga de manejar los indicadores del proceso de costos.

\subsection{Diagrama de flujo del subproceso en BPMN}

A continuación, se muestra el diagrama de flujo del subproceso 
Ilustración $\mathrm{N}^{\mathrm{o}} 45$. Diagrama de flujo del subproceso Lineamientos del proceso

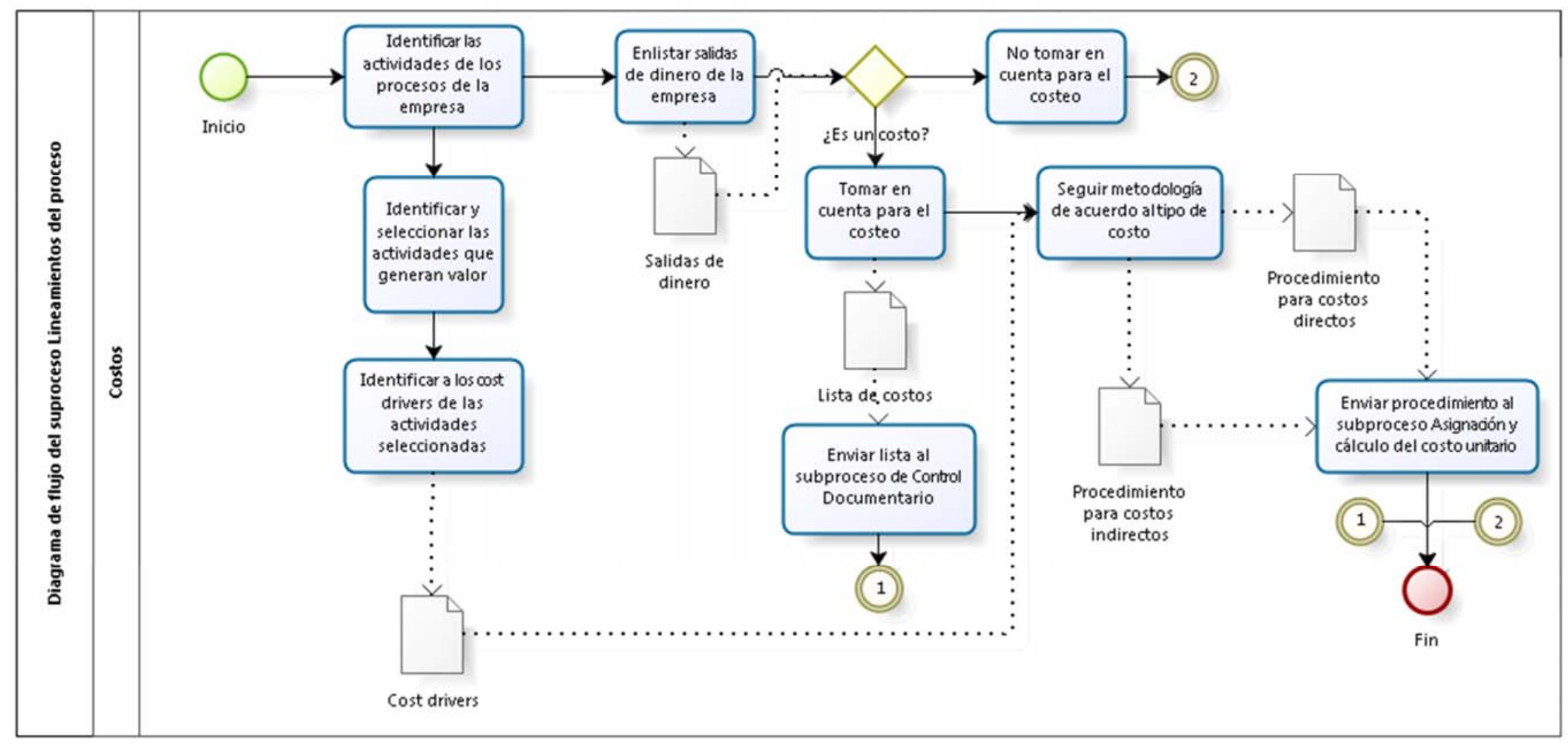

Fuente: Elaboración propia 
Como se evidencia en el diagrama de flujo, el subproceso busca que el micro y pequeño empresario identifique que salidas de dinero realmente son costos que puedan ser imputables al platillo de comida, esto gracias a la mejora de su sistema de costos en base a la metodología $\mathrm{ABC}$. Por esto, genera una lista de los costos que deben formar parte del costo del producto terminado (en este caso, de los platos de comida).

De la misma manera, el subproceso delimita los generadores de costo que se utilizan para generar el nexo entre los dos subprocesos claves del proceso de costo; así como los debidos procedimientos en los cuales se deben apoyar.

\subsection{Diagrama SIPOC tortuga}

A continuación, se presenta en diagrama SIPOC tortuga del subproceso en cuestión. 
Ilustración $\mathrm{N}^{\circ}$ 46. Diagrama SIPOC del subproceso Lineamientos del proceso

\section{Controles}

Metodología de costeo ABC (MET1, MET2, MET3, MET4)

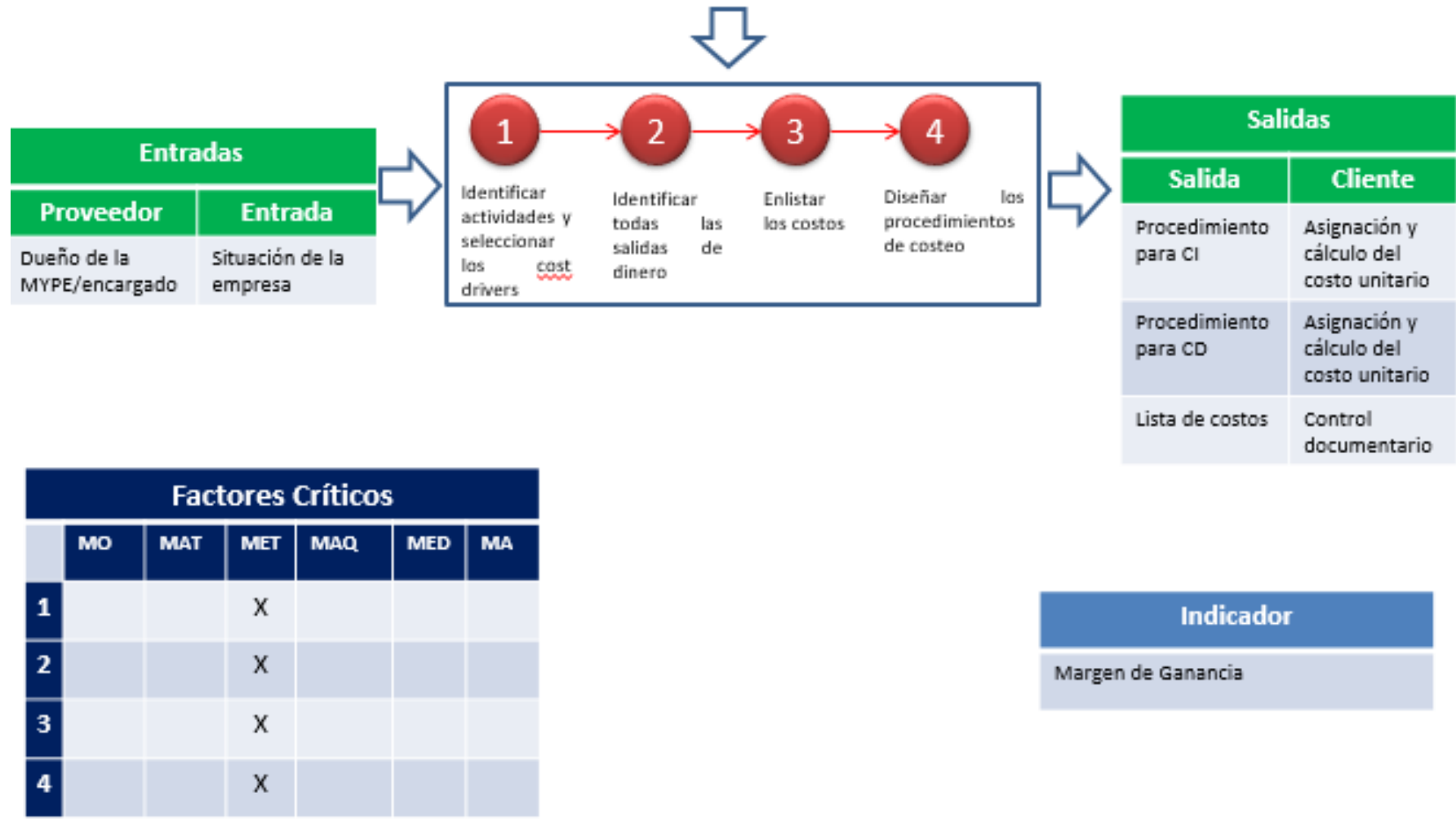

Fuente: Elaboración propia

\subsubsection{Subproceso de Control Documentario}

\subsection{Descripción del subproceso}

Este subproceso es el encargado de generar la relación entre el proceso de costos y los procesos de logística, finanzas y recursos humanos. El subproceso de Control Documentario tiene como misión recopilar toda aquella información de los costos en los cuales se ha incurrido para la elaboración de un platillo de comida. Cabe resaltar, que la información de qué costos recopilar lo provee el subproceso de Lineamientos del proceso. 


\subsection{Diagrama de flujo del subproceso BPMN}

Se muestra a continuación del diagrama de flujo correspondiente al subproceso de Control Documentario.

Ilustración $\mathrm{N}^{\mathrm{o}}$ 47. Diagrama de flujo del subproceso de Control Documentario

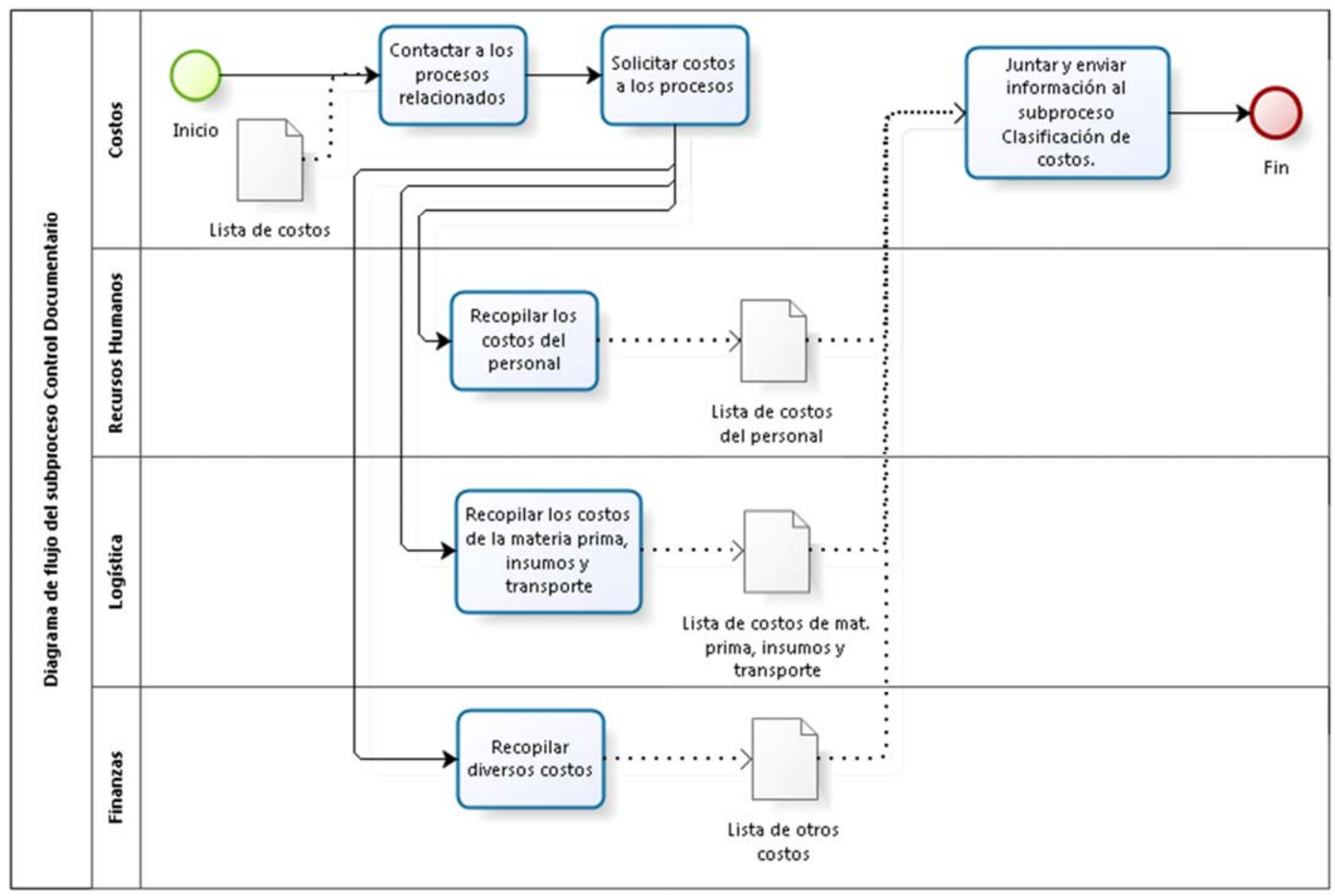

\section{Fuente: Elaboración propia}

Como se observa en el flujograma, todo comienza cuando se tiene la Lista de Costos que es proveída por el subproceso Lineamientos del proceso. Una vez que se tiene esta lista, se tiene que contactar y solicitar a cada proceso que envíe el detalle de los costos que está en esa lista. Una vez recopilado todos los costos, se tiene que pasar la información al subproceso de Clasificación de costos. 


\subsection{Diagrama SIPOC Tortuga}

Ilustración No 48. Diagrama SIPOC del subproceso Control Documentario

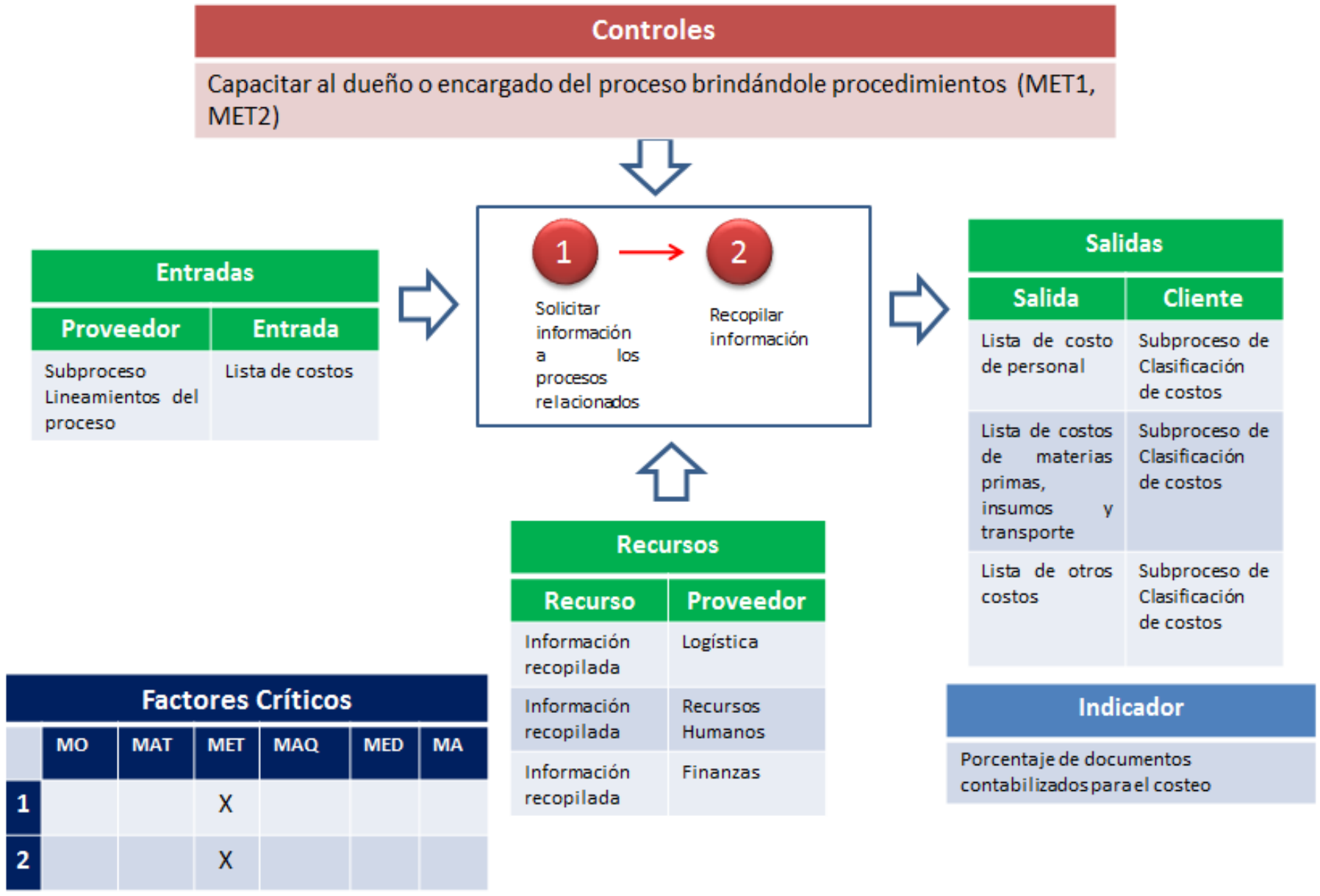

\section{Fuente: Elaboración Propia}

El diagrama SIPOC Tortuga muestra las actividades que pertenecen al subproceso de Control Documentario. La entrada del proceso es la lista de costos que el subproceso de Lineamientos del proceso considera importantes para poder realizar el costeo de los platillos de comida. Las actividades del subproceso se encuentran explicadas tanto en el diagrama de flujo del subproceso como en el SIPOC tortuga. Por otro lado, las salidas del subproceso son: Lista de costos de materias primas, transporte e insumos, Lista de costo de personal y Lista de otros costos.

Como está indicado, la metodología es el principal factor crítico debido a que los dueños de las MYPE del subsector restaurantes tienen muy bajos conocimientos en lo que respecta a 
temas de costos. Es por esto que se brinda un control que es capacitar al dueño o al empleado encargado de los costos con la utilización de un manual de procedimientos.

\subsubsection{Subproceso de Clasificación de costos}

\subsection{Descripción del subproceso}

Luego de haber recopilado la información necesaria en el subproceso de Control documentario, se procede a llevar las listas de costos hacia el subproceso de Clasificación de costos. Este subproceso tiene la misión de clasificar los costos en función a su relación directa o indirecta con el objeto de costo que viene a ser el plato de comida.

Este subproceso es importante debido a que es el primer paso antes de poder asignar los costos en base a la metodología del costeo ABC.

\subsection{Diagrama de flujo del subproceso}

A continuación, se muestra el diagrama de flujo correspondiente al subproceso de Clasificación bajo la metodología BPMN. 
Ilustración $\mathrm{N}^{\circ}$ 49. Diagrama de flujo del subproceso de Clasificación de costos

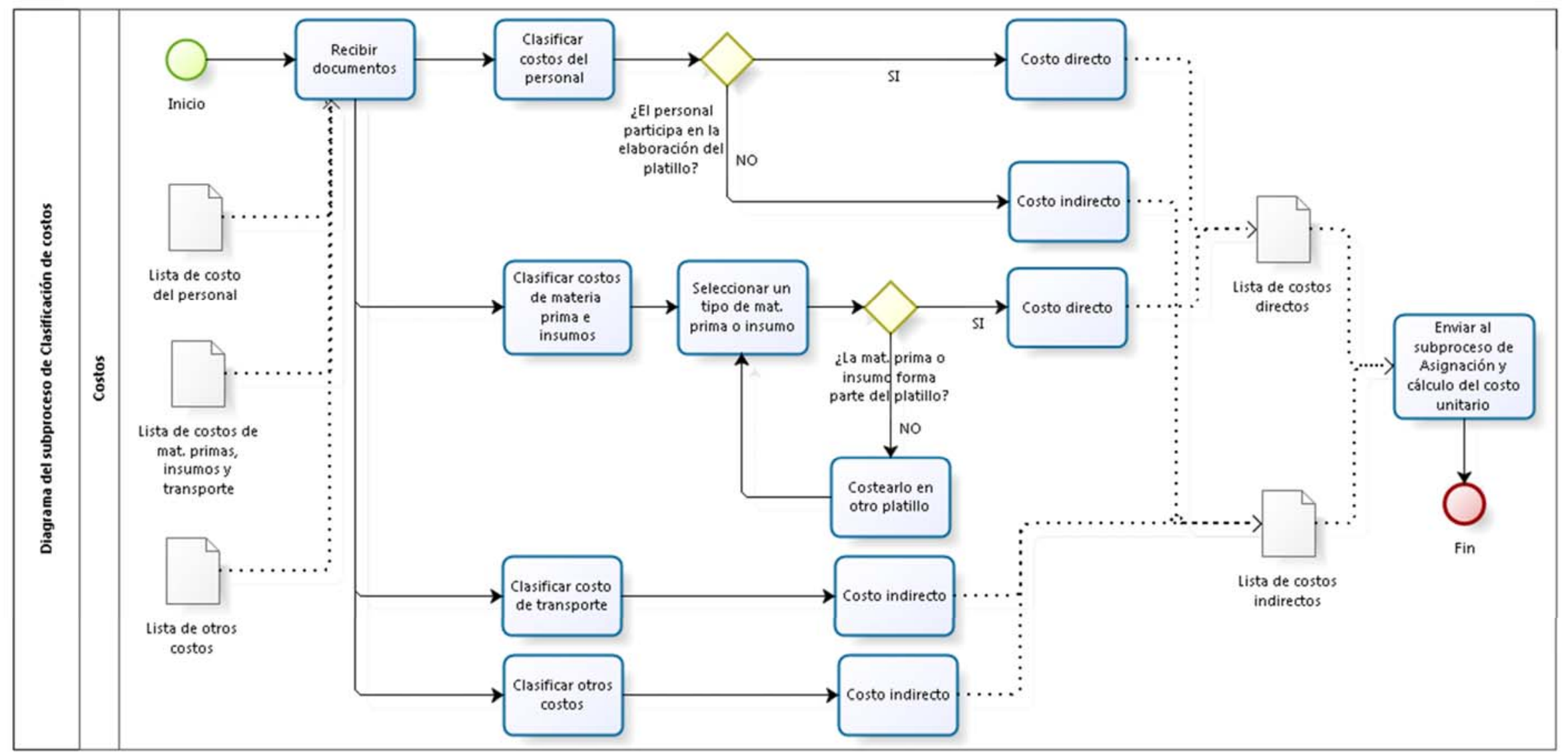

Fuente: Elaboración propia 
El subproceso comienza con la recepción de la lista de costos del subproceso Clasificación de costos y se divide en 4 partes: Salarios, materias primas e insumos, transporte y otros costos. Como se evidencia en el gráfico, de cada una de las partes surgen costos directos o costos indirectos dependiendo de su relación con el objeto de costos.

\subsection{Diagrama SIPOC tortuga}

Ilustración No 50. Diagrama SIPOC tortuga del subproceso de Clasificación de costos

\begin{tabular}{|l}
\hline Controles \\
\hline Capacitación al dueño o encargado en tema de manejo de documentos (MO1) \\
Procedimiento para la correcta clasificación de los costos (ME2)
\end{tabular}

\begin{tabular}{|l|l|}
\hline \multicolumn{2}{|c|}{ Entradas } \\
\hline Proveedor & \multicolumn{1}{|c|}{ Entrada } \\
\hline $\begin{array}{l}\text { Subproceso } \\
\text { Control } \\
\text { Documentario }\end{array}$ & $\begin{array}{l}\text { Lista de costos } \\
\text { de personal; } \\
\text { lista de costos } \\
\text { de mat. Prima, } \\
\text { insumos y } \\
\text { transporte; } \\
\text { otros costos }\end{array}$ \\
\hline
\end{tabular}

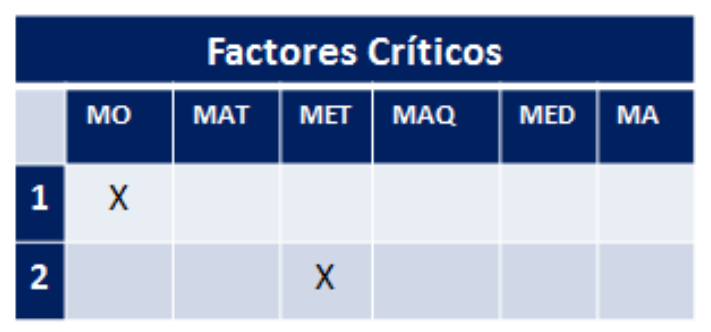

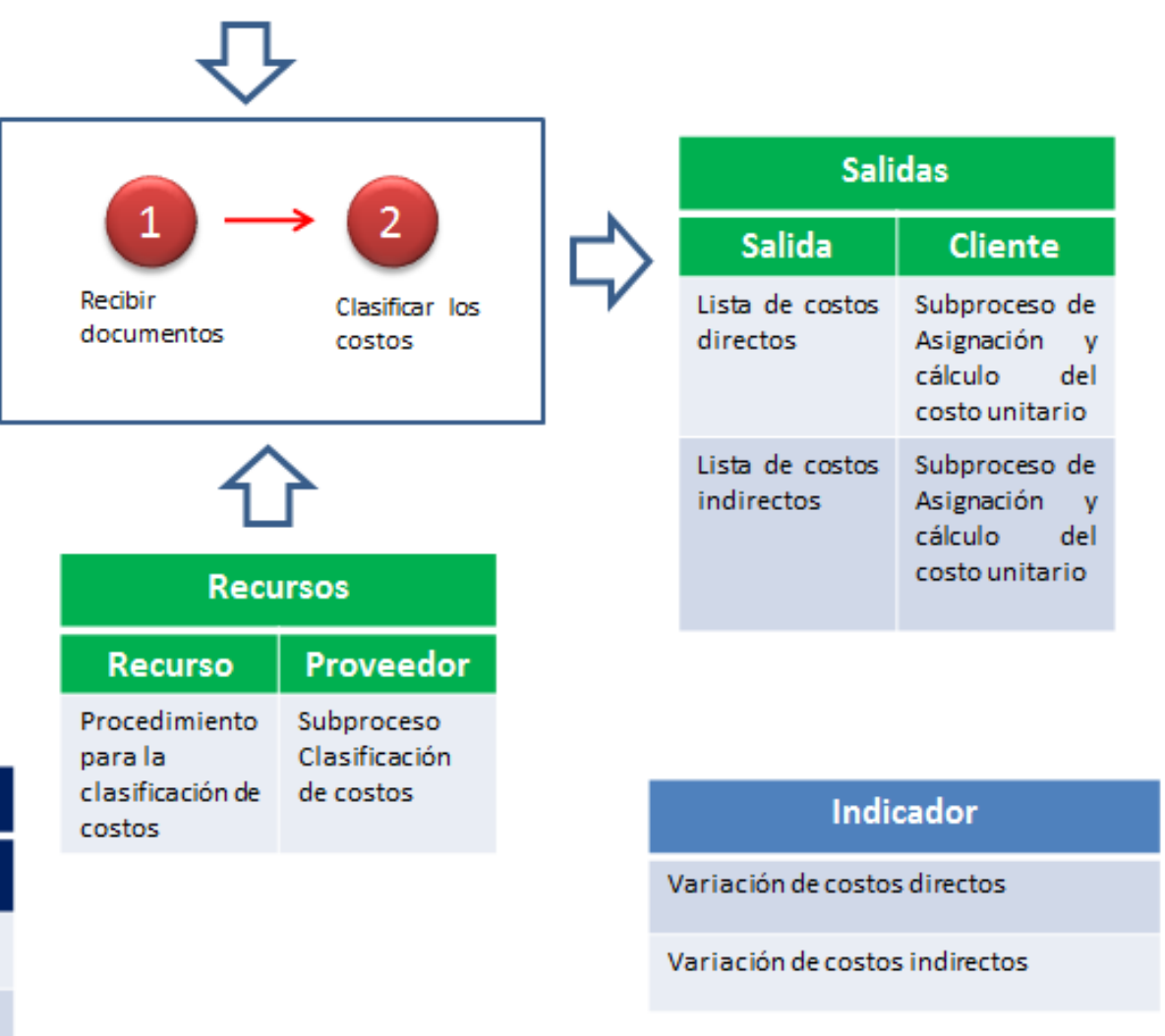

Fuente: Elaboración propia 


\subsubsection{Subproceso de Asignación y cálculo del costo unitario}

\subsection{Descripción del subproceso}

Luego del subproceso de Clasificación de costos, sigue el subproceso de asignación y cálculo del costo unitario.

Para relacionar al subproceso anterior con el presente, se necesita información del subproceso estratégico de Lineamientos del proceso ya que, dentro del desarrollo del mismo, se encuentran los generadores del costo que son de vital importancia para una distribución más real de todos los costos indirectos en los cuales se incurre.

La misión de este subproceso es asignar adecuadamente cada costo indirecto para poder obtener, junto con cada costo directo, los costos unitarios reales; lo que servirá como base para poder establecer precios adecuados.

\subsection{Diagrama de flujo del subproceso}

En la página siguiente, se observa el diagrama de flujo bajo metodología BPMN del subproceso. 
Ilustración $\mathrm{N}^{\mathrm{o}}$ 51. Diagrama de flujo del subproceso de Asignación y cálculo del costo unitario

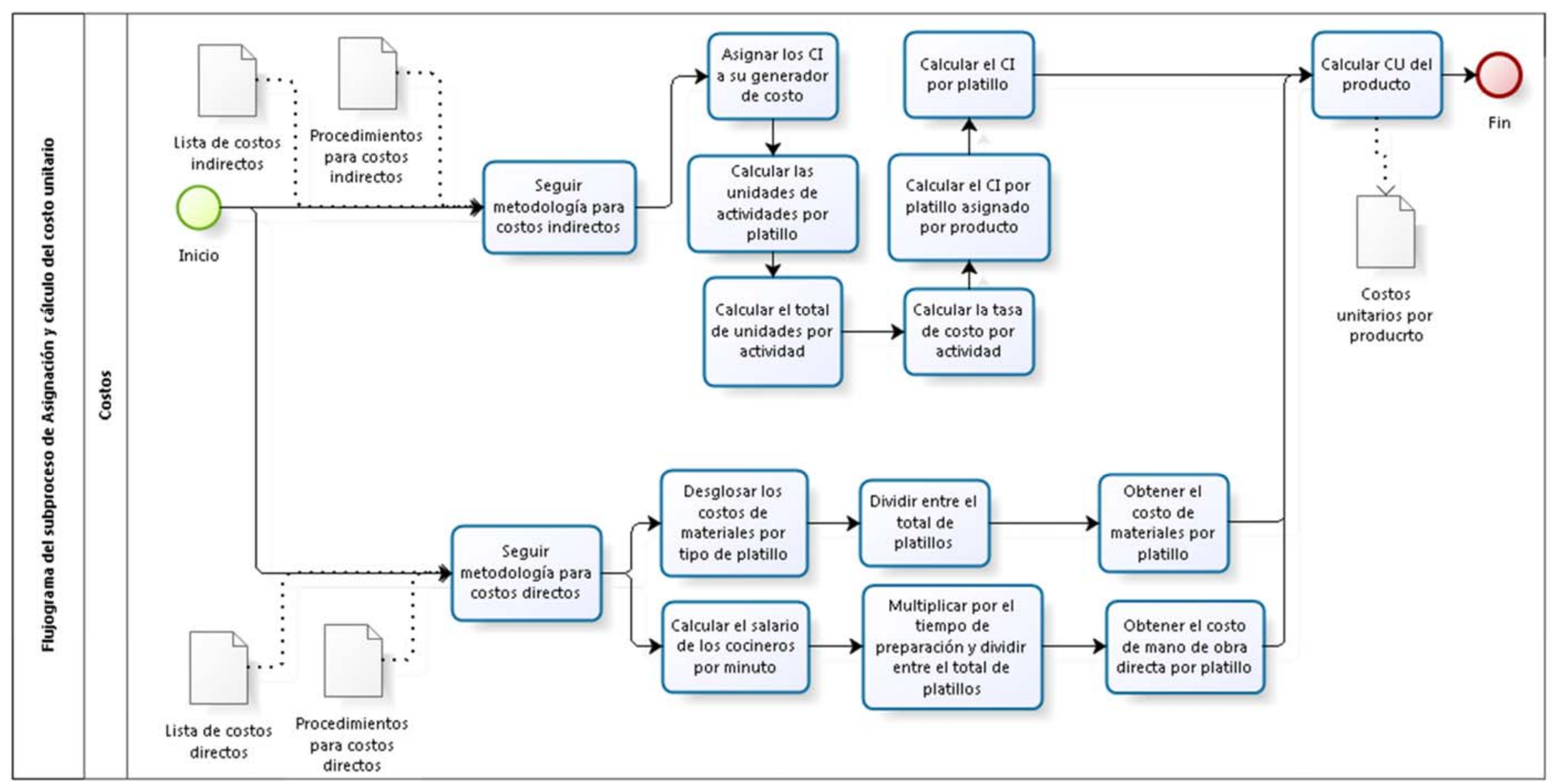

Fuente: Elaboración propia 
El diagrama de flujo recoge la metodología del costeo basado en actividad para poder realizar la mejor asignación de los costos indirectos de fabricación. Cabe resaltar, que los tecnicismos que se puedan encontrar en el diagrama anteriormente observado serán simplificados en los procedimientos para el modelo de costos debido a que este es lo que más le interesa al micro y pequeño empresario: Un modelo que sea fácil de entender y que distribuya mejor sus costos.

\subsection{Diagrama SIPOC Tortuga}

Ilustración $N^{o} 52$. Diagrama SIPOC tortuga del subproceso Asignación y cálculo del costo unitario

Controles
Cumplimiento del procedimiento para la asignación de costos directos (MET1, MET3, MET4)
Cumplimiento del procedimiento para la asignación de costos indirectos (MET1, MET2,
MET3,MET4)

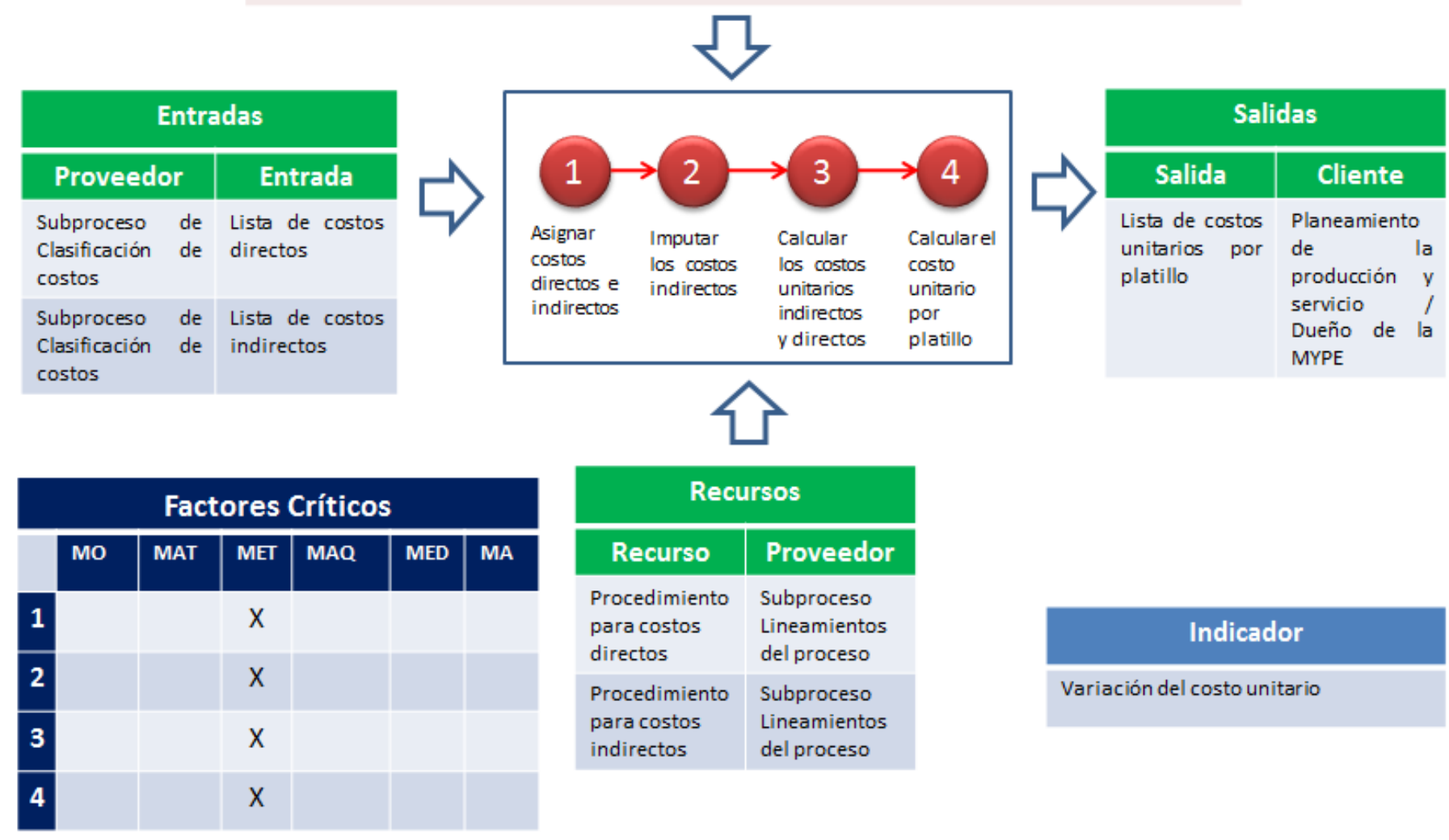




\section{Fuente: Elaboración propia}

El subproceso cuenta con 4 actividades que son importantes para la correcta asignación de todos los costos indirectos y directos de los platillos. El primer paso es la asignación de los costos indirectos a un generador de costos específico para que se puedan relacionar con el objeto de costo principal que vendría a ser el plato de comida. De la misma forma, se tiene que asignar los costos directos a cada tipo de producto que la MYPE ofrece.

Luego de asignar los costos, se los imputa a los diversos platos de comida que son fabricados; por último, se tiene que calcular los costos unitarios directos e indirectos por cada platillo de comida para poder sumarlos y obtener el costo unitario total de cada producto. Como se evidencia en el diagrama SIPOC, la metodología sigue siendo uno los principales factores críticos debido a los bajos conocimientos que las MYPE y/o el dueño de la MYPE tiene en lo que respecta a costo de un restaurante.

\subsubsection{Indicadores}

Para poder medir los resultados del proceso de costos, es necesario plantear una serie de indicadores que resulten relevantes para el modelo. Además, estos deben ser de fácil uso para el dueño de una MYPE del subsector restaurantes.

Para el presente modelo, se utilizarán dos indicadores:

- Margen de ganancia: El indicador por defecto de un modelo de costos es el margen de ganancia. De esta manera, el empresario podrá evaluar cuánto está ganando por cada platillo de comida que produce. Este indicador será manejado por el subproceso de Lineamientos del proceso.

- Porcentaje de documentos contabilizados para el costeo: Este indicador evalúa el cumplimiento total de procesar todos los documentos necesarios (facturas de compra, boletas, planillas, etc) para poder realizar el proceso de costeo. Este indicador será manejado por el subproceso Control Documentario.

- Variación de Costos Directos: Este indicador es importante ya que permite controlar la variación total de los costos directos dentro de un determinado periodo. De esta forma, es más sencillo encontrar posibles puntos de mejora. Este indicador será manejado por el subproceso de Clasificación de costos. 
- Variación de Costos Indirectos: Este indicador es importante ya que permite controlar la variación total de los costos indirectos dentro de un determinado periodo. De esta forma, es más sencillo encontrar posibles puntos de mejora y poder proponer planes para evitar su aumento desmesurado. Este indicador será manejado por el subproceso de Clasificación de costos.

- Variación del costo unitario: Este indicador ayudará a comparar los costos unitarios de un platillo de comida en dos tiempos diferentes. De esta forma, se puede tomar mejor una decisión.

Estos indicadores serán controlados por el subproceso de Lineamientos del proceso, esto debido a que es el subproceso estratégico dentro del proceso de costos. A continuación, se presentan las fichas de cada indicador.

Tabla N ${ }^{\circ}$ 21. Ficha del indicador Margen de Ganancia

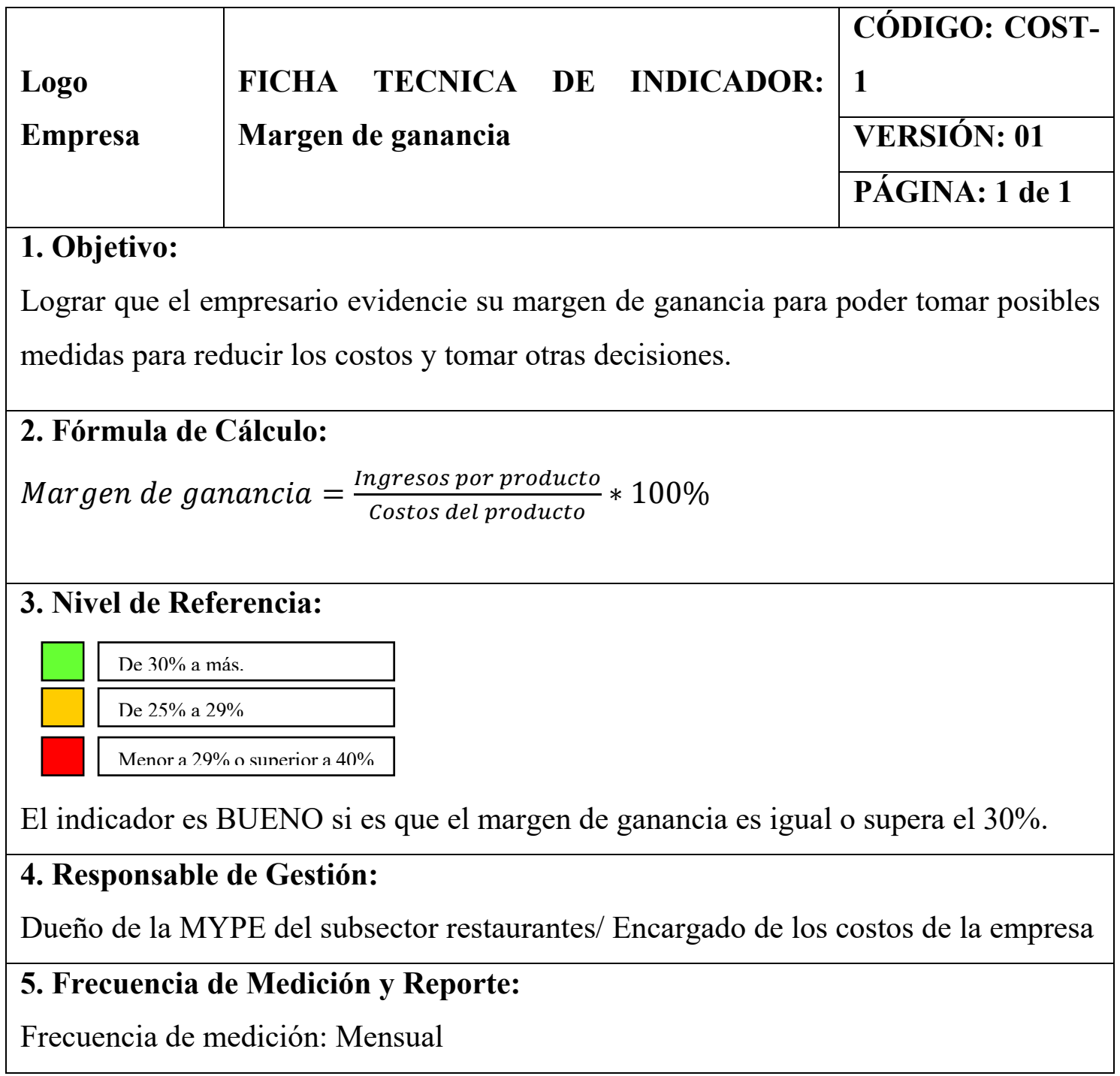


Responsable: Dueño de la MYPE/ Encargado de los costos de la empresa

6. Usuarios:

Proceso de costo, Dueño de la MYPE del subsector restaurantes

\section{Observaciones:}

Este reporte es para uso interno de la empresa. También se le tiene que enviar al proceso de Planeamiento de la Producción y Servicio

\section{Fuente: Elaboración propia}

Tabla $\mathrm{N}^{\mathrm{o}} 22$. Ficha del indicador Porcentaje de documentos contabilizados para el costeo

\begin{tabular}{|l|l|l|}
\hline \multirow{2}{*}{$\begin{array}{l}\text { Logo } \\
\text { Empresa }\end{array}$} & FICHA TECNICA DE INDICADOR: Porcentaje & CÓDIGO: COST-2 \\
\cline { 3 - 3 } & de documentos contabilizado para el costeo & PÁGINA: 1 de 1 \\
\cline { 3 - 3 } & &
\end{tabular}

\section{Objetivo:}

Lograr que el encargado de manejar los costos incluya todos los documentos relevantes (facturas, boletas, planillas, etc) para poder realizar el costeo de los objetos de costo.

\section{Fórmula de Cálculo:}

$\%$ de Doc. contabilizados para el costeo $=\frac{\text { Total de documentos que se tiene }}{\text { Total de documentos expedidos }} * 100 \%$

\section{Nivel de Referencia:}

$$
100 \%
$$

Menos a $100 \%$

El indicador es BUENO si es que se procesa el $100 \%$ de los documentos relevantes para poder hacer el costeo.

\section{Responsable de Gestión:}

Dueño de la MYPE del subsector restaurantes/ Encargado de los costos de la empresa

\section{Frecuencia de Medición y Reporte:}

Frecuencia de medición: Dependiendo del periodo de tiempo que se desee costear

Responsable: Dueño de la MYPE/ Encargado de los costos de la empresa

\section{Usuarios:}


Proceso de costo, Dueño de la MYPE del subsector restaurantes

\section{Observaciones:}

Este reporte es para uso interno de la empresa. Si se tiene el 100\% de documentos relevantes, el costeo será óptimo.

Fuente: Elaboración propia

Tabla $N^{\circ} 23$. Ficha del indicador Variación de Costos Directos

\begin{tabular}{|c|c|c|}
\hline \multirow{3}{*}{$\begin{array}{l}\text { Logo } \\
\text { Empresa }\end{array}$} & \multirow{3}{*}{$\begin{array}{l}\text { FICHA TECNICA DE INDICADOR: Variación } \\
\text { de costos directos }\end{array}$} & CÓDIGO: COST-3 \\
\hline & & VERSIÓN: 01 \\
\hline & & PÁGINA: 1 de 1 \\
\hline \multicolumn{3}{|c|}{ 1. Objetivo: } \\
\hline \multicolumn{3}{|c|}{$\begin{array}{l}\text { Lograr que el empresario controle la variación de sus costos totales directos con el fin de que } \\
\text { pueda aplicar planes de mejora para su reducción. }\end{array}$} \\
\hline \multicolumn{3}{|c|}{ 2. Fórmula de Cálculo: } \\
\hline \multicolumn{3}{|c|}{ Var. de $C D=\frac{\text { Total de CD Actual -Total de CD Pasado }}{\text { Total de CD Pasado }} * 100 \%$} \\
\hline \multicolumn{3}{|c|}{ 3. Nivel de Referencia: } \\
\hline \multicolumn{3}{|c|}{ De $15 \%$ a menos } \\
\hline \multicolumn{3}{|c|}{ Más de $15 \%$ y menor a $20 \%$} \\
\hline \multicolumn{3}{|c|}{ Superior a $20 \%$} \\
\hline \multicolumn{3}{|c|}{$\begin{array}{l}\text { El indicador es BUENO si es que la variación de los costos directos es inferior a } 15 \% \text {; o que } \\
\text { la variación sea negativa. }\end{array}$} \\
\hline \multicolumn{3}{|c|}{ 4. Responsable de Gestión: } \\
\hline \multicolumn{3}{|c|}{ Dueño de la MYPE del subsector restaurantes/ Encargado de los costos de la empresa } \\
\hline \multicolumn{3}{|c|}{ 5. Frecuencia de Medición y Reporte: } \\
\hline \multicolumn{3}{|c|}{ Frecuencia de medición: Mensual } \\
\hline \multicolumn{3}{|c|}{ Responsable: Dueño de la MYPE/ Encargado de los costos de la empresa } \\
\hline
\end{tabular}




\section{Usuarios:}

Proceso de costo, Dueño de la MYPE del subsector restaurantes

7. Observaciones:

Este reporte es para uso interno de la empresa.

Fuente: Elaboración propia

Tabla $\mathrm{N}^{\mathrm{o}} 24$. Ficha del indicador Variación de Costos Indirectos 


\begin{tabular}{|c|c|c|}
\hline \multirow{3}{*}{$\begin{array}{l}\text { Logo } \\
\text { Empresa }\end{array}$} & \multirow{3}{*}{$\begin{array}{l}\text { FICHA TECNICA DE INDICADOR: Variación } \\
\text { de costos indirectos }\end{array}$} & CÓDIGO: COST-4 \\
\hline & & VERSIÓN: 01 \\
\hline & & PÁGINA: 1 de 1 \\
\hline \multirow{2}{*}{\multicolumn{3}{|c|}{$\begin{array}{l}\text { 1. Objetivo: } \\
\text { Lograr que el empresario controle la variación de sus costos totales indirectos con el fin de } \\
\text { que pueda aplicar planes de mejora para su reducción. }\end{array}$}} \\
\hline & & \\
\hline \multicolumn{3}{|c|}{$\begin{array}{l}\text { 2. Fórmula de Cálculo: } \\
\text { Var.de } C I=\frac{\text { Total de CI Actual -Total de CI Pasado }}{\text { Total de CI Pasado }} * 100 \%\end{array}$} \\
\hline \multicolumn{3}{|c|}{ 3. Nivel de Referencia: } \\
\hline \multicolumn{3}{|c|}{ De $10 \%$ a menos } \\
\hline \multicolumn{3}{|c|}{ Más de $10 \%$ y menor a $15 \%$} \\
\hline \multicolumn{3}{|c|}{ Superior a $15 \%$} \\
\hline \multicolumn{3}{|c|}{$\begin{array}{l}\text { El indicador es BUENO si es que la variación de los costos directos es inferior a 10\%; o que } \\
\text { la variación sea negativa. }\end{array}$} \\
\hline \multicolumn{3}{|c|}{ 4. Responsable de Gestión: } \\
\hline \multicolumn{3}{|c|}{ Dueño de la MYPE del subsector restaurantes/ Encargado de los costos de la empresa } \\
\hline \multicolumn{3}{|c|}{ 5. Frecuencia de Medición y Reporte: } \\
\hline \multicolumn{3}{|c|}{ Frecuencia de medición: Mensual } \\
\hline \multicolumn{3}{|c|}{ Responsable: Dueño de la MYPE/ Encargado de los costos de la empresa } \\
\hline \multicolumn{3}{|c|}{ 6. Usuarios: } \\
\hline \multicolumn{3}{|c|}{ Proceso de costo, Dueño de la MYPE del subsector restaurantes } \\
\hline \multicolumn{3}{|c|}{ 7. Observaciones: } \\
\hline
\end{tabular}

Fuente: Elaboración propia

Tabla $N^{\circ} 25$. Ficha del indicador Variación de costos unitarios

\begin{tabular}{|l|l|l|}
\hline \multirow{2}{*}{$\begin{array}{l}\text { Logo } \\
\text { Empresa }\end{array}$} & FICHA TECNICA DE INDICADOR: Variación & CÓDIGO: COST-5 \\
\cline { 3 - 3 } & de costos unitarios & PERSÓN: 01 \\
\cline { 3 - 3 } & & PÁGINA: 1 de 1 \\
\hline
\end{tabular}




\section{Objetivo:}

Lograr que el empresario tenga un indicador que permita controlar el costo unitario de cada platillo comparándolo con un costo pasado.

\section{Fórmula de Cálculo:}

Variación de costos unitarios $=\frac{\text { C.U.Actual-C.U.Pasado }}{\text { C.U.Pasado }} * 100 \%$

\section{Nivel de Referencia:}

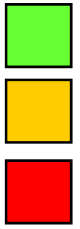

De $10 \%$ a menos

De $10 \%$ a $15 \%$

Superior a $15 \%$

El indicador es BUENO si es que la variación de costos unitarios de un tipo de platillos es de $10 \%$ a menos.

\section{Responsable de Gestión:}

Dueño de la MYPE del subsector restaurantes/ Encargado de los costos de la empresa

\section{Frecuencia de Medición y Reporte:}

Frecuencia de medición: Mensual

Responsable: Dueño de la MYPE/ Encargado de los costos de la empresa

\section{Usuarios:}

Proceso de costo, Dueño de la MYPE del subsector restaurantes

\section{Observaciones:}

Este reporte es para uso interno de la empresa. También se le tiene que enviar al proceso de Planeamiento de la Producción y Servicio

\section{Fuente: Elaboración propia}

\subsubsection{Procedimientos}

Como parte del enfoque de gestión por procesos, se ha elaborado los procedimientos para cada subproceso del proceso de costos.

Estos procedimientos pueden ser encontrados los anexos $N^{\circ} 1,2,3$ y 4 . 


\subsubsection{Modelo de costeo ABC estándar para MYE del subsector restaurantes}

Como está comentado anteriormente, uno de los objetivos de esta tesis es poder brindar al dueño de una MYPE del subsector restaurantes un modelo estándar y formato que pueda usar, en su día a día, y mejore la administración de sus costos.

En este punto, basándose en las actividades que figuran en el subproceso Lineamientos del proceso, se va a definir los que serían los objetos de costo, las actividades y los recursos de una MYPE del subsector restaurantes estándar; así como un formato estándar de operación. Además, con este punto el empresario podrá ayudarse a definir, por su propia cuenta, todo lo relevante a su proceso de costos.

\subsubsection{Identificación de objetos de costo}

Como está descrito en una de las actividades del subproceso de Lineamiento de costos, es necesario que el empresario dueño de una MYPE del subsector restaurantes identifique los productos o servicios que vendrían a ser sus objetos de costos.

Para el caso de un restaurante estándar, sus objetos de costo vendrían a ser los productos (platillos) que estos ofrecen debido a que consumen una amplia cantidad de recursos, los cuales se traducen como costos. Si bien en cierto que un restaurante estándar también ofrece bebidas, postres, etc, es preferible enfocarse en este punto solo en los platillos ya que son el punto base del negocio; aunque el mismo proceder se puede aplicar al caso de postre y bebidas.

Para hacer más dinámica y ordenada la identificación de objetos de costo, se puede utilizar un pequeño formato de lista estándar como la siguiente:

Tabla $\mathrm{N}^{\mathrm{0}} 26$. Formato de lista estándar

\begin{tabular}{|l|l|}
\hline $\mathbf{N}^{\mathbf{0}}$ & Tipo de platillo \\
\hline 1. & \\
\hline
\end{tabular}




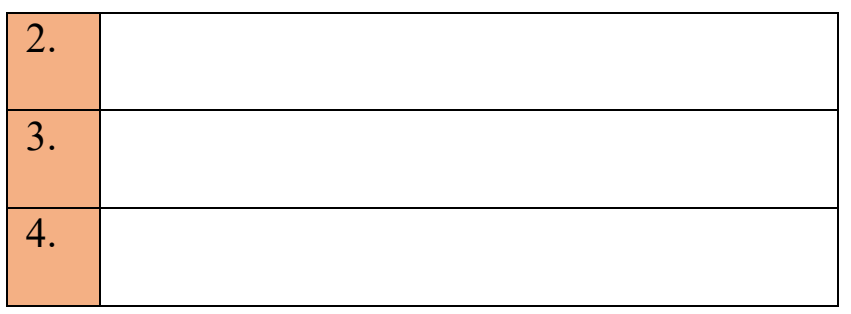

\section{Fuente: Elaboración propia}

\subsubsection{Actividades}

El siguiente paso, siguiendo la metodología del costeo $\mathrm{ABC}$, es identificar todas las actividades de la empresa que se encuentren relacionadas con los objetos de costo, en este caso, los platillos de comida. Para esto, es necesario tomar en cuenta el flujograma que se presentó en dicho capítulo para poder identificar las actividades.

Como se ha mencionado, al ser un modelo estándar o base, las actividades que se proponen en este punto son aquellas que son más comunes en cualquier restaurante.

El proceso común para poder elaborar un platillo comienza con el proceso de abastecimiento, prosigue con el proceso de atención al cliente, el de producción y termina con el de entrega del producto.

Para poder identificar y mejor las actividades, se recomienda usar el siguiente formato; en el cual se desarrolla las actividades estándar de cualquier restaurante. 
Tabla N ${ }^{0} 27$. Descripción de actividades

\begin{tabular}{|c|c|c|c|}
\hline Descripción de la actividad & Entradas & Salidas & Conductor de costo \\
\hline $\begin{array}{l}\text { Comprar materias primas, } \\
\text { insumos y demás. }\end{array}$ & $\begin{array}{l}\text { - } \text { Dinero } \\
\text { - Lista de materias } \\
\text { primas, insumos, etc } \\
\text { a comprar }\end{array}$ & $\begin{array}{lr}\text { Materias } & \text { primas, } \\
\text { insumos, } & \text { etc } \\
\text { adquiridos } & \end{array}$ & Cantidad adquirida (en $\mathrm{Kg}$ ) \\
\hline $\begin{array}{l}\text { Transportar materias primas, } \\
\text { insumos y demás }\end{array}$ & $\begin{array}{llr}\text { - } & \text { Materias } & \text { primas, } \\
\text { insumos, } & \text { etc } \\
\text { adquiridos } & \\
\text { - } & \text { Movilidad } & \\
\end{array}$ & $\begin{array}{l}\text { - Materias primas, } \\
\text { insumos, etc en el } \\
\text { almacén. }\end{array}$ & Cantidad adquirida (en $\mathrm{Kg}$ ) \\
\hline Preparación del local & $\begin{array}{ll}\text { - } & \text { Personal } \\
\text { - } & \text { Utensilios } \\
& \text { limpieza } \\
\text { - } & \text { Insumos y materias } \\
\text { primas }\end{array}$ & $\begin{array}{ll}\text { - } & \text { Local limpio y } \\
\text { ordenado } \\
\text { - } \\
\text { Insumos y materias } \\
\text { primas listas }\end{array}$ & - \\
\hline Planificación de la preparación & $\begin{array}{l}\text { Lista de platillos que } \\
\text { se pueden ofrecer }\end{array}$ & $\begin{array}{l}\text { - Lista de platillos que } \\
\text { serán pedidos }\end{array}$ & Orden de Pedido \\
\hline Recepción y atención al cliente & $\begin{array}{ll}- & \text { Cliente } \\
- & \text { Mozo }\end{array}$ & - $\quad$ Orden de pedido & Orden de Pedido \\
\hline Cocinar el pedido & - $\quad$ Orden de pedido & - $\quad$ Platillos preparados & Orden de Pedido \\
\hline Entregar el pedido & $\begin{array}{l}\text { - Platillos preparados } \\
\text { de acuerdo a la orden } \\
\text { del pedido }\end{array}$ & - $\quad$ Cliente atendido & Orden de Pedido \\
\hline Cobrar el pedido & $\begin{array}{lll}\text { - } & \text { Cuenta total de } \\
\text { pedidos } & \end{array}$ & $\begin{array}{ll}\text { - } & \text { Factura o boleta } \\
\text { - } & \begin{array}{l}\text { Ingreso para el } \\
\text { restaurante }\end{array}\end{array}$ & Orden de Pedido \\
\hline
\end{tabular}

Fuente: Elaboración propia 
- Descripción de actividades: Se tiene que describir el conjunto de actividades relacionadas al objeto de costo. Para el caso de los restaurantes, es recomendable comenzar desde el momento del abastecimiento y terminar con la cobranza.

- Entradas: Se tiene que hacer la pregunta ¿Qué necesito para desarrollar esta actividad? Para poder identificar todas las entradas de las actividades.

- Salidas: Se tiene que hacer la pregunta ¿Qué es lo que se obtiene de esa actividad? Para poder identificar las salidas de cada actividad.

- Conductor de costo: El cost driver es aquel al que se pueda imputar los costos de una actividad. Cada actividad debe tener un cost driver para poder realizar la repartición de los costos indirectos.

\subsubsection{Recursos}

Es principio del costeo $\mathrm{ABC}$ la idea de que los costos son productos de la ejecución de actividades, y estas, a su vez, consumen recursos. Lo que se tiene que hacer es enlistar todos los recursos que se utilizan para poder realizar las operaciones diarias.

Para este modelo, se propone los siguientes recursos utilizados por una MYPE estándar; lógicamente, el empresario tiene que adaptar la presente lista a su realidad.

Tabla N ${ }^{0} 28$. Descripción de recursos

\begin{tabular}{|c|l|}
\hline Recurso & \multicolumn{1}{|c|}{ Descripción } \\
\hline Mozos & $\begin{array}{l}\text { Persona encargada de brindar } \\
\text { atención constante al cliente. } \\
\text { Apoya en otras actividades. }\end{array}$ \\
\hline Cocineros & $\begin{array}{l}\text { Persona encargada de preparar } \\
\text { los platillos. Apoya en otras } \\
\text { actividades }\end{array}$ \\
\hline Cajera & $\begin{array}{l}\text { Persona encargada de realizar la } \\
\text { cobranza. Apoya en otras } \\
\text { actividades. }\end{array}$ \\
\hline Dueño & $\begin{array}{l}\text { Su papel principal es dirigir la } \\
\text { empresa. Él decide que se } \\
\text { preparará en el día o semana, así } \\
\text { como la cantidad que se va a } \\
\text { comprar. }\end{array}$ \\
\hline Local & $\begin{array}{l}\text { Típicamente, los restaurantes } \\
\text { operan en espacios alquilados. } \\
\text { El local ayuda a llevar a cabo } \\
\text { toda la operación }\end{array}$ \\
\hline
\end{tabular}




\begin{tabular}{|c|l|}
\hline Materias primas e insumos & $\begin{array}{l}\text { Utilizados para la producción de } \\
\text { alimentos }\end{array}$ \\
\hline Transporte & $\begin{array}{l}\text { Típicamente, los restaurantes } \\
\text { cuentan con un pequeño } \\
\text { transporte o alquilan uno para } \\
\text { poder movilizar sus compras. }\end{array}$ \\
\hline
\end{tabular}

\section{Fuente: Elaboración propia}

\subsubsection{Distribución estándar de recursos por actividades}

Una vez que se tiene definido los objetos de costos, los recursos y las actividades, el paso final es asignar cada recurso a la actividad correspondiente. Para realizar esto, se tiene que diseñar una matriz de Actividades y Recursos en el cual, mediante una ponderación porcentual, se describa cuanto del recurso (en unidad de tiempo, capacidad, etc) se utiliza en una determinada actividad.

De esta forma, es más fácil asignar un inductor de costo a los recursos utilizados. A continuación, se presenta el formato de la matriz:

Tabla $N^{\circ} 29$. Formato de matriz de Actividades y Recursos

\begin{tabular}{|c|c|c|c|c|c|c|}
\hline \multirow[b]{2}{*}{ Recursos } & \multirow[b]{2}{*}{ Unidad } & \multicolumn{4}{|c|}{ Actividades } & \multirow[b]{2}{*}{ Total (\%) } \\
\hline & & Act. 1 & Act. 2 & Act. 3 & Act. 4 & \\
\hline Rec. 1 & & & & & & \\
\hline Rec. 2 & & & & & & \\
\hline Rec. 3 & & & & & & \\
\hline Rec. 4 & & & & & & \\
\hline Rec. 5 & & & & & & \\
\hline Rec. 6 & & & & & & \\
\hline Rec. 7 & & & & & & \\
\hline
\end{tabular}

\section{Fuente: Elaboración propia}

A continuación, se muestra la matriz de actividades y recursos manejada para este proceso estándar: 
Tabla No 30. Matriz de Actividades y Recursos para el modelo estándar

\begin{tabular}{|c|c|c|c|c|c|c|c|c|c|c|}
\hline \multirow[b]{2}{*}{ Recursos } & \multirow[b]{2}{*}{ Unidad } & \multicolumn{8}{|c|}{ Actividades } & \multirow[b]{2}{*}{ Total $(\%)$} \\
\hline & & \begin{tabular}{|c|}
$\begin{array}{c}\text { Comprar materias } \\
\text { primas, insumos y } \\
\text { demás }\end{array}$ \\
\end{tabular} & $\begin{array}{c}\text { Transportar } \\
\text { materias primas, } \\
\text { insumos y demás }\end{array}$ & $\begin{array}{c}\text { Preparación } \\
\text { del local }\end{array}$ & $\begin{array}{c}\text { Planificación } \\
\text { de la } \\
\text { preparación }\end{array}$ & \begin{tabular}{|c|} 
Recepción y \\
atención al \\
cliente
\end{tabular} & $\begin{array}{l}\text { Cocinar el } \\
\text { pedido }\end{array}$ & $\begin{array}{c}\text { Entregar el } \\
\text { pedido }\end{array}$ & $\begin{array}{c}\text { Cobrar el } \\
\text { pedido }\end{array}$ & \\
\hline Mozos & Tiempo (Total horas) & $5 \%$ & $7 \%$ & $5 \%$ & - & $75 \%$ & - & $8 \%$ & - & $100 \%$ \\
\hline Cocinero & Tiempo (Total horas) & $5 \%$ & $5 \%$ & $5 \%$ & - & - & $85 \%$ & - & - & $100 \%$ \\
\hline Cajera & Tiempo (Total horas) & $5 \%$ & $5 \%$ & $5 \%$ & - & - & - & - & $85 \%$ & $100 \%$ \\
\hline Dueño & Tiempo (Total horas) & $5 \%$ & $5 \%$ & - & $90 \%$ & - & - & - & - & $100 \%$ \\
\hline Local & $\begin{array}{c}\text { Espacio (Total Metros } \\
\text { cuadrados) }\end{array}$ & - & - & - & - & $30 \%$ & $65 \%$ & - & $5 \%$ & $100 \%$ \\
\hline $\begin{array}{c}\text { Materias } \\
\text { primas e } \\
\text { insumos }\end{array}$ & $\begin{array}{l}\text { Peso (Total } \\
\text { kilogramos) }\end{array}$ & - & - & - & - & - & $100 \%$ & - & - & $100 \%$ \\
\hline Transporte & $\begin{array}{l}\text { Peso (Total } \\
\text { kilogramos) }\end{array}$ & - & $100 \%$ & - & - & - & - & - & - & $100 \%$ \\
\hline
\end{tabular}

\section{Fuente: Elaboración propia}

1. Mozos: Como se observa en la matriz, los mozos consumen el $75 \%$ de su tiempo en lo que es la actividad de Recepción y atención al cliente. Su salario al no ser un costo directo de los objetos de costo, tiene que ser distribuido mediante el cost driver de esta actividad. 
2. Cocinero: El 85\% de su tiempo está destinado a la actividad de Cocinar el pedido. Al trabajar directamente en la preparación de los platillos, su salario es considerado costo directo.

3. Cajera: El $85 \%$ de su tiempo permanece en la actividad Cobrar el pedido. Al no trabajar directamente en la preparación del platillo, su salario será imputado al cost driver de esta actividad.

4. Dueño: El 90\% de su tiempo lo emplea en desempeñar la actividad de Planificación de la producción. Al no participar directamente en la preparación de los platillos, su salario será imputado al cost driver de esta actividad al momento de distribuir costos.

5. Local: El 65\% de la capacidad total del local es empleada para que se pueda desarrollar la actividad de Cocinar el pedido. Al ser su costo uno de carácter indirecto, será imputado al cost driver de esta actividad.

6. Materias primas e insumos: La totalidad de este recurso es destinado a la actividad de Cocinar el pedido. Sin embargo, este insumo y la actividad están relacionadas directamente al objeto de costo. Por lo tanto, su costo es de tipo directo.

7. Transporte: El transporte de la empresa es usado en su totalidad en la actividad Transportar materias primas, insumos y demás, por lo tanto sus costos, los cuales son indirectos, serán imputados a esta actividad.

8. Por lo tanto, se presenta el siguiente cuadro resumen de cada recurso, que participa indirectamente de la fabricación del objeto de costo, la actividad a la cual será asignada y su cost driver: 


\begin{tabular}{|l|l|l|}
\hline \multicolumn{1}{|c|}{ Recurso } & \multicolumn{1}{|c|}{ Actividad } & \multicolumn{1}{c|}{ Cost Driver } \\
\hline Mozos & $\begin{array}{l}\text { Recepción y } \\
\text { atención } \\
\text { cliente }\end{array}$ & Orden de pedido \\
\hline Cajera & Cobrar el pedido & Orden de pedido \\
\hline Dueño & $\begin{array}{l}\text { Planificación de la } \\
\text { preparación }\end{array}$ & Orden de pedido \\
\hline Local & Cocinar el pedido & Orden de pedido \\
\hline Transporte & $\begin{array}{l}\text { Transportar } \\
\text { materias primas, } \\
\text { insumos y demás }\end{array}$ & $\begin{array}{l}\text { Cantidad } \\
\text { adquirida (en kg) }\end{array}$ \\
\hline
\end{tabular}

Fuente: Elaboración propia

\subsubsection{Políticas y consideraciones previas para usar el modelo de costos propuesto}

Antes de poder utilizar o adaptar el modelo de costeo basado en la metodología ABC propuesto, es necesario que el dueño de una MYPE del subsector restaurantes o el encargado de costos tenga en cuenta las siguientes políticas o consideraciones previas para poder adaptar el modelo a su realidad de una forma más precisa y ordenada:

1. Es necesario que la empresa cuenta con un modelo de planeamiento estratégico definido o una política clara sobre la producción de sus platillos de comida, postres o bebidas. En este modelo, las recetas deben estar estandarizadas tanto en cantidad a producir como en tiempo total de preparación. De la misma forma, debe estar estandarizado las cantidades (gramos, mililitros, onzas, etc) que se utilizarán de cada recurso.

2. En caso no tuviera estos puntos definidos, se propone tener en cuenta las siguientes recomendaciones:

- Para el caso de los platillos de comida, es necesario tener una estimación de la cantidad de platillos que se van a vender en un lapso de tiempo (días, semanas o meses) así como su tiempo global de preparación (en minutos) para poder realizar el costeo.

- En el caso de los insumos pequeños, llámese pimienta, comino, etc, al prepararse platillos en volúmenes grandes, se amplían. Por esta razón, se sugiere costear en 
volúmenes grandes para que sus cantidades y costos puedan ser representativas, y se pueda costear de una forma más sencilla.

- En el caso de las bebidas, es necesario que el empresario defina la cantidad de insumos líquidos que se va a utilizar en cada bebida. Se sugiere que sea en mililitros para hacer el costeo más sencillo. Sin embargo, dependiendo de la comodidad del microempresario, se puede calcular, también, en litros.

- Para insumos líquidos, tanto en bebidas como en postres y platillos, es necesario costearlo en mililitros. También puede ser costeado en $\mathrm{Kg}$, sin embargo, se necesitará una tabla de transformación de densidades para poder medir la cantidad y transformar el costo. Otro forma, es utilizando un balanza pequeña y calculando la cantidad (en $\mathrm{Kg}$ ) que se utilizará de cada insumo líquido.

- En el caso de los postres que son comprados, es necesario que se calcule cuantas piezas o porciones se extraerá. Este punto queda a libre determinación del encargado. Sin embargo, otra opción es que adquiera un instrumento, como una DMR, para cortar el postre en porciones iguales. Para el caso de postres redondos, se sugiere realizar cortes que se crucen en el centro y hasta de 8 grados.

- En el caso de las bebidas compradas para la venta directa, se puede utilizar una jarra de medición para estimar cuantas unidades (vasos, copas, etc) se extraerá de una botella.

3. En el caso del agua, solo se costea la cantidad usada en la producción; lo demás es considerado como gasto. El costo unitario se obtiene del recibo de agua.

4. Los CI serán absorbidos por el objeto de costo principal del restaurante: los platillos de comida. Esto se debe a que tanto postres como bebidas son productos alternativos o complementarios del negocio. El único costo indirecto que si puede ser imputado tanto a postres como bebidas sería el costo de transporte siempre y cuando estos dos hayan sido comprados directamente para la venta.

5. Para poder calcular y costear el uso de los insumos líquidos, se sugiere utilizar una garra medidora (en mililitros). De esta forma, será más sencillo saber cuánto se utiliza en cada platillo, postre o bebida.

6. Se recomienda que los indicadores sean trabajados en base a la premisa: cada platillo por mes. Sin embargo, el microempresario puede ajustarlo a su comodidad. 


\subsubsection{Formato estandarizado de costeo ABC}

Con lo planteado en puntos anteriores, se presenta el formato estandarizado de costeo ABC con el cual una MYPE del subsector restaurantes puede calcular sus costos de una forma más real y precisa, tanto para platillos como postres y bebidas. Este formato se encuentra en el Anexo $\mathrm{N}^{0}$ 5, 6, 7, 8 y 9. De igual forma, se presenta un procedimiento para que el dueño de la MYPE pueda utilizar el formato adecuadamente. Este se encuentra en el Anexo $\mathrm{N}^{\mathrm{o}} 10$. 


\section{CAPITULO IV}

El objetivo del presente capítulo es validar cada entregable y cada fuente académica que haya sido utilizada durante la elaboración del presente proyecto de investigación. Además de validar la viabilidad del modelo de costos basado en la hipótesis previa. Esta validación será sostenida mediante el juicio experto de 3 personas: un empresario y dos expertos académicos nacionales. 


\subsection{Validación de los entregables}

Al comienzo del proyecto de investigación se presentó el plan de tesis, en el cual se definió tanto el alcance del proyecto como cada entregable con el que se iba a contar. Cada capítulo del proyecto de tesis cuenta con un número determinado de entregables los cuales serán sometidos a una validación académica o de juicio experto.

En la siguiente tabla se presenta cada indicador de logro por capítulo del presente proyecto de tesis. Cada indicador de logro será validado a lo largo del presente capítulo.

Tabla $N^{o}$ 32. Indicadores de logro

\begin{tabular}{|c|c|}
\hline Capítulo & Indicador de logro \\
\hline Capítulo I & $\begin{array}{l}\text { - Usar un número de artículos académicos no menor de } 25 \text {. } \\
\text { - Usar artículos académicos y/o científicos así como } \\
\text { informes de investigación no mayor a } 10 \text { años de } \\
\text { antigüedad. }\end{array}$ \\
\hline Capítulo II & $\begin{array}{l}\text { - Diagnóstico general de la situación de las MYPE del } \\
\text { subsector restaurantes en Lima Metropolitana. } \\
\text { - Diagnóstico específico del manejo de los costos en las } \\
\text { MYPE del subsector restaurantes en Lima } \\
\text { Metropolitana. }\end{array}$ \\
\hline Capítulo III & $\begin{array}{l}\text { - Mapa de procesos general } \\
\text { - Diagrama interrelacional de procesos } \\
\text { - Mapa de subprocesos de costos } \\
\text { - Diagramas BPMN } \\
\text { - SIPOC Tortuga } \\
\text { - Fichas de indicadores } \\
\text { - Procedimientos }\end{array}$ \\
\hline Capítulo IV & $\begin{array}{l}\text { - Validación de los entregables y las fuentes académicas. } \\
\text { - Validación del modelo de costos propuestos por } 3 \\
\text { expertos en el tema. }\end{array}$ \\
\hline Capítulo V & $\begin{array}{l}\text { - Entregar las conclusiones del proyecto de investigación. } \\
\text { - Entregar las recomendaciones basadas en el proyecto de } \\
\text { investigación. }\end{array}$ \\
\hline
\end{tabular}

Fuente: Elaboración propia 


\subsection{Validación de la bibliografía}

\subsubsection{Validación de entregables del Capítulo I}

Durante la elaboración del Capítulo I del presento proyecto de investigación, se utilizó artículos académicos tanto generales como específicos, referente al modelo de costos, y una cantidad mayor si es que se le agrega las diversas fuentes científicas y de investigación que se han utilizado. Toda esta información que se ha utilizado debe estar con el parámetro de no mayor a 10 años de antigüedad para poder afirmar que el modelo de costos soluciona un problema actual.

A continuación, se presenta una tabla resumen de toda la literatura que se ha utilizado durante la elaboración del Capítulo 1.

Tabla No 33. Resumen de tipos de bibliografía

\begin{tabular}{|l|c|}
\hline \multicolumn{1}{|c|}{ Tipo de bibliografía } & Cantidad \\
\hline Artículos académicos sobre el tema general & 19 \\
\hline Artículos académicos sobre el tema específico & 12 \\
\hline $\begin{array}{l}\text { Informes de instituciones gubernamentales y/o no } \\
\text { gubernamentales }\end{array}$ & 23 \\
\hline Información de páginas web & 25 \\
\hline Libros especializados & 11 \\
\hline Leyes y normaticas & 2 \\
\hline
\end{tabular}

Fuente: Elaboración Propia

\subsubsection{Artículos científicos generales}

Como se mostró en la tabla anterior, el número de artículos científicos sobre el tema general es de 19. A continuación, se presentan todos los artículos generales utilizados, cabe resaltar que cada artículo académico cuenta con una certificación ISSN. 
Tabla $\mathrm{N}^{\circ} 34$. Artículos científicos generales

\begin{tabular}{|c|c|c|c|}
\hline $\mathbf{N}^{0}$ & Bibliografía & ISSN & $\begin{array}{c}\text { Año de } \\
\text { publicación }\end{array}$ \\
\hline 1 & $\begin{array}{l}\text { ABREU, José Luis (2012) Hipótesis, Método \& Diseño de } \\
\text { Investigación, pp. 187-197. En: International Journal of Good } \\
\text { Conscience. México: Facultad de Contaduría Pública y } \\
\text { Administración de la Universidad Autónoma de Nuevo León. }\end{array}$ & $\begin{array}{c}1870- \\
557 X\end{array}$ & 2012 \\
\hline 2 & $\begin{array}{l}\text { RIVERA FLORES, Iván (2012) Microeconomía de la pobreza: el } \\
\text { caso del Perú, pp. 9-52. En: Economía vol. 35, no 69. Lima: } \\
\text { Departamento de Economía de la Pontificia Universidad } \\
\text { Católica del Perú. }\end{array}$ & $\begin{array}{c}0254- \\
4415\end{array}$ & 2012 \\
\hline 3 & $\begin{array}{l}\text { LOAYZA, NORMAN (2008) El crecimiento económico en el } \\
\text { Perú, pp. 9-25. En Revista Económica, vol. 31, no } 61 \text {. } \\
\text { Departamento de Investigación del Banco Mundial. }\end{array}$ & $\begin{array}{c}0254- \\
4415\end{array}$ & 2008 \\
\hline 4 & $\begin{array}{l}\text { CHOY ZEVALLOS, ELSA ESTHER (2010) Competitividad de las } \\
\text { micro y pequeñas empresas (MYPES) ante el tratado de Libre } \\
\text { Comercio (TLC), pp. 127-132. En: Revista Quipukamayoc, vol. } \\
\text { 17, no 33. Lima: Facultad de Ciencias Contables de la } \\
\text { Universidad Nacional Mayor de San Marcos. }\end{array}$ & $\begin{array}{c}1609- \\
8196\end{array}$ & 2010 \\
\hline 5 & $\begin{array}{l}\text { YAMAKAWA, PETER y otros (2010) Modelo tecnológico de } \\
\text { integración de servicio para la Mype Peruana.Lima: ESAN } \\
\text { ediciones (Consulta: Agosto del } 2017 \text { ) } \\
\text { (http://www.esan.edu.pe/publicaciones/2010/10/20/libro\% } \\
\text { 20mype\%201.pdf) }\end{array}$ & $\begin{array}{l}2078- \\
7979\end{array}$ & 2010 \\
\hline 6 & $\begin{array}{l}\text { HERNANI MERINO, Martín y HAMANN PASTORINO, Antonieta } \\
\text { (2012) Percepción sobre el desarrollo sostenible de las MYPE } \\
\text { en el Perú, pp. 290-302. En: RAE- Revista de administración de } \\
\text { empresas, vol. 53, no 3. Sao Paulo. }\end{array}$ & $\begin{array}{c}0034- \\
7590\end{array}$ & 2012 \\
\hline 7 & $\begin{array}{l}\text { MALLAR, Miguel Ángel (2010) La Gestión por Procesos: un } \\
\text { enfoque de gestión eficiente. En: Visión de Futuro, vol. } 13 \text {. } \\
\text { no.1. (http://www.scielo.org.ar/scielo.php?pid=S1668- } \\
\text { 87082010000100004\&script=sci_arttext) (Consulta: Julio del } \\
\text { 2017) }\end{array}$ & $\begin{array}{c}1668- \\
8708\end{array}$ & 2010 \\
\hline 8 & $\begin{array}{l}\text { LLANES-FONT, Mariluz y otros (2014) De la gestión por } \\
\text { procesos a la gestión integrada por procesos, pp. 255-264. En: } \\
\text { Revista de la Facultad de Ingeniería Industrial, vol. 35, no } 3 . \\
\text { Holguín: Universidad de Holguín. }\end{array}$ & $\begin{array}{c}1815- \\
5936\end{array}$ & 2014 \\
\hline 9 & $\begin{array}{l}\text { RUIZ- FUENTES, Daysi y otros (2013) La gestión por procesos, } \\
\text { su surgimiento y aspectos teóricos, pp. 1-11. En: Revista } \\
\text { Ciencias Holguín, vol. 19, no } 4 \text {. Holgín: Centro de Información } \\
\text { y Gestión Tecnológica de Santiago de Cuba. }\end{array}$ & $\begin{array}{l}1027- \\
2127\end{array}$ & 2013 \\
\hline 10 & $\begin{array}{l}\text { LAMAS ABREU, Eduardo y RAMOS PEREZ, Maikel (2011) } \\
\text { Procedimiento para el diseño de un sistema de gestión de } \\
\text { calidad basado en un enfoque de procesos. En: } \\
\text { Contribuciones a la economía. }\end{array}$ & $\begin{array}{c}1696- \\
8360\end{array}$ & 2008 \\
\hline
\end{tabular}




\begin{tabular}{|c|c|c|c|}
\hline 11 & $\begin{array}{l}\text { MOREYRA, Mercedes (2007) Gestión por procesos y su } \\
\text { aplicación en la organización de información de Empresa de } \\
\text { Telecomunicaciones de Cuba, } \\
\text { (http://www.redalyc.org/pdf/1814/181414861002.pdf) } \\
\text { (Consulta: Agosto del } 2017\end{array}$ & $\begin{array}{c}0864- \\
4659\end{array}$ & 2007 \\
\hline 12 & $\begin{array}{l}\text { CUBA BUSTINZA, Elmer (2015) Economía peruana: el corto y } \\
\text { el mediano plazo, pp. 18-25. En: Revista Argumentos, vol. 1, } \\
\text { no 1. Lima: Instituto de Estudios Peruanos }\end{array}$ & $\begin{array}{l}2076- \\
7722\end{array}$ & 2015 \\
\hline 13 & $\begin{array}{l}\text { ORGANIZACIÓN PARA LA COOPERACIÓN Y EL DESARROLLO } \\
\text { ECONÓMICOS (OCDE)/ COMISIÓN ECONÓMICA PARA } \\
\text { AMÉRICA LATINA Y EL CARIBE (CEPAL) (2013) Perspectivas } \\
\text { económicas de América Latina 2013. Políticas de PYMES para } \\
\text { el Cambio Estructural (Consulta: } 12 \text { de Marzo del 2015) } \\
\text { (http://repositorio.cepal.org/bitstream/handle/11362/1463/ } \\
\text { S2012083 es.pdf?sequence=1 }\end{array}$ & $\begin{array}{c}2072- \\
5191\end{array}$ & 2013 \\
\hline 14 & $\begin{array}{l}\text { VERDERA RIBAS, Francisco (2007) La pobreza en el Perú: Un } \\
\text { análisis de sus causas y de las políticas para enfrentarla. Lima: } \\
\text { Fondo Editorial de la Pontificia Universidad Católica del Perú. }\end{array}$ & $\begin{array}{l}1019- \\
4509\end{array}$ & 2007 \\
\hline 15 & $\begin{array}{l}\text { GARCIA-VEGA, Emilio Humberto (2011) Competitividad en el } \\
\text { Perú: diagnóstico, sectores a priorizar y lineamientos a seguir } \\
\text { para el período 2011-2016, pp. 112-141. En: Revista Journal, } \\
\text { vol. 5, no 1. Georgetown: Georgetown University. }\end{array}$ & $\begin{array}{l}1988- \\
7116\end{array}$ & 2011 \\
\hline 16 & $\begin{array}{l}\text { LLAMAS ARÉCHIGA, Beatriz y otros (2014) Elementos que } \\
\text { promueven competitividad en las PYMES, un estudio general, } \\
\text { pp. 1-20. En: Revista de Investigación Académica sin Frontera, } \\
\text { año 7, no. 19. Sonora: Universidad de Sonora. }\end{array}$ & $\begin{array}{l}2007- \\
8870\end{array}$ & 2014 \\
\hline 17 & $\begin{array}{l}\text { HERRERA GARCIA, Beatriz (2011) Análisis estructural de las } \\
\text { MYPEs y PYMEs, pp. 69-89. En: Revista Quipukamayoc. Lima: } \\
\text { Facultad de Ciencias Contables. }\end{array}$ & $\begin{array}{l}1560- \\
9103\end{array}$ & 2011 \\
\hline 18 & $\begin{array}{l}\text { ARMESTÁR, Narciso (2013) De la Micro competitividad a la } \\
\text { competitividad nacional. En: Repositorio académico de la } \\
\text { Universidad Peruana de Ciencias Aplicadas. }\end{array}$ & $\begin{array}{l}2306- \\
6431\end{array}$ & 2013 \\
\hline 19 & $\begin{array}{l}\text { TORRES, Carlos Alonso (2014) Orientaciones para } \\
\text { implementar una gestión basada en procesos, pp. 159-171 } \\
\text { En: Revista de Ingeniería Industrial, vol XXXV no 2. Chile: } \\
\text { Universidad del Bio Bio. }\end{array}$ & $\begin{array}{c}1815- \\
5936\end{array}$ & 2014 \\
\hline
\end{tabular}

\section{Fuente: Elaboración propia}

\subsubsection{Artículos científicos específicos}

Independientemente de la cantidad de artículos académicos generales, el proyecto de investigación cuenta con una cantidad de 12 artículos académicos cuyo tema central son los costos. A continuación, se presenta la siguiente tabla de artículos indexados. 
Tabla $\mathrm{N}^{\mathrm{o}} 35$. Artículos científicos específicos

\begin{tabular}{|c|c|c|c|}
\hline $\mathbf{N}^{\circ}$ & Bibliografía & ISSN & $\begin{array}{c}\text { Año de } \\
\text { publicación }\end{array}$ \\
\hline 1 & $\begin{array}{l}\text { CHOY ZEVALLOS, Elsa Esther (2012) El dilema de los costos en } \\
\text { las empresas de servicios, pp.7-14. En: Revista Académica } \\
\text { Quipukamayoc, vol. 20, no 37. Lima: Facultad de Ciencias } \\
\text { Contables de la Universidad Nacional Mayor de San Marcos. }\end{array}$ & $\begin{array}{c}1560- \\
9103\end{array}$ & 2012 \\
\hline 2 & $\begin{array}{l}\text { SÁNCHEZ BARRAZA, Bernardo (2009) Problemática de } \\
\text { conceptos de costos y clasificación de costos, pp. 95-104. En: } \\
\text { Revista Académica Quipukamayoc, vol. 16, no 32. Lima: } \\
\text { Facultad de Ciencias Contables de la Universidad Nacional } \\
\text { Mayor de San Marcos. }\end{array}$ & $\begin{array}{c}1560- \\
9103\end{array}$ & 2009 \\
\hline 3 & $\begin{array}{l}\text { SÁNCHEZ BARRAZA, Bernando (2013) Implicancias del } \\
\text { método de costeo ABC, PP. 65-73. En: Revista Académica } \\
\text { Quipukamayoc, vol. 21, no 39. Lima: Facultad de Ciencias } \\
\text { Contables de la Universidad Nacional Mayor de San Marcos. }\end{array}$ & $\begin{array}{c}1560- \\
9103\end{array}$ & 2013 \\
\hline 4 & $\begin{array}{l}\text { GAVELÁN IZAGUIRRE, Jorge Jesús (2014) Sistema de costos en } \\
\text { MYPES industriales y de servicios en condiciones de } \\
\text { desorganización, pp. 121-134. En: Revista Académica } \\
\text { Quipukamayoc, vol. 22, no 41. Lima: Facultad de Ciencias } \\
\text { Contables de la Universidad Nacional Mayor de San Marcos. }\end{array}$ & $\begin{array}{c}1560- \\
9103\end{array}$ & 2014 \\
\hline 5 & $\begin{array}{l}\text { BUSTAMANTE SALAZAR, Alina Marcela (2015) Costeo basado } \\
\text { en actividades - ABC: Revisión de literatura, pp. 109-119. En: } \\
\text { Revista CEA, vol. 1, no 1. Medellín: Facultad de Ciencias } \\
\text { Económicas y Administrativas del Instituto Tecnológico } \\
\text { Metropolitano. }\end{array}$ & $\begin{array}{c}2390- \\
0725\end{array}$ & 2015 \\
\hline 6 & $\begin{array}{l}\text { CARRIÓN NIN, José (2005) Pautas básicas para una } \\
\text { implantación exitosa del Costeo Basado en Actividades (ABC), } \\
\text { pp. 47-52. En: Revista de la Facultad de Ingeniería Industrial, } \\
\text { vol. 8, no 1. Lima: Facultad de Ingeniería Industrial de la } \\
\text { Universidad Nacional Mayor de San Marcos. }\end{array}$ & $\begin{array}{c}1560- \\
9146\end{array}$ & 2005 \\
\hline 7 & $\begin{array}{l}\text { ESCOBAR CUELLO, JOSE (2009) El costeo por actividades, pp. } \\
\text { 79-83. En: Dictamen Libre, ed. } 5 \text {. Barranquilla: Universidad } \\
\text { Libre }\end{array}$ & $\begin{array}{l}\text { 0124- } \\
0099\end{array}$ & 2009 \\
\hline 8 & $\begin{array}{l}\text { VERGIÚ CANTO, Jorge (2005) Rentabilidad del producto } \\
\text { mediante el costeo basado en actividades. Caso en el sector } \\
\text { industrial, pp. 42-46. En: Revista de la Facultad de Ingeniería } \\
\text { Industrial, vol. 8, no 1. Lima: Facultad de Ingeniería Industrial } \\
\text { de la Universidad Nacional Mayor de San Marcos. }\end{array}$ & $\begin{array}{c}1560- \\
9146\end{array}$ & 2005 \\
\hline 9 & $\begin{array}{l}\text { VACA LÓPEZ, Andrea (2012) Los sistemas de costeo: bases y } \\
\text { metodologías, pp. 01-10. Armenia: Grupo de investigación } \\
\text { para la competitividad empresarial de la Corporación } \\
\text { Universitaria Empresarial Alexander von Humboldt. }\end{array}$ & $\begin{array}{c}2339- \\
3084\end{array}$ & 2012 \\
\hline
\end{tabular}




\begin{tabular}{|l|l|c|c|}
10 & $\begin{array}{l}\text { CHACÓN, Galia (2007) La contabilidad de costos, los sistemas } \\
\text { de control de gestión y la rentabilidad empresarial, pp. 29-45. } \\
\text { En: Revista Actualidad Contable Faces, vol 10 no 15. } \\
\text { Venezuela: Universidad de los Andes. }\end{array}$ & $\begin{array}{c}1316- \\
8533\end{array}$ & 2007 \\
\hline 11 & $\begin{array}{l}\text { DUQUE ROLDÁN, María Isabel y Osorio Agudelo, Jair Alberto } \\
\begin{array}{l}\text { (2013) Estado actual de la investigación en costos y } \\
\text { contabilidad de gestión en Colombia. En: Revista del Instituto } \\
\text { Internacional de Costos. }\end{array}\end{array}$ & $\begin{array}{l}1646- \\
6896\end{array}$ & 2013 \\
\hline 12 & $\begin{array}{l}\text { OCAMPO HERNÁNDEZ, Ana Milena (2011) Costos ABC. Una } \\
\text { concepción sistémica formal, pp. 73-96. En: Contraduría } \\
\text { Universidad de Antioquía. }\end{array}$ & $0120-$ & 2011 \\
\hline
\end{tabular}

\section{Fuente: Elaboración propia}

\subsubsection{Leyes y normativas de la República del Perú}

Debido a que el proyecto centra su investigación en la República del Perú, ha sido necesario utilizar algunas leyes que sirvan como marco legal. A continuación, se presentan las leyes utilizadas en el presente trabajo.

Tabla No 36. Leyes y normativas de la República del Perú

\begin{tabular}{|c|c|c|}
\hline $\mathbf{N}^{\circ}$ & \multicolumn{1}{|c|}{ Bibliografía } & $\begin{array}{c}\text { Año de } \\
\text { publicación }\end{array}$ \\
\hline 1 & $\begin{array}{l}\text { PERÚ. Congreso de la República (2013) Decreto de } \\
\text { ley 30056: ley que modifica diversas leyes para } \\
\text { facilitar la inversión, impulsar el desarrollo } \\
\text { productivo y el crecimiento empresarial. }\end{array}$ & 2013 \\
\hline 2 & $\begin{array}{l}\text { PERÚ. Congreso de la República (2003) Decreto de } \\
\text { ley 28015: ley de promoción y formalización de la } \\
\text { micro y pequeña empresa. }\end{array}$ & 2003 \\
\hline
\end{tabular}

\section{Fuente: Elaboración propia}

\subsubsection{Información de páginas web}

La era de la tecnología obliga al investigador a usar información y fuentes de datos que se encuentran en la red. Esta investigación no es ajena a esta tendencia, mas se mantiene el concepto de que la información de la red debe ser válida y sostenible. 
Tabla $\mathrm{N}^{\mathrm{o}} 37$. Información de páginas web

\begin{tabular}{|c|c|c|}
\hline $\mathbf{N}^{\circ}$ & Bibliografía & $\begin{array}{c}\text { Año de } \\
\text { publicación }\end{array}$ \\
\hline 1 & $\begin{array}{l}\text { UNIVERSIDAD DE } \quad \text { SONORA } \quad \text { (2015) } \text { Muestreo. } \\
\text { (http://www.estadistica.mat.uson.mx/Material/elmuestreo.pdf) } \\
\text { (Consulta: Junio 2017) }\end{array}$ & 2015 \\
\hline 2 & $\begin{array}{l}\text { DIARIO GESTIÓN (2017) La pobreza en Perú disminuiría a } 14 \% \text { si se } \\
\text { ejecutan proyectos } \quad \text { mineros en } \quad \text { cartera. } \\
\text { (http://gestion.pe/economia/pobreza-peru-disminuiria-14-si-se- } \\
\text { ejecutan-proyectos-mineros-cartera-2194811) (Consulta: Julio del 2017) }\end{array}$ & 2017 \\
\hline 3 & $\begin{array}{l}\text { Diario Perú } 21 \text { (2017) Pobreza extrema en el Perú cayó 0.3\% en 2016, } \\
\text { según el INEl. (http://peru21.pe/economia/pobreza-extrema-peru-cayo- } \\
\text { 03-2016-segun-inei-2281148) (Consulta: Mayo del 2017) }\end{array}$ & 2017 \\
\hline 4 & $\begin{array}{l}\text { DIARIO EL COMERCIO (2017) La corrupción es el principal freno al } \\
\text { desarrollo del } \\
\text { (http://archivo.elcomercio.pe/politica/gobierno/corrupcion-principal- } \\
\text { freno-al-desarrollo-peru-noticia-625122) (Consulta: Agosto del 2017) }\end{array}$ & 2017 \\
\hline 5 & $\begin{array}{l}\text { DIARIO PERU } 21 \text { (2017) La corrupción es el principal problema del Perú, } \\
\text { según INEI. (http://peru21.pe/economia/inei-corrupcion-principal- } \\
\text { problema-peru-2285342) (Consulta: Julio del 2017) }\end{array}$ & 2017 \\
\hline 6 & $\begin{array}{l}\text { MINISTERIO DE ECONOMÍA Y FINANZAS (2015) Conoce los conceptos } \\
\text { básicos para entender la economía peruana. } \\
\text { (http://www.mef.gob.pe/index.php?option=com_content\&view=article } \\
\text { \&id=61\%3Aconoce-los-conceptos-basicos-para-comprender-la- } \\
\text { economia-del-pais\&Itemid=100694\&lang=es) (Consulta: Agosto del } \\
\text { 2017) }\end{array}$ & 2015 \\
\hline 7 & $\begin{array}{l}\text { DIARIO EL COMERCIO (2014) ¿Por qué es importante que el PBI no caiga? } \\
\text { (http://elcomercio.pe/economia/peru/que-importante-que-pbi-no- } \\
\text { caiga-noticia-1743202) (Consulta: Agosto del 2017) }\end{array}$ & 2014 \\
\hline 8 & $\begin{array}{l}\text { DIARIO GESTIÓN (2017) } \mathrm{FMI} \text { elevó proyección de crecimiento de } \\
\text { economía peruana de } 4.1 \% \text { a } 4.3 \% \text { el } 2017 . \\
\text { (http://gestion.pe/economia/fmi-elevo-proyeccion-crecimiento- } \\
\text { economia-peruana-41-43-2017-2180315) (Consulta: Julio del 2017) }\end{array}$ & 2017 \\
\hline 9 & $\begin{array}{l}\text { DIARIO GESTIÓN (2017) FMI reduce a 3.5\% su proyección de crecimiento } \\
\text { económico de Perú para el 2017. (http://gestion.pe/economia/fmi- } \\
\text { reduce-35-su-proyeccion-crecimiento-economico-peru-2017-2187626) } \\
\text { (Consulta: Julio del 2017) }\end{array}$ & 2017 \\
\hline 10 & $\begin{array}{l}\text { DIARIO EL COMERCIO (2017) FMI reduce a 2,7\% su proyección de } \\
\text { crecimiento del Perú para 2017. (http://elcomercio.pe/economia/fmi- } \\
\text { ajusta-baja-proyeccion-crecimiento-peru-2017-426175) (Consulta: Julio } \\
\text { del 2017) }\end{array}$ & 2017 \\
\hline 11 & $\begin{array}{l}\text { DIARIO EL COMERCIO (2017) FMI: Destrabes de Línea } 2 \text { y Jorge Chávez se } \\
\text { incluirían en nuevo pronóstico de PBI. } \\
\text { (http://elcomercio.pe/economia/peru/fmi-destrabes-linea-2-jorge- } \\
\text { chavez-incluirian-nuevo-pronostico-pbi-noticia-448222) } \\
\text { Agosto del 2017) }\end{array}$ & 2017 \\
\hline
\end{tabular}




\begin{tabular}{|c|c|c|}
\hline 12 & $\begin{array}{l}\text { DIARIO EL COMERCIO (2015) Estos son los } 10 \text { mayores grupos } \\
\text { económicos del Perú. (http://elcomercio.pe/economia/peru/estos-son- } \\
\text { 10-mayores-grupos-economicos-peru-noticia-1837508) (Consulta: Mayo } \\
\text { del 2017) }\end{array}$ & 2015 \\
\hline 13 & $\begin{array}{l}\text { VILLARÁN, Fernando (2008) Recopilación de diapositivas titulada } \\
\text { Contribución de las MYPEs al empleo decente y al desarrollo sostenible. } \\
\text { (http://www.peru2021.org/repositorioaps/0/0/par/xiisimpfernandovilla } \\
\text { ran/simposio2008_fernandovillaran.pdf) (Consulta: Julio del 2017) }\end{array}$ & 2008 \\
\hline 14 & $\begin{array}{l}\text { ZEVALLOS, Emilio (2003) } \text { Micro, pequeñas y medianas empresas en } \\
\text { América Latina, pp. } 55 . \quad \text { En: revista CEPAL } \quad N^{\circ} 79 \\
\text { (http://www.alide.org/DataBank2007/Reclnformation/3APP_Enterprise } \\
\text { /51MicroPYMRZevallos.pdf) }\end{array}$ & 2003 \\
\hline 15 & $\begin{array}{l}\text { SÁNCHEZ BARRAZA, Bernando (2006) Las MYPES en Perú. Su importancia } \\
\text { y propuesta tributaria. En: Revista Académica Quipukamayoc, vol. 13, no. } \\
25 .\end{array}$ & 2006 \\
\hline 16 & $\begin{array}{l}\text { DIARIO OFICIAL EL PERUANO (2015) La fuerza de las pymes Lima,2015. } \\
\text { (http://www.elperuano.com.pe/edicion/noticia-la-fuerza-las-pymes- } \\
\text { 8257.aspx\#.VSy1IJM1E4I) (Consulta: Junio del 2017) }\end{array}$ & 2015 \\
\hline 17 & 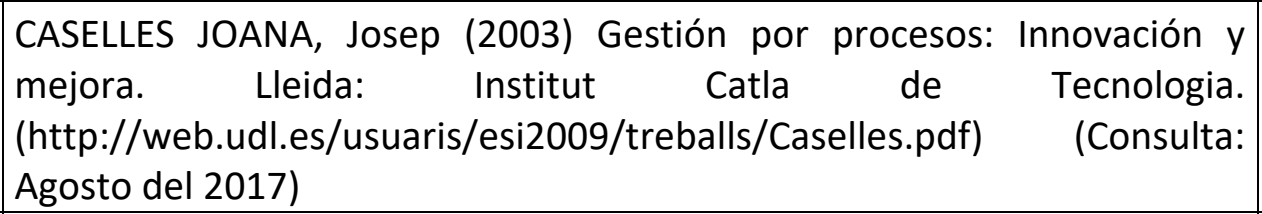 & 2003 \\
\hline 18 & $\begin{array}{l}\text { ADVANCED INTEGRATED TECHNOLOGIES GROUP INCORPORATED (2005) } \\
\text { SIPOC. (https://genesisyhwh.files.wordpress.com/2011/06/05-sipoc.pdf) } \\
\text { (Consulta: Agosto del 2017) }\end{array}$ & 2005 \\
\hline 19 & $\begin{array}{l}\text { SOCIEDAD LATINOAMERICANA PARA LA CALIDAD (2000) Diagrama de } \\
\text { Flujo (Flow Chart). (http://www.valoryempresa.com/archives/flow.pdf) } \\
\text { (Consulta: Agosto del 2017) }\end{array}$ & 2000 \\
\hline 20 & $\begin{array}{l}\text { UNIVERSIDAD VERACRUZANA (2013) Clasificación de los costos. } \\
\text { (http://www.uv.mx/personal/alsalas/files/2013/02/CLASIFICACION-DE- } \\
\text { LOS-COSTOS.pdf) (Consulta: Agosto del 2017)) }\end{array}$ & 2013 \\
\hline 21 & $\begin{array}{l}\text { UNIVERSIDAD MICHOACANA DE SAN NICOLAS DE HIDALGO (2013) } \\
\text { Sistemas de costos y contabilidad de costos industriales. } \\
\text { (http://www.fcca.umich.mx/coordinaciones/ceneval/archivos/2013_gui } \\
\text { as/CONTA/Costos.pdf) (Consulta: Agosto del 2017) }\end{array}$ & 2013 \\
\hline 22 & $\begin{array}{l}\text { BELLIDO SANCHEZ, Pedro Alberto (2003) Costos ABC. Lima: Pacífico } \\
\text { Editores. }\end{array}$ & 2003 \\
\hline 23 & $\begin{array}{l}\text { DIARIO GESTION (2017) Aumenta número de microempresas peruanas, } \\
\text { pero aún no es momento de alegrarse. } \\
\text { (http://gestion.pe/economia/aumenta-numero-mypes-peruanas-aun- } \\
\text { no-momento-alegrarse-2197184) (Consulta: Agosto del 2017) }\end{array}$ & 2017 \\
\hline
\end{tabular}




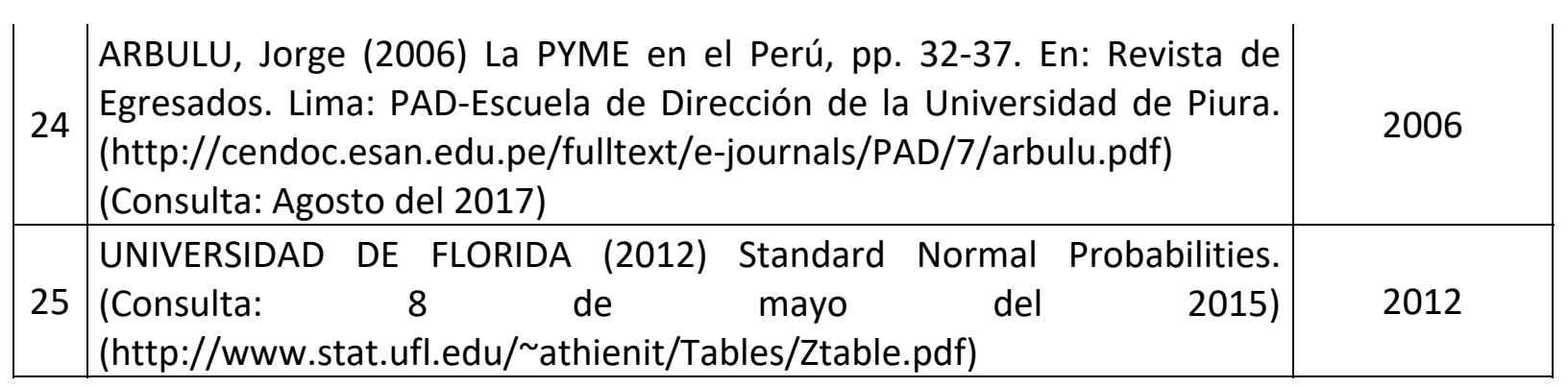

\section{Fuente: Elaboración propia}

\subsubsection{Información de entidades gubernamentales y no gubernamentales}

Para el desarrollo de la presente investigación se utilizó información y datos proporcionados por entidades gubernamentales como el INEI, Ministerio de Trabajo, CEDAL, ONU, Banco Mundial, etc. A continuación, se presenta una recopilación de todas las fuentes bibliográficas gubernamentales y no gubernamentales.

Tabla $\mathrm{N}^{\mathrm{o}}$ 38. Información de entidades gubernamentales y no gubernamentales

\begin{tabular}{|c|c|c|}
\hline $\mathbf{N}^{\circ}$ & Bibliografía & $\begin{array}{c}\text { Año de } \\
\text { publicación }\end{array}$ \\
\hline 1 & $\begin{array}{l}\text { INSTITUTO NACIONAL DE ESTADÍSTICA E INFORMÁTICA (2017) Evolución } \\
\text { de } \quad \text { la } \\
\text { (https://www.inei.gob.pe/media/cifras_de_pobreza/pobreza2016.pdf) } \\
\text { (Consulta: Mayo del 2017) }\end{array}$ & 2017 \\
\hline 2 & $\begin{array}{l}\text { INSTITUTO PERUANO DE } \quad \text { ECONOMIA } \quad \text { (2011) Glosario. } \\
\text { (http://www2.congreso.gob.pe/sicr/cendocbib/con4_uibd.nsf/C9C832F } \\
\text { 9AFEB7F4D05257BE3006F64D1/\$FILE/129129491-glosario-pdf.pdf) } \\
\text { (Consulta: Mayo del 2017) }\end{array}$ & 2011 \\
\hline 3 & 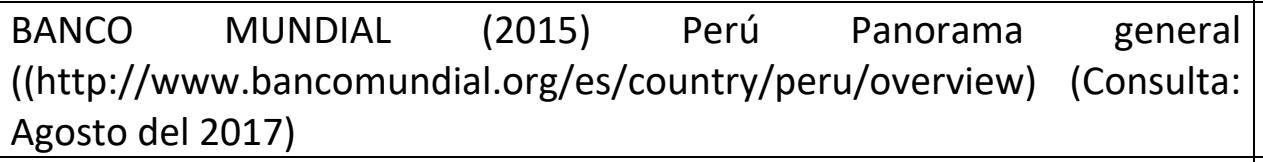 & 2015 \\
\hline 4 & 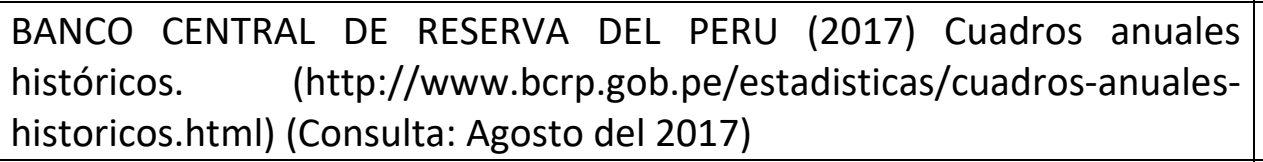 & 2017 \\
\hline 5 & $\begin{array}{l}\text { INSTITUTO NACIONAL DE ESTADÍSTICA E INFORMÁTICA (2017) } \\
\text { Comportamiento de la Economía Peruana en el Primer Trimestre de 2017. } \\
\text { (https://www.inei.gob.pe/media/MenuRecursivo/boletines/02-informe- } \\
\text { tecnico-n02_producto-bruto-interno-trimestral-2017i.pdf) (Consulta: } \\
\text { Agosto del 2017) }\end{array}$ & 2017 \\
\hline 6 & $\begin{array}{l}\begin{array}{l}\text { INSTITUTO PERUANO DE ECONOMÍA (2014) Sectores } \\
\text { (http://www.ipe.org.pe/content/sectores-productivos) }\end{array} \\
\text { Agosto del 2017) }\end{array}$ & 2014 \\
\hline
\end{tabular}


INSTITUTO NACIONAL DE ESTADÍSTICA E INFORMÁTICA (2017) Comportamiento de la Economía Peruana en el Cuarto Trimestre de 2016

7 (https://www.inei.gob.pe/media/MenuRecursivo/boletines/01-informetecnico-n01_producto-bruto-interno-trimestral-2016iv.PDF) (Consulta: Mayo 2017) MINISTERIO DE LA PRODUCCIÓN (2017) Las MIPYME en cifras 2015. Lima:

8 Oficina General de Evaluación de Impacto y Estudios Económicos. (http://demi.produce.gob.pe/images/publicaciones/publi09f3585ea5d4 c9eb9_27.pdf) (Consulta: Agosto del 2017)

MINISTERIO DE LA PRODUCCIÓN (2017) Estudio de la situación actual de las empresas peruanas. Lima: Oficina General de Evaluación de Impacto y

9 Estudios Económicos.

(http://demi.produce.gob.pe/images/publicaciones/publi81171136fe74 561a7_79.pdf) (Consulta: Agosto del 2017)

MINISTERIO DE LA PRODUCCIÓN (2016) Anuario estadístico industrial, $\begin{array}{llll}\text { MYPE } & Y & \text { comercio } & \\ & & \end{array}$

10 (http://www.produce.gob.pe/documentos/estadisticas/anuarios/anuari o-estadistico-mype-2015.pdf) (Consulta: Mayo del 2017)

MINISTERIO DE LA PRODUCCIÓN (2013) Anuario estadístico industrial, $\begin{array}{llll}\text { MYPE } & Y & \text { comercio } & 2012\end{array}$

11 (http://www.produce.gob.pe/documentos/estadisticas/anuarios/anuari o-estadistico-2012.pdf) (Consulta: Mayo del 2017)

ASOCIACION DE EMPRENDEDORES DEL PERU (2015) MYPES aportan el

12 40\% del PBI (https://asep.pe/mypes-aportan-el-40-del-pbi/) (Consulta: Mayo del 2017)

AGENCIA DE PROMOCIÓN DE LA INVERSIÓN PRIVADA (2006) MYPEqueña

13 empresa crece: Guía para el desarrollo de la micro y pequeña empresa. Proinversión - Esan.

CEDAL (2010) Planes de Desarrollo de Emprendedores y Microempresarios de Subsistencia de los Sub-Sectores de Confecciones

14 Textiles, Artesanía en Tejidos Textiles y Artesanía en Joyas. (http://cedalperu.org/wp-content/uploads/2013/03/planes-dedesarrollo-de-emprendedores-y-microempresarios.pdf) (Consulta: Julio del 2017)

ORGANIZACIÓN INTERNACIONAL PARA LA ESTANDARIZACIÓN (2008) Conjunto de documentos para la introducción y el Soporte de la serie de normas ISO 9000: Orientación sobre el Concepto y Uso del Enfoque

15 basado en procesos para los sistemas de gestión. Madrid 2008 (http://www.inlac.org/Doc/Doc_ISO-TS-

176_04_11/N544R3_Orientacion_sobre_el_Concepto_Enfoque_basado _procesos.pdf) ORGANIZACIÓN INTERNACIONAL PARA LA ESTANDARIZACIÓN (2005) Sistemas de gestión de la calidad-Fundamentos y vocabulario. Ginebra: 


\begin{tabular}{|c|c|c|}
\hline 17 & \begin{tabular}{|l} 
INSTITUTO NACIONAL DE ESTADÍSTICA E INFORMÁTICA (2017) Principales \\
indicadores \\
(https://www.inei.gob.pe/estadisticas/indice-tematico/economia/) \\
(Consulta: Agosto del 2017)
\end{tabular} & 2017 \\
\hline 18 & 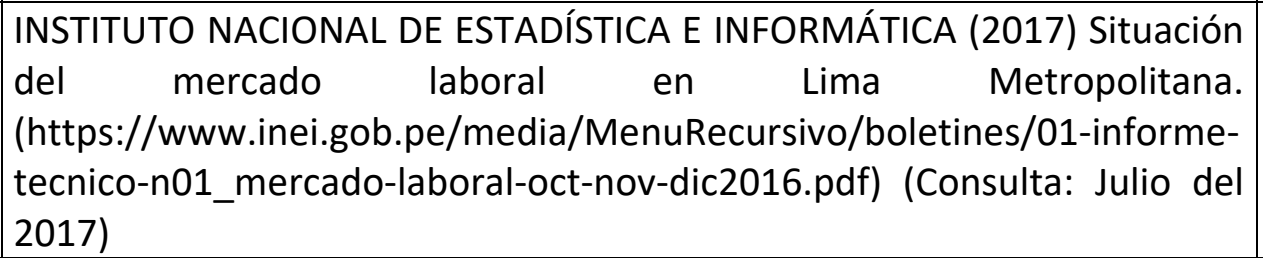 & 2017 \\
\hline 19 & $\begin{array}{l}\text { INSTITUTO NACIONAL DE ESTADÍSTICA E INFORMÁTICA (2014) Análisis de } \\
\text { la estructura empresarial de Lima Metropolitana, pp. 97-103. } \\
\text { (https://www.inei.gob.pe/media/MenuRecursivo/publicaciones_digitale } \\
\text { s/Est/Lib1262/cap04.pdf) (Consulta: Agosto del 2017) }\end{array}$ & 2014 \\
\hline 20 & $\begin{array}{|lr|}\text { INSTITUTO NACIONAL DE ESTADÍSTICA E INFORMÁTICA (2016) Perú: } & \text { empresarial } \\
\text { Estructura } & \text { empral } \\
\text { (http://www.inei.gob.pe/media/MenuRecursivo/publicaciones_digitales } \\
\text { /Est/Lib1382/index.html) (Consulta: Agosto del 2017) }\end{array}$ & 2016 \\
\hline 21 & $\begin{array}{l}\text { INSTITUTO NACIONAL DE ESTADÍSTICA E INFORMÁTICA (2017) } \\
\text { mencuesta } \\
\text { (https://www.inei.gob.pe/media/MenuRecursivo/boletines/boletin- } \\
\text { estadistico-del-sector-servicios-n-02-febrero-2017.pdf) } \\
\begin{array}{l}\text { Agosto del 2017) } \\
\text { (Consulta: }\end{array}\end{array}$ & 2017 \\
\hline 22 & \begin{tabular}{|lrr} 
INSTITUTO NACIONAL DE ESTADÍSTICA E INFORMÁTICA & (2017) \\
nacional & naducción \\
(https://www.inei.gob.pe/media/principales_indicadores/02-informe- \\
tecnico-n02_produccion-nacional-dic2016.pdf) (Consulta: Julio del 2017)
\end{tabular} & 2017 \\
\hline 23 & $\begin{array}{l}\text { SUPERINTENDENCIA NACIONAL DE ADMINISTRACIÓN TRIBUTARIA (2004) } \\
\text { Ley del impuesto a la la renta. Capítulo IX. } \\
\text { (http://www.sunat.gob.pe/legislacion/renta/regla/cap9.htm) (Consulta: } \\
\text { Marzo 2018) }\end{array}$ & 2004 \\
\hline
\end{tabular}

\section{Fuente: Elaboración propia}

\subsubsection{Libros especializados}

Como desde épocas antiguas, los libros siguen siendo una de las principales fuentes de conocimientos e investigación. Este proyecto no es ajeno a este pensamiento; a continuación, se presenta los libros que se utilizaron para justificar diversos pasajes de la investigación. 
Tabla No 39. Libros especializados

\begin{tabular}{|c|c|c|}
\hline $\mathbf{N}^{\circ}$ & Bibliografía & $\begin{array}{c}\text { Año de } \\
\text { publicación }\end{array}$ \\
\hline 1 & $\begin{array}{l}\text { HERNÁNDEZ SAMPIERI, Roberto, FERNÁNDEZ COLLADO, Carlos y } \\
\text { BAPTISTA LUCIO, María del Pilar (2010) Metodología de la investigación. } \\
\text { 5ta.ed. México D.F.: McGraw-Hill. }\end{array}$ & 2010 \\
\hline 2 & $\begin{array}{l}\text { CRESWELL, John (2003) Research Design: Qualitative, Quantitative, and } \\
\text { Mixed Methods Approaches. Editorial: SAGE Publications. Estados } \\
\text { Unidos, 2003. }\end{array}$ & 2003 \\
\hline 3 & $\begin{array}{l}\text { FERRARO, Carlo (2011) Apoyando a las pymes: Políticas de fomento en } \\
\text { América } \quad \text { Latina } \\
\text { (http://repositorio.cepal.org/bitstream/handle/11362/35359/S1100762 } \\
\text { _es.pdf?sequence=1) (Consulta: Julio del 2017) }\end{array}$ & 2011 \\
\hline 4 & $\begin{array}{l}\text { HOFFMAN, Douglas y Bateson, John (2012) Marketing de servicios. } \\
\text { Conceptos, estrategias y casos. 4ta. ed. South-Western. }\end{array}$ & 2012 \\
\hline 5 & $\begin{array}{l}\text { KRAJEWSKI, Lee; RITZMAN, Larry y MALHOTRA, Manoj (2008) Procesos y } \\
\text { cadenas de valor. 8va ed. México: Pearson Educación }\end{array}$ & 2008 \\
\hline 6 & $\begin{array}{l}\text { PEREZ, Jorge; RUIZ, Jairo y PARRA, Carlos (2007) Uso del enfoque por } \\
\text { procesos en la actividad investigativa, pp. 260-269. En: Ingeniare, vol.3. }\end{array}$ & 2007 \\
\hline 7 & PEREZ, José (2010) Gestión por procesos 4ta ed. Madrid: ESIC Editorial & 2010 \\
\hline 8 & $\begin{array}{l}\text { GRANERO CASTRO, Javier y FERRANDO SÁNCHEZ, Miguel (2005) Calidad } \\
\text { total: Modelo EFQM para la excelencia. Madrid: Fundación Confemetal. }\end{array}$ & 2005 \\
\hline 9 & $\begin{array}{l}\text { HERNANDEZ, Alejandro (2002) Gestión por procesos, pp. 4. En: Industrial, } \\
\text { vol. } \quad 24 . \quad \text { no. } \\
\text { (http://www.google.com/url?sa=t\&rct=j\&q=\&esrc=s\&source=web\&cd= } \\
\text { 2\&ved=0CCIQFjAB\&url=http\%3A\%2F\%2Fdialnet.unirioja.es\%2Fdescarga } \\
\text { \%2Farticulo\%2F4786734.pdf\&ei=xco9VeKZlobAggTXnYDoCg\&usg=AFQjC } \\
\text { NFq6v_h1uJAKVPpKcGhx9nCOYtOQg\&bvm=bv.91665533,d.eXY) } \\
\text { (Consulta: Agosto del 2017) }\end{array}$ & 2002 \\
\hline 10 & $\begin{array}{l}\text { HORNGREN, Charles, DATAR, Srikant y RAJAN, Madhav (2012) } \\
\text { Contabilidad de costos. 14ta.ed. México: Pearson Educación. }\end{array}$ & 2012 \\
\hline 11 & $\begin{array}{l}\text { GARCIA SUAREZ, José Luis (2012) Cálculo, análisis y gestión de costes: } \\
\text { Guía práctica para su aplicación en la empresa. 2da ed. Delta } \\
\text { Publicaciones }\end{array}$ & 2012 \\
\hline
\end{tabular}

\section{Fuente: Elaboración propia}




\subsubsection{Estadísticos}

Como está especificado en el Plan de Tesis, se estipula que las referencias bibliográficas no deben de ser mayores a los 10 años de antigüedad (se toma al año 2017 como base), a continuación, se presenta los estadísticos de los años de antigüedad de la bibliografía que compone este proyecto de investigación.

Ilustración $\mathrm{N}^{\circ}$ 53. Año de publicación

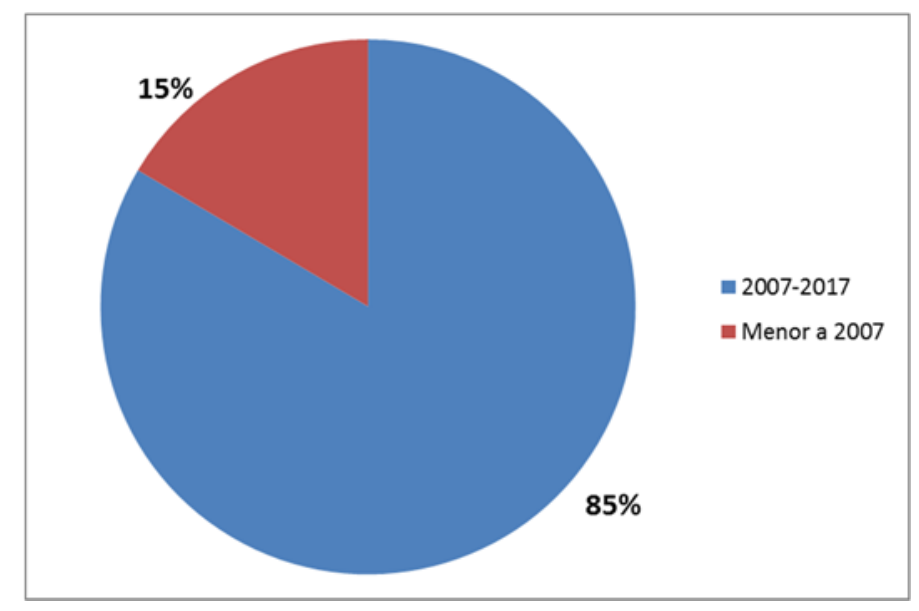

\section{Fuente: Elaboración propia}

El $85 \%$ de la bibliografía utilizada para la elaboración del presente proyecto de tesis cumple con una antigüedad no mayor a 10 años.

\subsubsection{Validación de entregables del Capítulo 2}

En el capítulo 2 del proyecto de investigación se abordó el análisis general y específico de la situación de las MYPE del subsector Restaurantes en Lima Metropolitana. Para la realización de este análisis, se encuesto a un total de 69 restaurantes MYPE de distintos distritos de Lima Metropolitana ya que, como se demostró en el mismo capítulo, son una muestra que cuenta con significancia.

A continuación, se presenta la siguiente tabla que engloba aquellos restaurantes que fueron encuestados con su respectivo encuestador: 
Tabla $\mathrm{N}^{\circ}$ 40. Tabla de MYPE del subsector restaurante encuestadas

\begin{tabular}{|c|c|}
\hline $\mathbf{N}^{\circ}$ & Razón social \\
\hline 1 & CHIFA TONG FONG \\
\hline 2 & GRUPO INVERSIONES EL GRAN BRILLO SAC. \\
\hline 3 & GAVILANO QUISPE GRIMALDO \\
\hline 4 & RAMIREZ VERASTEGUI GERSON BENIGNO \\
\hline 5 & RESTAURANTE POLLERÍA SAYURI \\
\hline 6 & NEGOCIOS Y CUBIERTOS \\
\hline 7 & RISCO RIVERA RAÚL GUSTAVO \\
\hline 8 & CHIFA YIEN PANT \\
\hline 9 & EL PULPO BEBÉ \\
\hline 10 & POLLERÍA MARACANA \\
\hline 11 & "LOBATON" \\
\hline 12 & ROKYS \\
\hline 13 & RESTAURANTE YOROKOBI \\
\hline 14 & CHIFA JIAN FU \\
\hline 15 & MAVITZA SOCIEDAD ANONIMA CERRADA \\
\hline 16 & GUO JING \\
\hline 17 & EL CHATO SABE SAC \\
\hline 18 & 20537142422 \\
\hline 19 & EN BOCA DE TODOS SOCIEDAD ANÃ'NIMA CERRADA \\
\hline 20 & RESTAURANTE SAZON PIURANA \\
\hline 21 & AVE CESAR - ANMIAR S.A.C. \\
\hline 22 & CORPORACIÃ ${ }^{3} \mathrm{~N}$ EL PAICHE DE ORO SAC \\
\hline 23 & RESTAURANT CEVICHERIA SNACK BAR COPA CABANA \\
\hline 24 & LOCHE RESTAURANT \\
\hline 25 & CRIMALU \\
\hline 26 & RESTAURANTE CAMPESTRE SANTA ROSA \\
\hline 27 & CHICKEN EXPRESS \\
\hline 28 & LA CASA DE ADELA \\
\hline 29 & EL PAISITA DE PIURA \\
\hline 30 & CHICOMA SILVA MARIA ELENA \\
\hline 31 & ZENG XUEMING S.A.C. \\
\hline 32 & KITSUTA TSUCHIYA JAIME \\
\hline 33 & EL OLIVAR GRILL E.I.R.L \\
\hline 34 & SALCHIBRASA S.A.C. \\
\hline 35 & EL SABOR DE NATY \\
\hline 36 & SUSPIRO CAFÉ SAC \\
\hline 37 & CERVECERIA NUEVO MUNDO SAC \\
\hline
\end{tabular}




\begin{tabular}{|l|l|}
\hline 38 & INVERSIONES Y RESTAURANT EL PIRATA E.I.R.L. \\
\hline 39 & $\begin{array}{l}\text { REPRESENTACIONES MI LANCHITA HERMANOS ASIS } \\
\text { S.R.L. }\end{array}$ \\
\hline 40 & VALEGA'S CATERING S.A.C. \\
\hline 41 & YUT WU S.A.C. \\
\hline 42 & CORPORACION SHINTY S.A.C. \\
\hline 43 & JH \& LB FOODS S.A.C. \\
\hline 45 & MAMANI MAMANI MARIA TERESA \\
\hline 46 & TAN \& ANY. NOMBRE COMERCIAL:MY HOME \\
\hline 47 & LA CASA VERDE DE SAN ISIDRO E.I.R.L \\
\hline 48 & APETITOS E.I.R.L. \\
\hline 49 & JS \& M INVERSIONES SAC \\
\hline 50 & CH/Y CHIFA CINCO ESTRELLAS S.A.C. \\
\hline 51 & AL PALO A LA PARRILLA S.A.C. \\
\hline 52 & ARAGON GORDILLO JOSE EUGENIO \\
\hline 53 & CEJANDRA \\
\hline 54 & RESTAURANT CHACHITA \\
\hline 55 & KINUCHY TANTA \\
\hline 56 & GUSTITOS CARLITOS \\
\hline 57 & EMPRESA BOULEVARD DEL CAFÉ SAC \\
\hline 58 & ASTUCURI SULCA, DINA (DONAL'S CAFÉ) \\
\hline 59 & RESTAURANT POLLERIA WIRA WALLPA S.A.C. \\
\hline 60 & MAD KAT CATERING \& EVENTOS E.I.R.L. \\
\hline 61 & MURAYAMA E.I.R.L. \\
\hline 62 & CHICHARRONERIA EL FAROLITO \\
\hline 63 & WARUN S.A.C \\
\hline 64 & HUI FON SAU HA \\
\hline 65 & COMERCIAL "VARGAS" \\
\hline 66 & EL MARINO GEM E.I.R.L. \\
\hline 67 & TROPICAL'S PIZZA S.A.C. \\
\hline 68 & INCA GAMING S.A.C. \\
\hline 69 & EL CANGREJO LOCO \\
\hline
\end{tabular}

\section{Fuente: Elaboración Propia}

\subsubsection{Validación de entregables del Capítulo 3}

Como indicador de logro del Capítulo 3, se fijó entregar documentación relevante para la gestión por procesos en una MYPE del subsector restaurantes. Durante ese capítulo, se entregó el mapa de procesos para una MYPE, así como el diagrama de interrelación de procesos. 
Con respecto al proceso de costos, se cumplió con entregar el mapa de subprocesos, así como el diagrama de relación con otros procesos. El proceso de costos cuenta con 4 subprocesos. A continuación, se presenta una tabla con los entregables de cada subproceso.

Tabla $\mathrm{N}^{\mathrm{o}}$ 41. Cumplimiento de entregables del proceso de costos

\begin{tabular}{|l|c|c|c|}
\hline $\begin{array}{l}\text { Entregable } \\
\text { Subproceso }\end{array}$ & $\begin{array}{c}\text { Diagrama de } \\
\text { flujo }\end{array}$ & SIPOC & Procedimiento \\
\hline Lineamientos del proceso & $\mathrm{X}$ & $\mathrm{X}$ & $\mathrm{X}$ \\
\hline Clasificación de costos & $\mathrm{X}$ & $\mathrm{X}$ & $\mathrm{X}$ \\
\hline $\begin{array}{l}\text { Asignación y cálculo del } \\
\text { costo unitario }\end{array}$ & $\mathrm{X}$ & $\mathrm{X}$ & $\mathrm{X}$ \\
\hline Control Documentario & $\mathrm{X}$ & $\mathrm{X}$ \\
\hline
\end{tabular}

\section{Fuente: Elaboración Propia}

En cuanto a los indicadores, se ha entregado 2 indicadores, junto con sus respectivos formatos, para que midan el desempeño del proceso de costos.

\subsubsection{Validación del Capítulo 4}

\subsubsection{Expertos}

Durante la realización del presente proyecto de investigación, se determinó que se necesitaba de expertos en el tema del manejo y control de los costos para la validación del modelo basado en el costeo ABC. Para esto, se cuenta con el apoyo de 2 académicos nacionales, y 1 empresario ya que su experiencia, tanto académica como laboral, es un buen referente para el presente proyecto y pueden brindar opiniones certeras y que generan valor.

A continuación, se presenta a los validadores del presente proyecto de investigación: 
Tabla $\mathrm{N}^{\circ} 42$. Ficha del validador $\mathrm{N}^{\circ} 1$

\section{VALIDADOR $\mathbf{N}^{\circ} 1$}

\section{HUMIBETO MARTIN GÁLVEZ RAIMONDI}

\section{Formación académica}

- Contador Público que ha conseguido la colegiatura por parte de la Universidad del Pacífico.

- Cuenta con un MBA otorgado por la Universidad Peruana de Ciencias Aplicadas.

- Especialista en sistemas de costeo tanto tradicional como ABC.

\section{Experiencia Profesional}

- Profesionalmente, ha desempeñado labores de Gerente de administración y Finanzas, Contador General y Contador de costos en Nature's Sunshine Products, Laboratorios Infarmasa, entre otras empresas.

- Actualmente, es consultor de costos en diversas empresas y tiene labores de docente en la Universidad del Pacífico, Universidad ESAN y la Universidad Peruana de Ciencias Aplicadas.

Fuente: Elaboración Propia 
Tabla $\mathrm{N}^{\circ} 43$. Ficha del validador $\mathrm{N}^{\circ} 2$

\section{VALIDADOR $\mathrm{N}^{\circ} 2$}

\section{JUAN PAULO RIVERO ZANATTA}

\section{Formación académica}

- Contador Público Colegiado.

- Licenciado en Contabilidad y Finanzas por la Universidad de Lima.

- Primer puesto de la promoción de graduados de la carrera de Contabilidad y Finanzas de la Universidad de Lima.

- Especialista en Costeo ABC y asesoría financiera.

\section{Experiencia Profesional}

- Experiencia en auditoria en contabilidad y administración en Interbank.

- Ha realizado auditorias de costeo para empresas como Cinemark International Inc, Deloitte, WIUS, y Aeropuertos del Perú S.A.

- Actualmente, trabaja en la docencia en la Universidad Peruana de Ciencias Aplicadas.

\section{Fuente: Elaboración propia}


Tabla $\mathrm{N}^{\circ} 44$. Ficha del validador $\mathrm{N}^{\circ} 3$

\section{VALIDADOR $\mathrm{N}^{\circ} 3$}

\section{JUAN CARLOS CRUZ CASTTELLO}

\section{Formación académica}

- Egresado de la carrera de contabilidad en el Instituto IDAT.

- Bachiller de la carrera de Administración en la Universidad San Ignacio de Loyola.

\section{Experiencia Profesional}

- Experiencia en tema de costos debido a su amplia experiencia en restaurantes como gerente de tienda de diversas sucursales de la empresa Norky's.

- Laboró como contador en la cadena de comida rápida Bembos.

- Actualmente, se encuentra en el diseño e implementación de un nuevo restaurante más en el Distrito de Miraflores.

\section{Fuente: Elaboración propia}


Tabla $\mathrm{N}^{\mathrm{o}} 45$. Ficha de Validador $\mathrm{N}^{\mathrm{o}} 4$

\section{VALIDADOR $N^{\circ} 4$}

\section{OTTO ARELLANO CEPEDA}

\section{Formación académica}

- Profesional de la carrera de Contabilidad de la Universidad Nacional del Chimborazo, Ecuador.

- Diversos estudios y maestría de contabilidad y gestión de costos

\section{Experiencia Profesional}

- Experiencia de más de 25 años como Contador Público e implementación de modelos de costos a diversas empresas industriales.

- Autor de artículos académicos en el último año.

- Docente en la Facultad de Ciencias Políticas y Administrativas y en la Carrera de Contabilidad y Auditoría de la UNACH.

- Colaboraciones con el Vice Rectorado de la Universidad Nacional del Altiplano.

- Ponente en el IX y XI Congreso Iberoamericano de Contabilidad de Gestión organizado por la PUCP. 
Tabla $\mathrm{N}^{\mathrm{o}} 46$. Ficha del Validador $\mathrm{N}^{\mathrm{o}} 5$

Fuente: Elaboración propia

VALIDADOR $\mathrm{N}^{\circ} 5$

\section{ELSA ALVAREZ MORALES}

\section{Formación académica}

- Profesional de la carrera de Ingeniería en Contabilidad y Auditoría en la Universidad Tecnológica de Quevedo, Ecuador.

- Maestría en Contabilidad de Costos.

- Estudios en emprendimiento social y contabilidad

\section{Experiencia Profesional}

- Experiencia de 20 años como contadora de costos en diversas empresas de Ecuador.

- Experiencia de 10 años realizando implementación de sistemas de costos a empresas de Ecuador.

- Participante y miembro de la Asociación para la Formación, Investigación y Desarrollo del Emprendimiento.

- Docente de gestión de costos en la Universidad Tecnológica de Quevedo, Ecuador.

- Autor de artículos académicos en el último año sobre compromiso social y gestión de costos.

- Docente miembro y validado para publicar en la Revista Cubana de Contabilidad y Finanzas. 


\subsubsection{Formato para la validación}

Para poder medir la opinión/validación de los expertos que aportaron a la mejora del presente modelo de costos, se propuso un formato el cual cuenta con 9 criterios cuya combinación reflejan el grado de validez de la hipótesis y, por ende, del modelo de costos. A continuación, se presenta los 9 criterios, junto con su, conceptos, para la respectiva validación.

Tabla $N^{\circ}$ 47. Criterios para la validación

\begin{tabular}{|l|l|}
\hline Criterio & \multicolumn{2}{|c|}{ Concepto } \\
\hline Claridad & $:$ Presenta un lenguaje claro, conciso y \\
& apropiado. \\
\hline Pertinencia & $:$ El modelo se ajusta a la realidad de las \\
& MYPE. \\
\hline Consistencia & $:$ Responde a los objetivos plateados. \\
\hline Originalidad & $:$ Agrega valor a la estructura de las \\
& MYPE. \\
\hline Sustentabilidad & $:$ Presenta artículos académicos que \\
& respalden el modelo. \\
\hline Suficiencia & $:$ Comprende todos los procesos necesarios \\
& para asegurar el éxito del modelo. \\
\hline Estructura & $:$ Presenta una secuencia lógica y \\
& ordenada. \\
\hline Mdaptabilidad & $:$ Los indicadores propuestos son \\
& relevantes para la medición y control del \\
& modelo. \\
\hline cambiantes del mercado. \\
\hline
\end{tabular}

Fuente: Elaboración propia

Bajo estos criterios, se estableció una calificación que puede ser: Deficiente, Regular, Bueno, Muy bueno, Excelente.

Junto con los criterios, se armó el Formato de calificación para la validación del modelo de costos. 
Tabla $\mathrm{N}^{\mathrm{o}} 48$. Formato de validación para el modelo de costos

\begin{tabular}{|c|c|c|c|c|c|c|c|}
\hline & & & \multicolumn{5}{|l|}{ Calificación } \\
\hline \multicolumn{3}{|c|}{ Criterios de evaluación } & Deficiente & Regular & Bueno & Muy & Excelente \\
\hline 1 & Claridad & \begin{tabular}{|lr}
$\begin{array}{lr}\text { Presenta } \\
\text { lenguaje }\end{array}$ & un \\
conciso & y \\
apropiado & \\
\end{tabular} & & & & & \\
\hline 2 & Pertinencia & $\begin{array}{l}\text { El modelo se ajusta } \\
\text { a la realidad de las } \\
\text { mypes }\end{array}$ & & & & & \\
\hline 3 & Consistencia & 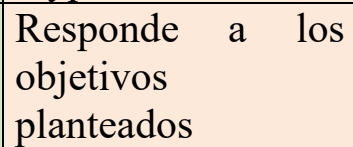 & & & & & \\
\hline 4 & Originalidad & $\begin{array}{l}\text { Agrega valor a la } \\
\text { estructura de las } \\
\text { mypes }\end{array}$ & & & & & \\
\hline 5 & Sustentabilidad & $\begin{array}{lr}\text { Presenta } & \text { artículos } \\
\text { académicos } & \text { que } \\
\text { respalden } & \text { el } \\
\text { modelo } & \\
\end{array}$ & & & & & \\
\hline 6 & Suficiencia & 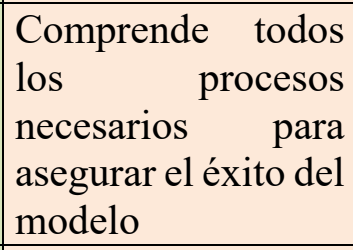 & & & & & \\
\hline 7 & Estructura & \begin{tabular}{|lr} 
Presenta r una \\
secuencia \\
ordenada
\end{tabular} & & & & & \\
\hline 8 & Medición & $\begin{array}{l}\text { Los indicadores } \\
\text { propuestos son } \\
\text { relevantes para la } \\
\text { medición y control } \\
\text { del modelo }\end{array}$ & & & & & \\
\hline & Adaptabilidad & $\begin{array}{l}\text { El modelo se ajusta } \\
\text { a las necesidades } \\
\text { cambiantes del } \\
\text { mercado }\end{array}$ & & & & & \\
\hline
\end{tabular}

Fuente: Elaboración propia 


\subsubsection{Resultados de la validación de los expertos}

Después de realizada la entrevista a los expertos, se realizó los consolidados de resultados. A continuación, se presenta los resultados individuales de cada validador.

\subsection{Resultados de Juan Paulo Rivero Zanatta}

Ilustración No 54. Resultados de validación de Juan Paulo Rivero Zanatta

FORMATO DE VALIDACIÓN DEL MODELO DE COSTOS

\begin{tabular}{|c|c|}
\hline Nombre & Juan Paulo Rivero Zanatta \\
\hline Cargo/ Puesto & Profesor de Costos y presupuestos \\
\hline
\end{tabular}

\begin{tabular}{|c|c|c|c|c|c|c|}
\hline \multirow{2}{*}{ CRITERIOS } & \multirow{2}{*}{ DESCRIPCIÓN } & \multicolumn{5}{|c|}{ CALIFICACIÓN DE CRITERIOS } \\
\hline & & DEFICIENTE (1) & REGULAR (2) & BUENO (3) & MUY BUENO (4) & EXCELENTE (5) \\
\hline 1. Claridad & $\begin{array}{l}\text { Presenta un lenguaje claro, conciso y } \\
\text { apropiado }\end{array}$ & & 2 & & & \\
\hline 2. Pertinencia & $\begin{array}{l}\text { El modelo se ajusta a la realidad de las } \\
\text { mypes }\end{array}$ & & 2 & & & \\
\hline 3.Consistencia & Responde a los objetivos planteados & & 2 & & & \\
\hline 4.Originalidad & $\begin{array}{l}\text { Agrega valor a la estructura de las } \\
\text { mypes }\end{array}$ & & & 3 & & \\
\hline 5.Sustentabilidad & $\begin{array}{l}\text { Presenta articulos académicos que } \\
\text { respalden el modelo }\end{array}$ & & 2 & & & \\
\hline 6.Suficiencia & $\begin{array}{l}\text { Comprende todos los procesos } \\
\text { necesarios para asegurar el éxito del } \\
\text { modelo }\end{array}$ & & 2 & & & \\
\hline 7.Estructura & \begin{tabular}{|l}
$\begin{array}{l}\text { Presenta una secuencia lógica y } \\
\text { ordenada }\end{array}$ \\
\end{tabular} & & & 3 & & \\
\hline 8.Medición & $\begin{array}{l}\text { Los indicadores propuestos son } \\
\text { relevantes para la medición y control } \\
\text { del modelo }\end{array}$ & & 2 & & & \\
\hline 9. Adaptabilidad & $\begin{array}{l}\text { El modelo se ajusta a las necesidades } \\
\text { cambiantes del mercado }\end{array}$ & & & 3 & & \\
\hline
\end{tabular}

Fuente: Elaboración propia 
Ilustración No 55 . Resultados de la validación de Humberto Gálvez Raimondi

\section{FORMATO DE VALIDACIÓN DEL MODELO DE COSTOS}

\begin{tabular}{|c|c|c|c|}
\hline Nombre & Humberto Gálvez Raimondi & Años de Experiencia & 20 \\
\hline Cargo/ Puesto & Profesor de costos y presupuestos & E-mail & humberto.galvez@upc.edu.pe \\
\hline
\end{tabular}

\begin{tabular}{|c|c|c|c|c|c|c|}
\hline \multirow{2}{*}{ CRITERIOS } & \multirow{2}{*}{ DESCRIPCIÓN } & \multicolumn{5}{|c|}{ CALIFICACIÓN DE CRITERIOS } \\
\hline & & DEFICIENTE (1) & REGULAR (2) & BUENO (3) & MUY BUENO (4) & EXCELENTE (5) \\
\hline 1. Claridad & $\begin{array}{l}\text { Presenta un lenguaje claro, conciso y } \\
\text { apropiado }\end{array}$ & & & & 4 & \\
\hline 2. Pertinencia & $\begin{array}{l}\text { El modelo se ajusta a la realidad de las } \\
\text { mypes }\end{array}$ & & & & 4 & \\
\hline 3.Consistencia & Responde a los objetivos planteados & & & & 4 & \\
\hline 4.Originalidad & $\begin{array}{l}\text { Agrega valor a la estructura de las } \\
\text { mypes }\end{array}$ & & & & 4 & \\
\hline 5.Sustentabilidad & $\begin{array}{l}\text { Presenta articulos académicos que } \\
\text { respalden el modelo }\end{array}$ & & & & & 5 \\
\hline 6.Suficiencia & $\begin{array}{l}\text { Comprende todos los procesos } \\
\text { necesarios para asegurar el éxito del } \\
\text { modelo }\end{array}$ & & & & 4 & \\
\hline 7.Estructura & \begin{tabular}{|l}
$\begin{array}{l}\text { Presenta una secuencia lógica y } \\
\text { ordenada }\end{array}$ \\
\end{tabular} & & & & 4 & \\
\hline 8.Medición & $\begin{array}{l}\text { Los indicadores propuestos son } \\
\text { relevantes para la medición y control } \\
\text { del modelo }\end{array}$ & & & 3 & & \\
\hline 9. Adaptabilidad & $\begin{array}{l}\text { El modelo se ajusta a las necesidades } \\
\text { cambiantes del mercado }\end{array}$ & & & & 4 & \\
\hline
\end{tabular}

Fuente: Elaboración propia 
Ilustración $\mathrm{N}^{\mathrm{0}}$ 56. Resultados de la validación de Juan Carlos Cruz

\section{FORMATO DE VALIDACIÓN DEL MODELO DE COSTOS}

\begin{tabular}{|c|c|}
\hline Nombre & Juan Carlos Cruz Casttello \\
\hline Cargo/ Puesto & $\begin{array}{c}\text { Contador de empresas de } \\
\text { Restaurantes/ Dueño de su propio } \\
\text { restaurante }\end{array}$ \\
\hline
\end{tabular}

\begin{tabular}{|c|c|c|c|c|c|c|}
\hline \multirow[b]{2}{*}{ CRITERIOS } & \multirow{2}{*}{ DESCRIPCIÓN } & \multicolumn{5}{|c|}{ CALIFICACIÓN DE CRITERIOS } \\
\hline & & DEFICIENTE (1) & REGULAR (2) & BUENO (3) & MUY BUENO (4) & EXCELENTE (5) \\
\hline 1. Claridad & $\begin{array}{l}\text { Presenta un lenguaje claro, conciso y } \\
\text { apropiado }\end{array}$ & & & & & 5 \\
\hline 2. Pertinencia & \begin{tabular}{|l|}
$\begin{array}{l}\text { El modelo se ajusta a la realidad de las } \\
\text { mypes }\end{array}$ \\
\end{tabular} & & & & & 5 \\
\hline 3.Consistencia & Responde a los objetivos planteados & & & & & 5 \\
\hline 4.Originalidad & $\begin{array}{l}\text { Agrega valor a la estructura de las } \\
\text { mypes }\end{array}$ & & & & & 5 \\
\hline 5.Sustentabilidad & $\begin{array}{l}\text { Presenta articulos académicos que } \\
\text { respalden el modelo }\end{array}$ & & & & & 5 \\
\hline 6.Suficiencia & $\begin{array}{l}\text { Comprende todos los procesos } \\
\text { necesarios para asegurar el éxito del } \\
\text { modelo }\end{array}$ & & & & & 5 \\
\hline 7.Estructura & \begin{tabular}{|l|l|l|}
$\begin{array}{l}\text { Presenta una secuencia lógica y } \\
\text { ordenada }\end{array}$ & & \\
\end{tabular} & & & & & 5 \\
\hline 8.Medición & $\begin{array}{l}\text { Los indicadores propuestos son } \\
\text { relevantes para la medición y control } \\
\text { del modelo }\end{array}$ & & & & & 5 \\
\hline 9. Adaptabilidad & $\begin{array}{l}\text { El modelo se ajusta a las necesidades } \\
\text { cambiantes del mercado }\end{array}$ & & & & & 5 \\
\hline
\end{tabular}

Fuente: Elaboración propia 
4.2.4.3.4 Resultados de la validación de Otto Arellano Cepeda

Ilustración No 57. Resultados de la validación de Otto Arellano Cepeda

FORMATO DE VALIDACION DEL MODELO DE COSTOS

\begin{tabular}{|c|c|c|c|}
\hline Nombre & Otto Arellano Cepeda & Años de experiencia & 25 \\
\hline Cargo/Puesto & Docentes de Contabilidad-UNACH & E-mail & oarellano@unach.edu.ec \\
\hline
\end{tabular}

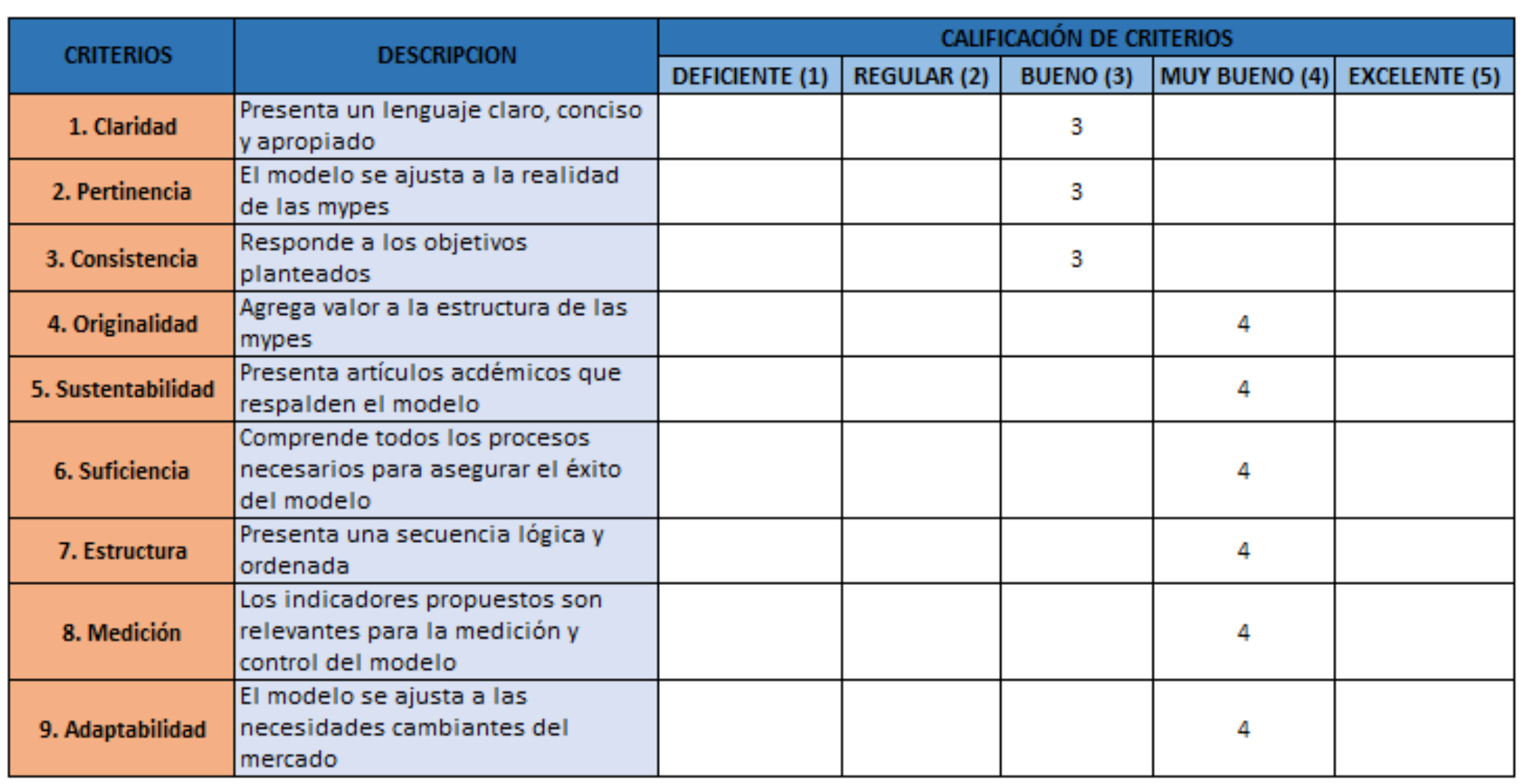

Fuente: Elaboración propia 
Ilustración $N^{\circ}$ 58. Resultados de la validación de Elsa Álvarez Morales

\section{FORMATO DE VALIDACION DEL MODELO DE COSTOS}

\begin{tabular}{|c|l|}
\hline Nombre & ELSA ALVAREZ MORALES \\
\hline Cargo/Puesto & DOCENTE /UNIVERSIDAD TECNICA ESTATAL DE QUEVEDO \\
\hline
\end{tabular}

\begin{tabular}{|c|c|c|c|c|c|c|}
\hline \multirow{2}{*}{ CRITERIOS } & \multirow{2}{*}{ DESCRIPCION } & \multicolumn{5}{|c|}{ CALIFICACIÓN DE CRITERIOS } \\
\hline & & DEFICIENTE (1) & REGULAR (2) & BUENO (3) & MUY BUENO (4) & EXCELENTE (5) \\
\hline 1. Claridad & Presenta un lenguaje claro, conciso y apropiado & & & & & $\mathrm{x}$ \\
\hline 2. Pertinencia & El modelo se ajusta a la realidad de las mypes & & & & & $x$ \\
\hline 3. Consistencia & Responde a los objetivos planteados & & & & & $x$ \\
\hline 4. Originalidad & Agrega valor a la estructura de las mypes & & & & & $\mathrm{x}$ \\
\hline 5. Sustentabilidad & Presenta artículos acdémicos que respalden el modelo & & & & & $x$ \\
\hline 6. Suficiencia & $\begin{array}{l}\text { Comprende todos los procesos necesarios para asegurar } \\
\text { el éxito del modelo }\end{array}$ & & & & & $\mathrm{x}$ \\
\hline 7. Estructura & Presenta una secuencia lógica y ordenada & & & & & $x$ \\
\hline 8. Medición & $\begin{array}{l}\text { Los indicadores propuestos son relevantes para la } \\
\text { medición y control del modelo }\end{array}$ & & & & & $\mathrm{x}$ \\
\hline 9. Adaptabilidad & $\begin{array}{l}\text { El modelo se ajusta a las necesidades cambiantes del } \\
\text { mercado }\end{array}$ & & & & & $x$ \\
\hline
\end{tabular}

Fuente: Elaboración propia 


\subsection{Resumen de los resultados generales}

Ilustración Nº 59. Resumen de los resultados generales de los validadores

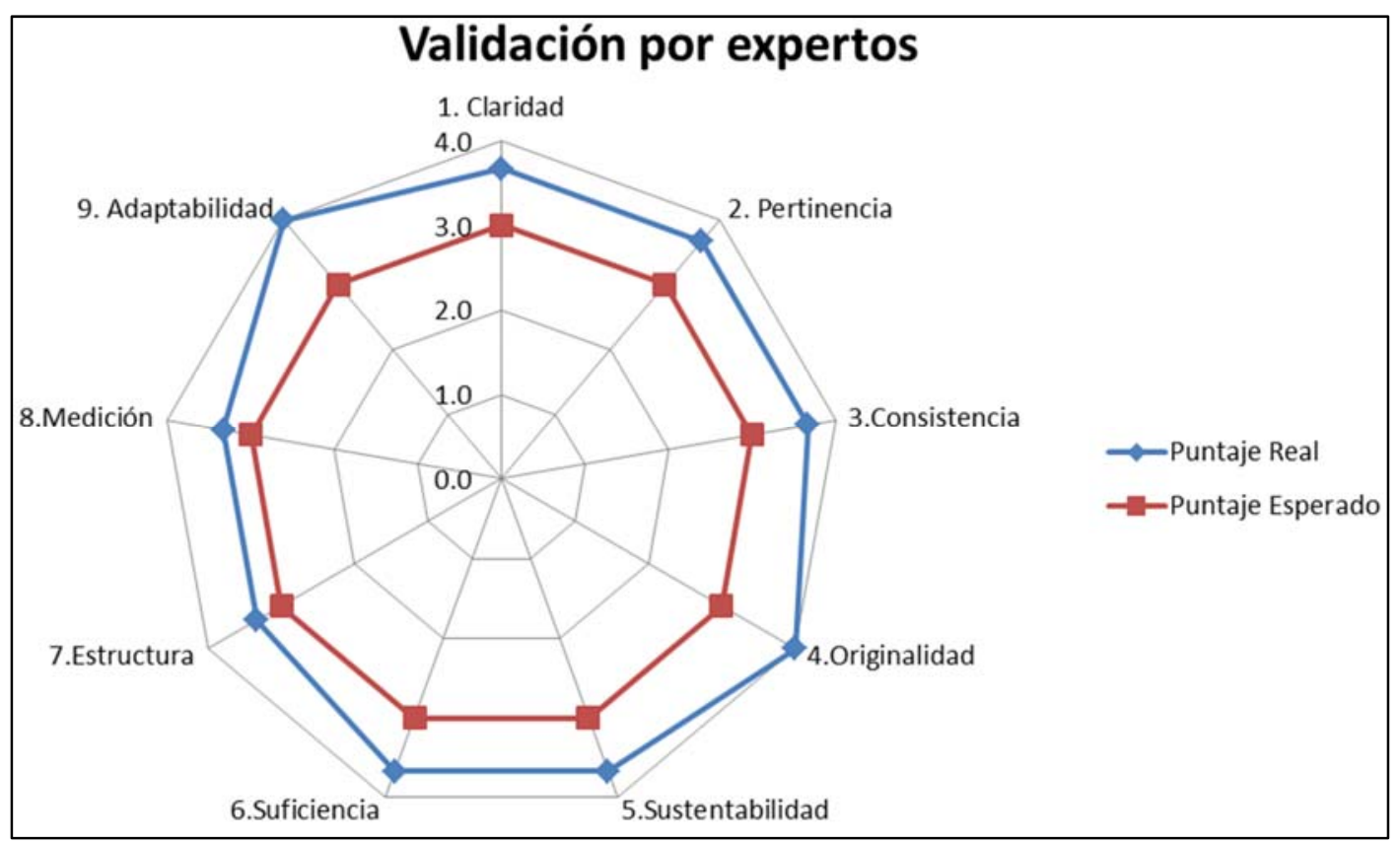

Fuente: Elaboración propia

Como se evidencia en la gráfica resumen anterior, el modelo ha superado las expectativas académicas. Sus puntos más fuertes son la Pertinencia, Consistencia, Originalidad. Sustentabilidad y Adaptabilidad; siendo este último uno de los más importantes ya que el propósito de este modelo basado en el costeo ABC es que sea maleable para la realidad específica de cada empresa del subsector restaurante. 


\subsection{Análisis de los stakeholders}

Como en todo proyecto innovador, siempre una nueva visión o una nueva forma de realizar las cosas genera un impacto el cual puede ser recibido de una manera positiva o negativa dependiente de la persona interesada (stakeholder). En una empresa, sea pequeña o grande, siempre va a existir personas que vean sus intereses afectados, de un menor o mayor grado, cuando se enfrentan a una nueva forma de realizar las cosas. Por otro lado, no solo dentro de la empresa se puede tener stakeholders, fuera de ella, existe todo un mundo empresarial y político complejo con muchos interesados que pueden ver afectados sus actividades o intereses.

A continuación, se presenta la lista de stakeholders que se tiene que tener en cuenta dentro del margen de un modelo de costos, estos interesados son miembros y no miembros de una MYPE del subsector restaurantes

Tabla No 49. Descripción de stakeholders

\begin{tabular}{|c|c|c|}
\hline Skateholders & Intereses & Obligaciones \\
\hline Dueño & $\begin{array}{l}\text { - Generar más } \\
\text { ingresos. } \\
\text { - Hacer crecer el } \\
\text { negocio. } \\
\text { - Aumentar la } \\
\text { rentabilidad. } \\
\text { - Pagar menos } \\
\text { impuestos. } \\
\text { - Disminuir los } \\
\text { costos y gastos } \\
\text { de la empresa. }\end{array}$ & 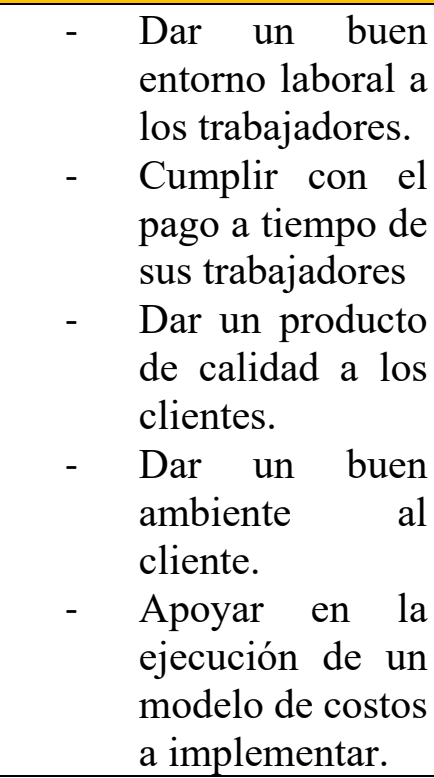 \\
\hline $\begin{array}{l}\text { Mozos } \\
\text { cocineros }\end{array}$ & 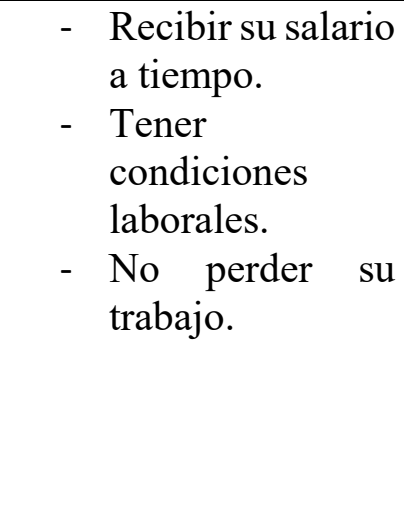 & $\begin{array}{l}\text { - Servir un plato } \\
\text { de comida al } \\
\text { cliente de la } \\
\text { manera más } \\
\text { adecuada. } \\
\text { Trabajo ético y } \\
\text { moral. } \\
\text { - Servir a tiempo } \\
\text { al cliente. } \\
\text { Cortesía en el } \\
\text { servicio. }\end{array}$ \\
\hline
\end{tabular}




\begin{tabular}{|c|c|c|}
\hline $\begin{array}{lll}\text { Contador } & \text { (si } \\
\text { existiera en la } \\
\text { empresa) }\end{array}$ & 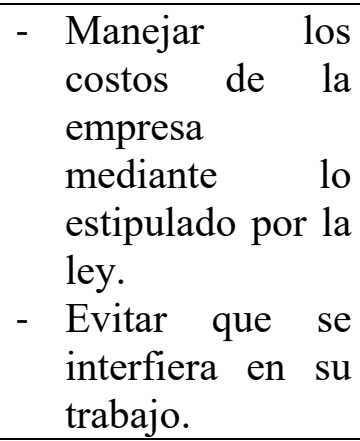 & $\begin{array}{llr}\text { - } & \text { Realizar } & \text { los } \\
\text { estados } & \text { de } \\
\text { cuentas de } & \text { la } \\
\text { empresa. } & \\
\text { - } & \text { Administrar los } \\
\text { costos. } & & \end{array}$ \\
\hline Clientes & 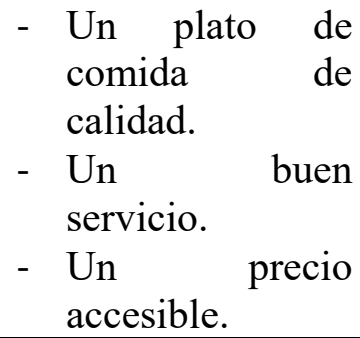 & $\begin{array}{l}\text { - Pagar el plato de } \\
\text { comida. }\end{array}$ \\
\hline Proveedores & $\begin{array}{l}\text { - } \text { Tener los menos } \\
\text { costos logísticos. } \\
\text { - } \text { Que el cliente } \\
\text { page a tiempo. }\end{array}$ & $\begin{array}{ll}\text { - } & \text { Dar materias } \\
\text { primas e insumos } \\
\text { de calidad y buen } \\
\text { precio. }\end{array}$ \\
\hline Estado & $\begin{array}{l}\text { - Mayor pago de } \\
\text { impuesto posible } \\
\text { por parte de las } \\
\text { MYPE. }\end{array}$ & \begin{tabular}{llr} 
- & \multicolumn{2}{l}{ Brindar } \\
& \multicolumn{2}{l}{ retribución por el } \\
& pago & de \\
& impuestos. & \\
- & Apoyar & al \\
& crecimiento de & das MYPE.
\end{tabular} \\
\hline
\end{tabular}

Fuente: Elaboración propia

La tabla anterior muestra a todos los posibles stakeholders de una MYPE del subsector restaurantes.

En este caso, los interesados a tomar en cuenta son: el dueño, el contador, el cliente, los trabajadores, los proveedores y el Estado. Los stakeholders previamente descritos tienen intereses que deben ser satisfechos de mayor o menor medida para poder alcanzar el éxito empresarial de una MYPE.

Por otro lado, es necesario entablar un criterio que permita dimensionar a los stakeholders para que se identifique cuáles de estos resultan ser más importantes y, por ende, merecen tener una mayor atención. Para lograr esto, se utiliza las siguientes dimensiones para la posterior identificación de stakeholders: 
Tabla $N^{0} 50$. Descripción de las dimensiones de los stakeholders

\begin{tabular}{|c|c|c|}
\hline & Dimensión & Descripción \\
\hline 1. & $\begin{array}{l}\text { Por } \\
\text { responsabilidad }\end{array}$ & $\begin{array}{l}\text { Son aquellos interesados con los cuales se tiene } \\
\text { responsabilidades legales, operativas y/o financieras. }\end{array}$ \\
\hline 2. & Por influencia & $\begin{array}{l}\text { Personas que tienen la posibilidad de influenciar dentro de las } \\
\text { empresas para alcanzar sus metas personales. Estas personas } \\
\text { pueden impulsar o impedir el avance de una medida. }\end{array}$ \\
\hline 3. & Por dependencia & $\begin{array}{l}\text { Son los interesados que más dependen de la empresa, } \\
\text { generalmente, conformado por los empleados, clientes } \\
\text { dependientes del producto o proveedores. }\end{array}$ \\
\hline 4. & Por cercanía & $\begin{array}{l}\text { Son aquellos interesados que, constantemente, interactúan con } \\
\text { la empresa o algunos otros interesados. Típicamente, la empresa } \\
\text { depende de ellos para sus operaciones cotidianas. }\end{array}$ \\
\hline 5. & $\begin{array}{l}\text { Por } \\
\text { representación }\end{array}$ & $\begin{array}{l}\text { Son interesados que, a partir de la estructura jerárquica, cultural } \\
\text { o tradicional, representan a más personas. Generalmente, } \\
\text { conformado por representantes sindicales. }\end{array}$ \\
\hline
\end{tabular}

Fuente: Adaptado de Krick y otros 2006

En base a las dimensiones planteadas y a la lista de interesados, se presenta el siguiente cuadro:

Tabla $N^{0}$ 51. Skateholder con su respectiva dimensión

\begin{tabular}{|l|c|c|c|c|c|}
\hline \multirow{2}{*}{ Skateholder } & \multicolumn{5}{|c|}{ Dimensiones } \\
\cline { 2 - 6 } & $\begin{array}{c}\text { Por } \\
\text { responsab } \\
\text { ilidad }\end{array}$ & $\begin{array}{c}\text { Por } \\
\text { influenc } \\
\text { ia }\end{array}$ & $\begin{array}{c}\text { Por } \\
\text { dependen } \\
\text { cia }\end{array}$ & $\begin{array}{c}\text { Por } \\
\text { cercan } \\
\text { ía }\end{array}$ & $\begin{array}{c}\text { Por } \\
\text { representac } \\
\text { ión }\end{array}$ \\
\hline Dueño & $\mathrm{X}$ & $\mathrm{X}$ & $\mathrm{X}$ & & $\mathrm{X}$ \\
\hline $\begin{array}{l}\text { Mozos } \\
\text { cocineros }\end{array}$ & $\mathrm{X}$ & $\mathrm{X}$ & $\mathrm{X}$ & $\mathrm{X}$ & $\mathrm{X}$ \\
\hline Contador & $\mathrm{X}$ & $\mathrm{X}$ & $\mathrm{X}$ & $\mathrm{X}$ & \\
\hline Clientes & & $\mathrm{X}$ & & $\mathrm{X}$ & \\
\hline Proveedores & $\mathrm{X}$ & & $\mathrm{X}$ & & \\
\hline
\end{tabular}




\begin{tabular}{|l|l|l|l|l|l|}
\hline Estado & X & & & & \\
\hline
\end{tabular}

\section{Fuente: Elaboración Propia}

- Dueño: En este caso, el dueño tiene 4 dimensiones debido a que tiene responsabilidades financieras a con sus trabajadores; por su posición, puede influenciar fácilmente a las demás personas que trabajan en la empresa $\mathrm{y}$, por ende, más personas dependen de él. Por otro lado, típicamente suelen ser los líderes dentro de su empresa y representan a sus trabajadores en caso hubiera alguna situación con algún factor externo como las municipalidades.

- Mozos y cocineros: Estos skateholders presentan las 5 dimensiones. El dueño de la empresa tiene el compromiso de pagarles su salario; por otro lado, en caso hubiera un sindicato, cada trabajador puede influenciar a otro trabajador para lograr un objetivo personal o común. Sin embargo, depende mucho de la empresa para poder seguir mantenimiento a sus familias, por lo cual siempre interactúan con todos los skateholders para poder obtener sus beneficios. Generalmente, un trabajador representa a un conjunto cuando se suele presentar un reclamo.

- Contador: En caso hubiera un contador en la empresa, este tiene 4 dimensiones. Tiene la obligación de realizar las operaciones contables de la compañía; además, suelen tener un contacto muy cercano al skateholder más importante: el dueño, esto es importante ya que, si es que viera que alguna medida lo perjudicaría o beneficiaría, lo conversaría lo antes posible con él. Por esta razón, es un dependiente de la empresa y de las medidas que se tomen.

- Clientes: Los clientes tienen la dimensión de influencia ya que pueden influenciar fácilmente en la empresa para lograr lo que quieren: mejor trato, nuevas comidas, mejores precios, etc. Esto se puede gracias a que interactúan bastante con el personal que labora en la empresa,

- Proveedores: A este interesado le importa bastante que le paguen en el tiempo acordado los productos que vende a la empresa. Un conflicto con ellos no es recomendable, es por esto, que el dueño suele tener un contacto bien directo con ellos.

- Estado: El único interés del estado sería que la empresa pague sus tributos en las fechas establecidas. Cualquier aumento o descenso de los ingresos de la empresa, podría afectar la recaudación de dinero por parte de ellos. 


\subsection{Análisis de la matriz de impactos del proceso de costos}

\subsubsection{Criterios considerables}

Como se comenta anteriormente, frente a todo nuevo cambio, siempre habrá algunos impactos más fuertes que otros. Estos impactos pueden suceder a nivel social, empresarial, tributario, etc. A continuación se presentan los posibles impactos que podrían llegar a tener el modelo de costos basado en el costeo ABC si fuera implementado en una MYPE del subsector restaurantes.

\subsubsection{Impactos sociales}

Dentro de los impactos sociales se tiene:

- Adaptabilidad al cambio: La adaptabilidad al cambio hace referencia al nivel de respuesta, sea positiva o negativa, de las personas que forman parte de la empresa cuando se encuentran al frente de un posible giro drástico en la forma en la cual realizan sus funciones.

- Mejora de la gestión: Mediante un modelo basado en la gestión por costos, se puede llegar a mejorar la rentabilidad de una empresa. Además, se mejora la forma en la cual la empresa y el dueño de la empresa manejan los costos de sus productos.

- Fidelidad y compromiso: Esto tiene dos enfoques: por un lado, una mejor gestión en la empresa ayudará a que el cliente se fidelice y, por otro lado, una mejor gestión de la empresa ayuda a que los propios trabajadores se sientan comprometidos con la causa de la empresa.

- Aumenta la demanda de trabajadores: Si una empresa se vuelve muy rentable y tiene muy buena frecuencia de clientes, se va a necesitar contratar más personal para poder manejarla.

\subsubsection{Impactos económicos}

- Aumento de los ingresos: Una empresa que se gestiona mediante un sistema estandarizado tiene el potencial de mejorar sus ingresos significativamente. Un aumento de los ingresos repercute en poder realizar planes para la empresa a corto, mediano y/o largo plazo. 
- Reducción y mejor manejo de costos: Una reducción de costos no es simplemente eliminar o reemplazar algo que cuesta caro por algo más barato, un correcto manejo del proceso de costos ayuda a poder entenderlos y generar planes de reducción que causen el menos impacto posible.

- Nuevos proyectos de expansión: Las MYPE debe tener la visión para poder afrontar nuevos retos. Una mejora de sus procesos ayuda en que, en el mediano o largo plazo, estas puedan expandirse.

- Mejor competitividad en el mercado: Al tener un mejor servicio producto de una mejor gestión en la empresa, se logra atraer más clientes y generar una mejor posición de la empresa en el mercado. De esta forma, la empresa puede poco a poco a explorar nuevos nichos o posicionarse en lo más alto del suyo.

- Recursos mejor distribuidos: Una mejora en la gestión ayuda a valorar y distribuir mejor los recursos de una empresa. De esta forma, se logra disminuir las pérdidas de dinero.

\subsubsection{Impactos tributarios}

- Tributación al Estado: Debido a que el presente modelo aborda el tema de los costos con su respectivo manejo, es muy importante tener en cuenta la Ley $\mathrm{N}^{\circ} 29645$ debido a que es el marco legal del Impuesto a la Renta. Autores académicos como Sánchez Barraza recalcan que uno de los principales impactos que tiene un modelo de costeo $\mathrm{ABC}$ es a esta ley debido a que plantea una forma de cálculo de impuesto mediante el costeo tradicional ${ }^{219}$.

\subsubsection{Actividades de consideración}

Para poder diseñar la matriz de impactos, es necesario relacionar los criterios junto con actividades de la propuesta de modelo de costos. Por esta razón, se considerarán las siguientes actividades por ser las más importantes dentro de su subproceso:

- Identificar actividades y seleccionar los cost drivers

- Enlistar los costos

${ }^{219}$ Cfr. Sánchez 2013: 72 
- Recopilar información

- Clasificar los costos

- Calcular el costo unitario por platillo

\subsubsection{Matriz de Leopold y rango de calificación}

La matriz de impactos que se presentará está basada en la Matriz de Leopold, el cual es un tipo de matriz que es utilizada para poder establecer relaciones de causa-efecto. Esta matriz tiene la peculiaridad de servir como una lista de control bidimensional, perfecto para el análisis de información cualitativa ${ }^{220}$.

Al utilizar este tipo de matriz y para evaluar el impacto del modelo, se tomará dos tipos de impacto: Magnitud de impacto e importancia. Para calificarlos se utilizará la siguiente tabla:

Tabla $\mathrm{N}^{\mathrm{o}}$ 52. Valores de calificación para la matriz de impactos

\begin{tabular}{|l|c|c|}
\hline \multicolumn{1}{|c|}{ Tipo de impacto } & Magnitud & Importancia \\
Calificación & & 1 \\
\hline Bajo & 1 & 2 \\
\hline Medio & 2 & 3 \\
\hline Alto & 3 & No hay existe relación alguna \\
\hline Espacio en blanco & \multicolumn{2}{|c|}{} \\
\hline
\end{tabular}

Fuente: Elaboración propia

Como se comenta anteriormente, al ser bidimensional, cada relación entre los dos aspectos a ser sometidos a evaluación tiene dos valores de calificación en un cuadro. Siguiendo la explicación de la información brindada por la Universidad Nacional de Rio Negro, la matriz se calificará de la siguiente forma:

- Calificación de la magnitud: Esta se colocará a la izquierda de cada casillero.

- Calificación de la importancia: Esta se colocará a la derecha de cada casillero.

Con estas calificaciones ya establecidas, se puede diseñar la matriz de impactos.

${ }^{220}$ Cfr. Universidad Nacional de Rio Negro 2013: 20 


\subsubsection{Matriz de impacto}

Tabla $\mathrm{N}^{\mathrm{o}}$ 53. Matriz de impactos

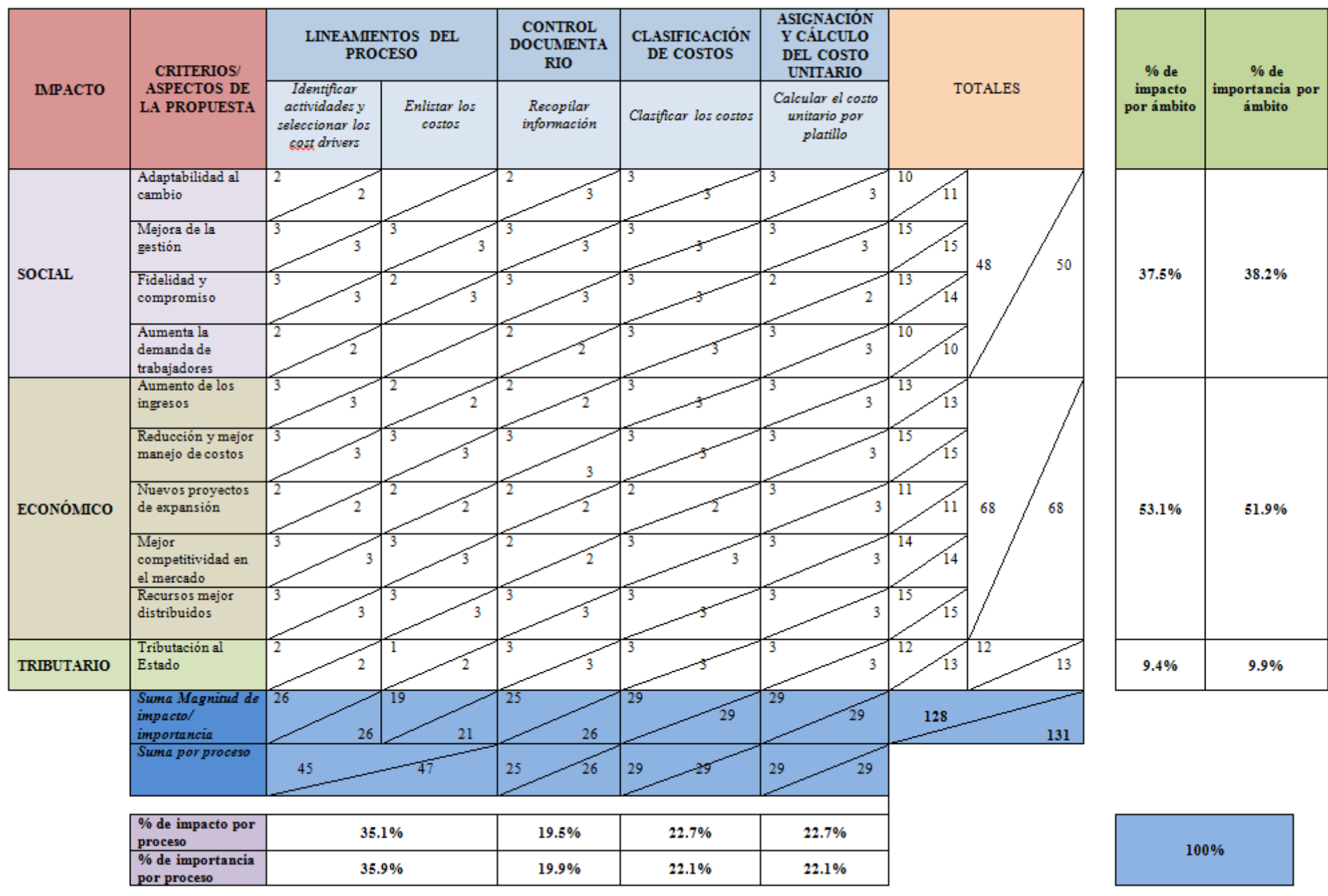

Fuente: Elaboración propia 
Como se muestra en la matriz, el impacto de modelo de costos es significativo. Como era de esperar, un mayor porcentaje de impacto se lo lleva el ámbito económico, esto debido a que este es un modelo de costos y, por ende, maneja bastante el dinero de la empresa. Por otro lado, el subproceso de Lineamientos del proceso es quien más impacto tiene dentro del modelo, esto se debe a que es quien controla todo el proceso de costos, da los lineamientos y es el subproceso por el cual se comienza la gestión de costos. 


\section{CAPITULO V}

En el presente capítulo se presentan las conclusiones finales producto de la investigación académica, así como algunas recomendaciones por parte del autor de esta investigación. 


\subsection{Conclusiones}

- A lo largo de esta intensa y extensa investigación, se puede evidenciar el claro potencial que las MYPE, en general, poseen ya que representan casi la totalidad del número de empresas que existen en el Perú. Sin embargo, no necesariamente cantidad significa calidad o mayor participación en el mercado debido a que abarcan poco más del $40 \%$ del PBI nacional.

- Las MYPE han surgido y seguirán surgiendo a lo largo y ancho de todo el territorio nacional dada su importancia en el sustento económico de muchas familias. Si bien es cierto que este tipo de empresas suelen ser construidas debido a una urgencia económica o a una oportunidad única en el mercado, no todas han sido diseñadas para ser competitivas a lo largo del tiempo y he aquí uno de sus principales talones de Aquiles; es por esto que desarrollar una metodología o modelo de trabajo es importante para que les sirva de guía y puedan ser sustentables a lo largo del tiempo.

- Las MYPE se han desarrollado principalmente en el seno de la capital del Perú debido a que, a pesar de la actual situación económica que atraviesa el país, sigue siendo vista como la ciudad de las oportunidades y donde se puede crecer tanto socialmente como económicamente. Es por esta razón que las MYPE siguen y seguirán creciendo en todo Lima ya que la población está aumentando y, muy posiblemente, la demanda de productos o servicios también crezca. Esto representa una oportunidad única para todas las MYPE ya que si la demanda está creciendo, la oferta también debe de hacerlo para poder satisfacer al mercado. Sin embargo, las nuevas tendencias mundiales sugieren que el mercado sea satisfecho en base a la calidad del servicio y del producto; algo que es del total desconocimiento de muchas de estas empresas.

- La desorganización, la falta de conocimiento y la falta de modelos de gestión ha provocado de muchas de este tipo de empresas cierren sus puertas a lo largo de los últimos tiempos ya que no lograron volverse competitivos y no lograron, de forma principal, mejorar su situación empresarial.

- La carencia de un modelo de gestión se ve reflejada cuando una MYPE se encuentra desorganizada y no sabe cómo manejar su propio negocio o cómo generar utilidades sin tener que aumentar significativamente los precios de su familia de productos. A pesar de esta situación, las MYPE que pertenecen al subsector restaurantes han 
aprendido a sobrevivir dentro de un panorama tan competitivo como lo es este rubro.

- El crecimiento de la demanda es muy importante para un rubro como el de restaurantes debido a que este necesita que su mercado se amplié para poder generar más dinero y más empresas. Como se puede evidenciar a lo largo de la investigación, el sector restaurantes es uno de los sectores que tiene un mayor potencial para explotar debido a que aún el Perú vive, y seguirá viviendo, el denominado y tan alabado "boom gastronómico".

- Las MYPE del subsector restaurantes son importantes porque representan una oportunidad para crecer tanto para sus propietarios como para el mismo Estado Peruano. Si es que estas empresas son gestionadas y apoyadas correctamente, los micros y pequeños empresarios podrán desarrollarse, tanto como personas y como empresarios, y el estado podrá percibir una mayor cantidad de impuestos recolectados y podrá, potencialmente, aumentar el Producto Bruto Interno Nacional.

- Si bien es cierto que las MYPE del subsector restaurantes presentan mucho potencial para poder desarrollarse en un mercado cada vez más competitivo donde tienen que luchar contras grandes franquicias nacionales e internacionales, no todas están a la altura de poder sobrevivir ya que, la gran mayoría, carecen de modelos que les permita guiar a sus empresas. En este punto, las MYPE deben de tomar como estrategia no solo la innovación de sus platos, sino, también, la calidad y el precio que estos supone ya que el mercado de comensales peruanos se caracteriza por comprar una comida que se encuentre al precio más accesible.

- Muchas MYPE, en general, carecen de conocimientos académicos para poder aplicarlos a su día a día, lo que genera que no manejen adecuadamente sus empresas. Como se puede evidenciar en las encuestas que se realizaron a lo largo de esta investigación junto con todos los conocimientos bibliográficos que se utilizaron para la elaboración del este proyecto de investigación, las MYPE, en general, carecen de modelos de gestión, basados en temas académicos, que les permita desenvolverse mejor no solo en su rubro, también ante sus clientes y proveedores. 
- La gestión por procesos es importante para poder asegurar el adecuado manejo de una empresa ya que no solo brinda orden dentro de la organización empresarial, también brinda metodologías importantes que toda empresa debería de cumplir para poder manejar su negocio de la forma más factible posible. La gestión por procesos representa una nueva forma de manejar una empresa en el Perú; por esta razón, es importante adaptar sus puntos teóricos básicos a la situación que se encuentran viviendo estas empresas para que pueda beneficiarse de este tipo de sistemas.

- Al no contar con modelos de gestión para MYPE del subsector restaurantes, los problemas que afrontan son casi cotidianos y no logran ser superados debido a que, poco a poco, asumen que estos problemas son naturales en sus empresas y no merecen mucho esfuerzo para poder solucionarlos. Aquí se refleja aún más el problema de la falta de un modelo que guie a las MYPE para poder solucionar muchos de sus problemas cotidianos; se necesita un modelo que sea sencillo y preciso para que estas empresas puedan entender y poner en marcha lo que se les plantea. De esta forma se logra asegurar el crecimiento y desarrollo de las MYPE del subsector restaurantes.

- Las MYPE del subsector restaurantes tienen distintos problemas los cuales deben solucionar; en base a las encuestas realizadas, su principal preocupación radica en las compras debido a que es lo más visible dentro de un restaurante. Sin embargo, una empresa no puede crecer si es que sus ingresos no crecen o si no aumentan el margen de ganancia de sus productos. Como en toda empresa, las salidas y los beneficios son cuantificables, y son representados por el dinero invertido y por el dinero obtenido. Siguiendo este parámetro, las MYPE presentan un problema en el manejo de su dinero de salida también llamados costos debido a que no lo consideran un problema tan importante debido a que desconocen cómo gestionarlos adecuadamente.

- Los costos son realmente un problema en empresas tan reducidas como suelen ser las MYPE ya que muchas de estas no saben en qué gastan tanto y no conocen cuánto es su costo unitario por plato de comida.

- Las MYPE del subsector restaurantes presentan un problema en el manejo adecuado de sus costos debido a la carencia de conocimientos técnicos y académicos acerca de modelos de costos; además, el costeo básico de este tipo de empresas está basado 
en el denominado costeo tradicional, un tipo de costeo que está perdiendo vigencia en el mercado debido a que carece de herramientas modernas para el cálculo real de los costos de un determinado producto. Su problema de manejo de costos se sustenta en los resultados que se obtuvieron de las encuestas realizadas a una muestra representativa de las MYPE del subsector restaurantes que se encuentran ubicados en la provincia de Lima. En estas encuestas, se puede evidenciar que este tipo de restaurantes, en su gran mayoría, no han calculado el costo unitario de alguno de sus platos de comida ofrecidos y, en el peor de los casos, desconocen el concepto de costo unitario.

- El inadecuado manejo de los costos de una MYPE del subsector restaurantes ha llegado a afectar la fijación de precios ya que estas no se basan en sus costos para poder formular una estrategia de precios competitivos, sino, se fundamentan en las empresas competidoras sin importar que sus costos no estén siendo cubiertos totalmente o que, en el peor de los casos, estén generando pérdidas de dinero. Esta tendencia de fijar un precio sin importar un estudio de costos unitarios previos se fundamenta en que las MYPE del subsector restaurantes no quieren perder su porción del mercado o cuota del mercado ya que la oferta de restaurantes es muy grande en la ciudad de Lima.

- El descuidar sus precios al no contar con una base sustentada de costos unitarios puede llegar a ocasionar que las pérdidas de una empresa, al mediano o largo plazo, se hagan cada vez más evidentes $\mathrm{y}$, potencialmente, conllevarían a que una determinada empresa tenga que cerrar las puertas de su negocio. Es por esto que resulta peligroso que una MYPE del subsector restaurantes no maneje un determinado modelo que les permita calcular sus costos unitarios de sus platillos ya que, potencialmente, la empresa podría ser llevada a la quiebra.

- Si bien está claro que las MYPE del subsector restaurantes necesitan un modelo de costos que se ajuste a su realidad, también es apropiado que este modelo de costos este basado en la metodología del costeo $\mathrm{ABC}$ porque su metodología se centra en realizar una distribución más exacta y real de los costos fijos. Sin embargo, si bien el costeo $\mathrm{ABC}$ es todo un sistema que incluye un mapeo de procesos y mucha investigación que podría demorar semanas o meses, las MYPE solo necesitan un modelo sencillo de entender y de utilizar que esté basado en la metodología ABC 
para que se pueda disminuir la curva de aprendizaje y pueden manejar sus costos de forma sencilla y exacta.

- El modelo de costos basado en el costeo ABC planteado es un modelo estándar que puede ser utilizado para cualquier restaurante perteneciente a una MYPE del subsector restaurantes ya que reconocer las particularidades de cada restaurante restaría la especificación del proyecto de investigación.

- El modelo se centra en distribuir los costos fijos que representan los salarios de los cocineros, mozos, dueños y transporte ya que son el estándar que se encuentra en cualquier MYPE del subsector restaurantes. Explicando a la situación de una forma más profunda, los salarios de un mozo representan uno de los más importantes costos fijos de una MYPE del subsector restaurantes ya que, dependiendo de la cantidad, estos suelen aumentar. Por otro lado, el alquiler también representa una fuerte inversión para una MYPE ya que el boom inmobiliario ha generado que los costos de alquiler para negocios aumenten. En diversas entrevistas que se realizaron durante la elaboración del proyecto de investigación, los encuestados revelaron que el costo de alquiler supone un gran problema ya que no saben cómo distribuir este costo en sus diversos platos de comida.

- En base a este modelo, se ha tenido a designar a las actividades que serían las que albergaran los inductores de costo. En este punto, los generadores de costo que se utilizan en el modelo de costos son la orden de pedido y la cantidad de materia prima transportada en kilogramos. En el caso del segundo cost driver, esto se fundamenta en que se puede distribuir el costo del transporte al inducirlo en la cantidad de materia prima que es transportada para la elaboración de un determinado plato de comida.

- En el caso del cost driver "pedido", este se basa en que es el principal eje del negocio y al que se le puede atribuir los costos de los salarios de los mozos y del dueño. Por otro lado, este cost driver es el más sencillo de identificar y con el que se puede familiarizar tanto a los costos fijos de la empresa como con los conocimientos empíricos del dueño o del encargado que manejar los costos de una MYPE del subsector restaurantes.

- Si bien es cierto que cada cost driver puede ser considerado como un indicador de costos cuando se trata de un modelo que se basa en el costeo $\mathrm{ABC}$, en este caso, el 
mayor indicador y el indicador guía es la rentabilidad. Esto se debe a que la eficiencia global del modelo se verá reflejada en cuan rentable se está volviendo un negocio de restaurantes; además, al dueño de una MYPE, en la fase inicial, le va interesar solamente manejar un indicador que refleje la situación global de su negocio.

- En cuanto a los stakeholders dentro de una eventual implementación de un modelo de costeo $\mathrm{ABC}$ en una MYPE del subsector restaurantes, se debe tener mucho cuidado con los empleados ya que pueden ver como una amenaza a esta nueva forma de costear. Esto se debe a que el costeo $\mathrm{ABC}$ refleja el costo unitario más real de un determinado producto, en este caso se trata de un plato de comida, y, lo más común, es que los dueños vean que los platos de comida tienen un precio elevado y, para disminuir los costos, prefieran disminuirles el sueldo a sus trabajadores o, en el peor de los casos, despedirlos.

- Por otro lado, se refleja que uno de los principales stakeholders del modelo es el dueño ya que, dependiendo de su interés, el modelo puede funcionar en una MYPE del subsector restaurantes o solo puede quedar como una buena intención que pretendía mejorar el actual sistema de costos de una empresa. Por esta razón es muy importante que el dueño se encuentre totalmente comprometido con su empresa para poder sacar adelante los beneficios de que un modelo de costos basado en el costeo $\mathrm{ABC}$ puede suponer.

- Siguiendo el mismo marco, un contador tradicional puede ser otro de los principales interesados cuando se trata de un modelo de costos basado en el costeo $\mathrm{ABC}$ ya que este rompe con el paradigma del costeo tradicional que es muy utilizado en el Perú para rendir cuentas en los Estados Financieros y los Balances de fin de mes. Si bien es cierto que un modelo de costeo $\mathrm{ABC}$ no es práctico, aún, para poder ofrecer estados financieros, su objetivo es más operacional ya que se centra en la gestión de los costos dentro de una empresa. Por esta razón, es importarte enseñarle al contador tradicional que su importancia va a radicar en el manejo de los costos más que en la elaboración de los estado financieros de una empresa.

- A esto se suma que es de vital importancia que el tiempo de aprendizaje del modelo de costeo ABC para el dueño o el encargado de costos sea el menor posible debido a que, dependiendo del caso de cada empresa en particular, son estas personas las 
que se encargan de tomar toda decisión importante que pueda generar o acarrear algún tipo de costo en específico.

\subsection{Recomendaciones}

- Si bien es cierto que el modelo de costos que se ha planteado a lo largo de este proyecto de investigación parte de una investigación teórica, su adaptabilidad le permite ser implementado con éxito en todo tipo de MYPE del subsector restaurantes. Sin embargo, se tienen que tener en cuenta una serie de recomendaciones que son necesarias al momento de decidir que se implementará el modelo de costos que se ha propuesto.

- Una de las principales recomendaciones al momento de aplicar la propuesta del modelo de costos a una MYPE es que se tiene que analizar las particularidades de cada empresa, siendo más específicos, se tiene que analizar que otros costos importantes tienen que ser tomados en cuenta al momento de decidir si es que son incluidos en el costo unitario de un plato de comida. Por ejemplo, un restaurante de mariscos es muy distinto a un chifa ya que, a pesar de formar parte de un mismo subsector o un mismo tipo de empresa, tienen costos que pueden ser diferentes unos de otros o costos que sean más relevantes en un tipo de restaurantes que en otros. Partiendo de este ejemplo, se tiene que tener en cuenta que algunas MYPE que se encuentran en camino a ser mediana empresas ya se encuentran importando sus propios ingredientes; se tendría que evaluar si los costos de transacción de estas encomiendas afecta directamente al costo unitario del producto o si, simplemente, se los tomará como una gasto necesario para poder obtener un ingrediente.

- Es importante partir que los generadores de costos planteados en el modelo son útiles y representan, en su gran mayoría, a las MYPE del subsector restaurantes, no son universales y pueden ser puestos a observación si es que el dueño o el encargado de los costos así lo crea conveniente. Siguiendo la misma lógica, es importante que el microempresario ajuste sus conocimientos empíricos acerca de su negocio para poder aplicarlos directamente en una eventual modificación del modelo de costos.

- Dependiendo de la empresa, se tiene que tener en cuenta si es que las actividades que se plantean en el modelo son las correctas y representan la gran realidad de su situación. Si bien es cierto que la propuesta de modelo se ha buscado estandarizar las actividades de una MYPE del subsector restaurantes, también puede ser sujeta 
a una eventual revisión ya que, dependiendo de la empresa, estas actividades podrían tener más costos representativos que necesiten ser redistribuidos.

- Un punto importante es el dueño, siguiendo las bases de la gestión de costos, siempre se ha recomendado que el dueño tenga un determinado sueldo para no caer en el error que el dinero o las ganancias del negocio representan el dinero del dueño. Por esta razón, se recomienda que el dueño, antes de la implementación del modelo de costos basado en el costeo $\mathrm{ABC}$, fije un determinado salario que sea para el mismo. De esta manera, se podrá trabajar mejor el modelo y los resultados serán más resaltantes.

- En este modelo de costos no se incluye lo que representa los costos de agua, electricidad y combustible. Como uno de los validadores del proyecto de investigación recalcó, estos costos son importantes pero, a la vez, resultan un tanto impredecibles ya que se necesita mucho tiempo y una cantidad moderada de dinero invertido para poder reconocer sus inductores de costo y, de esta forma, poder ser parte de un modelo de costos.

- Se recomienda que con el paso del tiempo (después de que el modelo de costos esté puesto en marcha y el encargado de manejar los costos haya asimilado todos los conocimientos necesarios) se comience un estudio detallado de los costos de agua, electricidad y combustible para encontrar la manera de incluirlos en el modelo de costos estándar.

- Si bien los formatos de costos es lo que más abunda en este tipo de modelos, se sugiere que con el tiempo, todo se realice empíricamente para que el costeo $\mathrm{ABC}$ sea algo que perdure en el tiempo y no solo sea visto como un modelo aplicable a un solo momento.

- La recomendación más importante es separar la generación de estados financieros de los resultados que se obtienen de un modelo de costos basado en el costeo ABC ya que ambos son utilizados para propósitos muy diferentes. Se recomienda que el costeo $\mathrm{ABC}$ sea tratado como una herramienta que mejore la gestión de los costos de una MYPE del subsector restaurantes que permita fijar un precio adecuada para la empresa y así asegurar que los márgenes de ganancia sean lo suficientemente rentables para la empresa. 


\section{ANEXOS}

Anexo $N^{o}$ 1. Procedimiento del subproceso Lineamientos del proceso 


\section{OBJETIVO}

El presente procedimiento marca el inicio del proceso de costos de una MYPE del subsector restaurantes. El objetivo es plantear los lineamientos que una MYPE debe seguir para poder identificar los costos que van en su costo unitario y la metodología que deben seguir para poder distribuirse para obtener el costo unitario de cada plato de comida.

\section{ALCANCE}

Este procedimiento tiene interferencia directa con los procesos clave y con el proceso de apoyo. Marca un estándar para la creación de generadores de costo.

\section{DOCUMENTOS A CONSULTAR}

\section{NINGUNO}

\section{DEFINICIONES}

- Costo: Es todo aquello que simboliza un desembolso de dinero con el fin de invertirlo en un producto o servicio para obtener utilidades.

- Costo directo: Es aquel costo que es fácilmente identificable o que participa directamente en la elaboración de un plato de comida.

- Costo indirecto: Es aquel costo que no es fácilmente identificable con el plato de la comida.

- Generador de costo: El generador de costo es aquella base sobre la cual se asignan los costos indirectos al plato de comida. 


\section{RESPONSABILIDADES}

Micro y pequeño empresario: Se compromete a brindar toda la información acerca de los costos que maneja y cómo los maneja Además, se compromete a aprender la metodología del modelo de costos.

$>$ Proceso de costos: Se compromete a brindar toda la información teórica ajustada a la realidad del micro y pequeño empresario. Diseñar un modelo lo más cercano a la realidad del microempresario.

\section{PROCEDIIIENTO}

1. Primero, el micro y pequeño empresario debe identificar, en base a su experiencia, cuáles son las actividades cotidianas y repetitivas dentro de su empresa.

2. En caso no existiera, se debe comprender que el dinero de la empresa no es el dinero del dueño o de alguna otra persona a fin. Esto es importante para poder tener un costo más exacto el cual pueda ser utilizado para poder generar un margen de ganancia óptimo para la empresa.

3. Se debe formar una Lista de Costos en el cual se registre cuáles son los costos y gastos más importantes en los que incurre el restaurante.

4. Después de realizar el punto anterior, se debe seleccionar cuáles serian los costos que se deben imputar al plato de comida. En este puesto, se sugiere que costos como energía o agua no formen parte del costo final del producto.

5. Para los siguientes proces os, hay dos formas de tratar un costo o gasto.

\section{PROCEDIIIENTO DE COSTO DIRECTO:}

5.1 Utilizando la Lista de Costos Directos, se desglosa los costos de Materia prima al colocar las cantidades (KG, gramos, etc) y los costos (Soles) por cada platillo en el cual se haya desembolsado.

5.2 Sumar los costos directos incurridos por platillo para obtener el Costo Total de Materiales Directos por total de platos preparados.

5.3 Dividir el Costo total de materiales directos entre la cantidad de platillos preparados para obtener el Costo Total de Materiales por Plato. 


\begin{tabular}{|c|c|c|c|c|}
\hline 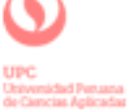 & $\begin{array}{l}\text { TíTULO: } \\
\text { Procedimiento del subproceso } \\
\text { Lineamientos del proceso }\end{array}$ & $\begin{array}{c}\text { CODIGO: } \\
\text { PRO-1 }\end{array}$ & $\begin{array}{c}\text { VER SION } \\
01\end{array}$ & $\begin{array}{l}\text { PAGINA } \\
3 \text { de } 3\end{array}$ \\
\hline
\end{tabular}

5.4 Por segundo higar, se debe dividir el salario mensual de los cocineros y obtener el salario por minuto. Finalmente se multịlica por el número de cocineros que existe en el restaurante.

5.5 Después, se multiplica el salario por minuto por la duración de la preparación del plato y se divide entre la cantidad de platillos producidos. Con esto se obtiene el Costo de Mano de obra directa por plato de comida.

\section{PROCEDIMIENTO DE COSTO INDIRECTO}

5.6 Los costos indirectos deben ser asignados a una actividad que haya sido previamente descrita para que puedan ser imputados al objeto de costo principal.

$5.7 \mathrm{El}$ costo indirecto debe estar relacionado a un generador de costo con el cual sea identificable; con esto se pueda distribuir el costo indirecto total entre el total de platos que se haya elaborado.

5.8 Se recomienda, en lo posible, que el generador de costo sea una orden de pedido. En caso fuera un abastecimiento, es preferible utilizar la unidad de Kilogramos.

5.9 Se debe obtener una tasa por orden de plato para poder imputarlo al costo unitario de un plato de comida.

\section{REGISTROS}

8. ANEXOS

Fuente: Elaboración Propia 
Anexo $\mathrm{N}^{\mathrm{o}}$ 2. Procedimiento del subproceso Control Documentario

\begin{tabular}{|l|l|c|c|c|}
\hline$(1)$ & TítuLO: & CODIGO: \\
Procedimiento de Recolección & $\begin{array}{c}\text { VER SION } \\
\text { ING-02 }\end{array}$ & $\begin{array}{c}\text { PAGINA } \\
1 \text { de 2 }\end{array}$ \\
\hline
\end{tabular}

\section{OBJETTVO}

El presente procedimiento tiene como objetivo describir lo pasos que un dueño o encargado de los costos de una MYPE debe tener en cuenta para recopilar todos los costos sea de salario, materia primas, insumos y otros gastos para poder, posteriormente, clasificarlos..

\section{ALCANCE}

Este procedimiento abarca todos los costos y gastos que puedan surgir dentro de MYPE. Cabe res altar, que se trabaja bajo un estándar para poder generalizar todos los cas os de costos.

\section{DOCUMENTOS A CONSULTAR}

\section{NINGUNO}

\section{DEFINICIONES}

- Periodos: Es el tramo de tiempo durante el cual se efectúa una acción que genera un costo. Puede ser un mes, semana o semestre.

\section{RESPONSABILIDADES}

\section{- Proceso de costos}

Establecer reglas para la recolección de las distintas boletas o facturas donde se encuentren los costos.

-Dueño de la MYPE

$>$ Aprender los procedimientos secuenciales y ordenados para la recolección.

>Saber toda la información respecto a los costos y gastos de su negocio. 


\begin{tabular}{|l|l|c|c|c|}
\hline (1) & TítuLO: & PODIGO: \\
Procedimiento de Recolección & $\begin{array}{c}\text { VER SION } \\
\text { ING-02 }\end{array}$ & 01 & PAGINA \\
2 de 2 \\
\hline
\end{tabular}

6. PROCEDIIENTO

1. Primero, se debe recopilar toda la información de los costos de todas las compras, salarios o gastos en las que se haya incurrido en un mismo tiempo.

2. Se hace una pequeña lista de los sueldos de los empleados que trabajan en el local. Generalmente, se puede agrupar en cocineros, meseros y personal administrativo (cajero o dueño).

3. Se realiza una lista de la materia prima que se ha comprado para la elaboración de los platos de comida, los insumos y, de existir el caso, también del transporte que se utilizó.

4. Por último, se junta realiza una pequeña lista de todos los gastos de la empresa como pueden ser alquiler, electricidad o agua.

7. REGISTROS

8. ANiexos

Fuente: Elaboración Propia 
Anexo $\mathrm{N}^{\mathrm{o}}$ 3. Procedimiento del subproceso Clasificación de costos

\begin{tabular}{|l|l|l|c|c|}
\hline$(4)$ & TíTULO: & CÓDIGO: \\
Procedimiento del subproceso & VERSIÓN & PÁGINA \\
COST-03 & 01 & 1 de 2 \\
\hline
\end{tabular}

\section{OBJETIVO}

El objetivo del procedimiento para la clasificación de los costos es darle al micro y pequeño empresario las pautas que debe conocer para que pueda relacionar y reconocer de forma directa 0 indirecta sus costos con los platillos que se cocina. De esta forma, se sienta las bases para la posterior distribución de los costos indirectos.

\section{ALCANCE}

Este procedimiento marca una situación estándar que puede darse en cualquier restaurante. Solo se concentra en aquellos costos que fueron recopilados en el subproceso anterior.

\section{DOCUMENTOS A CONSULTAR}

$>$ Lista de salarios, costos de materias primas e insumos y otros gastos.

\section{DEFINICIONES}

- Objeto de costo: Es el producto el cual se va a costear. En este caso, puede ser cualquier plato de comida que produzca el restaurante.

- Costo directo: Se les denomina así a todos aquellos costos que tienen relación directa con el objeto del costo. En otras palabras, es fácil de determinar y relacionar su participación en un plato de comida.

- Costo indirecto: Se les denomina así a todos aquellos costos o gastos a los que no se le puede relacionar directamente con el objeto de costo. En otras palabras, su participación es indirecta y suele participar en muchos platillos de comida.

\section{RESPONSABILIDADES}

- Proceso de costos

$\checkmark$ Brindar el conocimiento y los pasos necesarios en un lenguaje sencillo para que el micro y pequeño empresario pueda clasificar bien sus costos.

\section{- Dueño de la MYPE}

$\checkmark$ Aprender los conocimientos secuenciales para poder clasificar los costos de sus restaurantes.

$\checkmark$ Reconocer la relación, tanto directa como indirecta, de los costos y gastos que tiene en cada platillo para poder distribuir todos los costos en directos o indirectos. 


\section{PROCEDIMIENTO}

1. Primero, se tiene que utilizar la lista de costos y gastos que se elaboró con anterioridad para poder clasificarlos de una manera más ordenada.

2. Primero se va a distribuir los salarios de todo el personal, aquel personal que participó en la cocción del platillo es considerado como un costo directo (cocineros); las personas que no (pueden ser el dueño, el mesero, la cajera), son consideradas costos indirectos debido a que participación no está directamente relacionada con la preparación del platillo. Se separa en una pequeña lista a aquellos costos directos de los indirectos.

3. Segundo, la materia prima siempre es un costo directo ya que es parte del plato de comida y es muy obvio establecer su relación con el mismo. Sin embargo, no todas las materias primas o insumos participan en un plato de comida por lo que se va a identificar qué materia prima e insumos participan en que plato de comida. Cabe resaltar que todos son costos directos.

4. Tercero, en caso existiera un costo de transporte, este es de carácter indirecto al plato de comida.

5. Cuarto, los otros costos y gastos del restaurante son costos indirectos. Estos pueden ser el alquiler, la electricidad.

6. Por último, se tiene que agrupar todos los costos en una pequeña lista de costos directos e indirectos para tenerlos clasificados y ordenados.

\section{REGISTROS}

8. ANEXOS

Fuente: Elaboración propia 
Anexo $\mathrm{N}^{\mathrm{o}}$ 4. Procedimiento del subproceso Asignación y cálculo del costo unitario

\begin{tabular}{|l|l|l|l|l|}
\hline$(6)$ & $\begin{array}{l}\text { Título: } \\
\text { Procedimiento del subproceso } \\
\text { Asignación y cálculo del costo unitario }\end{array}$ & $\begin{array}{c}\text { CODIGO: } \\
\text { COST-04 }\end{array}$ & $\begin{array}{c}\text { VER SIÓN } \\
01\end{array}$ & $\begin{array}{c}\text { PÁGINA } \\
1 \text { de 2 }\end{array}$ \\
\hline
\end{tabular}

\section{OBJETIVO}

El presente procedimiento es la parte final del proceso de costos. Su objetivo es intersectar los costos directos e indirectos que se tienen del subproceso anterior, con los generadores de costo que el subproces o estratégico brinda. De esta manera se cuenta con un costo unitario más real y preciso.

\section{ALCANCE}

Este procedimiento toma solo en cuenta los costos directos e indirectos que se obtiene del proceso anterior.

\section{DOCUMENTOS A CONSULTAR}

- Procedimientos para los costos indirectos

- Procedimientos para los costos directos

\section{DEFINICIONES}

- Asignar: Es la acción de señalar una determinada cantidad de costos indirectos a una actividad que tiene un generador de costo con el fin de poder relacionar el costo indirecto con un determinado plato de comida.

- Imputar: Es la acción de atribuir cierta cantidad de dinero a un determinado producto. En este caso, es la acción de atribuir una cantidad de costos indirectos a los distintos platos de comida que se elabora.

\section{RESPONSABILIDADES}

> Micro y pequeño empresario: Se compromete a ser el responsable de los costos de su empresa mediante el aprendizaje de la metodologia para obtener el costo unitario.

> Proceso de costos: Se compromete a brindar toda la información necesaria y los formatos adecuados para que el micro empresario pueda calcular el costo unitario de sus productos de la forma más sencilla posible.

\section{PROCEDIIIENTO}

1. Con las lista de costos directos e indirectos, se procede a realizar la metodologia tanto para costos directos como para costos indirectos.

2. Se asigna $\operatorname{los} \mathrm{CI}$ a sus respectivos generadores

3. Se calcula las unidades de actividad porplatillo

4. Se calcula el total de unidades por actividad y se procede a calcular la tasa de costo por actividad. 


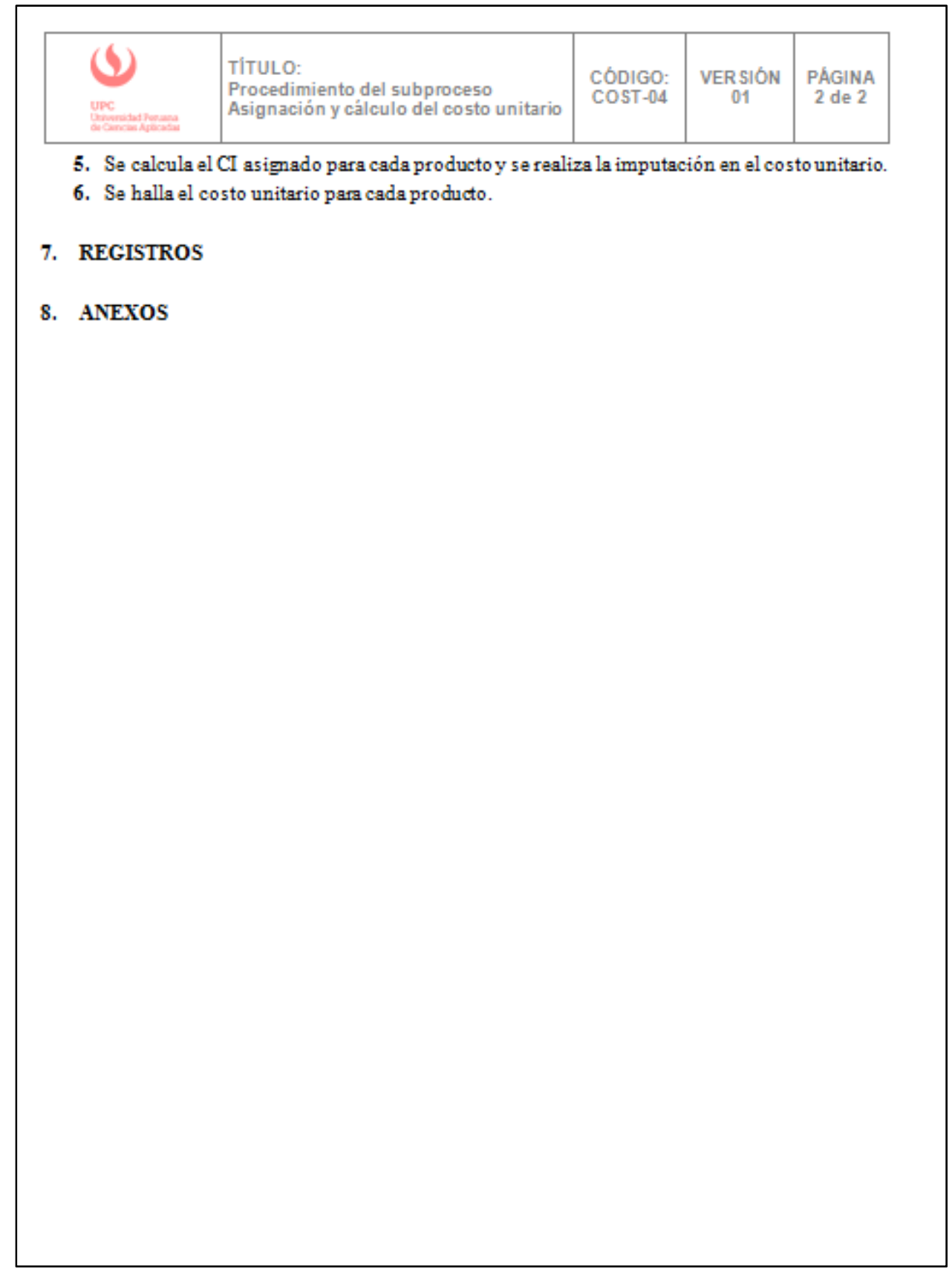

Fuente: Elaboración Propia 
FORMATO DE COSTOS

\begin{tabular}{|c|c|c|c|c|c|c|c|c|}
\hline \multicolumn{9}{|c|}{ PLATOS DE COMIDA } \\
\hline \multicolumn{3}{|c|}{ Arroz con pollo } & \multicolumn{3}{|c|}{ Aji de gallina } & \multicolumn{3}{|c|}{ Sudado de pollo } \\
\hline Platos & 70 & UNIDADES & Platos & 72 & UNIDADES & Platos & 60 & UNIDADES \\
\hline Tiempo de preparación & 40 & MINUTOS & Tiempo de preparació & 35 & MINUTOS & T. de preparación & 50 & MINUTOS \\
\hline Mate ria prima & Unidades (KG) & Total (SOLES) & Mate ria prima & Unidades (KG) & Total (SOLES) & Mate ria prima & Unidades (KG) & Total (SOLES) \\
\hline Pollo & 7 & 77.00 & Pollo & 8 & 88.00 & Pollo & 7.5 & 82.50 \\
\hline Arroz & 5 & 15.00 & Arroz & 5 & 15.00 & Arroz & 4.5 & 13.50 \\
\hline Papa & 3 & 4.00 & Papa & 3 & 4.00 & Papa & 2 & 4.00 \\
\hline Especias & 0.4 & 3.00 & Especias & 0.3 & 2.50 & Especias & 0.3 & 2.50 \\
\hline TOTALES & 15.4 & 99.00 & TOTALES & 16.3 & 109.50 & TOTALES & 14.3 & 102.50 \\
\hline & $\begin{array}{l}\text { CD MAT } \\
\text { (SOLES/PLATO) }\end{array}$ & 1.41 & & $\begin{array}{l}\text { CD MAT } \\
\text { (SOLES/PLATO) }\end{array}$ & 1.52 & & $\begin{array}{l}\text { (SOLES/PLAT } \\
\text { O) }\end{array}$ & 1.71 \\
\hline
\end{tabular}

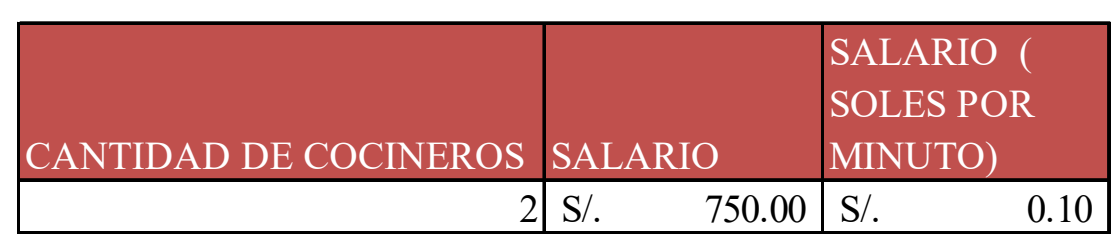

\begin{tabular}{|l|ll|}
\hline COSTOS DE COCINEROS & \multicolumn{2}{|l|}{ COSTO (Soles/plato) } \\
\hline ARROZ CON POLLO & S/. & 0.06 \\
\hline AJI DE GALLINA & S/. & 0.05 \\
\hline SUDADO DE POLLO & S/. & 0.09 \\
\hline
\end{tabular}




\begin{tabular}{|c|c|c|c|c|c|c|c|}
\hline \multirow[b]{3}{*}{ Recurs os } & \multirow[b]{3}{*}{ Actividades } & \multirow[b]{3}{*}{ Generador } & \multirow[b]{3}{*}{$\mid$ TOTAL CI (SOLES) $\mid$} & \multicolumn{3}{|c|}{ PLATILLOS } & \multirow[b]{3}{*}{ TOTAL } \\
\hline & & & & ARROZ CON POLLO & AJI DE GALLINA & SUDADO DE POLLO & \\
\hline & & & & $\begin{array}{l}\text { UNIDADES POR } \\
\text { ACTIVIDAD }\end{array}$ & $\begin{array}{c}\text { UNIDADES POR } \\
\text { ACTIVIDAD }\end{array}$ & $\begin{array}{c}\text { UNIDADES POR } \\
\text { ACTIVIDAD }\end{array}$ & \\
\hline MOZOS & $\begin{array}{l}\text { RECEPCIÓN Y } \\
\text { ATENCION DEL } \\
\text { CLIENTE } \\
\end{array}$ & ORDEN DE PEDIDO & 700.00 & 70 & 72 & 60 & 202 \\
\hline CAJERA & \begin{tabular}{|l} 
COBRAR EL \\
PEDIDO \\
\end{tabular} & ORDEN DE PEDIDO & 700.00 & 70 & 72 & 60 & 202 \\
\hline DUEÑO & $\begin{array}{l}\text { PLANIFICACIÓN } \\
\text { DE LA } \\
\text { PREPARACIÓN }\end{array}$ & ORDEN DE PEDIDO & $1,000.00$ & 70 & 72 & 60 & 202 \\
\hline LOCAL & $\begin{array}{l}\text { COCINA EL } \\
\text { PEDIDO }\end{array}$ & ORDEN DE PEDIDO & 600.00 & 70 & 72 & 60 & 202 \\
\hline TRANSPORTE & \begin{tabular}{|l|} 
TRANSPORTAR \\
MATERIAS PRMAS, \\
INSUMOS Y DEMÁS
\end{tabular} & CANTIDAD (KG) & 120.00 & 15.4 & 16.3 & 14.3 & 46 \\
\hline
\end{tabular}

\begin{tabular}{|c|c|c|c|c|}
\hline Recurs os & Tasa (Soles por Orde & $\begin{array}{l}\text { CIF ASIG ARROZ } \\
\text { CON POLLO } \\
\end{array}$ & $\begin{array}{l}\text { CIF AJI DE } \\
\text { GALLINA } \\
\end{array}$ & CIF ASIG SUDADO \\
\hline MOZOS & $\begin{array}{|ll|}\text { S/. } & 3.47 \\
\end{array}$ & $\begin{array}{|ll|}\mathrm{S} / . & 242.57 \\
\end{array}$ & $\begin{array}{|ll|}\mathrm{S} / . & 249.50 \\
\end{array}$ & 207.92 \\
\hline CAJERA & 3.47 & 242.57 & 249.50 & 207.92 \\
\hline DUEÑO & 4.95 & 346.53 & 356.44 & 297.03 \\
\hline LOCAL & 2.97 & 207.92 & 213.86 & 178.22 \\
\hline \multirow[t]{3}{*}{ TRANSPORTE } & 2.61 & 40.17 & 42.52 & 37.30 \\
\hline & TOTAL CIF & $1,079.78$ & $1,111.83$ & 928.39 \\
\hline & C/U INDIRECTO & 15.43 & 15.44 & 15.47 \\
\hline
\end{tabular}


REPORTE:

\begin{tabular}{|l|lc|}
\hline \multicolumn{1}{|c|}{ PLATO } & \multicolumn{2}{|c|}{$\begin{array}{c}\text { COSTO UNITARIO } \\
\text { (SOLES/ PLATO) }\end{array}$} \\
\hline ARROZ CON POLLO & S/. & 16.90 \\
\hline AJI DE GALLINA & S/. & 16.91 \\
\hline SUDADO DE POLLO & S/. & 17.27 \\
\hline
\end{tabular}

Fuente: Elaboración Propia 
Anexo $\mathrm{N}^{\mathrm{o}}$ 6. Formato estandarizado de costeo $\mathrm{ABC}$ - Postres preparados

\section{FORMATO DE COSTOS PARA PREPARACION DE POSIRES}

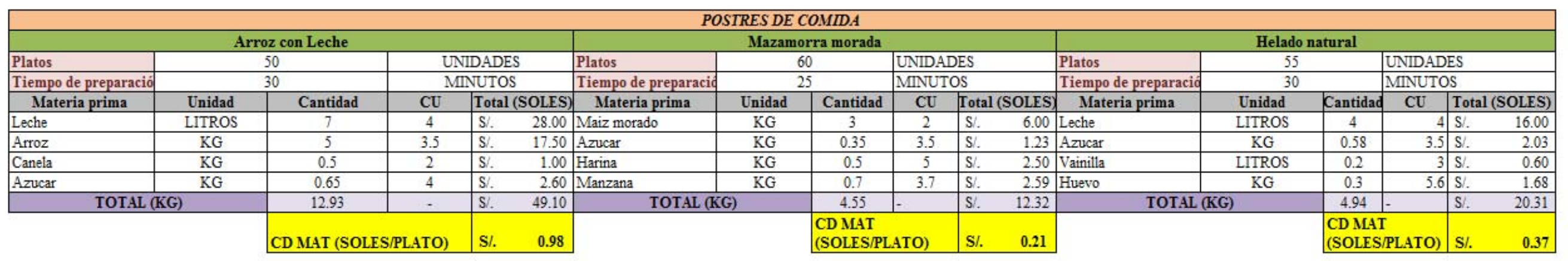

\section{MANODE OBRA}

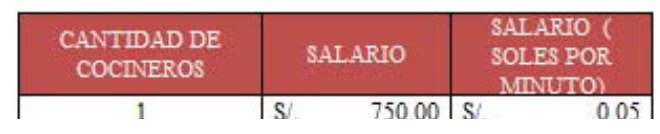

\section{REPORTE:}

\begin{tabular}{|l|lc|}
\hline \multicolumn{1}{|c|}{ POSTRE } & \multicolumn{2}{c|}{ COSTO UNITARIO } \\
\hline ARROZ CON LECHE & $\mathrm{S} /$. & 2.54 \\
\hline $\begin{array}{l}\text { MAZAMORRA } \\
\text { MORADA }\end{array}$ & $\mathrm{S} /$. & 1.51 \\
\hline HELADO NATURAL & $\mathrm{S} /$. & 1.93 \\
\hline
\end{tabular}

\section{Fuente: Elaboración propia}


FORMATO DE COSTOS PARA COMPRA DE POSTRES

\begin{tabular}{|c|c|c|c|c|c|c|c|c|c|}
\hline \multicolumn{10}{|c|}{ POSTRES DE COMIDA } \\
\hline \multirow[b]{2}{*}{ TORTAS } & Cantidad & Peso [en kg] & Pedazos & COSTO & \multirow[b]{2}{*}{ PIE } & Cantidad & eso (en k & Pedazos & COSTO \\
\hline & 1unidad entera & 2 & 12 & SI. 25.00 & & $\begin{array}{c}\text { Tunidad } \\
\text { entera }\end{array}$ & 1.5 & 8 & St. 13.00 \\
\hline
\end{tabular}

COSTO POR PEDAZO

\begin{tabular}{|l|lr|}
\hline TORTAS & Sl. & 2.08 \\
\hline PIE & Sl. & 1.63 \\
\hline
\end{tabular}

\begin{tabular}{|c|c|c|c|c|c|c|}
\hline \multirow[b]{3}{*}{ Recursos } & \multirow[b]{3}{*}{ Actiuidades } & \multirow[b]{3}{*}{$\begin{array}{c}\text { Generad } \\
\text { or }\end{array}$} & \multirow[b]{3}{*}{$\begin{array}{l}\text { TOTAL CI } \\
\text { [SOLES] }\end{array}$} & \multicolumn{3}{|c|}{ POSTRES } \\
\hline & & & & TORTAS & PIE & \\
\hline & & & & $\begin{array}{l}\text { UNIDADES PQR } \\
\text { ACTIVIDAD }\end{array}$ & $\begin{array}{l}\text { UTIDADES } \\
\text { POR } \\
\text { ACTWIDAD }\end{array}$ & TOTAL \\
\hline TRANSPORTE & $\begin{array}{l}\text { TRANSPORTAR } \\
\text { MATERIAS PRMAS, } \\
\text { INSUMOSY YEMÁS }\end{array}$ & $\begin{array}{l}\text { CANTIDAD } \\
\text { (KG) }\end{array}$ & 60.00 & 2 & 1.5 & 3.5 \\
\hline
\end{tabular}

\begin{tabular}{|c|c|c|c|}
\hline Recursos & \begin{tabular}{|l} 
Tasa [Soles \\
por Drden]
\end{tabular} & $\begin{array}{l}\text { CIF ASIG } \\
\text { TORTAS }\end{array}$ & $\begin{array}{l}\text { CIF ASIG } \\
\text { PIE }\end{array}$ \\
\hline \multirow[t]{3}{*}{ TRANSPORTE } & 17.14 & 34.29 & Si. 25.71 \\
\hline & TOTAL CIF & 34.29 & Si. 25.71 \\
\hline & CIUINDIRECTO & 2.86 & 3.21 \\
\hline
\end{tabular}

\begin{tabular}{|l|lr|}
\hline \multicolumn{1}{|c|}{ PQSTRE } & CU por Porción \\
\hline TORTAS & Sl. & 4.94 \\
\hline PIE & Sl. & 4.84 \\
\hline
\end{tabular}

Fuente: Elaboración propia 
Anexo $\mathrm{N}^{\circ}$ 8. Formato estandarizado de costeo ABC - Bebidas

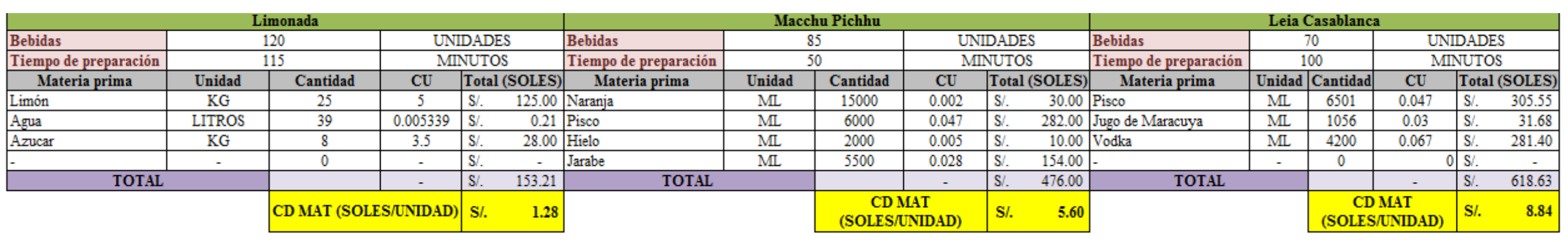

\section{MANO DE OBRA}

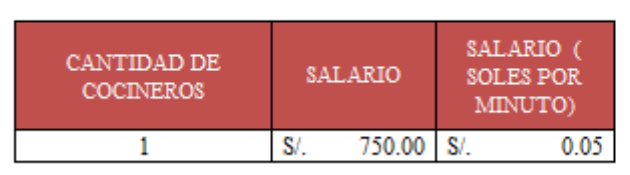

\section{REPORTE:}

\begin{tabular}{|l|lr|}
\hline \multicolumn{1}{|c|}{ BEBIDA } & \multicolumn{2}{c|}{ COSTO UNITARIO } \\
\hline LIMONADA & S/. & 7.27 \\
\hline MACCHU PICCHU & S/. & 8.20 \\
\hline LEIA CASABLANCA & S/. & 14.05 \\
\hline
\end{tabular}

Fuente: Elaboración propia 
Anexo $\mathrm{N}^{\circ}$ 9. Formato estandarizado de costo $\mathrm{ABC}$ - Bebidas adquiridas

\section{FORMATO DE COSTOS PARA COMPRA DE BEBIDAS}

\begin{tabular}{|c|c|c|c|c|c|c|c|c|c|}
\hline \multicolumn{10}{|c|}{ BEBIDAS } \\
\hline CERUEZA & Cantidad & $\begin{array}{c}\text { Cantidad [en } \\
\mathrm{ml} \text { ) }\end{array}$ & Unidades & costo & VINO & Cantidad & $\begin{array}{c}\text { Cantidad } \\
\text { (en ml) }\end{array}$ & Unidades & costo \\
\hline & 1botella & 650 & 3 & 6.00 & & 1botella & 750 & 13 & SI. 72.00 \\
\hline
\end{tabular}

COSTO POR UNIDAD

\begin{tabular}{|l|ll|}
\hline CERVEZA & Si. & 2.00 \\
\hline VINO & Si. & 5.54 \\
\hline
\end{tabular}

\begin{tabular}{|c|c|c|c|c|c|c|}
\hline \multirow[b]{3}{*}{ Recursos } & \multirow[b]{3}{*}{ Actividades } & \multirow[b]{3}{*}{ Generador } & \multirow[b]{3}{*}{$\begin{array}{l}\text { TOTAL CI } \\
\text { [SOLES] }\end{array}$} & \multicolumn{3}{|c|}{ POSTRES } \\
\hline & & & & CERWEZA & VIND & \\
\hline & & & & $\begin{array}{l}\text { UNIDADES POR } \\
\text { ACTIYIDAD }\end{array}$ & $\begin{array}{l}\text { UNIDADES } \\
\text { POR } \\
\text { ACTIVIDAD }\end{array}$ & TOTAL \\
\hline TRANSPORTE & \begin{tabular}{|l} 
TRANSFORTAR \\
MATERIAS PRMMAS, \\
IIHSUMOSYOEMASS
\end{tabular} & CANTIDAD (KG) & 60.00 & 659.75 & 742.5 & 1402.25 \\
\hline
\end{tabular}

\begin{tabular}{|c|c|c|c|}
\hline Recursos & Tasa [Soles por Orden] & $\begin{array}{l}\text { CIF ASIG } \\
\text { TORTAS }\end{array}$ & $\begin{array}{l}\text { CIF ASIE } \\
\text { WIND }\end{array}$ \\
\hline \multirow[t]{3}{*}{ TRANSPORTE } & 0.04 & 28.23 & 31.77 \\
\hline & TOTAL CIF & 28.23 & 31.77 \\
\hline & CIU INDIRECTO & 9.41 & 2.44 \\
\hline
\end{tabular}

\begin{tabular}{|l|lr|}
\hline \multicolumn{1}{|c|}{ Bebida } & \multicolumn{2}{c|}{ CU por recipiente } \\
\hline CERVEZA & Si. & 11.41 \\
\hline VIND & Si. & 7.98
\end{tabular}

\section{Fuente: Elaboración propia}


Anexo $\mathrm{N}^{\mathrm{o}}$ 10. Procedimiento para el uso del Formato Estándar de Costos

\begin{tabular}{|c|c|c|c|c|}
\hline $\begin{array}{l}\text { UPC } \\
\text { Universidad Penanaa } \\
\text { de ciencias Aplicadas }\end{array}$ & $\begin{array}{l}\text { TíTULO: } \\
\text { Procedimiento para el uso del Formato } \\
\text { Estándar de Costos }\end{array}$ & $\begin{array}{l}\text { CÓDIGO: } \\
\text { COST-05 }\end{array}$ & $\begin{array}{c}\text { VERSIÓN } \\
01\end{array}$ & $\begin{array}{l}\text { PÁGINA } \\
209 \text { de } \\
227\end{array}$ \\
\hline
\end{tabular}

\section{OBJETIVO}

El objetivo de este procedimiento es poder orientar al dueño de una MYPE del subsector restaurantes en el uso correcto del formato estándar de costos. De esta forma, aunque no cuenta con un nivel intermedio en uso de MX Excel, podrá utilizarlo sin ningún problema.

\section{ALCANCE}

Este procedimiento se usa siempre y cuando el dueño de una MYPE del subsector restaurantes utilice el formato estándar de costos, el cual es resultado del modelo estándar de costos propuesto.

\section{DOCUMENTOS A CONSULTAR}

Lista de salarios, costos de materias primas e insumos y otros gastos, producción de platillos en un determinado rango de tiempo.

\section{DEFINICIONES}

- $\quad$ Platos: Todos aquellos potajes que serán producidos en el establecimiento.

- Materia prima: Todos aquellos insumos necesarios, junto con su cantidad, para poder llevar a cabo la totalidad de platos que se van a fabricar.

- $\quad$ CD MAT: Es el costo directo de materias primas por plato.

- $\quad$ SALARIO (Soles por minuto): Es el salario que gana por minuto cada cocinero que trabaja en la empresa.

- COSTOS DE COCINEROS: Es el costo total directo de cocineros por plato de comida producido.

- UNIDADES POR ACTIVIDAD: Son el total de unidades consumidas (recursos consumidos) para llevar a cabo esa actividad.

- TOTAL CI: Es el costo total (salario, pagos, etc) de un recurso utilizado indirectamente en la fabricación o servicio. En este caso, los mozos, cajera y dueño tienen salarios; el local, alquiler y el transporte, costo de transporte.

- TASA: Es la tasa que cuesta cada recurso. Esta indicado en soles por tipo de cost driver de cada actividad a la que pertenecen. Hay dos tipos de tasa: Soles por orden de pedido y Soles por cantidad transportada, válido solo para el recurso transporte. 
- CIF: Es el costo total indirecto de fabricación de cada platillo por recurso.

- $\quad$ TOTAL CIF: Es el total de costos indirectos de un platillo de comida.

- $\quad \mathrm{C} / \mathrm{U}$ INDIRECTO: Es el costo unitario indirecto por platillo. Es calculado como la división entre el TOTAL CIF y la cantidad de platos producidos

- $\quad$ COSTO UNITARIO: Expresado en Soles por plato. Es el costo total de cada plato de comida.

- $\quad$ COSTO POR RECIPIENTE: Costo Unitario de cada porción de bebida adquirida que se va a vender.

\section{RESPONSABILIDADES}

- Proceso de costos

$\checkmark$ Brindar un procedimiento sencillo para que el dueño de una MYPE del subsector restaurantes pueda calcular fácilmente sus costos unitarios.

- Dueño de la MYPE

$\checkmark$ Aprender el procedimiento.

$\checkmark$ Controlar sus costos unitarios.

\section{PROCEDIMIENTO}

\section{A. PLATillos}

1. Primero, se debe llenar el espacio de arriba:

FORMATO DE COSTOS

\begin{tabular}{|c|c|c|c|c|c|c|c|c|c|}
\hline \multicolumn{10}{|c|}{ PLATOS DE COMIDA } \\
\hline \multicolumn{3}{|c|}{ Arroz con pollo } & \multicolumn{3}{|c|}{ Aji de gallina } & \multicolumn{4}{|c|}{ Sudado de pollo } \\
\hline Platos & & UNIDADES & Platos & & UNIDADES & Platos & 60 & UNII & \\
\hline Tiempo de preparación & & MINUTOS & Tiempo de preparación & 35 & MINUTOS & T. de preparación & 50 & MINT & \\
\hline Materia prima & Unidades (KG) & Total (SOLES) & Materia prima & Unidades (KG) & Total (SOLES) & Materia prima & Unidades (KG) & Tota & OLES) \\
\hline Pollo & & & Pollo & 8 & 88.00 & Pollo & 7.5 & S/. & 82.50 \\
\hline Arroz & & & Arroz & 5 & 15.00 & Arroz & 4.5 & S/. & 13.50 \\
\hline Papa & & & Papa & 3 & 4.00 & Papa & 2 & $\mathrm{~S} /$ & 4.00 \\
\hline Especias & & & Especias & 0.3 & 2.50 & Especias & 0.3 & S/. & 2.50 \\
\hline TOTALES & 0 & $\mathrm{~S} /$. & TOTALES & 16.3 & 109.50 & TOTALES & 14.3 & S/. & 102.50 \\
\hline & \begin{tabular}{|l} 
CD MAT \\
(SOLES/PLATO)
\end{tabular} & - & & $\begin{array}{l}\text { CD MAT } \\
\text { (SOLES/PLATO) }\end{array}$ & 1.52 & & $\begin{array}{l}\text { CD MAT } \\
\text { (SOLES/PLATO) }\end{array}$ & S/. & 1.71 \\
\hline
\end{tabular}

En ese espacio, se debe colocar el platillo de comida, en la parte inferior, se debe colocar el número de platos que se van a producir y su tiempo de preparación. El primero debe estar en unidades y el segundo en minutos.

En la columna de "Materia prima", se debe ingresar todas las materias primas e insumos que se utilizan para producir el plato de comida. De igual forma, debe ingresarse las unidades que se utilizan (en $\mathrm{kg}$ ) y el costo total (en soles) de cada materia prima e insumo. De forma automática, se calcularán los TOTALES y el CD MAT. 
2. Después, se debe calcular el Costo de los cocineros:

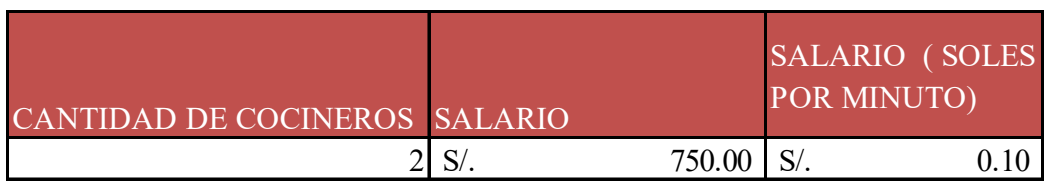

En ese cuadro, como figura en el ejemplo, se debe ingresar la cantidad de cocineros que se tiene, así como su salario. De forma automática, se calcula el salario por minuto que gana cada cocinero.

\begin{tabular}{|l|lr|}
\hline COSTOS DE COCINEROS & COSTO (Soles/plato) \\
\hline ARROZ CON POLLO & S/. & 0.06 \\
\hline AJI DE GALLINA & S/. & 0.05 \\
\hline SUDADO DE POLLO & S/. & 0.09 \\
\hline
\end{tabular}

Finalmente, de forma automática, se calcula el costo de cocineros por plato de comida. Este costo es resultado de multiplicar el salario (soles por minuto) por el tiempo de preparación de cada plato respectivo, divido entre el total de platos que se producen.

3. Luego, se tiene el siguiente cuadro:

\begin{tabular}{|c|c|c|c|c|c|c|c|}
\hline \multirow[b]{3}{*}{ Recursos } & \multirow[b]{3}{*}{ Actividades } & \multirow[b]{3}{*}{ Generador } & \multirow[b]{3}{*}{ TOTAL CI (SOLES) } & \multicolumn{3}{|c|}{ PLATILLOS } & \multirow[b]{3}{*}{ TOTAL } \\
\hline & & & & ARROZ CON POLLO & AJI DE GALLINA & SUDADO DE POLLO & \\
\hline & & & & $\begin{array}{c}\text { UNIDADES POR } \\
\text { ACTINIDAD }\end{array}$ & $\begin{array}{l}\text { UNIDADES POR } \\
\text { ACTINIDAD }\end{array}$ & $\begin{array}{l}\text { UNIDADES POR } \\
\text { ACTIVIDAD }\end{array}$ & \\
\hline MOZOS & $\begin{array}{l}\text { RECEPCIÓN Y } \\
\text { ATENCION DEL } \\
\text { CLIENTE } \\
\end{array}$ & ORDEN DE PEDIDO & 700.00 & 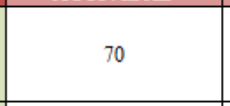 & 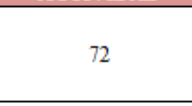 & 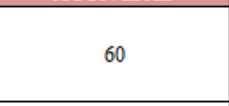 & 202 \\
\hline CAJERA & COBRAR EL PEDIDO & ORDEN DE PEDIDO & 700.00 & 70 & 72 & 60 & 202 \\
\hline DUEÑO & $\begin{array}{l}\text { PLANIFICACIÓN DE LA } \\
\text { PREPARACIÓN }\end{array}$ & ORDEN DE PEDIDO & $1,000.00$ & 70 & 72 & 60 & 202 \\
\hline LOCAL & COCINA EL PEDIDO & ORDEN DE PEDIDO & 600.00 & 70 & 72 & 60 & 202 \\
\hline TRANSPORTE & $\begin{array}{l}\text { TRANSPORTAR } \\
\text { MATERIAS PRMAS, } \\
\text { INSUMOS Y DEMÁS }\end{array}$ & CANTIDAD (KG) & 120.00 & 15.4 & 16.3 & 14.3 & 46 \\
\hline
\end{tabular}


El cuadro jala, automáticamente, las unidades por actividad de cada recurso. Lo único que se tiene que completar es la columna de TOTAL CI (Soles), el cual es el costo total que se paga por cada recurso.

4. Los resultados que se obtienen en el cuadro anterior, sirven para llenar, de forma automática, el cuadro que se presenta a continuación:

\begin{tabular}{|c|c|c|c|c|c|c|c|c|}
\hline Recursos & \multicolumn{2}{|c|}{ Tasa (Soles por Orden) } & \multicolumn{2}{|c|}{$\begin{array}{l}\text { CIF ASIG ARROZ } \\
\text { CON POLLO }\end{array}$} & \multicolumn{2}{|c|}{ CIF AJI DE GALLINA } & \multicolumn{2}{|c|}{ CIF ASIG SUDADO } \\
\hline MOZOS & $\mathrm{S} /$. & 3.47 & $\mathrm{~S} /$. & 242.57 & $\mathrm{~S} /$. & 249.50 & $\mathrm{~S} /$. & 207.92 \\
\hline CAJERA & $\mathrm{S} /$. & 3.47 & $\mathrm{~S} /$ & 242.57 & $\mathrm{~S} /$. & 249.50 & $\mathrm{~S} /$. & 207.92 \\
\hline DUEÑO & $\mathrm{S} /$. & 4.95 & $\mathrm{~S} /$. & 346.53 & $\mathrm{~S} /$. & 356.44 & $\mathrm{~S} /$. & 297.03 \\
\hline LOCAL & $\mathrm{S} /$. & 2.97 & $\mathrm{~S} /$ & 207.92 & $\mathrm{~S} /$. & 213.86 & $\mathrm{~S} /$. & 178.22 \\
\hline TRANSPORTE & $\mathrm{S} /$. & 2.61 & $\mathrm{~S} /$ & 40.17 & $\mathrm{~S} /$. & 42.52 & $\mathrm{~S} /$. & 37.30 \\
\hline & TO1 & & S/. & $1,079.78$ & S/. & $1,111.83$ & S/. & 928.39 \\
\hline & $\mathrm{C} / \mathrm{U}$ & & S/. & 15.43 & S/. & 15.44 & $\mathrm{~S} /$. & 15.47 \\
\hline
\end{tabular}

Ese cuadro calcula el CU Indirecto. El cual sirve para calcular el costo unitario total.

5. El reporte de costos unitarios se calcula de forma automática, el costo unitario de cada plato es la suma del CU Indirecto, el CD de materia prima y el CD de cocineros.

\section{REPORTE:}

\begin{tabular}{|l|ll|}
\hline \multicolumn{1}{|c|}{ PLATO } & \multicolumn{2}{|c|}{$\begin{array}{c}\text { COSTO UNITARIO } \\
\text { (SOLES/ PLATO) }\end{array}$} \\
\hline ARROZ CON POLLO & S/. & 16.90 \\
\hline AJI DE GALLINA & S/. & 16.91 \\
\hline SUDADO DE POLLO & S/. & 17.27 \\
\hline
\end{tabular}

\section{B. BEBIDAS \\ - Bebidas preparadas}

1. Se debe contar con una receta estandarizada para saber cuánto de cada insumo líquido se está utilizando para generar una unidad (copa, vaso, etc). En caso este no sea el caso, es necesario contar con una jarra de medición y hacer los cálculos respectivos. 


\section{- Bebidas adquiridas para la venta directa}

1. Para este caso, es necesario que se defina la cantidad de unidades que se extraerán de una botella.

2. Primero, se tiene que ingresar la cantidad ( 1 botella) junto con su cantidad (en ml). Además, se ingresa la Unidades (copas, vasos, etc) que se extraerán y el costo de la bebida adquirida.

FORMATO DE COSTOS PARA COMPRA DE BEBIDAS

\begin{tabular}{|c|c|c|c|c|c|c|c|c|c|}
\hline \multicolumn{10}{|c|}{ BEBDAS } \\
\hline CERVEZA & Cantidad & Cantidad (en ml) & Unidades & costo & VINO & Cantidad & \begin{tabular}{|c|}
$\begin{array}{c}\text { Cantidad (en } \\
\text { ml) }\end{array}$ \\
\end{tabular} & Unidades & costo \\
\hline & 1 botella & 650 & 3 & 6.00 & & 1 botella & 750 & 13 & 72.00 \\
\hline
\end{tabular}

Junto con esa información, se procede a dividir el costo entre las Unidades que se extraerán para hallar el costo por unidad.

3. Como, por política, si se le asignará la absorción de un costo indirecto (en este caso Transporte) se tiene que calcular las unidades por actividad. Sin embargo, debido a que este generador de costos está en la unidad de medida de $\mathrm{Kg}$. Es necesario transformar la cantidad en mililitros a KG.

Esto se tiene que realizar con la ayuda de una tabla de densidades o utilizando la balanza y calcular la masa del líquido de cada botella adquirida.

Una vez realizado esto, se calcula la tasa de orden (TOTAL CI/TOTAL) y se calcula el CU Indirecto. 


\begin{tabular}{|c|c|c|c|c|c|c|}
\hline \multirow[b]{3}{*}{ Recursos } & \multirow[b]{3}{*}{ Actividades } & \multirow[b]{3}{*}{ Generador } & \multirow{3}{*}{$\begin{array}{l}\text { TOTAL CI } \\
\text { (SOLES) }\end{array}$} & \multicolumn{3}{|c|}{ POSTRES } \\
\hline & & & & CERVEZA & VINO & \\
\hline & & & & $\begin{array}{c}\text { UNIDADES POR } \\
\text { ACTIVIDAD }\end{array}$ & POR & TOTAL \\
\hline TRANSPORTE & \begin{tabular}{|l} 
TRANSPORTAR \\
MATERIAS PRMAS, \\
INSUMOSY DEMASS
\end{tabular} & $\begin{array}{l}\text { CANTIDAD } \\
(\mathrm{KG})\end{array}$ & 60.00 & 659.75 & 742.5 & 1402.25 \\
\hline
\end{tabular}

\begin{tabular}{|c|lr|lr|lr|}
\hline \multirow{2}{*}{ Recursos } & $\begin{array}{l}\text { Tasa (Soles por } \\
\text { Orden) }\end{array}$ & \multicolumn{2}{l|l|}{$\begin{array}{l}\text { CIF ASIG } \\
\text { TORTAS }\end{array}$} & \multicolumn{2}{l|}{$\begin{array}{l}\text { CIF ASIG } \\
\text { VINO }\end{array}$} \\
\hline TRANSPORTE & S/. & 0.04 & S/. & 28.23 & S/. & 31.77 \\
\hline \multirow{3}{*}{} & TOTAL CIF & S/. & 28.23 & S/. & 31.77 \\
\cline { 2 - 6 } & C/U INDIRECTO & S/. & 9.41 & S/. & 2.44 \\
\cline { 2 - 6 }
\end{tabular}

4. Finalmente, se suman el CU Indirecto y el Costo por Unidad para obtener el CU por recipiente.

\begin{tabular}{|l|lr|}
\hline \multicolumn{2}{|c|}{ Bebida } & \multicolumn{2}{c|}{ CU por recipiente } \\
\hline CERVEZA & S/. & 11.41 \\
\hline VINO & S/. & 7.98 \\
\hline
\end{tabular}

\section{- Postres preparados}

1. Siguiendo la lógica el punto de bebidas preparadas, es importante que el microempresario tenga definida la receta con la cantidad exacta de ingredientes del total de platos que se van a producir.

2. El primer paso es ingresar la cantidad de unidades que se van a producir de cada postre y su tiempo de preparación. De la misma forma, se tiene que ingresar los insumos, sus cantidades, unidades y su costo unitario por unidad. Finalmente, se calculará el costo directo de materia prima por plato.

\section{FORMATO DE COSTOS PARA PREPARACION DE POSTRES}

\begin{tabular}{|c|c|c|c|c|c|c|c|c|c|c|c|c|c|c|c|}
\hline \multicolumn{16}{|c|}{ POSTRES DE COMIDA } \\
\hline \multicolumn{5}{|c|}{ Arroz con Leche } & \multicolumn{5}{|c|}{ Mazamorra morada } & \multicolumn{6}{|c|}{ Helado natural } \\
\hline Platos & \multicolumn{2}{|c|}{50} & \multirow{2}{*}{\multicolumn{2}{|c|}{$\begin{array}{l}\text { UNIDADES } \\
\text { MINUTOS }\end{array}$}} & Platos & \multirow{2}{*}{\multicolumn{2}{|c|}{$\frac{60}{25}$}} & \multicolumn{2}{|c|}{ UNIDADES } & Platos & \multirow{2}{*}{\multicolumn{2}{|c|}{$\frac{55}{30}$}} & \multicolumn{3}{|c|}{ UNIDADES } \\
\hline Tiempo de preparacio & \multicolumn{2}{|c|}{30} & & & Tiempo de preparacio & & & \multicolumn{2}{|c|}{ MINUTOS } & Tiempo de preparación & & & \multicolumn{3}{|c|}{ MINUTOS } \\
\hline Materia prima & Unidad & Cantidad & \multicolumn{2}{|c|}{\begin{tabular}{|l|l|}
\multicolumn{2}{|c|}{ MINUTOS } \\
CU & Total (SOLES)
\end{tabular}} & Materia prima & \multicolumn{2}{|c|}{\begin{tabular}{|l|l|} 
Unidad & Cantidad
\end{tabular}} & $\mathrm{CU}$ & Total (SOLES) & Materia prima & Unidad & Cantidad & $\mathrm{CU}$ & & OLES) \\
\hline Leche & LITROS & 7 & 4 & 28.00 & Maiz morado & KG & 3 & 2 & 6.00 & Leche & LITROS & 4 & 4 & S. & 16.00 \\
\hline Arroz & KG & 5 & 3.5 & 17.50 & Azucar & KG & 0.35 & 3.5 & 1.23 & Azucar & KG & 0.58 & 3.5 & S. & 2.03 \\
\hline Canela & KG & 0.5 & 2 & 1.00 & Harina & KG & 0.5 & 5 & 2.50 & Vainilla & LITROS & 0.2 & 3 & S. & 0.60 \\
\hline Azucar & KG & 0.65 & 4 & 2.60 & Manzana & $\mathrm{KG}$ & 0.7 & 3.7 & 2.59 & Huevo & $\mathrm{KG}$ & 0.3 & 5.6 & S\%. & 1.68 \\
\hline \multicolumn{2}{|c|}{ TOTAL (KG) } & 12.93 & - & 49.10 & \multicolumn{2}{|c|}{ TOTAL (KG) } & 4.55 & 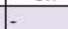 & 12.32 & \multicolumn{2}{|c|}{ TOTAL (KG) } & 4.94 & $\ldots$ & S/. & 20.31 \\
\hline & & CD MAT (SO & ATO) & 0.98 & & & \begin{tabular}{|l|} 
CD MAT \\
(SOLES/PL
\end{tabular} & ATO) & 0.21 & & & \multicolumn{2}{|c|}{$\begin{array}{l}\text { CD MAT } \\
\text { (SOLES/PLATO) }\end{array}$} & S/. & 0.37 \\
\hline
\end{tabular}

3. Se ingresa la cantidad de cocineros y su salario. Esto para poder calcular el salario en soles por minuto. 


\begin{tabular}{|c|lc|lc|}
\hline $\begin{array}{c}\text { CANTIDAD DE } \\
\text { COCINEROS }\end{array}$ & SALARIO & $\begin{array}{l}\text { SALARIO ( SOLES } \\
\text { POR MINUTO) }\end{array}$ \\
\hline 1 & $\mathrm{~S} /$. & 750.00 & S/. & 0.05 \\
\hline
\end{tabular}

4. Finalmente, se suma el CD MAT de cada uno y la multiplicación del tiempo de preparación de cada postre por el salario en minutos. De esta forma, se obtiene el costo unitario por unidad de postre.

REPORTE:

\begin{tabular}{|l|rr|}
\hline \multicolumn{1}{|c|}{ PLATO } & \multicolumn{2}{|c|}{ COSTO UNITARIO (SOLES/ PLATO) } \\
\hline LIMONADA & S/. & 7.27 \\
\hline MACCHU PICCHU & S/. & 8.20 \\
\hline LEIA CASABLANCA & S/. & 14.05 \\
\hline
\end{tabular}

\section{- Postres adquiridos para venta directa.}

1. Se tiene que ingresar la cantidad del postre adquirido ( 1 unidad entera), su peso (en $\mathrm{kg}$ ), la cantidad de pedazos que se pueden extraer de esa unidad y su costo de adquisición.

\section{FORMATO DE COSTOS PARA COMPRA DE POSTRES}

\begin{tabular}{|c|c|c|c|c|c|c|c|c|c|}
\hline & & & PO & RES DE COM & & & & & \\
\hline \multirow{2}{*}{ TORTAS } & Cantidad & Peso (en kg) & Pedazos & COSTO & \multirow{2}{*}{ PIE } & Cantidad & Peso (en kg) & Pedazos & COSTO \\
\hline & & 2 & 12 & 25.00 & & 1 unidad entera & 1.5 & 8 & 13.00 \\
\hline
\end{tabular}

\section{COSTO POR PEDAZO}

\begin{tabular}{|l|lr|}
\hline TORTAS & S/. & 2.08 \\
\hline PIE & S/. & 1.63 \\
\hline
\end{tabular}

Una vez que se ingresan estos valores, se podrá calcula el costo por pedazo de cada postre. Esto es resultado de la división entre el costo de adquisición y la cantidad de pedazos. 
2. Se tiene que imputar el costo indirecto de transporte. Para esto, se tiene que ingresas las unidades por actividad; en este caso, el peso de cada postre adquirido ya que cuentan con la misma unidad que el generador de costos. Se calcula la tasa y, finalmente, el CU Indirecto.

\begin{tabular}{|c|c|c|c|c|c|c|}
\hline \multirow[b]{3}{*}{ Recursos } & \multirow[b]{3}{*}{ Actividades } & \multirow[b]{3}{*}{ Generador } & \multirow[b]{3}{*}{$\begin{array}{l}\text { TOTAL CI } \\
\text { (SOLES) }\end{array}$} & \multicolumn{3}{|c|}{ POSTRES } \\
\hline & & & & TORTAS & PIE & \\
\hline & & & & $\begin{array}{l}\text { UNIDADES POR } \\
\text { ACTIVIDAD }\end{array}$ & $\begin{array}{c}\text { UNIDADES } \\
\text { POR } \\
\text { ACTIVIDAD }\end{array}$ & TOTAL \\
\hline TRANSPORTE & \begin{tabular}{|l} 
TRANSPORT AR \\
MATERIAS PRMAS, \\
INSUMOS Y DEMÁS
\end{tabular} & $\begin{array}{l}\text { CANTIDAD } \\
\text { (KG) }\end{array}$ & 60.00 & 2 & 1.5 & 3.5 \\
\hline
\end{tabular}

\begin{tabular}{|c|lr|lr|lr|}
\hline \multirow{2}{*}{$\begin{array}{l}\text { Recursos } \\
\text { Orden) }\end{array}$} & $\begin{array}{l}\text { Tasa (Soles por ASIG } \\
\text { TORTAS }\end{array}$ & \multicolumn{2}{|l|}{ CIF ASIG } \\
PIE
\end{tabular}

3. Finalmente, se tiene que calcular el costo unitario de cada porción sumando el costo por pedazo con el CU indirecto de cada postre.

\begin{tabular}{|l|lr|}
\hline \multicolumn{1}{|c|}{ POSTRE } & \multicolumn{2}{c|}{ CU por Porción } \\
\hline TORTAS & S/. & 4.94 \\
\hline PIE & S/. & 4.84 \\
\hline
\end{tabular}

\section{REGISTROS}

\section{ANEXOS}

- ANEXO N ${ }^{\circ}$ 5: FORMATO ESTANDARIZADO DE COSTOS ABC PLATILLOS

- ANEXO N ${ }^{\circ}$ 6: FORMATO ESTANDARIZADO DE COSTOS ABC POSTRES

- ANEXO N $\mathrm{N}^{\circ}$ 7: FORMATO ESTANDARIZADO DE COSTOS ABC POSTRES ADQUIRIDOS

- ANEXO No 8: FORMATO ESTANDARIZADO DE COSTOS ABC BEBIDAS

- ANEXO No 9: FORMATO ESTANDARIZADO DE COSTOS ABC BEBIDAS ADQUIRIDAS

\section{Fuente: Elaboración propia}

\section{REFERENCIAS BIBLIOGRÁFICAS}

- HERNÁNDEZ SAMPIERI, Roberto, FERNÁNDEZ COLLADO, Carlos y BAPTISTA LUCIO, María del Pilar (2010) Metodología de la investigación. $5^{\text {ta }}$.ed. México D.F.: McGraw-Hill. 
- UNIVERSIDAD

DE

SONORA

(2015)

Muestreo.

(http://www.estadistica.mat.uson.mx/Material/elmuestreo.pdf) (Consulta: Junio 2017)

- CRESWELL, John (2003) Research Design: Qualitative, Quantitative, and Mixed Methods Approaches. Editorial: SAGE Publications. Estados Unidos, 2003.

- INSTITUTO NACIONAL DE ESTADÍSTICA E INFORMÁTICA (2017) Evolución de la $\quad$ Pobreza $\quad$ Monetaria 2007-2016.

(https://www.inei.gob.pe/media/cifras_de_pobreza/pobreza2016.pdf) (Consulta: Mayo del 2017)

- DIARIO GESTIÓN (2017) La pobreza en Perú disminuiría a 14\% si se ejecutan proyectos mineros en cartera. (http://gestion.pe/economia/pobreza-peru-disminuiria14-si-se-ejecutan-proyectos-mineros-cartera-2194811) (Consulta: Julio del 2017)

- RIVERA FLORES, Iván (2012) Microeconomía de la pobreza: el caso del Perú, pp. 9-52. En: Economía vol. 35, no 69. Lima: Departamento de Economía de la Pontificia Universidad Católica del Perú.

- INSTITUTO PERUANO DE ECONOMIA (2011) Glosario. (http://www2.congreso.gob.pe/sicr/cendocbib/con4_uibd.nsf/C9C832F9AFEB7F4D 05257BE3006F64D1/\$FILE/129129491-glosario-pdf.pdf) (Consulta: Mayo del 2017)

- Diario Perú 21 (2017) Pobreza extrema en el Perú cayó 0.3\% en 2016, según el INEI. (http://peru21.pe/economia/pobreza-extrema-peru-cayo-03-2016-segun-inei2281148) (Consulta: Mayo del 2017)

- DIARIO EL COMERCIO (2017) La corrupción es el principal freno al desarrollo del Perú. (http://archivo.elcomercio.pe/politica/gobierno/corrupcion-principal-freno-aldesarrollo-peru-noticia-625122) (Consulta: Agosto del 2017)

- DIARIO PERU 21 (2017) La corrupción es el principal problema del Perú, según INEI. ( $\quad$ http://peru21.pe/economia/inei-corrupcion-principal-problema-peru2285342) (Consulta: Julio del 2017)

- BANCO MUNDIAL (2015) Perú Panorama general (http://www.bancomundial.org/es/country/peru/overview) (Consulta: Agosto del 2017) 
- LOAYZA, NORMAN (2008) El crecimiento económico en el Perú, pp. 9-25. En Revista Económica, vol. 31, no 61. Departamento de Investigación del Banco Mundial.

- MINISTERIO DE ECONOMÍA Y FINANZAS (2015) Conoce los conceptos básicos para entender la economía peruana. (http://www.mef.gob.pe/index.php?option $=$ com_content\&view $=$ article\&id $=61 \% 3 \mathrm{~A}$ conoce-los-conceptos-basicos-para-comprender-la-economia-delpais\&Itemid=100694\&lang=es) (Consulta: Agosto del 2017)

- BANCO CENTRAL DE RESERVA DEL PERU (2017) Cuadros anuales históricos. (http://www.bcrp.gob.pe/estadisticas/cuadros-anuales-historicos.html) (Consulta: Agosto del 2017)

- DIARIO EL COMERCIO (2014) ¿Por qué es importante que el PBI no caiga? (http://elcomercio.pe/economia/peru/que-importante-que-pbi-no-caiga-noticia1743202) (Consulta: Agosto del 2017)

- DIARIO GESTIÓN (2017) FMI elevó proyección de crecimiento de economía peruana de $4.1 \%$ a $4.3 \%$ el 2017. (http://gestion.pe/economia/fmi-elevo-proyeccioncrecimiento-economia-peruana-41-43-2017-2180315) (Consulta: Julio del 2017)

- DIARIO GESTIÓN (2017) FMI reduce a 3.5\% su proyección de crecimiento económico de Perú para el 2017. (http://gestion.pe/economia/fmi-reduce-35-suproyeccion-crecimiento-economico-peru-2017-2187626) (Consulta: Julio del 2017)

- DIARIO EL COMERCIO (2017) FMI reduce a 2,7\% su proyección de crecimiento del Perú para 2017. (http://elcomercio.pe/economia/fmi-ajusta-baja-proyeccioncrecimiento-peru-2017-426175) (Consulta: Julio del 2017)

- DIARIO EL COMERCIO (2017) FMI: Destrabes de Línea 2 y Jorge Chávez se incluirían en nuevo pronóstico de PBI. (http://elcomercio.pe/economia/peru/fmidestrabes-linea-2-jorge-chavez-incluirian-nuevo-pronostico-pbi-noticia-448222)

(Consulta: Agosto del 2017)

- INSTITUTO NACIONAL DE ESTADÍSTICA E INFORMÁTICA (2017) Comportamiento de la Economía Peruana en el Primer Trimestre de 2017. (https://www.inei.gob.pe/media/MenuRecursivo/boletines/02-informe-tecnicon02_producto-bruto-interno-trimestral-2017i.pdf) (Consulta: Agosto del 2017) 
- INSTITUTO PERUANO DE ECONOMÍA (2014) Sectores Productivos. (http://www.ipe.org.pe/content/sectores-productivos) (Consulta: Agosto del 2017)

- INSTITUTO NACIONAL DE ESTADÍSTICA E INFORMÁTICA (2017) Comportamiento de la Economía Peruana en el Cuarto Trimestre de 2016 (https://www.inei.gob.pe/media/MenuRecursivo/boletines/01-informe-tecnicon01_producto-bruto-interno-trimestral-2016iv.PDF) (Consulta: Mayo 2017)

- PERÚ. Congreso de la República (2013) Decreto de ley 30056: ley que modifica diversas leyes para facilitar la inversión, impulsar el desarrollo productivo y el crecimiento empresarial.

- CHOY ZEVALLOS, ELSA ESTHER (2010) Competitividad de las micro y pequeñas empresas (MYPES) ante el tratado de Libre Comercio (TLC), pp. 127-132. En: Revista Quipukamayoc, vol. 17, no 33. Lima: Facultad de Ciencias Contables de la Universidad Nacional Mayor de San Marcos.

- MINISTERIO DE LA PRODUCCIÓN (2017) Las MIPYME en cifras 2015. Lima: Oficina General de Evaluación de Impacto y Estudios Económicos. (http://demi.produce.gob.pe/images/publicaciones/publi09f3585ea5d4c9eb9_27.pdf) (Consulta: Agosto del 2017)

- MINISTERIO DE LA PRODUCCIÓN (2017) Estudio de la situación actual de las empresas peruanas. Lima: Oficina General de Evaluación de Impacto y Estudios Económicos.

(http://demi.produce.gob.pe/images/publicaciones/publi81171136fe74561a7_79.pdf ) (Consulta: Agosto del 2017)

- MINISTERIO DE LA PRODUCCIÓN (2016) Anuario estadístico industrial, MYPE y comercio exterior 2015. (http://www.produce.gob.pe/documentos/estadisticas/anuarios/anuario-estadisticomype-2015.pdf) (Consulta: Mayo del 2017)

- MINISTERIO DE LA PRODUCCIÓN (2013) Anuario estadístico industrial, MYPE $\begin{array}{lll}\text { y comercio } & 2012\end{array}$ (http://www.produce.gob.pe/documentos/estadisticas/anuarios/anuario-estadistico2012.pdf) (Consulta: Mayo del 2017) 
- DIARIO EL COMERCIO (2015) Estos son los 10 mayores grupos económicos del Perú. (http://elcomercio.pe/economia/peru/estos-son-10-mayores-gruposeconomicos-peru-noticia-1837508) (Consulta: Mayo del 2017)

- ASOCIACION DE EMPRENDEDORES DEL PERU (2015) MYPES aportan el 40\% del PBI (https://asep.pe/mypes-aportan-el-40-del-pbi/) (Consulta: Mayo del 2017)

- VILLARÁN, Fernando (2008) Recopilación de diapositivas titulada Contribución de las MYPEs al empleo decente $y$ al desarrollo sostenible. (http://www.peru2021.org/repositorioaps/0/0/par/xiisimpfernandovillaran/simposio2 008_fernandovillaran.pdf) (Consulta: Julio del 2017)

- ZEVAlLOS, Emilio (2003) Micro, pequeñas y medianas empresas en América $\begin{array}{lllllll}\text { Latina, } & \text { pp. } 55 . \quad \text { En: revista } & \text { CEPAL } & \mathrm{N}^{\circ}\end{array}$ (http://www.alide.org/DataBank2007/RecInformation/3APP_Enterprise/51MicroPY MRZevallos.pdf )

- FERrARO, Carlo (2011) Apoyando a las pymes: Políticas de fomento en América Latina $\mathrm{y}$ el Caribe. (http://repositorio.cepal.org/bitstream/handle/11362/35359/S1100762_es.pdf?seque nce=1) (Consulta: Julio del 2017)

- PERÚ. Congreso de la República (2003) Decreto de ley 28015: ley de promoción y formalización de la micro y pequeña empresa.

- AGENCIA DE PROMOCIÓN DE LA INVERSIÓN PRIVADA (2006) MYPEqueña empresa crece: Guía para el desarrollo de la micro y pequeña empresa. Proinversión - Esan.

- CEDAL (2010) Planes de Desarrollo de Emprendedores y Microempresarios de Subsistencia de los Sub-Sectores de Confecciones Textiles, Artesanía en Tejidos Textiles y Artesanía en Joyas. (http://cedalperu.org/wpcontent/uploads/2013/03/planes-de-desarrollo-de-emprendedores-ymicroempresarios.pdf) (Consulta: Julio del 2017)

- YAMAKAWA, PETER y otros (2010) Modelo tecnológico de integración de servicio para la Mype Peruana. Lima: ESAN ediciones (Consulta: Agosto del 2017) (http://www.esan.edu.pe/publicaciones/2010/10/20/libro\%20mype\%201.pdf) 
- SÁNCHEZ BARRAZA, Bernando (2006) Las MYPES en Perú. Su importancia y propuesta tributaria. En: Revista Académica Quipukamayoc, vol. 13, no. 25.

- HERNANI MERINO, Martín y HAMANN PASTORINO, Antonieta (2012) Percepción sobre el desarrollo sostenible de las MYPE en el Perú, pp. 290-302. En: RAE- Revista de administración de empresas, vol. 53, no 3. Sao Paulo.

- DIARIO OFICIAL EL PERUANO (2015) La fuerza de las pymes Lima,2015. (http://www.elperuano.com.pe/edicion/noticia-la-fuerza-las-pymes8257.aspx\#.VSy1IJM1E4I) (Consulta: Junio del 2017)

- HOFFMAN, Douglas y Bateson, John (2012) Marketing de servicios. Conceptos, estrategias y casos. 4ta. ed. South-Western.

- MALLAR, Miguel Ángel (2010) La Gestión por Procesos: un enfoque de gestión eficiente. En: Visión de Futuro, vol. 13. no.1. (http://www.scielo.org.ar/scielo.php?pid=S166887082010000100004\&script=sci_arttext) (Consulta: Julio del 2017)

- LLANES-FONT, Mariluz y otros (2014) De la gestión por procesos a la gestión integrada por procesos, pp. 255-264. En: Revista de la Facultad de Ingeniería Industrial, vol. 35, no 3. Holguín: Universidad de Holguín.

- KRAJEWSKI, Lee; RITZMAN, Larry y MALHOTRA, Manoj (2008) Procesos y cadenas de valor. 8va ed. México: Pearson Educación

- PEREZ, Jorge; RUIZ, Jairo y PARRA, Carlos (2007) Uso del enfoque por procesos en la actividad investigativa, pp. 260-269. En: Ingeniare, vol.3.

- PEREZ, José (2010) Gestión por procesos 4ta ed. Madrid: ESIC Editorial

- GRANERO CASTRO, Javier y FERRANDO SÁNCHEZ, Miguel (2005) Calidad total: Modelo EFQM para la excelencia. Madrid: Fundación Confemetal.

- RUIZ- FUENTES, Daysi y otros (2013) La gestión por procesos, su surgimiento y aspectos teóricos, pp. 1-11. En: Revista Ciencias Holguín, vol. 19, no 4. Holgín: Centro de Información y Gestión Tecnológica de Santiago de Cuba.

- ORGANIZACIÓN INTERNACIONAL PARA LA ESTANDARIZACIÓN (2008) Conjunto de documentos para la introducción y el Soporte de la serie de normas ISO 9000: Orientación sobre el Concepto y Uso del Enfoque basado en procesos para los 
sistemas de gestión. Madrid (http://www.inlac.org/Doc/Doc_ISO-TS176_04_11/N544R3_Orientacion_sobre_el_Concepto_Enfoque_basado_procesos.p df)

- ORGANIZACIÓN INTERNACIONAL PARA LA ESTANDARIZACIÓN (2005) Sistemas de gestión de la calidad-Fundamentos y vocabulario. Ginebra: Secretaria Central de ISO (http://www.uco.es/sae/archivo/normativa/ISO_9000_2005.pdf) (Consulta: Agosto del 2017)

- LAMAS ABREU, Eduardo y RAMOS PEREZ, Maikel (2011) Procedimiento para el diseño de un sistema de gestión de calidad basado en un enfoque de procesos. En: Contribuciones a la economía.

- HERNANDEZ, Alejandro (2002) Gestión por procesos, pp. 4. En: Industrial, vol. 24. no. (http://www.google.com/url?sa $=\mathrm{t} \& \mathrm{rct}=\mathrm{j} \& \mathrm{q}=\& \mathrm{esrc}=\mathrm{s} \&$ source $=$ web $\& \mathrm{~cd}=2 \& \mathrm{ved}=0 \mathrm{C}$ CIQFjAB\&url=http\%3A\%2F\%2Fdialnet.unirioja.es\%2Fdescarga $\% 2$ Farticulo\%2F4 786734.pdf\&ei=xco9VeKZIobAggTXnYDoCg\&usg=AFQjCNFq6v_h1uJAKVPpK cGhx9nCOYtOQg\&bvm=bv.91665533,d.eXY) (Consulta: Agosto del 2017)

- MOREYRA, Mercedes (2007) Gestión por procesos y su aplicación en la organización de información de Empresa de Telecomunicaciones de Cuba, S.A. (http://www.redalyc.org/pdf/1814/181414861002.pdf) (Consulta: Agosto del 2017

- CASELLES JOANA, Josep (2003) Gestión por procesos: Innovación y mejora. Lleida: $\quad$ Institut Catla de Tecnologia. (http://web.udl.es/usuaris/esi2009/treballs/Caselles.pdf) (Consulta: Agosto del 2017)

- ADVANCED INTEGRATED TECHNOLOGIES GROUP INCORPORATED (2005) SIPOC. (https://genesisyhwh.files.wordpress.com/2011/06/05-sipoc.pdf) (Consulta: Agosto del 2017)

- SOCIEDAD LATINOAMERICANA PARA LA CALIDAD (2000) Diagrama de Flujo (Flow Chart). (http://www.valoryempresa.com/archives/flow.pdf) (Consulta: Agosto del 2017)

- CHOY ZEVALLOS, Elsa Esther (2012) El dilema de los costos en las empresas de servicios, pp.7-14. En: Revista Académica Quipukamayoc, vol. 20, no 37. Lima: Facultad de Ciencias Contables de la Universidad Nacional Mayor de San Marcos. 
- SÁNCHEZ BARRAZA, Bernardo (2009) Problemática de conceptos de costos y clasificación de costos, pp. 95-104. En: Revista Académica Quipukamayoc, vol. 16, no 32. Lima: Facultad de Ciencias Contables de la Universidad Nacional Mayor de San Marcos.

- SÁNCHEZ BARRAZA, Bernando (2013) Implicancias del método de costeo ABC, PP. 65-73. En: Revista Académica Quipukamayoc, vol. 21, no 39. Lima: Facultad de Ciencias Contables de la Universidad Nacional Mayor de San Marcos.

- HORNGREN, Charles, DATAR, Srikant y RAJAN, Madhav (2012) Contabilidad de costos. 14ta.ed. México: Pearson Educación.

- GAVELÁN IZAGUIRRE, Jorge Jesús (2014) Sistema de costos en MYPES industriales y de servicios en condiciones de desorganización, pp. 121-134. En: Revista Académica Quipukamayoc, vol. 22, no 41. Lima: Facultad de Ciencias Contables de la Universidad Nacional Mayor de San Marcos.

- UNIVERSIDAD VERACRUZANA (2013) Clasificación de los costos. (http://www.uv.mx/personal/alsalas/files/2013/02/CLASIFICACION-DE-LOSCOSTOS.pdf) (Consulta: Agosto del 2017))

- GARCIA SUAREZ, José Luis (2012) Cálculo, análisis y gestión de costes: Guía práctica para su aplicación en la empresa. 2da ed. Delta Publicaciones

- UNIVERSIDAD MICHOACANA DE SAN NICOLAS DE HIDALGO (2013) Sistemas de costos y contabilidad de costos industriales. (http://www.fcca.umich.mx/coordinaciones/ceneval/archivos/2013_guias/CONTA/ Costos.pdf) (Consulta: Agosto del 2017)

- BELLIDO SANCHEZ, Pedro Alberto (2003) Costos ABC. Lima: Pacífico Editores.

- BUSTAMANTE SALAZAR, Alina Marcela (2015) Costeo basado en actividades ABC: Revisión de literatura, pp. 109-119. En: Revista CEA, vol. 1, no 1. Medellín: Facultad de Ciencias Económicas y Administrativas del Instituto Tecnológico Metropolitano.

- CARRIÓN NIN, José (2005) Pautas básicas para una implantación exitosa del Costeo Basado en Actividades (ABC), pp. 47-52. En: Revista de la Facultad de Ingeniería Industrial, vol. 8, no 1. Lima: Facultad de Ingeniería Industrial de la Universidad Nacional Mayor de San Marcos. 
- ESCOBAR CUELlO, JOSE (2009) El costeo por actividades, pp. 79-83. En: Dictamen Libre, ed. 5. Barranquilla: Universidad Libre

- VERGIÚ CANTO, Jorge (2005) Rentabilidad del producto mediante el costeo basado en actividades. Caso en el sector industrial, pp. 42-46. En: Revista de la Facultad de Ingeniería Industrial, vol. 8, no 1. Lima: Facultad de Ingeniería Industrial de la Universidad Nacional Mayor de San Marcos.

- VACA LÓPEZ, Andrea (2012) Los sistemas de costeo: bases y metodologías, pp. 0110. Armenia: Grupo de investigación para la competitividad empresarial de la Corporación Universitaria Empresarial Alexander von Humboldt.

- INSTITUTO NACIONAL DE ESTADÍSTICA E INFORMÁTICA (2017) Principales indicadores macroeconómicos. (https://www.inei.gob.pe/estadisticas/indice-tematico/economia/) (Consulta: Agosto del 2017)

- INSTITUTO NACIONAL DE ESTADÍSTICA E INFORMÁTICA (2017) Situación del mercado laboral en Lima Metropolitana. (https://www.inei.gob.pe/media/MenuRecursivo/boletines/01-informe-tecnicon01_mercado-laboral-oct-nov-dic2016.pdf) (Consulta: Julio del 2017)

- DIARIO GESTION (2017) Aumenta número de microempresas peruanas, pero aún no es momento de alegrarse. (http://gestion.pe/economia/aumenta-numero-mypesperuanas-aun-no-momento-alegrarse-2197184) (Consulta: Agosto del 2017)

- ARBULU, Jorge (2006) La PYME en el Perú, pp. 32-37. En: Revista de Egresados. Lima: PAD-Escuela de Dirección de la Universidad de Piura. (http://cendoc.esan.edu.pe/fulltext/e-journals/PAD/7/arbulu.pdf) (Consulta: Agosto del 2017)

- INSTITUTO NACIONAL DE ESTADÍSTICA E INFORMÁTICA (2014) Análisis de la estructura empresarial de Lima Metropolitana, pp. 97-103. (https://www.inei.gob.pe/media/MenuRecursivo/publicaciones_digitales/Est/Lib126 2/cap04.pdf) (Consulta: Agosto del 2017)

- INSTITUTO NACIONAL DE ESTAdíStiCA E INFORMÁTICA (2016) Perú: Estructura empresarial 2015. 
(http://www.inei.gob.pe/media/MenuRecursivo/publicaciones_digitales/Est/Lib1382 /index.html) (Consulta: Agosto del 2017)

- INSTITUTO NACIONAL DE ESTADÍSTICA E INFORMÁTICA (2017) Encuesta mensual del sector servicios. (https://www.inei.gob.pe/media/MenuRecursivo/boletines/boletin-estadistico-delsector-servicios-n-02-febrero-2017.pdf) (Consulta: Agosto del 2017)

- INSTITUTO NACIONAL DE ESTADÍSTICA E INFORMÁTICA (2017) Producción nacional (https://www.inei.gob.pe/media/principales_indicadores/02informe-tecnico-n02_produccion-nacional-dic2016.pdf) (Consulta: Julio del 2017)

- UNIVERSIDAD DE FLORIDA (2012) Standard Normal Probabilities. (Consulta: 8 de mayo del 2015) (http://www.stat.ufl.edu/ athienit/Tables/Ztable.pdf)

- CUBA BUSTINZA, Elmer (2015) Economía peruana: el corto y el mediano plazo, pp. 18-25. En: Revista Argumentos, vol. 1, no 1. Lima: Instituto de Estudios Peruanos.

- ORGANIZACIÓN PARA LA COOPERACIÓN Y EL DESARROLLO ECONÓMICOS (OCDE)/ COMISIÓN ECONÓMICA PARA AMÉRICA LATINA Y EL CARIBE (CEPAL) (2013) Perspectivas económicas de América Latina 2013. Políticas de PYMES para el Cambio Estructural. (http://repositorio.cepal.org/bitstream/handle/11362/1463/S2012083 es.pdf?sequenc $\underline{\mathrm{e}=1})$ (Consulta: Julio del 2017)

- VERDERA RIBAS, Francisco (2007) La pobreza en el Perú: Un análisis de sus causas y de las políticas para enfrentarla. Lima: Fondo Editorial de la Pontificia Universidad Católica del Perú.

- GARCIA-VEGA, Emilio Humberto (2011) Competitividad en el Perú: diagnóstico, sectores a priorizar y lineamientos a seguir para el período 2011-2016, pp. 112-141. En: Revista Journal, vol. 5, no 1. Georgetown: Georgetown University.

- LlAMAS ARÉCHIGA, Beatriz y otros (2014) Elementos que promueven competitividad en las PYMES, un estudio general, pp. 1-20. En: Revista de Investigación Académica sin Frontera, año 7, no. 19. Sonora: Universidad de Sonora.

- CHACÓN, Galia (2007) La contabilidad de costos, los sistemas de control de gestión y la rentabilidad empresarial, pp. 29-45. En: Revista Actualidad Contable Faces, vol 10 no 15. Venezuela: Universidad de los Andes. 
- DUQUE ROLDÁN, María Isabel y Osorio Agudelo, Jair Alberto (2013) Estado actual de la investigación en costos y contabilidad de gestión en Colombia. En: Revista del Instituto Internacional de Costos.

- HERRERA GARCIA, Beatriz (2011) Análisis estructural de las MYPEs y PYMEs, pp. 69-89. En: Revista Quipukamayoc. Lima: Facultad de Ciencias Contables.

- OCAMPO HERNÁNDEZ, Ana Milena (2011) Costos ABC. Una concepción sistémica formal, pp. 73-96. En: Contraduría Universidad de Antioquía.

- ARMESTÁR. Narciso (2013) De la Micro competitividad a la competitividad nacional. En: Repositorio académico de la Universidad Peruana de Ciencias Aplicadas.

- TORRES, Carlos Alonso (2014) Orientaciones para implementar una gestión basada en procesos, pp. 159-171 En: Revista de Ingeniería Industrial, vol XXXV no 2. Chile: Universidad del Bio Bio.

- ABREU, José Luis (2012) Hipótesis, Método \& Diseño de Investigación, pp. 187197. En: International Journal of Good Conscience. México: Facultad de Contaduría Pública y Administración de la Universidad Autónoma de Nuevo León.

- KRICK, Thomas y otros (2006) De las palabras a la acción. El compromiso con los skateholders. Manual para la práctica de las relaciones con los grupos de interés. Canada: United Nations Environment Programe.

- UNIVERSIDAD NACIONAL DEL RÍO NEGRO (2013) Evaluación del impacto ambiental. Argentina.

- SUPERINTENDENCIA NACIONAL DE ADMINISTRACIÓN TRIBUTARIA (2004) Ley del impuesto a la renta. Capítulo IX. (http://www.sunat.gob.pe/legislacion/renta/regla/cap9.htm) (Consulta: Marzo 2018) 